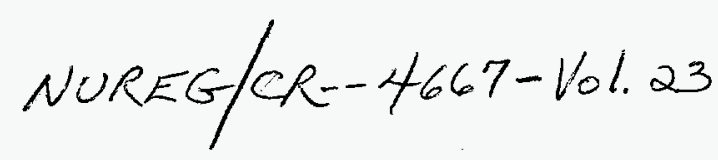

NUREG/CR-4667, Vol. 23

ANL-97/10

\title{
Environmentally Assisted
}

\section{Cracking in}

\section{Light Water Reactors}

\section{Semiannual Report}

July 1996 - December 1996

Manuscript Completed: August 1997

Date Published: October 1997

Prepared by

O. K. Chopra, H. M. Chung, D. J. Gavenda, E. E. Gruber

T. H. Hughes, T. F. Kassner, P. R. Luebbers, J. -H. Park

W. E. Ruther, W. J. Shack, W. K. Soppet, R. V. Strain

J. Zhang, P. Dong, F. W. Brust ${ }^{b}$

"Argonne National Laboratory

9700 South Cass Avenue

Argonne, IL 60439

Subcontractor:

battelle Columbus Laboratories

505 King Avenue

Columbus, $\mathrm{OH} 43201$

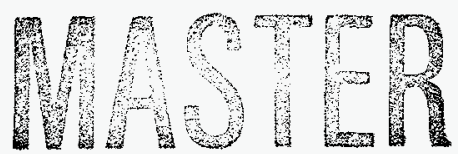

M. McNeil, NRC Project Manager

\section{Prepared for}

Division of Engineering Technology Office of Nuclear Regulatory Research U.S. Nuclear Regulatory Commission Washington, DC 20555-0001

NRC Job Code W6610

\section{DISCLAIMER}

This report was prepared as an account of work sponsored by an agency of the United States Government. Neither the United States Government nor any agency thereof, nor any of their employees, makes any warranty, express or implied, or assumes any legal liability or responsibility for the accuracy, completeness, or usefulness of any information, apparatus, product, or process disclosed, or represents that its use would not infringe privately owned rights. Reference herein to any specific commercial product, process, or service by trade name, trademark, manufacturer, or otherwise does not necessarily constitute or imply its endorsement, recommendation, or favoring by the United States Government or any agency thereof. The views and opinions of authors expressed herein do not necessarily state or reflect those of the United States Government or any agency thereof.

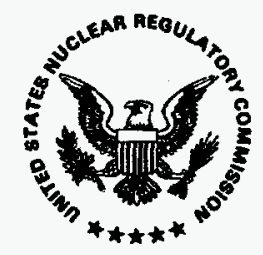




\section{Previous Documents in Series}

Environmentally Assisted Cracking in Light Water Reactors Semiannual Report April-September 1985, NUREG/CR-4667 Vol. I, ANL-86-31 (June 1986).

Environmentally Assisted Cracking in Light Water Reactors Semiannual Report October 1985-March 1986, NUREG/CR-4667 Vol. II, ANL-86-37 (September 1987).

Environmentally Assisted Cracking in Light Water Reactors Semiannual Report April-September 1986, NUREG/CR-4667 Vol. III, ANL-87-37 (September 1987).

Environmentally Assisted Cracking in Light Water Reactors Semiannual Report October 1986-March 1987, NUREG/CR-4667 Vol. IV, ANL-87-41 (December 1987).

Environmentally Assisted Cracking in Light Water Reactors Semiannual Report April-September 1987, NUREG/CR-4667 Vol. V, ANL-88-32 (June 1988).

Environmentally Assisted Cracking in Light Water Reactors Semiannual Report October 1987March 1988, NUREG/CR-4667 Vol. 6, ANL-89/10 (August 1989).

Environmentally Assisted Cracking in Light Water Reactors Semiannual Report April-September 1988, NUREG/CR-4667 Vol. 7, ANL-89/40 (March 1990).

Environmentally Assisted Cracking in Light Water Reactors Semiannual Report October 1988March 1989, NUREG/CR-4667 Vol. 8, ANL-90/4 (June 1990).

Environmentally Assisted Cracking in Light Water Reactors Semiannual Report April-September 1989. NUREG/CR-4667 Vol. 9, ANL-90/48 (March 1991).

Environmentally Assisted Cracking in Light Water Reactors Semiannual Report October 1989March 1990, NUREG/CR-4667 Vol. 10, ANL-91/5 (March 1991).

Environmentally Assisted Cracking in Light Water Reactors Semiannual Report April-September 1990, NUREG/CR-4667 Vol. 11, ANL-91/9 (May 1991).

Environmentally Assisted Cracking in Light Water Reactors Semiannual Report October 1990March 1991, NUREG/CR-4667 Vol. 12, ANL-91/24 (August 1991).

Environmentally Assisted Cracking in Light Water Reactors Semiannual Report April-September 1991, NUREG/CR-4667 Vol. 13, ANL-92/6 (March 1992).

Environmentally Assisted Cracking in Light Water Reactors Semiannual Report October 1991March 1992, NUREG/CR-4667 Vol. 14, ANL-92/30 (August 1992).

Environmentally Assisted Cracking in Light Water Reactors Semiannual Report April-September 1992, NUREG/CR-4667 Vol. 15, ANL-93/2 (June 1993).

Environmentally Assisted Cracking in Light Water Reactors Semiannual Report October 1992March 1993, NUREG/CR-4667 Vol. 16, ANL-93/27 (September 1993).

Environmentally Assisted Cracking in Light Water Reactors Semiannual Report April-September 1993, NUREG/CR-4667 Vol. 17, ANL-94/26 (June 1994).

Environmentally Assisted Cracking in Light Water Reactors Semiannual Report October 1993March 1994, NUREG/CR-4667 Vol. 18, ANL-95/2 (March 1995).

Environmentally Assisted Cracking in Light Water Reactors Semiannual Report April-September 1994, NUREG/CR-4667 Vol. 19, ANL-95/25 (September 1995).

Environmentally Assisted Cracking in Light Water Reactors Semiannual Report October 1994March 1995, NUREG/CR-4667 Vol. 20, ANL-95/41 (January 1996).

Environmentally Assisted Cracking in Light Water Reactors Semiannual Report April-December 1995, NUREG/CR-4667 Vol. 21, ANL-96/ 1 (July 1996).

Environmentally Assisted Cracking in Light Water Reactors Semiannual Report January 1996June 1996, NUREG/CR-4667 Vol. 22, ANL-97/9 (June 1997). 


\section{DISCLAMMER}

Portions of this document may be illegible in electronic image produets. Images are produced from the best available original document. 


\title{
Environmentally Assisted Cracking in Light Water Reactors Semiannual Report July 1996-December 1996
}

\author{
by \\ O. K. Chopra, H. M. Chung, D. J. Gavenda, E. E. Gruber, T. H. Hughes, \\ T. F. Kassner, P. R. Luebbers, J.-H. Park, W. E. Ruther, \\ W. J. Shack, W. K. Soppet, and R. V. Strain \\ (Argonne National Laboratory) \\ J. Zhang, P. Dong, and F. W. Brust \\ (Battelle Columbus Laboratories)
}

\begin{abstract}
This report summarizes work performed by Argonne National Laboratory on fatigue and environmentally assisted cracking (EAC) in light water reactors from July 1996 to December 1996. Topics that have been investigated include (a) fatigue of carbon, low-alloy, and austenitic stainless steels (SSs) used in reactor piping and pressure vessels, (b) irradiationassisted stress corrosion cracking of Type 304 SS, (c) EAC of Alloy 600, and (d) characterization of residual stresses in welds of boiling water reactor (BWR) core shrouds by numerical models. Fatigue tests were conducted on ferritic and austenitic SSs in water that contained various concentrations of dissolved oxygen to determine whether a slow strain rate applied during various portions of a tensile-loading cycle are equally effective in decreasing fatigue life. Slow-strain-rate-tensile tests were conducted in simulated BWR water at $288^{\circ} \mathrm{C}$ on $\mathrm{SS}$ specimens irradiated to a low fluence in the Halden reactor and the results were compared with similar data from a control-blade sheath and neutron-absorber tubes irradiated in BWRs to the same fluence level. Crack-growth-rate tests were conducted on compact-tension specimens from a low-carbon content heat of Alloy 600 in high-purity oxygenated water at $289^{\circ} \mathrm{C}$. Residual stresses and stress intensity factors were calculated for BWR core shroud welds.
\end{abstract}





\section{Contents}

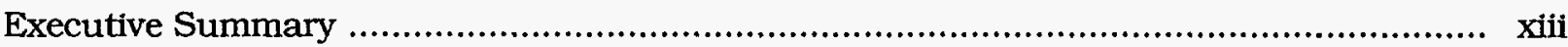

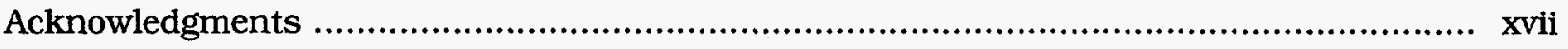

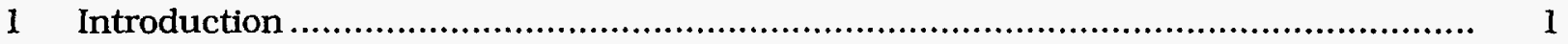

2 Environmental Effects on Fatigue Strain-versus-Life (S-N) Behavior of Primary Pressure Boundary Materials ............................................................. $\quad 2$

2.1 Crack Initiation and Crack Growth Characteristics of Carbon and Low-Alloy Steels...................................................................................... 6

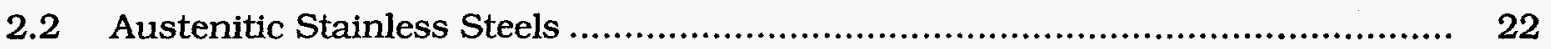

$3 \quad$ Irradiation-Assisted Stress Corrosion Cracking of Austenitic SS .......................... 31

3.1 Slow-Strain-Rate-Tensile Tests of Austenitic Stainless Steels Irradiated in the Halden Reactor

$3.2 \quad$ Properties of Stainless Steel Welds ............................................... 35

3.3 Analysis of Fluorine in BWR Components ...................................... 41

3.4 Development of Hot-Cell J-R Test Facility ......................................... 42

4 Environmentally Assisted Cracking of Alloys 600 and 690 in

Simulated LWR Water

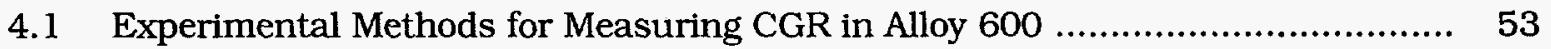

4.2 Tensile Properties of Solution-Annealed and Thermally Treated Alloy $600 \ldots . . . . \quad 55$

4.3 Crack Growth Rates of Low-Carbon Alloy 600 in

HP Oxygenated Water at $289^{\circ} \mathrm{C}$

4.4 Comparison of CGRs of Alloy 600 in HP Oxygenated Water and Air .................. 63

4.5 Morphology of Crack Path and Fracture Surface of Alloy 600 Specimens .......... 65

$5 \quad$ Modeling of Residual Stresses in Core Shroud Structures............................... 67

5.1 Core Shroud Weld Geometry and Calculation of Residual Stress

Distributions

5.2 Effects of Specimen Removal on Residual Stress Distributions 
5.3 Calculation of Stress Intensity Factors for Welds with Flaws

6 Summary of Results.

6.1 Environmental Effects on Fatigue S-N Behavior of Primary

Pressure Boundary Materials

79

6.2 Irradiation Assisted Stress Corrosion Cracking...................................... 80

6.3 Environmentally Assisted Cracking of Low-Carbon Alloy 600 in Simulated LWR Water

6.4 Modeling of Residual Stresses in Core Shroud Structures 


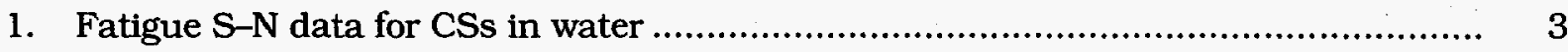

2. Fatigue data for CS and LAS vessels tested in room-temperature water................. 6

3. Growth of cracks in smooth fatigue specimens ............................................ 9

4. Morphology and length of surface crack after varying number of cycles for A533Gr B steel tested in air at room temperature, $0.75 \%$ strain range, and slow $/$ fast saw-tooth waveform.

5. Fracture surface and probable crack front after varying numbers of fatigue cycles for surface crack shown in Fig. 4

6. Beach marks produced by four of five block loading sequences on the fracture surface of $\mathrm{A} 533-\mathrm{Gr} \mathrm{B}$ steel tested at $288^{\circ} \mathrm{C}$ in high-DO water

7. Fatigue lives of A533-Gr B steel tested at room temperature in air and high-DO water

8. Fatigue lives of A533-Gr B steel tested at $288^{\circ} \mathrm{C}$ in simulated PWR and high-DO water

9. Fatigue lives of $\mathrm{A} 106-\mathrm{Gr}$ B steel tested at $288^{\circ} \mathrm{C}$ in high-DO water.

10. Photomicrographs of fractured specimens tested with slow/fast waveform at $0.8 \%$ strain range interrupted every 30 cycles and subjected to 170 cycles at lower strain range, and $0.38 \%$ strain range interrupted every 420 cycles and subjected to 170 cycles at fast strain rate

11. Depth of largest crack as a function of fatigue cycles for A533-Gr B LAS and A106-Gr B CS in air and water environments

12. Depth of largest crack as a function of fractional life for A533-Gr B LAS and A106-Gr B CS in air and water environments

13. Crack depth as a function of fractional life for CSs and LASs tested in roomtemperature air.

14. Photomicrographs of surface cracks along longitudinal sections of A533-Gr B LAS and A106-Gr B CS in air, high-DO water, and simulated PWR environments....

15. Crack growth rates as a function of crack depth for A533-Gr B LAS tested in air and water environments

16. Crack growth rates determined from smooth cylindrical fatigue test specimens and ASME Section XI reference curves for CSs and LASs in air and water environments 
17. Fatigue $\mathrm{S}-\mathrm{N}$ behavior for Types 304,316 , and $316 \mathrm{NG} \mathrm{SS}$ in air at various temperatures

18. Total-strain-range versus fatigue-life data for Types $316 \mathrm{NG}$ and $304 \mathrm{SS}$ in air

19. Total-strain-range-versus-fatigue-life data for Types 316NG and 304 SS in air and water

20. Effect of strain rate on fatigue lives of austenitic SSs in air and in simulated PWR and high-DO water environments

21. SEM photomicrographs of gage surface of Type 316NG SS specimens tested in air, simulated PWR, and high-DO-water environments

22. Photomicrographs of fracture surface of Type 316NG SS specimens tested at $288^{\circ} \mathrm{C}$ and $0.75 \%$ strain range in air, high-DO water, and simulated low-DO PWR water

23. Photomicrographs of surface cracks along longitudinal sections of Type 316NG $\mathrm{SS}$ in air and water environments at strain rates of 0.4 and $0.004 \% / \mathrm{s}$

24. Stress-versus-elongation behavior of laboratory Heat L7 of Type 304 SS in air and water that contained $\approx 8$ ppin DO

25. Percent IGSCC of SS heats irradiated in helium in Halden reactor to fluence of $\approx 0.45 \times 10^{21} \mathrm{n} \cdot \mathrm{cm}^{-2}(\mathrm{E}>1 \mathrm{MeV})$.

26. Percent TGSCC of SS heats irradiated in Halden reactor to fluence of $\approx 0.45 \mathrm{x}$ $10^{21} \mathrm{n} \cdot \mathrm{cm}^{-2}(\mathrm{E}>1 \mathrm{MeV})$

27. Combined percent IGSCC and TGSCC of SS heats irradiated in Halden reactor to fluence of $\approx 0.45 \times 10^{21} \mathrm{n} \cdot \mathrm{cm}^{-2}(\mathrm{E}>1 \mathrm{MeV})$

28. Grain size of HAZ in SMA weld of Type $304 \mathrm{SS}$, Heat C1, as function of distance from fusion zone

29. Schematic representation of SMA weld of Type 304 SS Heat C.

30. Microhardness of SMA weld HAZ of Type 304 SS Heat C1 as function of distance from fusion zone

31. Microhardness of HAZ in SMA weld of Type 304 SS, Heat C1, as function of distance from weld surface smoothed with a grinding wheel to simulate BWR core shroud weld surface finish

32. Microhardness profiles of cold-worked HAZs of Type 304 SS, Heat C1, and BWR core shroud welds as function of distance from ground surface

33. Vickers microhardness of $\mathrm{HAZ}$ in SMA weld of Type $304 \mathrm{SS}$, Heat C1, as function of distance from ground surface and fusion zone.... 
34. Fluorine and oxygen ion maps of SMA weld of Type 304 SS, Heat C1, determined by SIMS analysis

35. Fluorine 625-eV intensities from spots on ductile and intergranular fracture surfaces in CP and HP BWR neutron-absorber tubes

36. Intensity of fluorine AES signal as function of sputter distance from grain boundary surface in Type 304L core-shroud weld HAZ, Specimen 507-B

37. Schematic representation of hot-cell $\mathrm{J}-\mathrm{R}$ test facility

38. Schematic representation of actuator, load cell, load train, and furnace

39. Photograph of actuator, load cell, load train, and furnace

40. Detailed drawing of specimen load cage 45

41. Configuration of compact-tension specimen in this study 46

42. DCT and CT specimen designs from other investigations 46

43. Elastic compliance correction for specimen rotation

44. Machine compliance expressed in terms of load-versus-displacement of loading points at room temperature and $288^{\circ} \mathrm{C}$ and plastic component of machine compliance at $288^{\circ} \mathrm{C}$

45. Unloading machine compliance at $288^{\circ} \mathrm{C}$ for maximum loads of 667 and $2981 \mathrm{~N}$.....

46. Measured and estimated values of load-line displacement for solution-annealed and $50 \%$ cold-worked Type 304 SS tested at room temperature

47. Measured and estimated values of crack length of solution-annealed Type 304 SS specimen precracked at room temperature

48. Load-versus-load-line displacement curves for solution-annealed Type 304 SS at room temperature and $288^{\circ} \mathrm{C}$

49. Fracture toughness J-R curves for solution-annealed Type $304 \mathrm{SS}$ at room temperature and $288^{\circ} \mathrm{C}$

50. Relationship between ASTM grain size number and average grain diameter

51. Dependence of $0.2 \%$ yield stress at 25 and $290^{\circ} \mathrm{C}$ on grain size of solutionannealed and thermally treated Alloy 600 specimens

52. Dependence of CGRs in oxygenated $\mathrm{HP}$ water at $289^{\circ} \mathrm{C}$ on $\Delta \mathrm{K}$ of Alloy 600 specimens solution-annealed at $1025^{\circ} \mathrm{C}$ and solution-annealed at this temperature and thermally treated at $600^{\circ} \mathrm{C}$ for $24 \mathrm{~h}$

53. Dependence of CGRs in oxygenated HP water at $289^{\circ} \mathrm{C}$ on $\Delta \mathrm{K}$ of Alloy 600 specimens solution-annealed at $1115^{\circ} \mathrm{C}$ and solution-annealed at this temperature and thermally treated at $600^{\circ} \mathrm{C}$ for $24 \mathrm{~h}$ 
54. Dependence of CGRs in oxygenated HP water at $289^{\circ} \mathrm{C}$ on $\Delta \mathrm{K}$ of solution-

annealed Alloy 600 specimens.

55. Dependence of CGRs in oxygenated HP water at $289^{\circ} \mathrm{C}$ on $\Delta \mathrm{K}$ of thermally treated Alloy 600 specimens

56. Combined data for dependence on $\triangle \mathrm{K}$ of $\mathrm{CGR}$ of low-carbon heat of Alloy 600 in HP oxygenated water at $289^{\circ} \mathrm{C}$

57. Dependence on $\triangle \mathrm{K}$ of CGR of Alloys 600 and 690 in air at $289^{\circ} \mathrm{C}$

58. Dependence on $\Delta \mathrm{K}$ of ratio of CGRs of solution-annealed $\left(1025^{\circ} \mathrm{C}\right)$ and thermally treated Alloy 600 in HP oxygenated water to CGRs of mill-annealed Alloy 600 in air at $289^{\circ} \mathrm{C}$

59. Dependence on $\Delta \mathrm{K}$ of ratio of CGRs of solution-annealed $\left(1115^{\circ} \mathrm{C}\right)$ and thermally treated Alloy 600 in HP oxygenated water to CGRs of mill-annealed Alloy 600 in air at $289^{\circ} \mathrm{C}$

60. Dependence on $\Delta K$ of ratio of CGRs in HP oxygenated water of a low-carbon heat of Alloy 600 with differing heat treatments to CGRs in air of mill-annealed Alloy 600 at $289^{\circ} \mathrm{C}$

61. Dependence on $\Delta \mathrm{K}$ of ratio of CGRs in HP deoxygenated water of Alloy 600 with $0.08 \mathrm{wt} . \%$ carbon and differing heat treatments to CGRs in air of mill-annealed Alloy 600 at $289^{\circ} \mathrm{C}$

62. Crack path, fracture surface, and fracture morphology of 1TCT solution-annealed $\left(1025^{\circ} \mathrm{C}\right.$ for $2 \mathrm{~h}$ ) specimen of Alloy 600 (No. J320-02) after crack growth experiment in $\mathrm{HP}$ oxygenated water at $289^{\circ} \mathrm{C}$

63. Crack path, fracture surface, and fracture morphology of 1TCT solution-annealed and thermally treated $\left(1025^{\circ} \mathrm{C}\right.$ for $2 \mathrm{~h}$ and $600^{\circ} \mathrm{C}$ for $\left.24 \mathrm{~h}\right)$ specimen of Alloy 600 (No. J321-02) after crack growth experiment in HP oxygenated water at $289^{\circ} \mathrm{C}$.

64. Crack path, fracture surface, and fracture morphology of 1TCT solution-annealed $\left(1115^{\circ} \mathrm{C}\right.$ for $2 \mathrm{~h}$ ) specimen of Alloy 600 (No. J310-02) after crack growth experiment in $\mathrm{HP}$ oxygenated water at $289^{\circ} \mathrm{C}$

65. Crack path, fracture surface, and fracture morphology of 1TCT solution-annealed and thermally treated $\left(1115^{\circ} \mathrm{C}\right.$ for $2 \mathrm{~h}$ and $600^{\circ} \mathrm{C}$ for $24 \mathrm{~h}$ ) specimen of Alloy 600 (No. J311-02) after crack growth experiment in HP oxygenated water at $289^{\circ} \mathrm{C}$

66. Core shroud structure and $\mathrm{H} 4$ weld geometry

67. Axisymmetric finite-element model for $\mathrm{H} 4$ weld analysis.

68. Throughwall residual stress clistribution in $\mathrm{H} 4$ weld, axial stress and hoop stress ....

69. Contour plots of residual stress distributions in $\mathrm{H} 4$ weld

70. Residual stress distributions along inner and outer surfaces of core shroud, axial stress and hoop stress 
71. Evolution of axial residual stress through shroud wall at $\mathrm{H} 4$ weld centerline

72. Evolution of hoop residual stress through shroud wall at $\mathrm{H} 4$ weld centerline.

73. 3-D shell element model used to evaluate effect of specimen removal on residual stress distribution in $\mathrm{H} 4$ weld

74. Axial residual stress distribution at inner surface of core shroud

75. Throughwall residual stresses at center of a specimen removed from core shroud .... 75

76. Equivalent boundary forces and moments on removed specimen.

77. Stress intensity factor solutions for complete circumferential cracks in H4 weld growing from inner surface on $\mathrm{H} 3$ side $\mathrm{HAZ}$ as function of crack depth

78. Redistribution of residual stress due to crack growth

79. Stress intensity factor solutions for complete circumferential cracks in $\mathrm{H} 4$ weld growing from outer surface on $\mathrm{H} 5$ side $\mathrm{HAZ}$ as function of crack depth

80. Stress intensity factors for surface cracks in weld centerline of $\mathrm{H} 4$ weld

\section{Tables}

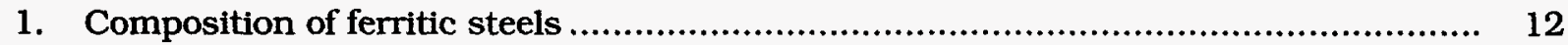

2. Average room-temperature tensile properties of CS and LAS ............................ 12

3. Fatigue results for CSs and LASs in air and water environments ....................... 14

4. Composition of austenitic SSs used for fatigue tests ................................... 22

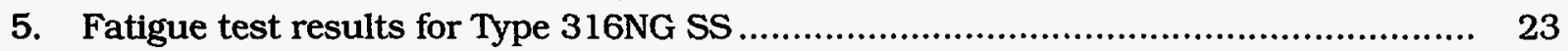

6. Fatigue test results for Type 304 SS ...................................................... 24

7. Composition of model SS alloys used for SSRT tests in simulated BWR water at $\approx 288^{\circ} \mathrm{C}$

8. SSRT test and SEM fractography results for specimens of austenitic SSs irradiated in helium at $288^{\circ} \mathrm{C}$ in Halden reactor.

9. Composition of commercial heats of Types $304,304 \mathrm{~L}$, and 316 SS that were used to investigate SCC and IASCC behavior of welds with respect to BWR core shroud cracking.

10. Composition of SMA weld HAZ and base metal of commercial heat C1 of Type 304 SS

11. Composition of SMA weld HAZ and base metal of commercial heat C21 of Type 316 SS 
12. Composition of GTA weld HAZ and base metal of commercial heat $\mathrm{Cl}$ of Type 304 SS

13. Composition of GTA weld $\mathrm{HAZ}$ and base metal of commercial heat C21 of Type 316 SS.

14. Material type, composition, and fluence of BWR components

15. Composition of Alloy 600 used for corrosion fatigue tests

16. Tensile properties of Alloy 600 under various heat-treatment conditions

17. Crack growth results at $289^{\circ} \mathrm{C}$ in $\mathrm{HP}$ water with $\approx 300 \mathrm{ppb}$ DO for Alloy 600 specimens annealed at $1025^{\circ} \mathrm{C}$.

18. Crack growth results at $289^{\circ} \mathrm{C}$ in $\mathrm{HP}$ water with $\approx 300 \mathrm{ppb}$ DO for Alloy 600 specimens annealed at $1115^{\circ} \mathrm{C}$

19. Welding parameters for $\mathrm{H} 4$ weld 


\section{Environmental Effects on Fatigue Strain-versus-Life (S-N) Behavior of Primary Pressure Boundary Materials}

Plain carbon steels (CSs) and low-alloy steels (LASs) are used extensively in steam supply systems of pressurized and boiling water nuclear reactors (PWRs and BWRs) as piping and pressure vessel materials. Fatigue tests are being conducted on CSs and LASs in water and in air to establish the effects of material and loading variables on fatigue life. The results indicate a significant decrease in fatigue life when five conditions are satisfied simultaneously, viz., when applied strain range, service temperature, dissolved-oxygen (DO) in the water, and sulfur content of the steel are above a minimum threshold level, and the loading strain rate is below a threshold value. Only a moderate decrease in fatigue life is observed in light water reactor (LWR) environments when any one threshold condition is not satisfied. This report presents (a) results of fatigue tests that examine the influence of the reactor environment on crack initiation and crack growth of CSs and LASs, and (b) data on austenitic stainless steel (SS) that establish the effects of various loading and environmental variables on fatigue lives of these steels.

Crack lengths as a function of fatigue cycles were determined for A533-Gr B LAS and A106-Gr B CS in air and water environments. The results indicate that, in air, fatigue cracks that are $10 \mu \mathrm{m}$ or longer, form quite early during fatigue $(<10 \%$ of life) even at low strain ranges $(\approx 0.4 \%)$. The decrease in fatigue life of CS and LASs in high-DO water is primarily caused by the effects of environment on the growth of short cracks. During the initial stages of fatigue damage (for cracks $<100 \mu \mathrm{m}$ ), crack growth rates are nearly two orders of magnitude greater in high-DO water than in air, and one order of magnitude greater for cracks $>100 \mu \mathrm{m}$ long. Metallographic examination of test specimens indicates that in high-DO water, the surface cracks appear to grow entirely as Mode I tensile cracks normal to the stress axis, whereas, in air or low-DO water, growth of surface cracks initially occurs as shear cracks at $\approx 45^{\circ}$ to the stress axis.

Fatigue tests have also been conducted on Types $316 \mathrm{NG}$ and $304 \mathrm{SS}$ at $288^{\circ} \mathrm{C}$ in LWR coolant environments. The results indicate a significant decrease in fatigue life of the water relative to that in air. The decrease in life depends both on strain rate and DO content in water. Environmental effects on fatigue life are the same for Types 304 and $316 \mathrm{NG}$ SS. However, unlike CS and LASs, environmental effects are more pronounced in low-DO than in high-DO water. At $\approx 0.004 \% / \mathrm{s}$ strain rate, reduction in fatigue life in water that contains $<10 \mathrm{ppb} D O$ is greater by a factor of $\approx 2$ than in water that contains $\geq 200 \mathrm{ppb} D O$. A detailed examination of test specimens indicates that the formation and growth of surface cracks appear to be different in simulated PWR water than in air. In all environments, cracks primarily form within persistent slip bands. In air, and for most cases in high-DO water, surface cracks initially grow along slip planes as shear cracks at $45^{\circ}$ to the stress axis in Stage I growth. In simulated PWR water ( $<10 \mathrm{ppb} D O)$, the surface cracks grow entirely as tensile cracks normal to the stress axis in Stage II growth. 


\section{Irradiation Assisted Stress Corrosion Cracking}

Slow-strain-rate-tensile (SSFT) tests were conducted in simulated BWR water at $288^{\circ} \mathrm{C}$ on model SS alloys that were irradiated at $288^{\circ} \mathrm{C}$ in helium to a fluence of $\approx 0.45 \times 10^{21} \mathrm{n} \cdot \mathrm{cm}^{-2}$ $(\mathrm{E}>1 \mathrm{MeV})$ in the Halden reactor. Initial results indicate that the ductility of irradiated commercial-purity Type 304 SS sheet specimens is higher than that of BWR neutron-absorber tubes at a comparable fluence level. High-purity (HP) Type 316 SS was more susceptible to intergranular stress corrosion cracking (IGSCC). This behavior is similar to that observed for HP heats of Type 304 SS. Type 304 SS heats high in carbon content were more susceptible to transgranular stress corrosion cracking (TGSCC) but less susceptible to IGSCC. Unusually high levels of oxygen and sulfur in SS appear to have a deleterious effect on SCC of Type 304 $\mathrm{SS}$, even in the nonirradiated state, during SSRT tests in $\mathrm{HP}$ oxygenated water at $288^{\circ} \mathrm{C}$.

Shielded-metal-arc (SMA) welds were prepared from Types $304.304 \mathrm{~L}$, and 316 SS to simulate BWR core shroud welds. Significant contamination by oxygen, sulfur, and fluorine was observed in the heat-affected zone (HAZ) of the SMA welds. This contamination originates at the coating on the welding electrode and from the air atmosphere. In contrast, contamination in gas-tungsten-arc welds was insignificant.

Microhardness profiles were obtained for the fusion zone and HAZ of an SMA weld of Type 304 SS. A region of maximum hardness was in the $H A Z$ at a distance of $\approx 0.8-3 \mathrm{~mm}$ from the fusion zone. This region appears to coincide with the region of most frequent cracking in BWR core shroud welds. When the surface of the weld was smoothed with a grinding wheel, hardness near the ground surface was significantly higher, indicating that a cold-worked surface layer may facilitate crack nucleation. The local hardening characteristics, together with contamination by oxygen, fluorine, and sulfur, may be important factors that promote susceptibility of core shroud welds to SCC in BWRs.

Analysis by Auger electron spectroscopy shows that fluorine atoms segregate to grain boundaries in BWR neutron-absorber tubes and a core shroud weld. However, the exact mechanism of the segregation (i.e., thermal, irradiation-induced, or both) is not understood. Because fluorine and oxygen are virtually insoluble in steel, they are likely to segregate by a thermal process to local sites such as matrix/precipitate interfaces, grain boundaries, and stacking faults. In addition to thermal segregation, irradiation-induced segregation cannot be ruled out, and further investigation is needed.

The design, fabrication, and calibration of a facility for J-R testing of the fracture toughness irradiated compact-tension specimens in a hot cell has been completed. Several out-of-cell fracture toughness J-R. tests have been conducted on annealed and nonirradiated Type 304 SS specimens according to the "Standard Test Method for J-Integral Characterization of Fracture Toughness," which is currently under consideration within the ASTM technical committee. The results indicate that both the elastic compliance method or DC potential-drop technique can be used to estimate crack length during $\mathrm{J}-\mathrm{R}$ or fatigue crack growth tests. These findings will be validated by (a) conducting fracture toughness $\mathrm{J}-\mathrm{R}$ curve tests at room temperature and $288^{\circ} \mathrm{C}$ on two heats of thermally aged CF-8M cast SS and on $50 \%$ cold-worked Type $316 \mathrm{NG}$ SS, and (b) performing fatigue crack growth studies on the same three materials at $288^{\circ} \mathrm{C}$ in air. 


\section{Environmentally Assisted Cracking of Low-Carbon Alloy 600 in Simulated LWR Water}

Corrosion-fatigue experiments were conducted on compact-tension specimens of a lowcarbon content ( $0.03 \mathrm{wt} . \%)$ heat of Alloy 600 in HP oxygenated water to investigate the effects of load ratio on crack growth rates (CGRs) at $289^{\circ} \mathrm{C}$. The specimens were fabricated from blocks of material that were solution-annealed at 1025 and $1115^{\circ} \mathrm{C}$ for $2 \mathrm{~h}$ and heat treated at $600^{\circ} \mathrm{C}$ for $24 \mathrm{~h}$ after solution annealing at the two temperatures. Solution annealing at 1025 and $1115^{\circ} \mathrm{C}$ produced ASTM grain sizes of $\approx 1.0-1.5$ and 0.2 , respectively, which correspond to large average grain diameters of $\approx 210-250$ and $340 \mu \mathrm{m}$. Based on results from four specimens, these heat treatment conditions did not have a significant effect on the CGRs in HP oxygenated water. Other heats of material with differing carbon content and heat treatment conditions could produce a wider variation in the results.

"Best-fit" correlations for the CGRs in water that contained $\approx 300$ ppb DO versus $\Delta K$ were obtained for each specimen and for the combined data from the four specimens of the same material with differing heat treatments. The effect of HP oxygenated water on the CGRs relative to that of air was determined from (a) a ratio of the CGRs at $289^{\circ} \mathrm{C}$ in water to the CGRs of another heat of Alloy 600 in air at $289^{\circ} \mathrm{C}$, and (b) a ratio of the CGRs from the combined data in water for all of the heat treatment conditions to the CGR in air at $289^{\circ} \mathrm{C}$. The results indicate that the rates for Alloy 600 are higher in water than in air at $\Delta \mathrm{K}$ values $<18 \mathrm{MPa} \cdot \mathrm{m}^{1 / 2}$ and are lower in water than in air at higher values of $\Delta \mathrm{K}$. At a $\Delta \mathrm{K}$ of $\approx 2 \mathrm{MPa} \cdot \mathrm{m}^{1 / 2}$, the rate is higher by a factor of $\approx 10$ in water than in air. At this $\Delta \mathrm{K}$, CGRs for specimens from other heats of Alloy 600 were higher by a factor of $\approx 2$ in HP water that contained $<5 \mathrm{ppb}$ DO than in air.

The morphology of corrosion-fatigue cracks in the Alloy 600 specimens was that of transgranular cracking in HP oxygenated water because of the strong contribution of mechanical cyclic loading in tests at load ratios of 0.1-0.8 and because of the relatively small degree of crack extension that occurred in tests at load ratios $>0.8$.

\section{Modeling of Residual Stresses in Core Shroud Structures}

Under a subcontract with Argonne National Laboratory (ANL), Battelle Columbus Laboratories has used numerical models to characterize weld residual stresses and the associated stress intensity factors at BWR core shroud welds. A detailed description of the weld residual stresses has been obtained for the $\mathrm{H} 4$ weld. The multipass welding process was simulated with an axisymmetrical solid-element model. A shell element analysis was performed to quantify the effects of specimen removal on residual stress measurements. The residual stress results formed the basis for the calculation of stress intensity factors.

The H4 weld is a multipass submerged-arc weld that joins two Type 304 SS cylinders. The axial residual stresses for this weld show a "thick-shell" type of distribution. In the middle of the wall, the axial residual stresses are compressive, whereas tensile stresses were present at both inner and outer surfaces of the pipe except at the weld centerline, where a small-amplitude compressive stress is present on the outer surface. This compressive axial stress was primarily due to axial bending of the wall caused by radial shrinkage of the weld and the presence of a weld cap. The axial stresses are tensile in the HAZs on the inner and outer surfaces. At these cross sections, the maximum tensile axial stresses are at the inner surface of the shroud wall. The hoop stresses are tensile almost throughout these cross 
sections. The maximum tensile hoop stress occurs at the weld centerline between the midthickness and outer surfaces. At the HAZs, the tensile stresses peak at the inner and outer surfaces. However, their magnitudes are much smaller than the peak value at the weld centerline.

After the residual stress distributions in the uncracked weldment were determined, stress intensity factors $\mathrm{K}$ for weldments that contained flaws were determined. Complete $360^{\circ}$ cracks and a surface crack that extends over only a portion of the circumference of the cylinder were considered. For the axisymmetrical case with a complete $360^{\circ}$ crack, the results indicate that a crack growing from the inside to the outside of the vessel surface, or vice versa, would be likely to stop growing at approximately midwall, because $\mathrm{K}$ becomes negative for deeper cracks. For the surface crack that extends over only a portion of the circumference, the $\mathrm{K}$ values at the deepest point of the crack decrease as the crack depth increases. However, the $\mathrm{K}$ values along the crack front near the surface remain positive, and in fact, increase as the crack grows deeper. These results suggest that cracks, if driven by corrosion mechanisms that depend on $\mathrm{K}$, will tend to increase in length in the angular direction much more rapidly than they will grow throughwall. Indeed, there will be a tendency for full $360^{\circ}$ cracks to develop; the average depth of the cracks is expected to be $\approx 50 \%$ of the wall thickness, although local perturbations in the stress distributions could produce localized regions of deeper cracking. 


\section{Acknowledgments}

The authors thank W. F. Burke, T. M. Galvin, and D. R. Perkins for their contributions to the experimental effort. This work is sponsored by the Office of Nuclear Regulatory Research, U.S. Nuclear Regulatory Commission, under Job Code W6610; Program Manager: Dr. M. B. McNeil. 


\section{Introduction}

Since 1967, the U.S. Nuclear Regulatory Commission (NRC) and its predecessor the U.S. Atomic Energy Commission, have conducted research programs that address aging of reactor components. The results of the research have been used to evaluate and establish regulatory guidelines to ensure acceptable levels of reliability for light water reactor (LWR) components. The products of these programs have been technical reports, methodologies for evaluating licensee submittals, and other inputs to the regulatory process. The results have led to the resolution of regulatory issues, as well as the development, validation, and improvement of regulations and regulatory guides. The current research on the effects of simulated reactor coolant environments on cracking of reactor components was initiated to resolve remaining critical technical issues related to cracking phenomena in LWR components. Initially, this project addressed cracking of boiling water reactor (BWR) pipes. Subsequently, in response to requests from the NRC Division of Nuclear Reactor Regulation (NRR) for assistance in dealing with cracking problems that were developing in aging reactors, the focus shifted to other problems in environmentally assisted cracking (EAC) of LWR components.

The overall objective of the current program is to provide data and physical models that can be used by the NRC staff to assess environmentally assisted degradation of primary pressure boundary components in LWRs. The research is divided into five tasks as follows:

(a) Effects of environment on fatigue, crack growth, and stress corrosion cracking

Fatigue and EAC of piping, pressure vessels, and core components in LWRs are important concerns in plant operation and for extended reactor lifetimes. The degradation processes in U.S. reactors include fatigue, intergranular stress corrosion cracking (IGSCC), and propagation of fatigue or stress corrosion cracks that initiate in the weld-sensitized heat-affected zone (HAZ) of stainless steel (SS) components. Occurrences of fatigue failures induced by mechanical vibration and thermal fluctuation in LWR plants have also been documented. The objective of this task is to improve fatigue design curves and assess the additivity of fatigue damage in piping and vessel steels under load histories typical of LWR components. The results of this work will be used to assess industry fatigue evaluations related to license renewal.

(b) Vulnerability of components to irradiation-assisted stress corrosion cracking Irradiation-assisted stress corrosion cracking (IASCC) of in-core components of both BWRs and pressurized water reactors (PWRs) is becoming a more common problem as reactors age. The general pattern of the observed failures indicates that, as nuclear plants age and neutron fluence increases, many apparently nonsensitized austenitic materials become susceptible to intergranular failure by IASCC. Some of these failures have been reported for components subjected to relatively low or negligible stress levels, e.g., control-blade sheaths and handles and instrument dry tubes of BWRs. Although most failed components can be replaced, some safety-significant structural components, such as the BWR top guide, core plate, and shroud, would be very difficult or impractical to replace. The objective of this task is to provide data and models that are needed to assess industry analyses of the likelihood of degradation and failure of core internal components due to IASCC, and to evaluate licensee submissions that concern inspection and remediation. 
(c) Cracking of nickel alloy components of LWR primary systems

Internal components of reactor vessels are made of nickel-base alloys, e.g., Alloys 600 , $\mathrm{X750}$, and 182, which are susceptible to IGSCC. The causes and mechanisms of the cracking of these alloys are not adequately understood and increase the uncertainty when licensee submissions are evaluated for factors such as damage accumulation and inspection intervals. The objective of this task is to provide technical data on the effects of cracks in nickel-alloy components on residual life, inspection, and repair. The results will be used to support NRR staff assessment of industry crack growth models, and potential detection and mitigation measures.

(d) Analysis of postweld heat treatment processes and validation of flaw acceptance criteria

The objective of this task is to evaluate the effect of postweld heat treatment on longterm resistance to environmental cracking by assessing sensitization and other microstructural changes. Emphasis is to be placed on components made of welded Alloy 600 . This evaluation will provide insights to NRC that will be useful in reviewing licensee submittals.

(e) Assessment of industry crack-growth models

This task has two objectives. The first is to perform an independent evaluation of industry models that are used to establish inspection intervals and repair criteria. The second objective is to perform more detailed analyses of flaw acceptance criteria.

Research during the past six months has focused on fatigue of carbon steels (CSs) and low-alloy ferritic steels (LASs) and SSs used in piping and pressure vessels, IASCC during slow-strain-rate tensile (SSRT) tests in simulated BWR water of SS specimens that were irradiated to a low fluence in the Halden reactor, EAC of Alloy 600 in air and in high-purity (HP) oxygenated water, and modeling of residual stresses in core shroud structures.

\section{Environmental Effects on Fatigue Strain-versus-Life (S-N) Behavior of Primary Pressure Boundary Materials}

The ASME Boiler and Pressure Vessel Code Section III, Subsection NB, 1 which contains rules for the construction of Class 1 components for nuclear power plants, recognizes fatigue as a possible mode of failure in pressure vessel steels and piping materials. Cyclic loadings on a structural component occur because of changes in the mechanical and thermal loadings as the system goes from one load set: (e.g., pressure, temperature, moment, and force loading) to any other load set. For each pair of load sets, an individual fatigue usage factor is determined by the ratio of the number of cycles anticipated during the lifetime of the component to the allowable cycles. Figures I-9.1 to I-9.6 of Appendix I to Section III of the Code specify fatigue design curves that define the allowable number of cycles as a function of applied stress amplitude. The cumulative usage factor (CUF) is the sum of the individual usage factors. The ASME Code Section III requires that the CUF at each location must not exceed 1.

The Code design fatigue curves are based on strain-controlled tests of small polished specimens at room temperature in air. In most studies, the fatigue life of a test specimen is defined as the number of cycles needed for the tensile stress to drop $25 \%$ from its peak value, which corresponds to an $\approx 3-\mathrm{mm}$-deep crack. Consequently, fatigue life $\mathrm{N}$ represents the 
number of cycles required to initiate a crack that is $\approx 3 \mathrm{~mm}$ deep. In the Code, the best-fit curves to the experimental data are expressed in terms of the Langer equation ${ }^{2}$ of the form

$$
\varepsilon_{\mathrm{a}}=\mathrm{B}(\mathrm{N})^{-\mathrm{b}}+\mathrm{A},
$$

where A, B, and $\mathrm{b}$ are parameters of the model. Equation 1 may be written in terms of stress amplitude $S_{a}$ instead of strain amplitude $\varepsilon_{a}$, in which case stress amplitude is the product of strain amplitude and elastic modulus, i.e., $\mathrm{S}_{\mathrm{a}}=\mathrm{E} \cdot \varepsilon_{\mathrm{a}}$. The design fatigue curves were obtained by decreasing the best-fit curves by a factor of 2 on stress or 20 on cycles, whichever was more conservative, at each point on the best-fit curve. As described in the Section III criteria document, these factors are intended to account for the differences and uncertainties that are encountered when the fatigue lives of laboratory test specimens are related to those of actual reactor components. The factor of 20 on cycles is the product of three separate subfactors: 2 for scatter of data (minimum to mean), 2.5 for size effects, and 4 for surface finish, atmosphere, etc. ${ }^{3}$ "Atmosphere" was intended to reflect the effects of an industrial environment rather than the controlled environment of a laboratory. The factors of 2 and 20 are not safety margins but rather conversion factors that must be applied to the experimental data to obtain reasonable estimates of the lives of actual reactor components. They do not intend to address the effects of reactor coolant environments on fatigue life.

Subsection NB-3121, of Section III of the Code states that the data on which the fatigue design curves (Figs. I-9.1 to I-9.6) are based do not include tests in the presence of corrosive environments that might accelerate fatigue failure. Article B-2131 in Appendix B to Section III states that the owner's design specifications should provide information about any reduction to fatigue design curves that was necessitated by environmental conditions. Recent fatigue S-N data demonstrate potentially significant effects of LWR coolant environments on the fatigue resistance of CSs, and LASs, ${ }^{4-10}$ and austenitic SSs. ${ }^{11}$ As shown in Fig. 1, under certain conditions of loading and environment, fatigue lives of CSs can be a factor of 70 lower in water than in air. Therefore, the margins in the ASME Code may be less conservative than originally intended.

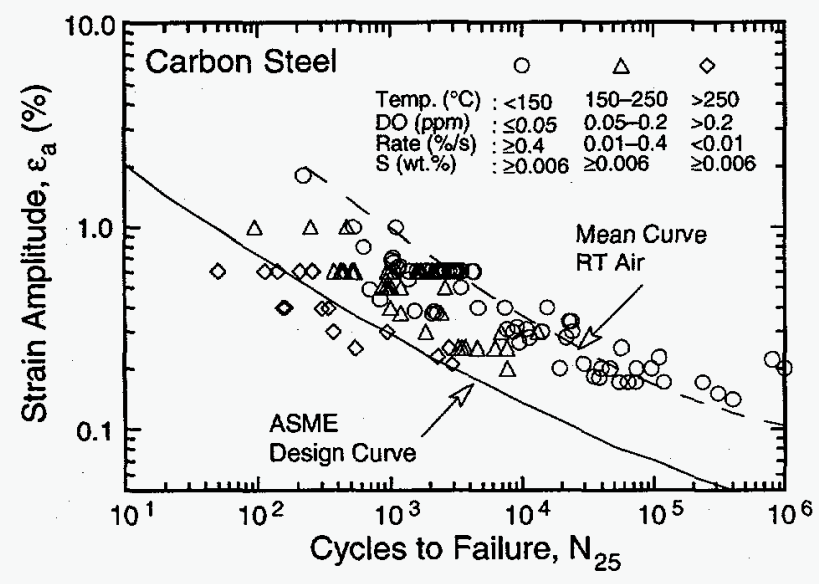

Figure 1.

Fatigue S-N data for CSs in water

Experience with operating nuclear plants worldwide reveals that many failures may be attributed to fatigue. Examples of such failures include emergency core cooling or residual heat removal systems (USNRC Bulletin No. 88-08), pressurizer surge lines (USNRC Bulletin No. 88-11), PWR feedwater lines (USNRC Information Notice No. 79-13), BWR pressure vessels 
(USNRC Information Notice No. 90-29), PWR steam generator vessels (USNRC Information Notice No. 90-04), and steam generator feedwater distribution piping (USNRC Information Notice No. 91-19 and No. 93-20). These failures may be classified into three categories: thermal fatigue caused by thermal stratification, cycling, and striping loadings; mechanical fatigue due to vibratory loading; and corrosion fatigue from exposure to a corrosive environment. Significant thermal loadings due to stratification were not included in the original design basis analysis. Some of these fatigue sensitive locations are routinely monitored in nuclear power plants worldwide to better define the transients and more accurately assess CUF. Occurrences of mechanical-vibration- and thermal-fluctuation induced fatigue failures in LWR plants in Japan have also been documented. 12

In 1991, the USNRC issued a draft Branch Technical Position (BTP) on fatigue evaluation of nuclear plant components for license renewal. The BTP raised a concern about the adequacy of the ASME Code in addressing the effects of environment on fatigue resistance of materials in operating PWRs and BWRs, whose primary-coolant pressure boundary components are constructed as specified in Section III of the Code. Researchers at Argonne National Laboratory (ANL) have compiled and reviewed the existing fatigue S-N data to identify key variables that influence the fatigue life of primary pressure boundary materials. ${ }^{8,9} \mathrm{~A}$ program was initiated at ANL to obtain fatigue data under conditions where information was lacking in the existing data base. The results from the study have been presented in previous progress reports. ${ }^{13-19}$ Researchers at ANL have developed interim design fatigue curves that are based on the existing S-N data. The curves address the effects of environment on fatigue life of CSs, LASs, and austenitic SSs. 20 Statistical models have also been developed for estimating the effects of various material and loading conditions on fatigue life of these materials. 21,22 Results of the statistical analysis have been used to estimate the probability of fatigue cracking in reactor components. The Pressure Vessel Research Council has also been compiling and evaluating fatigue S-N data related to the effects of LWR coolant environments on the fatigue life of pressure boundary materials; the results have been presented by Van Der Sluys and Yukawa. 23

In 1993, the USNRC directed its staff to treat fatigue as a potential safety issue within the existing regulatory process for operating reactors. The staff developed a Fatigue Action Plan (FAP) to resolve three principal issues: (a) the adequacy of fatigue resistance of older vintage plants designed to the United States of America Standard (USAS) B31.1 Code that did not require an explicit fatigue analysis of components, (b) the effect of LWR environments on the fatigue resistance of primary pressure boundary materials, and (c) the appropriate corrective action required when the limits allowable by the Code have been exceeded, i.e., when the CUF is $>1$. The Idaho National Engineering Laboratory assessed the significance of the interim fatigue design curves by performing fatigue evaluations of several components in the reactor coolant pressure boundary. ${ }^{24}$ In all, six locations were evaluated from facilities designed by each of the four U.S. nuclear steam supply system vendors. Selected components from older vintage plants designed to comply to B31.1 Code were also included in the evaluation. An assessment of risk to components in the reactor coolant pressure boundary from failure due to fatigue was performed under Gerieric Safety Issue 78, "Monitoring of Fatigue Transient Limits for the Reactor Coolant System." On the basis of these studies, it was concluded that no immediate action is necessary to deal with fatigue issues addressed in the FAP. The risk

* Policy Issue, SECY-95-245, Completion of the Fatigue Action Plan, Sept. 25, 1995. 
study indicated that a fatigue failure of piping is not a significant contributor to core-melt frequency. Although fatigue cracks may occur, they may not propagate to failure and, even if failure did occur, safety systems, such as an emergency core cooling system, mitigate the consequences. On the basis of the risk assessment, a backfit of the environmental fatigue data to operating plants cannot be justified.

The types and extent of conservatisms present in the ASME Section III fatigue evaluations and the effects of LWR environments on fatigue margins have been documented by Structural Integrity Associates, Inc., under contract to Sandia National Laboratories for the U.S. Department of Energy and in cooperation with the Electric Power Research Institute (EPRI). 25 A review of numerous stress reports indicated a substantial amount of conservatism in many existing component fatigue evaluations. The sources of conservatism include design transients considerably more severe than those experienced in service, grouping of transients, simplified elastic/plastic analysis, and Code rules prior to 1979. Environmental effects on two components, the BWR feedwater nozzle/safe end and PWR steam generator feedwater nozzle/safe end, known to be affected by severe thermal transients were also investigated in the study. The report concludes that reductions in fatigue life due to environmental effects (factors of up to 40 and 22 for PWR and BWR nozzles, respectively) are more than offset by the margins in fatigue life ( $\approx 60$ and 90 , respectively, for PWR and BWR nozzles) found in typical ASME Code fatigue evaluations. The margins in fatigue life were determined from the ratio of CUFs based on the mean experimental S-N curve and the Code design fatigue curve. The margins of $\approx 60$ and 90 would be true only if it was demonstrated that the fatigue $\mathrm{S}-\mathrm{N}$ curve for these specific components was comparable to or better than the mean experimental curve, and that the effects of mean stress, loading history, or component size and geometry are insignificant. As discussed earlier, the factors of 2 on stress and 20 on cycles should not be considered as safety margins but rather conversion factors that are required to obtain reasonable estimates of the lives of actual reactor components.

The conservatism in ASME Code fatigue evaluation procedures have also been demonstrated in fatigue tests on piping welds and components. ${ }^{26}$ In air, the margins on the number of cycles to failure for elbows and tees were 118-2500 and 123-1700, respectively, for CSs; and 47-170 and 25-322, respectively, for SSs. The margins for girth butt welds were significantly lower, e.g., 14-128 and 6-76, respectively, for CSs and SSs. However, in these tests on welds and components, the fatigue life was expressed as the number of cycles for the crack to penetrate through the wall, which ranged from 6 to $18 \mathrm{~mm}(0.237$ to $0.719 \mathrm{in}$.). The fatigue design curves represent the number of cycles to form a 3-mm-deep crack. Consequently, depending on wall thickness, the actual margins to failure may be lower by more than a factor two.

In addition, fatigue tests conducted on vessels at the Southwest Research Institute for the Pressure Vessel Research Council 27 show that $\approx 5$-mm deep cracks can form in CSs and LASs; very close to the values predicted by the ASME Code design curve, as shown in Fig. 2 . The tests were performed in room-temperature water on $0.914-\mathrm{m}$ (36-in.)-diameter vessels with 19-mm (0.75-in.) walls. These results clearly demonstrate that the Code design curves do not necessarily guarantee any margin of safety. A new nonmandatory Appendix to Section XI has been developed that does account for environmental effects. 


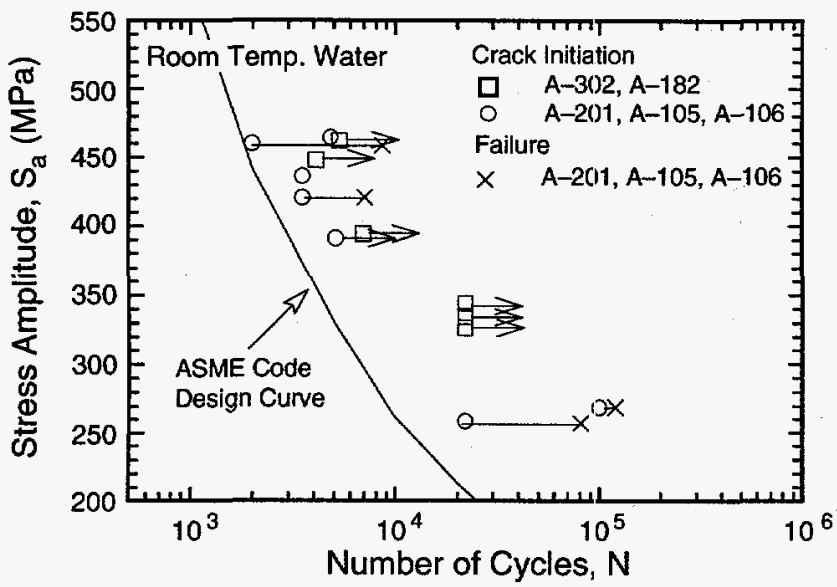

Figure 2.

Fatigue data for CS and LAS vessels

tested in room-temperature water

The objective of this task is to provide data and models for predicting the effects of environment on fatigue design curves and to assess the additivity of fatigue damage in piping and vessel steels under load histories typical of LWR components. The data will be used by the NRC staff to assess industry fatigue evaluations related to license renewal. The information, which will be helpful in assessing applicant submissions with regard to residual lifetimes of components subjected to fatigue in reactor coolant environments, will be provided to the ASME to help improve the design curves. Fatigue tests are being conducted to establish the effects of various loading and environmental variables on the fatigue $\mathrm{S}-\mathrm{N}$ behavior of pressure boundary steels. Progress on this task during the current reporting period is presented below.

\subsection{Crack Initiation and Crack Growth Characteristics of Carbon and Low-Alloy Steels (D. J. Gavenda, P. R. Luebbers, and O. K. Chopra)}

Available fatigue S-N data for CSs and LASs in an air environment indicate significant heat-to-heat variation. At $288^{\circ} \mathrm{C}$, fatigue life may vary up to a factor of 5 above or below the mean value. The results also indicate that the ASME mean curve for LASs is in good agreement with the experimental clata, and that for CSs it is somewhat conservative.

In air, the fatigue life of CSs and LASs depends on steel type, temperature, orientation (rolling or transverse), and strain rate. The fatigue life of CSs is a factor of $\approx 1.5$ lower than that of LASs. For both steels, fatigue life decreases with increase in temperature up to $320^{\circ} \mathrm{C}$. Some heats of CSs and LASs exhibit effects of strain rate and orientation. For these heats, fatigue life decreases with decreasing strain rate. Also, based on the distribution and morphology of sulfides, the fatigue properties in the transverse orientation may be inferior to those in the rolling orientation. Both CSs and LASs exhibit dynamic strain aging at temperatures between 200 and $370^{\circ} \mathrm{C}$, which leads to enhanced cyclic hardening, a secondary hardening stage, and negative strain rate sensitivity, i.e., cyclic stress increases with decreases in strain rate. The temperature range and extent of dynamic strain aging vary with compositional and structural factors. However, at the temperatures of dynamic strain aging. fatigue life of the steel may increase or decrease.

The fatigue S-N data in water indicate that environmental effects on fatigue life are significant when five conditions are satisfied simultaneously, viz., applied strain range, temperature, dissolved oxygen (DO) in water, and sulfur content in steel are above a minimum 
threshold level, and strain rate is below a critical value. There is little or no difference in susceptibility to environmental degradation of fatigue life of CSs and LASs.

For both steels, the fatigue data indicate threshold values of $150^{\circ} \mathrm{C}, 0.05 \mathrm{ppm} \mathrm{DO}$, and $\approx 0.003 \mathrm{wt} . \%$ sulfur, above which fatigue life in LWR environments may decrease. The effect of DO content on life saturates at $0.5 \mathrm{ppm}$. The data also indicate a threshold strain rate of $1 \% / \mathrm{s}$, below which fatigue life in LWR environments decreases; the effect saturates at $\approx 0.001 \% / \mathrm{s}$. Limited data suggest that the threshold strain is either equal to or slightly greater than the fatigue limit of the material. In the temperature range of $150-320^{\circ} \mathrm{C}$, fatigue life decreases linearly with temperature. When the threshold conditions for all five parameters are satisfied, fatigue life decreases logarithmically with decreasing strain rate and DO level.

Only a moderate decrease in fatigue life is observed in LWR environments when any one of the threshold conditions is not satisfied, e.g., at temperatures $\leq 150^{\circ} \mathrm{C}$, or in low-DO PWR environments ( $\leq 0.05 \mathrm{ppm} \mathrm{DO})$, or for low-sulfur steels ( $\leq 0.003 \mathrm{wt} \%$ sulfur). Under these conditions, life is $30-50 \%$ lower in water than in air. The fatigue life of these steels in air and LWR environments can be estimated from statistical models. 21,22 The models have recently been updated because we determined that, in the range of $0.05-0.5 \mathrm{ppm}$, the effect of DO was more logarithmic than linear. ${ }^{*}$ In air, fatigue life $\mathrm{N}$, defined as the number of cycles to form of a 3-mm-deep crack, of CSs is expressed as

$$
\ln (\mathrm{N})=6.570-0.00133 \mathrm{~T}-1.871 \ln \left(\varepsilon_{\mathrm{a}}-0.11\right)
$$

and that of LASs, as

$$
\ln (\mathrm{N})=6.667-0.00133 \mathrm{~T}-1.687 \ln \left(\varepsilon_{\mathrm{a}}-0.15\right)
$$

where $\varepsilon_{\mathrm{a}}$ is applied strain amplitude (\%) and $\mathrm{T}$ is temperature $\left({ }^{\circ} \mathrm{C}\right)$. For LWR environments the fatigue life $\mathrm{N}$ of CSs is expressed as

$$
\ln (\mathrm{N})=6.186-1.871 \ln \left(\varepsilon_{\mathrm{a}}-0.11\right)+0.1097 \mathrm{~S}^{*} \mathrm{~T}^{*} \mathrm{O}^{*} \dot{\varepsilon}^{*}
$$

and that of LASs, as

$$
\ln (\mathrm{N})=5.901-1.687 \ln \left(\varepsilon_{\mathrm{a}}-0.15\right)+0.1097 \mathrm{~S}^{*} \mathrm{~T}^{*} \mathrm{O}^{*} \dot{\varepsilon}^{*},
$$

where $\varepsilon_{\mathbf{a}}$ is the applied strain amplitude (\%); $\mathrm{T}$ is test temperature $\left({ }^{\circ} \mathrm{C}\right)$; and $\mathrm{S}^{*}, \mathrm{~T}^{*}$, $\mathrm{O}^{*}$, and $\dot{\varepsilon}^{*}$ are transformed sulfur content $(w t . \%)$, temperature $\left({ }^{\circ} \mathrm{C}\right), \mathrm{DO}(\mathrm{ppm})$, and strain rate $(\% / \mathrm{s})$, respectively, defined as follows:

$$
\begin{array}{ll}
\mathrm{S}^{*}=\mathrm{S} & (0<\mathrm{S} \leq 0.015) \\
\mathrm{S}^{*}=0.015 & (\mathrm{~S}>0.015) \\
\mathrm{T}^{*}=0 & (\mathrm{~T}<150) \\
\mathrm{T}^{*}=\mathrm{T}-150 & (\mathrm{~T}=150-350)
\end{array}
$$

\footnotetext{
* O. K. Chopra, presented at the joint meeting of the working groups on Evaluation Methods and S/N Data Analysis, Pressure Vessel Research Council, April 1996, Orlando, FL.
} 


$$
\begin{array}{ll}
\mathrm{O}^{*}=0 & (\mathrm{DO}<0.05) \\
\mathrm{O}^{*}=\ln (\mathrm{DO} / 0.04) & (0.05 \leq \mathrm{DO} \leq 0.5) \\
\mathrm{O}^{*}=\ln (12.5) & (\mathrm{DO}>0.5) \\
\dot{\varepsilon}^{*}=0 & (\dot{\varepsilon}>1) \\
\dot{\varepsilon}^{*}=\ln (\dot{\varepsilon}) & (0.001 \leq \dot{\varepsilon} \leq 1) \\
\dot{\varepsilon}^{*}=\ln (0.001) & (\dot{\varepsilon}<0.001)
\end{array}
$$

The functional forms for $\mathrm{S}^{*}, \mathrm{~T}^{*}, \mathrm{O}^{*}$, and $\dot{\varepsilon}^{*}$ were defined on the basis of the experimental data. The last term in Eqs. $3 \mathrm{a}$ and $3 \mathrm{~b}$ is zero when any one of the critical threshold conditions is not satisfied, e.g., in low-DO (DO levels $<0.05 \mathrm{ppm}$ ) PWR environments, or at temperatures $<150^{\circ} \mathrm{C}$, or strain rates $>1 \% / \mathrm{s}$.

Fatigue tests are also being, conducted to determine the crack initiation and crack growth characteristics of CSs and LASs in air and LWR environments. Results of fatigue tests that examine the influence of reactor environment on formation and growth of short cracks in A533-Gr B LAS have been presented earlier. ${ }^{19}$ The results indicate that in air, fatigue cracks $10 \mu \mathrm{m}$ or longer form quite early during fatigue $(<10 \%$ of life). The largest crack is $<100 \mu \mathrm{m}$ at half life. The decrease in fatigue life in high-DO water is primarily caused by the effects of environment during early stages of fatigue damage, i.e., growth of cracks $<100 \mu \mathrm{m}$ deep. For cracks $>100 \mu \mathrm{m}$ deep, crack growth rates are an order of magnitude higher in high-DO water than in air.

During this reporting period, additional fatigue tests have been conducted to determine the crack initiation and crack growth characteristics of A533-Gr B LAS and A106-Gr B CS in water. Results of these tests and data obtained earlier are presented below and the effects of LWR environments on the formation and growth of short cracks are discussed.

\subsubsection{Mechanism of Fatigue Crack Initiation}

The fatigue S-N curve represents the process of fatigue crack initiation (or fatigue damage accumulation). It specifies that, for a given stress or strain amplitude, the number of cycles needed to form an "engineering" crack (e.g., a 3-mm-deep crack), is defined as the fatigue life of the material. Deformation and microstructural changes in the surface grains control fatigue cracking. During cyclic straining, irreversibility of dislocation glide leads to the development of surface roughness. Also, strain localization in persistent slip bands (PSBs) results in the formation of extrusions and intrusions. With continued cycling, microcracks ultimately form in the PSBs or at the edges of slip-band extrusions. At high strain amplitudes, microcracks form in notches that develop at grain or twin boundaries. Similarly, microcracks can also develop at phase boundaries (e.g., ferrite/pearlite boundaries) or by cracking of second-phase particles (e.g., sulfide or oxide inclusions).

Once a microcrack forms, it continues to grow along its slip plane or a PSB as a Mode II (shear) crack in Stage I growth (orientation of the crack is usually at $45^{\circ}$ to the stress axis). At low strain amplitudes, a Stage I crack may extend across several grain diameters before the increasing stress intensity of the crack promotes slip on systems other than the primary slip. A dislocation cell structure normally forms at the crack tip. Because slip is no longer confined to planes at $45^{\circ}$ to the stress axis, the crack begins to propagate as a Mode I (tensile) crack, normal to the stress axis in Stage II growth. At high strain amplitudes, the stress intensity is quite large and the crack propagates entirely by the Stage II process. Stage II crack 
propagation continues until the crack reaches engineering size $(\approx 3 \mathrm{~mm}$ deep). In air or mildly corrosive environments, Stage II fracture is characterized by fatigue striations.

Fatigue life, or number of allowable cycles, has conventionally been represented by two stages: (a) initiation, which represents the cycles $\mathrm{N}_{i}$ for formation of microcracks on the surface; and (b) propagation, which represents cycles $\mathrm{N}_{\mathrm{p}}$ for propagation of the surface cracks to engineering size. Thus, fatigue life $\mathrm{N}$ is the sum of the two stages, i.e., $\mathrm{N}=\mathrm{N}_{1}+\mathrm{N}_{\mathrm{p}}$. The $\mathrm{N}_{\mathrm{i}}$ stage is considered to be sensitive to the stress or strain amplitude, e.g., most of the life may be spent in initiating a crack at low strain amplitudes, whereas, at high strain amplitudes, cracks initiate easily.

An alternative approach considers fatigue life to be entirely composed of crack propagation;28,29 for polycrystalline materials, the period for the formation of surface cracks is zero (Fig. 3). Fatigue damage in a material is the current size of a fatigue crack, and damage accumulation is the rate of crack growth. 29 During fatigue loading of smooth test specimens, cracks form immediately at surface irregularities/discontinuities either already in existence or produced by slip bands, grain boundaries, second-phase particles, etc. Growth of these surface cracks may be divided into three regimes: (a) initial period which involves growth of microstructurally small cracks (MSCs) that are characterized by decelerating crack growth, as shown in region $A B$ of Fig. 3; (b) a final period of growth characterized by accelerating crack growth, region $\mathrm{CD}$; and (c) a transition period controlled by a combination of the two regimes, region $\mathrm{BC}$.

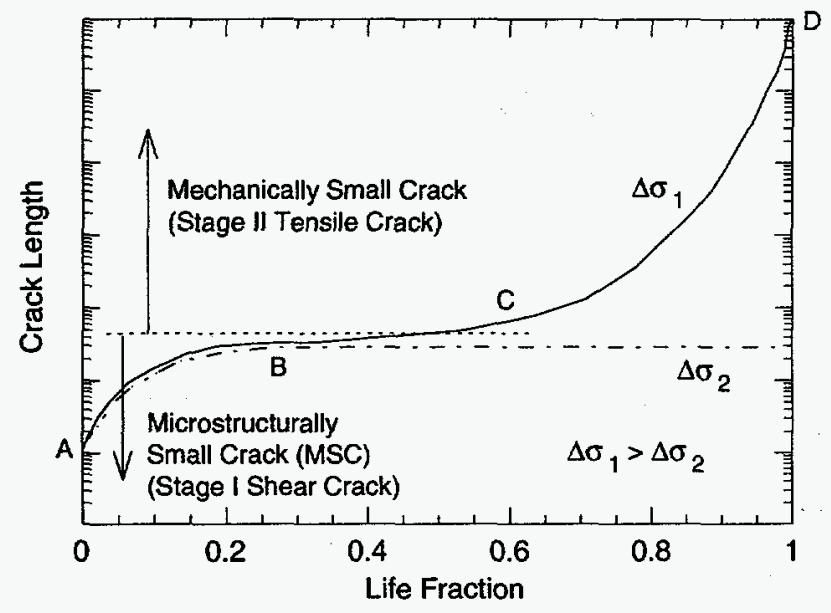

Figure 3. Growth of cracks in smooth fatigue specimens

The growth of MSCs is very sensitive to microstructure. ${ }^{30-33}$ The MSCs correspond to Stage I cracks and grow along slip planes as shear cracks in the early stage of growth. For MSCs, microstructural effects are strong because of the Stage I growth, i.e., crystallographic growth. Grain boundaries, triple points, and phase boundaries markedly decrease growth rates. In ferritic-pearlitic steels, fatigue cracks initiate and propagate preferentially in the ferrite phase that forms as long allotriomorphs at the prior austenite phase boundaries. 32,33 The ferrite-pearlite phase boundaries act as strong barriers to crack propagation, and growth rates decrease significantly when small cracks grow into the pearlite from the ferrite. 32 Limited data suggest that microstructural effects are more pronounced at negative stress 
ratios; the compressive component of the applied load plays an important role in the formation of Stage I facets and as a driving force for cracking. 31

Fatigue cracks greater than the critical length of MSCs show little or no influence of microstructure and are called mechanically small cracks. 31 For a stress ratio of -1 , the transition from an MSC to a mechanically small crack for several materials has been estimated to be approximately eight times the unit size of the microstructure. 31 Mechanically small cracks correspond to Stage II, or tensile, cracks characterized by striated crack growth, with a fracture surface normal to the maximum principal stress. Their growth rates tend to decrease as the cracks grow because crack closure becomes more significant for larger cracks. For ferritic-pearlitic steels, Stage II crack propagation occurs when stress intensity and mode of growth attain a critical level, break through the pearlite, and join other ferrite cracks.

At low stress levels, e.g., $\Delta \sigma_{2}$ in Fig. 3, the transition from MSC growth to accelerating crack growth does not occur and the cracks are nonpropagating. This circumstance represents the fatigue limit for the smooth specimen. Although cracks can form below the fatigue limit, they can grow to engineering size only at stresses greater than the fatigue limit. Possible preexisting large cracks in the material, e.g., defects in welded samples, or those created by growth of microcracks at high stresses, can grow at stress levels below the fatigue limit.

Reduction in fatigue life in LWR coolant environments may arise from easy formation of surface microcracks and/or an increase in growth rates of cracks, during either the initial stage of MSC and shear crack growth or the transition and final stage of tensile crack growth. Carbon steel and LAS specimens tested in water show surface micropitting and cavities that were produced by either corrosion or dissolution of MnS inclusions. ${ }^{13,14}$ These micropits can act as sites for the formation of fatigue cracks.

Detailed metallographic studies of fatigue specimens 13,14 and exploratory tests 8,9 have been conducted to evaluate the contributions of environment to the formation of surface microcracks. The results indicate that the reduction in fatigue life in high-DO water is primarily due to environmental effects on crack propagation. Environment appears to have little or no effect on the formation of surface microcracks. Although all specimens tested in water show surface micropitting, there is no indication that these micropits enhance cracking. Irrespective of environment, cracks in CS and LAS nucleate either along slip bands, sulfide inclusions, carbide particles, or at the ferrite/pearlite phase boundaries.

The environmental enhancernent of fatigue crack growth in pressure vessel steels in hightemperature oxygenated water and the effects of sulfur content, loading rate, and flow velocities are well known. ${ }^{34-39}$ The enhanced growth rates in LWR environments have been attributed to either slip dissolution 40,41 or hydrogen-induced cracking 42 mechanisms. The requirements for a slip dissolution model are that a protective oxide film is thermodynamically stable so that a crack will propagate with a high aspect ratio without degrading into a blunt pit, and that a strain increment occurs to rupture the film and thereby exposes the underlying matrix to the environment. Once the passive oxide film is ruptured, crack extension is controlled by dissolution of freshly exposed surfaces and by the oxidation characteristics. Hydrogen-induced cracking of LASs is explained as follows: hydrogen produced by the oxidation reaction at or near the crack tip is partly absorbed into the metal; the absorbed hydrogen diffuses ahead of the crack tip, interacts with MnS inclusions, and leads to the 
formation of cleavage cracks at the inclusion/matrix interface; and linkage of the cleavage cracks results in discontinuous crack extension in addition to extension caused by mechanical fatigue.

Both mechanisms depend on oxide rupture rates, passivation rates, and liquid diffusion rates. For the environment to affect fatigue life, a critical level of sulfide ions must be present at the crack tip. Dissolution of MnS inclusions changes the water chemistry near the crack tip, making it more aggressive. The result is enhanced crack growth rate (CGR) because either the dissolved sulfides decrease the repassivation rate, which increases the amount of metal dissolution for a given oxide rupture rate; 41 or the dissolved sulfide poisons the recombination of hydrogen atoms liberated by corrosion, which enhances hydrogen uptake by the steel at the crack tip. ${ }^{43}$ Recent studies, based on a balance between sulfide supply rate due to exposure of sulfide inclusions from an advancing crack and mass transport of sulfur ions away from the crack tip by diffusion, indicate that in low-DO PWR water, the average critical crack velocity for environmental enhancement of crack growth is inversely proportional to the crack depth. ${ }^{34}$ Furthermore, the critical velocity must be maintained for a minimum crack extension of $\approx 0.3 \mathrm{~mm}$ for enhancement to occur. The results indicate that for cracks $<0.3 \mathrm{~mm}$, a low-DO environment should not effect the rate, and for cracks $0.3-3 \mathrm{~mm}$, velocities of $3.8 \times 10^{-9}$ to $4.2 \times 10^{-10} \mathrm{~m} \cdot \mathrm{s}^{-1}$ are required for the environment to decrease fatigue life. Although these velocities are not achieved under loading conditions typically used in fatigue tests, low-DO water can decrease fatigue life of steels that have a favorable distribution and morphology of sulfides. In these steels, a critical concentration of sulfide ions can be maintained at the crack tip because the probability of an advancing crack to intercept sulfide inclusions is higher. The existing fatigue $\mathrm{S}-\mathrm{N}$ data are consistent with these results; fatigue life of CSs and LASs in lowDO water $(<0.01 \mathrm{ppm} \mathrm{DO})$ at $288^{\circ} \mathrm{C}$ is lower than that in air by a factor of $<2$. However, it is plausible that, in high-DO water environments, MSCs or nonpropagating cracks could grow by anodic dissolution or other processes and thereby decrease the fatigue life of the material.

\subsubsection{Experimental}

Low-cycle fatigue tests have been conducted on A106-Gr B CS and A533-Gr B LAS. The A533-Gr B material was obtained from the lower head of the Midland reactor vessel, which was scrapped before the plant was completed. The A106-Gr B material was obtained from a 508-mm-diameter Schedule 140 pipe fabricated by the Cameron Iron Works, Houston, TX. The compositions of the two materials are given in Table 1, and average room-temperature tensile properties provided by the material suppliers are given in Table 2 . The CS has a pearlitic structure, whereas the LAS consists of tempered bainite. Smooth cylindrical specimens with a diameter of $9.5 \mathrm{~mm}$ and a gage length of $19 \mathrm{~mm}$ were used for the fatigue tests. The specimen gage length was given a $1-\mu \mathrm{m}$ surface finish in the axial direction to prevent circumferential scratches that might act as sites for crack initiation.

The tests in water were conducted in a small autoclave, under stroke control, where the specimen strain was controlled between two locations outside the autoclave. All tests were conducted at $288^{\circ} \mathrm{C}$ with fully reversed axial loading (i.e., $\mathrm{R}=-1$ ) and a triangular or sawtooth waveform. The strain rate for the triangular wave and for the fast-loading half of the sawtooth wave was $0.4 \% / \mathrm{s}$. Tests in air were performed under strain control with an axial extensometer; specimen strain between the two locations that were used in the water tests was also recorded. Information from the air tests was used to determine the stroke required to 
Table 1. Composition (wt.\%) of ferritic steels

\begin{tabular}{|c|c|c|c|c|c|c|c|c|c|}
\hline Material & Source & C & P & $\mathbf{S}$ & Si & $\mathrm{Cr}$ & $\mathrm{Ni}$ & $\mathbf{M n}$ & Mo \\
\hline \multirow[t]{2}{*}{ A106-Gr Ba } & ANL & 0.29 & 0.013 & 0.015 & 0.25 & 0.19 & 0.09 & 0.88 & 0.05 \\
\hline & Supplier & 0.29 & 0.016 & 0.015 & 0.24 & - & - & 0.93 & - \\
\hline \multirow[t]{2}{*}{$A 533-G r B^{b}$} & ANL & 0.22 & 0.010 & 0.012 & 0.19 & 0.18 & 0.51 & 1.30 & 0.48 \\
\hline & Supplier & 0.20 & 0.014 & 0.016 & 0.17 & 0.19 & 0.50 & 1.28 & 0.47 \\
\hline
\end{tabular}

a Schedule 140 pipe 508-mm O.D., fabricated by Cameron Iron Works, Heat J-7201. Actual heat treatment not known.

b Hot-pressed plate, $162 \mathrm{~mm}$ thick, from Midland reactor lower head. Austenitized at $871-899^{\circ} \mathrm{C}$ for $5.5 \mathrm{~h}$ and brine quenched, then tempered at $649-663^{\circ} \mathrm{C}$ for $5.5 \mathrm{~h}$ and brine quenched. The plate was machined to a final thickness of $127 \mathrm{~mm}$. The inside surface was inlaid with $4.8-\mathrm{mm}$ weld cladding and stress relieved at $607^{\circ} \mathrm{C}$ for $23.8 \mathrm{~h}$.

Table 2. Average room-temperature tensile properties of CS and LAS

\begin{tabular}{ccccc}
\hline \multicolumn{1}{c}{ Material } & $\begin{array}{c}\text { Yield Stress } \\
(\mathrm{MPa})\end{array}$ & $\begin{array}{c}\text { Ultimate Stress } \\
(\mathrm{MPa})\end{array}$ & $\begin{array}{c}\text { Elongation } \\
(\%)\end{array}$ & $\begin{array}{c}\text { Reduction in } \\
\text { Area (\%) }\end{array}$ \\
\hline A106-Gr B & 301 & 572 & 23.5 & 44.0 \\
A533-Gr B & 431 & 602 & 27.8 & 66.6 \\
\hline
\end{tabular}

maintain constant strain in the specimen gage length for tests in water; the stroke was gradually increased during the test to account for cyclic hardening of the material and to maintain constant strain in the specimen gage section. Details about the test facility and procedure have been described elsewhere. 8,13

Surface replication by an acetate film was employed to measure surface length of cracks in specimens tested in room-temperature air. This technique provides $\approx 1-\mu \mathrm{m}$ resolution of the surface and allows surface features such as PSBs and cracking to be identified. The tests were interrupted periodically to allow for surface replication. A detailed examination of the gage surface of the specimen was conducted to establish the morphology of final fatigue cracks. The region on surface replicas that corresponded to the final cracks was examined to determine the length of surface cracks as a function of fatigue cycles.

The crack morphology and length of the final crack for an A533-Gr B specimen tested at $0.75 \%$ strain range with a sawtooth waveform (Test No. 1779, Specimen Id. 44-67) are shown in Fig. 4. Surface crack lengths were used as reference markers to define probable crack fronts on the fracture surface. Fatigue striations on the fracture surface were used as guidelines to determine the shape of the crack fronts. The probable crack fronts for the surface crack in Fig. 4, after 5316, 5779, 5955, and 6195 cycles, are shown in Fig. 5 . The results indicate that three cracks merged to form the final fracture surface. The primary crack was initiated near an inclusion and reached a surface length of $\approx 100 \mu \mathrm{m}$ after 3062 cycles (i.e., $\approx 50 \%$ of fatigue life). Two secondary cracks merged with the primary crack after $\approx 5700$ and 6000 cycles. Crack depth, a, was determined from the surface crack length $S$ from the relationship

$$
\frac{\mathrm{a}}{\mathrm{S}}:=\frac{1}{\pi}
$$

The calculated values agree closely with measurements of the probable crack depth on the fracture surface. 


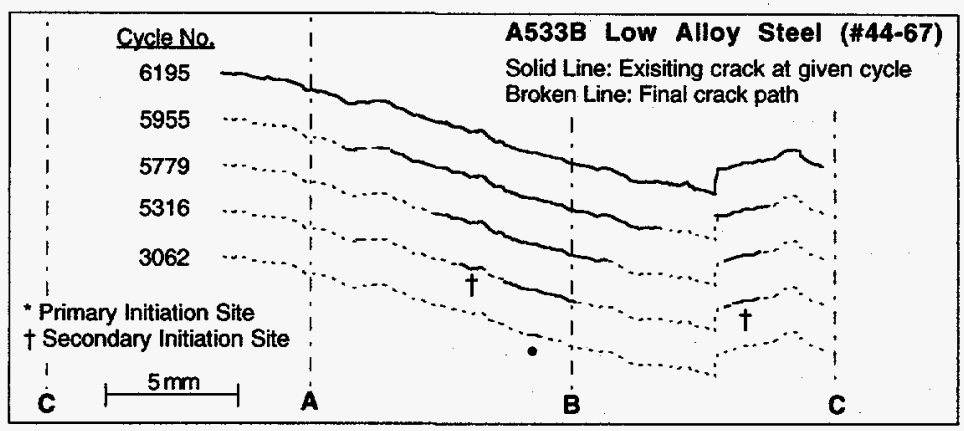

Figure 4. Morphology and length of surface crack after varying number of cycles for A533-Gr B steel tested in air at room temperature, $0.75 \%$ strain range, and slow/fast sawtooth waveform. Letters denote reference points used to locate the same regions on replicas.

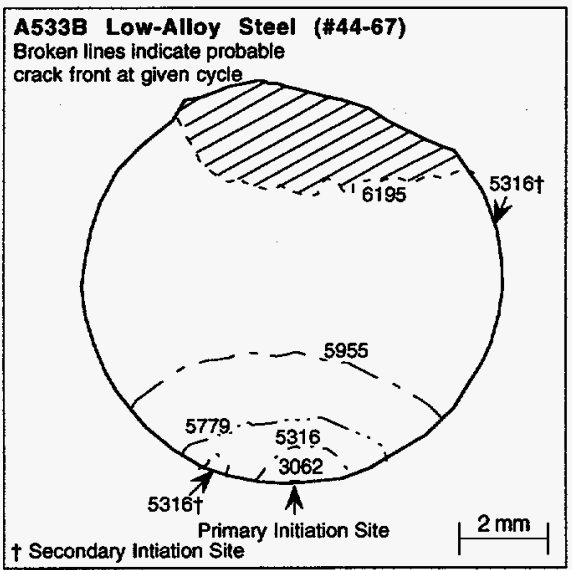

Figure 5.

Fracture surface and probable crack front after varying numbers of fatigue cycles for surface crack shown in Fig. 4

For the tests in high-temperature water, crack growth characteristics were determined with block loading, e.g., the slow/fast fatigue tests were interrupted each period at $\approx 10 \%$ of life, and the specimen was subjected to a block of fast/fast cycles at either the same or a lower strain range. The block of fast/fast cycles leaves a beach mark on the fracture surface that can be used to characterize crack size as a function of fatigue cycles for the slow/fast test. A photomicrograph of the fracture surface of a slow/fast test at $0.75 \%$ strain range, interrupted every 50 cycles and subjected to 170 cycles of fast/fast loading at $0.4 \%$ strain range, is shown in Fig. 6. Beach marks produced by four of the five fast/fast loading sequences at the low strain range can be seen clearly on the fracture surface.

\subsubsection{Fatigue Life}

The results of room-temperature tests in air with surface replication and block loading tests in water at $288^{\circ} \mathrm{C}$ are given in Table 3. Relevant data obtained earlier $8,9,17$ on A533Gr B and A106-Gr B steels in air and water environments are also listed in the table. The results from the present study and data obtained earlier are shown in Figs. 7-9. Estimates of fatigue lives based on statistical models, Eqs. 2-4, are also included in the figures. The recent test results are consistent with the earlier data. 


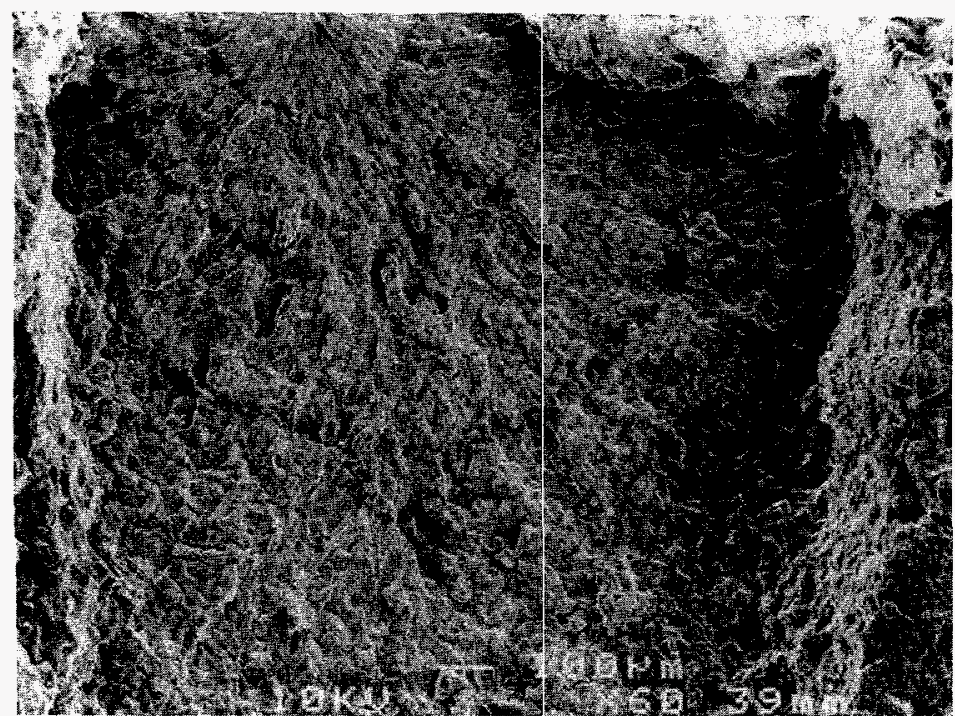

Figure 6.

Beach marks produced by four of five block loading sequences on the fracture surface of $\mathrm{A533-Gr} B$ steel tested at $288^{\circ} \mathrm{C}$ in high-DO water

Table 3. Fatigue results for CSs and LASs in air and water environments

\begin{tabular}{|c|c|c|c|c|c|c|c|c|c|}
\hline \multirow[b]{2}{*}{ Test No. } & \multirow[b]{2}{*}{ Environ. ${ }^{a}$} & \multirow{2}{*}{$\begin{array}{c}\text { Temp. } \\
\left({ }^{\circ} \mathrm{C}\right)\end{array}$} & \multirow{2}{*}{$\begin{array}{c}\text { Strain } \\
\text { Range } \\
(\%)\end{array}$} & \multicolumn{2}{|c|}{$\begin{array}{c}\text { Strain Rate } \\
(\% / \mathrm{s})\end{array}$} & \multirow{2}{*}{$\begin{array}{l}\text { Stress } \\
\text { Range } \\
\text { (MPa) }\end{array}$} & \multirow{2}{*}{$\begin{array}{c}\text { Life } \\
\mathrm{N}_{25} \\
\text { (Cycles) }\end{array}$} & \multirow{2}{*}{$\begin{array}{c}\text { Number } \\
\text { of } \\
\text { Blocks }\end{array}$} & \multirow[b]{2}{*}{ CUF ${ }^{b}$} \\
\hline & & & & Ten. & Comp. & & & & \\
\hline \multicolumn{10}{|c|}{ A533-Gr B Low-Alloy Steel } \\
\hline 1785 & Air & 25 & 0.76 & 0.4 & 0.4 & 763.7 & 8,840 & c & 0.974 \\
\hline 1779 & & & 0.76 & 0.004 & 0.4 & 759.8 & 5,960 & c & 0.657 \\
\hline 1786 & & & 0.40 & 0.4 & 0.4 & 687.7 & 61,100 & c & 0.513 \\
\hline 1533 & PWR & 288 & 0.77 & 0.004 & 0.4 & 916.0 & 3,416 & - & 0.812 \\
\hline 1818 & & & 0.80 & 0.004 & 0.4 & 919.0 & 2,030 & $5^{d}$ & 0.536 \\
\hline 1645 & High DO & 288 & 0.72 & 0.4 & 0.4 & 831.1 & 2,736 & - & 0.819 \\
\hline 1626 & & & 0.79 & 0.004 & 0.4 & 910.1 & 247 & - & 0.794 \\
\hline 1715 & & & 0.81 & 0.004 & 0.4 & 904.1 & 381 & - & 1.310 \\
\hline 1718 & & & 0.81 & 0.004 & 0.4 & 904.3 & 346 & - & 1.190 \\
\hline 1800 & & & 0.81 & 0.004 & 0.4 & 897.9 & 303 & $5^{e}$ & 1.042 \\
\hline 1803 & & & 0.82 & 0.004 & 0.4 & 913.9 & 272 & $7^{\mathrm{f}}$ & 0.966 \\
\hline 1641 & & & 0.39 & 0.4 & 0.4 & 693.0 & 17,367 & - & 0.387 \\
\hline 1665 & & & 0.38 & 0.004 & 0.4 & 717.0 & 3,455 & - & 0.522 \\
\hline 1815 & & & 0.38 & 0.004 & 0.4 & 735.8 & 2,200 & $5 g$ & 0.332 \\
\hline \multicolumn{10}{|c|}{ A106-Gr B Carbon Steel } \\
\hline 1619 & Air & 288 & 0.40 & 0.4 & 0.4 & 741.7 & 37,142 & - & 0.844 \\
\hline 1636 & & & 0.40 & 0.4 & 0.4 & 749.6 & 34,829 & - & 0.791 \\
\hline 1634 & High DO & 288 & 0.40 & 0.4 & 0.4 & 733.2 & 19,318 & - & 0.743 \\
\hline 1624 & & & 0.46 & 0.004 & 0.4 & 775.7 & 2,276 & - & 2.104 \\
\hline 1639 & & & 0.42 & 0.004 & 0.4 & 751.6 & 2,951 & - & 1.940 \\
\hline 1816 & & & 0.43 & 0.004 & 0.4 & 759.6 & 1,410 & $5 g$ & 1.015 \\
\hline \multicolumn{10}{|c|}{$\begin{array}{l}\text { PWR = simulated PWR water that contains } 2 \mathrm{ppm} \text { lithium and } 1000 \mathrm{ppm} \text { boron; high-DO } \\
=\text { deionized water with } 0.6-0.8 \mathrm{ppm} \text { DO. } \\
\mathrm{b} \text { Fatigue usage factor based on the statistical model, i.e., usage = observed life } / \text { life estimated } \\
\text { from the model. } \\
\text { c Interrupted periodically to allow for surface replication. } \\
\mathrm{d} \text { Every } 450 \text { cycles, a block of } 170 \text { fast } / \text { fast cycles at } 0.4 \% \text { strain range and } 0.4 \% / \mathrm{s} \text { strain rate. } \\
\text { e Every } 50 \text { cycles, a block of } 170 \text { fast } / \text { fast cycles at } 0.4 \% \text { strain range and } 0.4 \% / \mathrm{s} \text { strain rate. } \\
\text { f Every } 30 \text { cycles, a block of } 170 \text { fast/fast cycles at } 0.4 \% \text { strain range and } 0.4 \% / \mathrm{s} \text { strain rate. } \\
\text { g Every } 420 \text { cycles, a block of } 500 \text { fast/fast cycles at the same strain range but } 0.4 \% / \mathrm{s} \text { strain } \\
\text { rate. }\end{array}$} \\
\hline
\end{tabular}




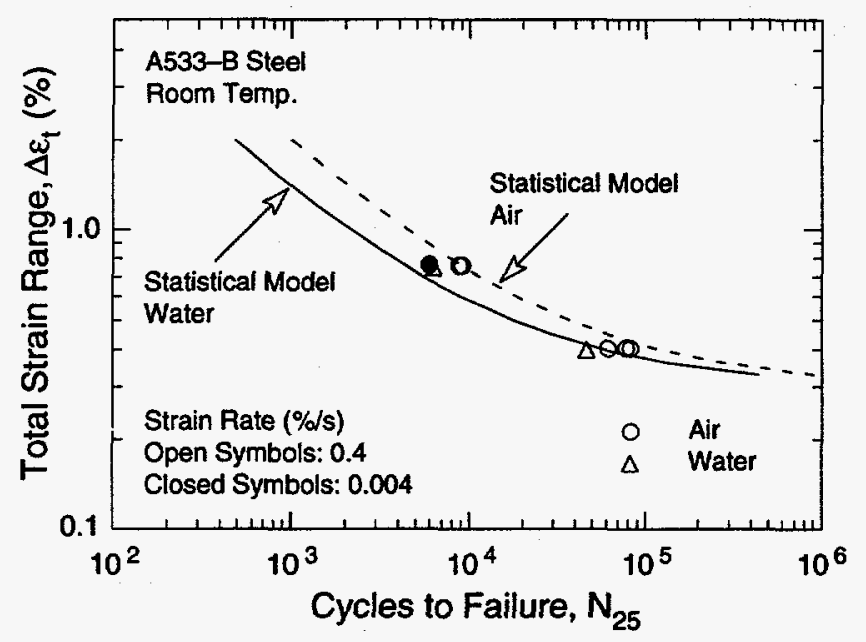

Figure 7.

Fatigue lives of $A 533-G r B$ steel tested at room temperature in air and high-DO water
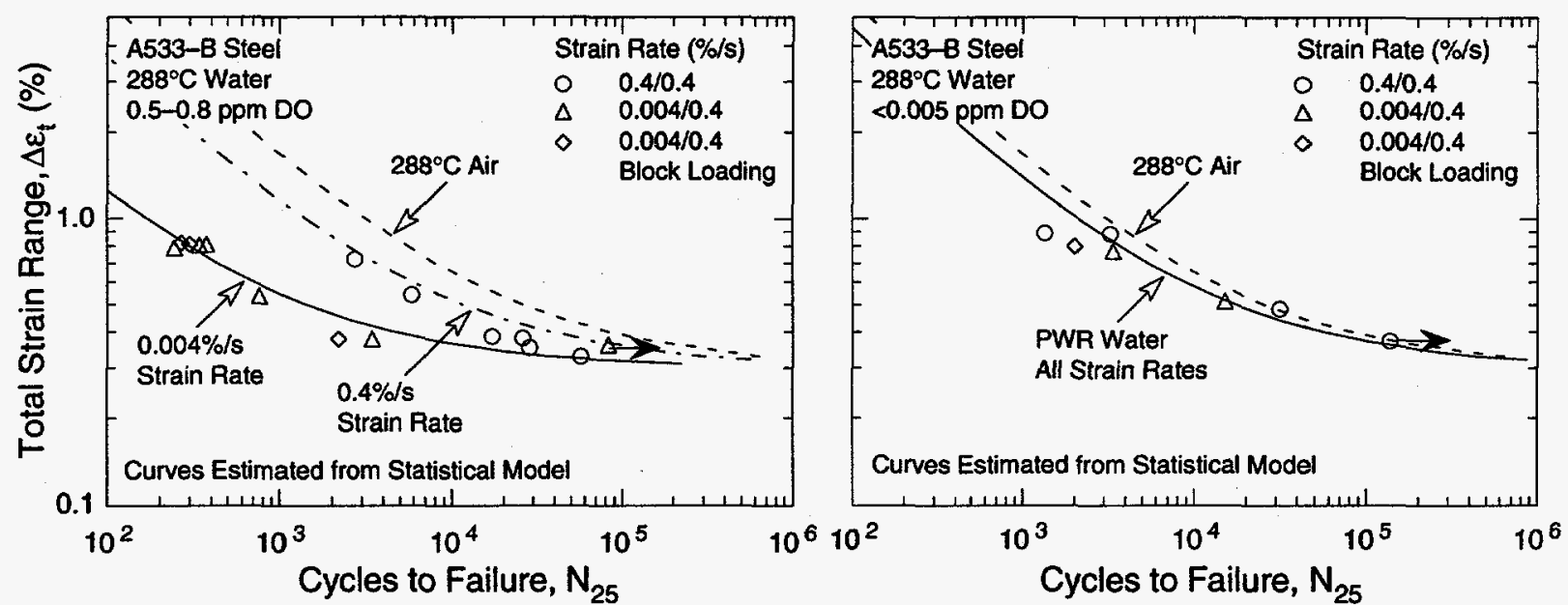

Figure 8. Fatigue lives of $A 533-G r B$ steel tested at $288^{\circ} \mathrm{C}$ in simulated PWR and high-DO water

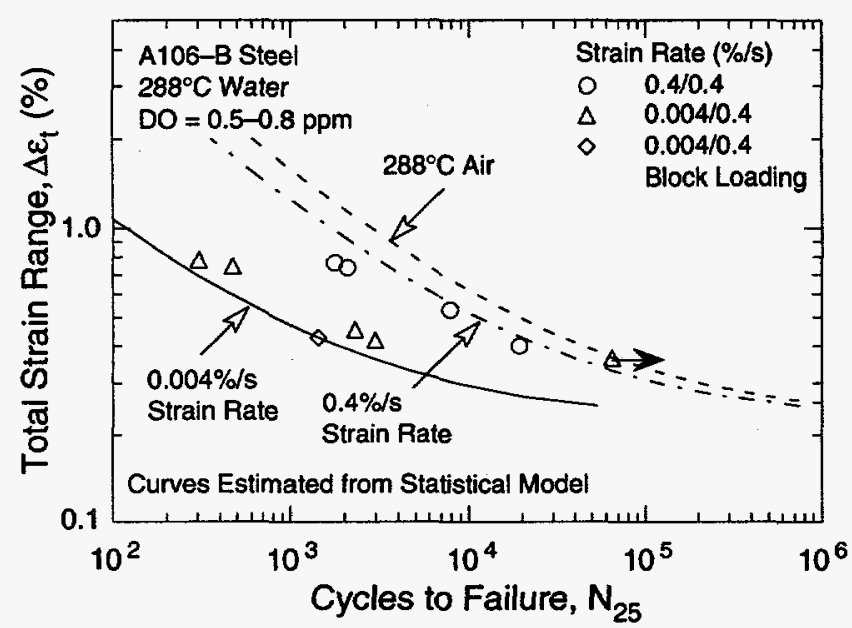

Figure 9.

Fatigue lives of $A 106-G r B$ steel tested at $288^{\circ} \mathrm{C}$ in high-DO water 


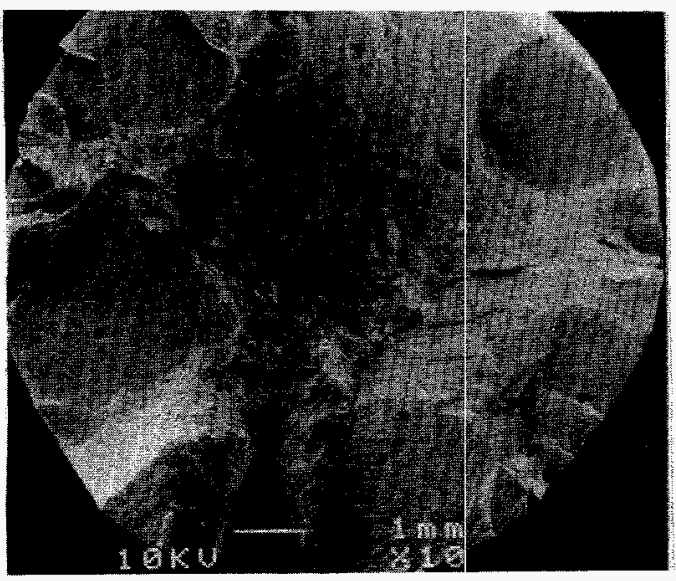

(a)

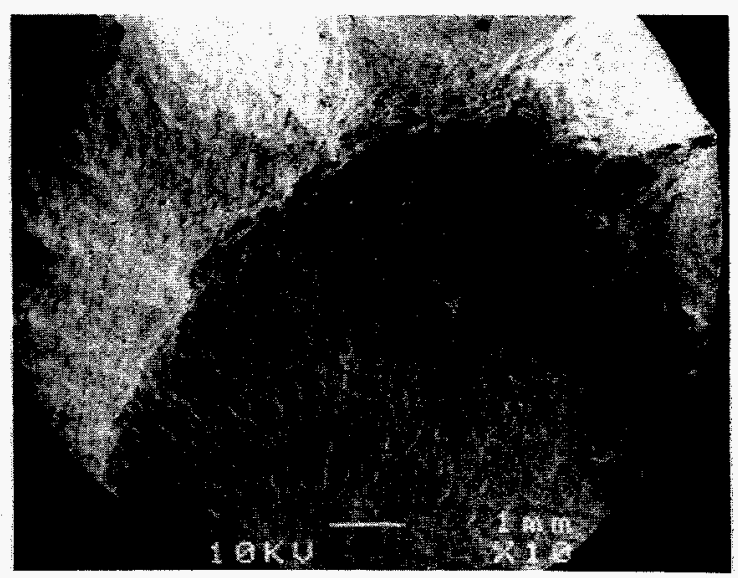

(b)

Figure 10. Photomicrographs of fractured specimens tested with slow/fast waveform at (a) $0.8 \%$ strain range interrupted every 30 cycles and subjected to 170 cycles at lower strain range, and (b) $0.38 \%$ strain range interrupted every 420 cycles and subjected to 170 cycles at fast strain rate

At room temperature, the fatigue life in water is $\approx 50 \%$ lower than in air. The difference in fatigue lives of specimens tested at 0.4 and $0.004 \% / \mathrm{s}$ strain rate may be attributed to experimental scatter and not to strain rate effects. Although the available $\mathrm{S}-\mathrm{N}$ data indicate that, in air, strain rate may influence fatigue life of some CSs and LASs, these effects occur in the temperature range for dynamic strain aging $\left(200-370^{\circ} \mathrm{C}\right) .^{9}$ In room-temperature air, strain rate has little or no effect on the fatigue life of CSs and LASs.

The results of the block loading tests are consistent with results obtained from tests conducted at constant strain range and strain rate (Figs. 8 and 9). Both A533-Gr B LAS and A106-Gr B CS show significant reduction in fatigue life in high-DO water at $288^{\circ} \mathrm{C}$ and a strong dependence on strain rate. Fatigue life decreases rapidly with decreasing strain rate; however, a few differences may be observed between the results from tests with block loading and those obtained at constant strain range and rate. For both steels, the fatigue lives of specimens subjected to block loading are consistently lower than those of specimens subjected to constant strain range and rate. The fatigue lives, expressed as CUF, were estimated from a statistical model and are listed in Table 3. For a specific test condition, the fatigue usage factor is expressed as the ratio of the observed and estimated values of fatigue life; CUF is the sum of individual usage factors.

The fracture behavior during block loading tests also differs from that observed during constant strain tests. Photomicrographs of the fracture surface of A533-Gr B specimens tested at 0.38 and $0.82 \%$ strain range are shown in Fig. 10. Both fracture surfaces consist of several cracks that were initiated at different axial and circumferential locations. These cracks do not merge into a single primary crack. The fracture surface of specimens tested at constant strain range consist of a single crack, or a few cracks that merge to form the final fracture surface, as shown in Fig. 5.

\subsubsection{Fatigue Crack Depth}

For the tests in air and water environments, the depth of the largest crack is plotted as a function of fatigue cycles in Fig. 11, and as a function of fractional life in Fig. 12. The results 

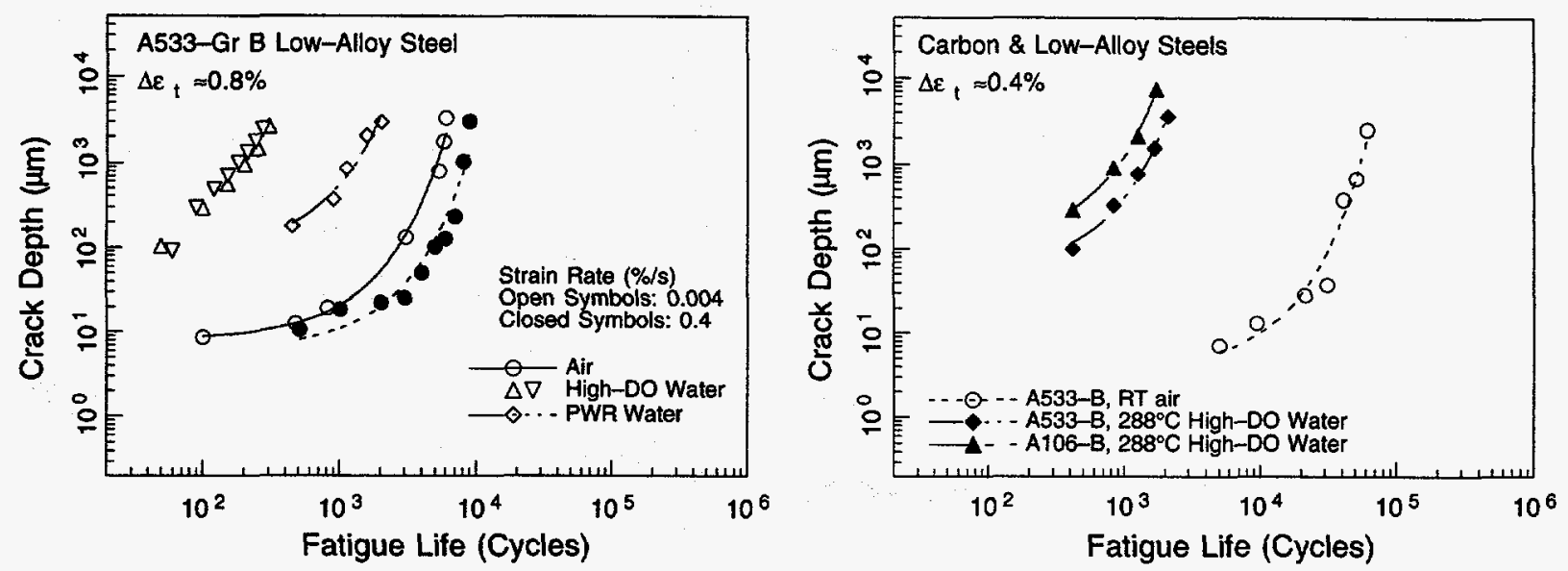

Figure 11. Depth of largest crack as a function of fatigue cycles for A533-Gr B LAS and A106-Gr B CS in air and water environments
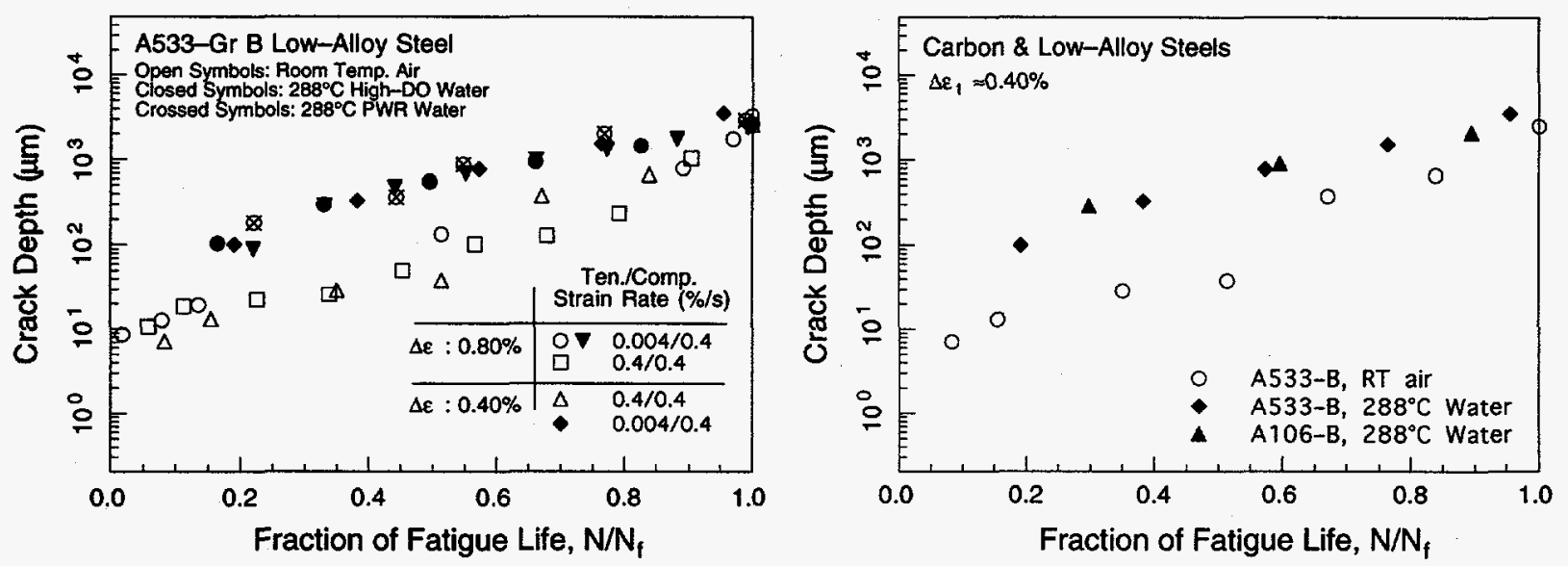

Figure 12. Depth of largest crack as a function of fractional life for A533-Gr B LAS and A106-Gr B CS in air and water environments

indicate that, in room-temperature air, $\approx 10-\mu \mathrm{m}$ cracks form quite early during fatigue, e.g., $<10 \%$ of fatigue life. Also, depth of the largest crack is $<100 \mu \mathrm{m}$ at half life. The results in high-DO water show that the decrease in fatigue life of both A106-Gr B CS and A533-Gr B LAS is primarily caused by the effects of environment during early stages of fatigue damage, i.e., growth of cracks $<100 \mu \mathrm{m}$ in depth (Stage I crack growth). For the same life fraction, crack depth is greater in high- or low-DO water than in air. At $\approx 0.8 \%$ strain range, only $30-50$ cycles are needed to form a $100-\mu \mathrm{m}$ crack in high-DO water (average growth rate of $2-3 \mu \mathrm{m} /$ cycle), whereas it takes more than 3000 cycles to form a $100-\mu \mathrm{m}$ crack in air (average growth rate of $0.033 \mu \mathrm{m} /$ cycle). In low-DO PWR environment, the growth of cracks is faster than it is in air but slower than it is in high-DO water.

Figure 12 shows that in both air and water environments, fatigue crack size at different life fractions is independent of strain range, strain rate, and DO content of the water. The depth of the largest crack at different life fractions is approximately the same at 0.75 and $0.4 \%$ strain ranges. These results show good agreement with earlier studies on $\mathrm{CSs}^{32,44}$ and LASs 45 (see Fig. 13); crack depth was determined from the surface crack length with Eq. 5. 

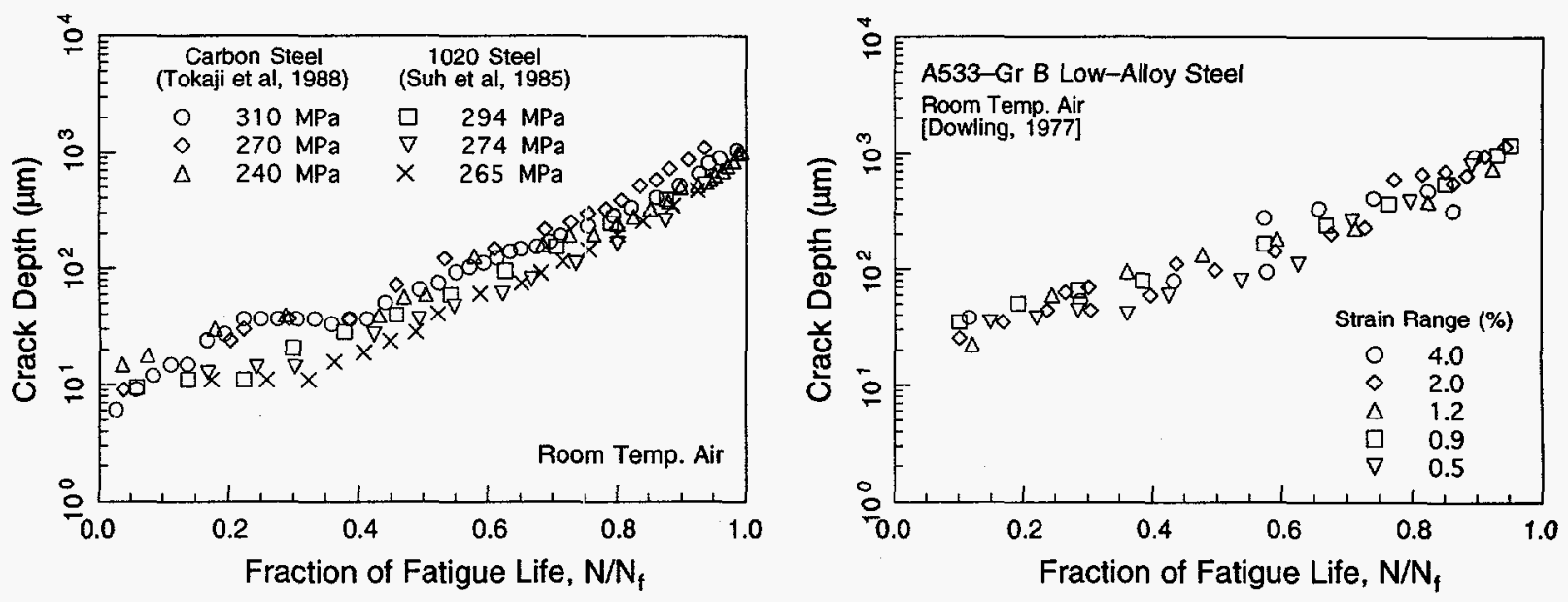

Figure 13. Crack depth as a function of fractional life for CSs and LASs tested in roomtemperature air

These results indicate that, for strain or stress ranges above the fatigue limit, linear damage summation (Miner's rule) is valid for CS and LAS in both air and water environments.

A detailed examination of the fatigue test specimens was conducted to investigate the role of high-temperature oxygenated water on fatigue cracking. Photomicrographs of longitudinal sections of A533-Gr B and AlD6-Gr B specimens tested in air, PWR, and high-DO environments at $288^{\circ} \mathrm{C}, \approx 0.8 \%$ strain range, and a slow/fast waveform (sawtooth) are shown in Fig. 14. In both steels, the formation and growth of surface cracks appear to be different in high-DO water than in air or simulated PWR water. In air and low-DO PWR environments, surface cracks grow as Mode II (shear) cracks in Stage I growth along planes that were usually at $45^{\circ}$ to the stress axis. The Stage I crack extends across several grains until the increasing stress intensity of the crack prornotes slip on systems other than the primary slip, and the crack begins to propagate as a Mode I (tensile) crack normal to the stress axis. Furthermore, in A106-Gr B CS, Stage I crack growth occurs entirely along the soft ferrite grains, avoiding the relatively hard pearlite regions.

In high-DO water, the surface cracks appear to grow entirely as Mode I tensile cracks normal to the stress axis. In A106-Gr B CS, cracks propagate across both ferrite and pearlite regions. The absence of Stage I crack growth suggests that factors other than mechanical fatigue are important for growth of surface cracks in high-DO water. These results are consistent with a slip dissolution model for enhanced crack growth rates in LWR environments.

\subsubsection{Crack Growth Rate}

The CGRs determined from the crack-depth-versus-cycles data of Fig. 11 are plotted as a function of crack depth in Fig. 15. The results indicate that, for the same crack depth, growth rates for the tests at $0.8 \%$ strain range are higher than those at $0.4 \%$ strain range. At both 0.8 and $0.4 \%$ strain range, CGRs in high-DO water are one order of magnitude higher than in air. Crack growth rates in a low-DO PWR environment are higher than those in air by a factor of 2 to 3 . As discussed in the previous section, the average growth rate during the early stage of fatigue damage is $\approx 2.5,0.22$ and $0.033 \mu \mathrm{m} /$ cycle, respectively, in high-DO water, low-DO water, and air environments. 
A533-Gr B LAS

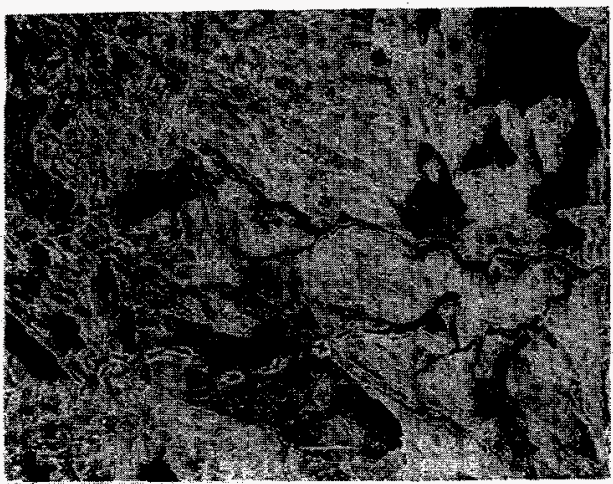

Air

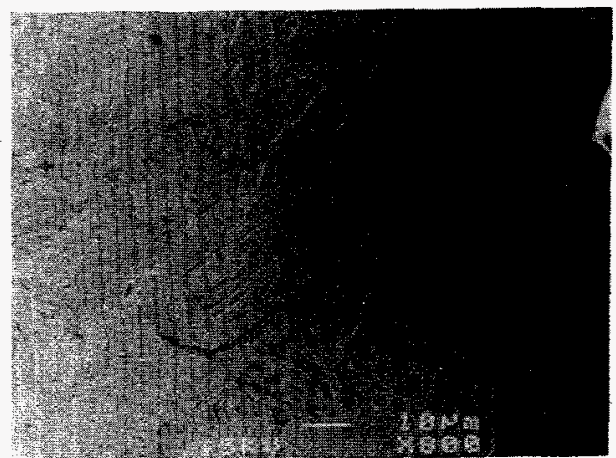

A106-Gr B CS
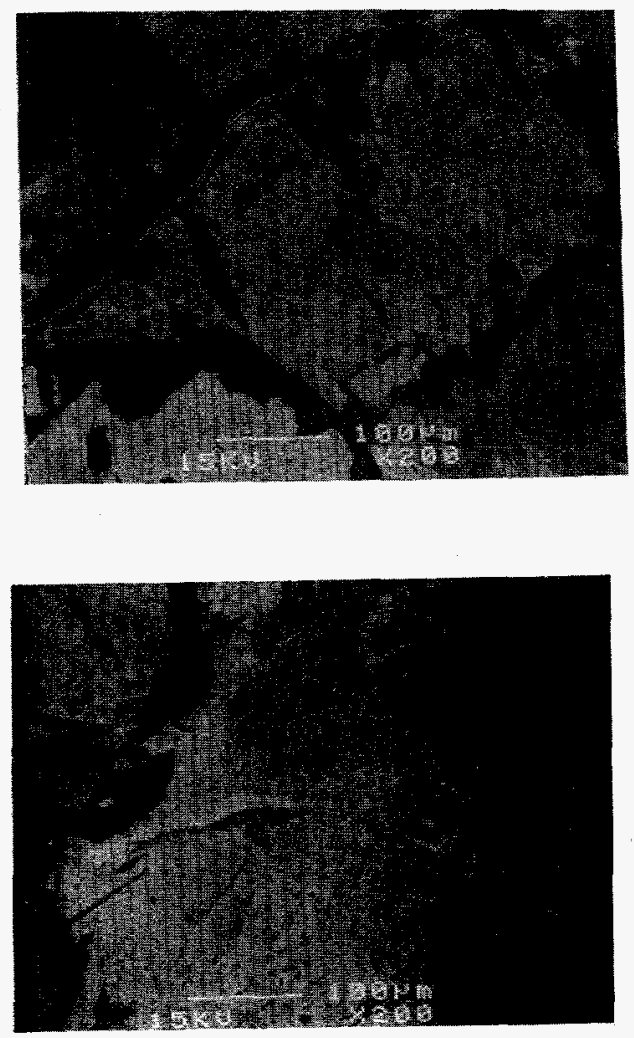

Simulated PWR Water
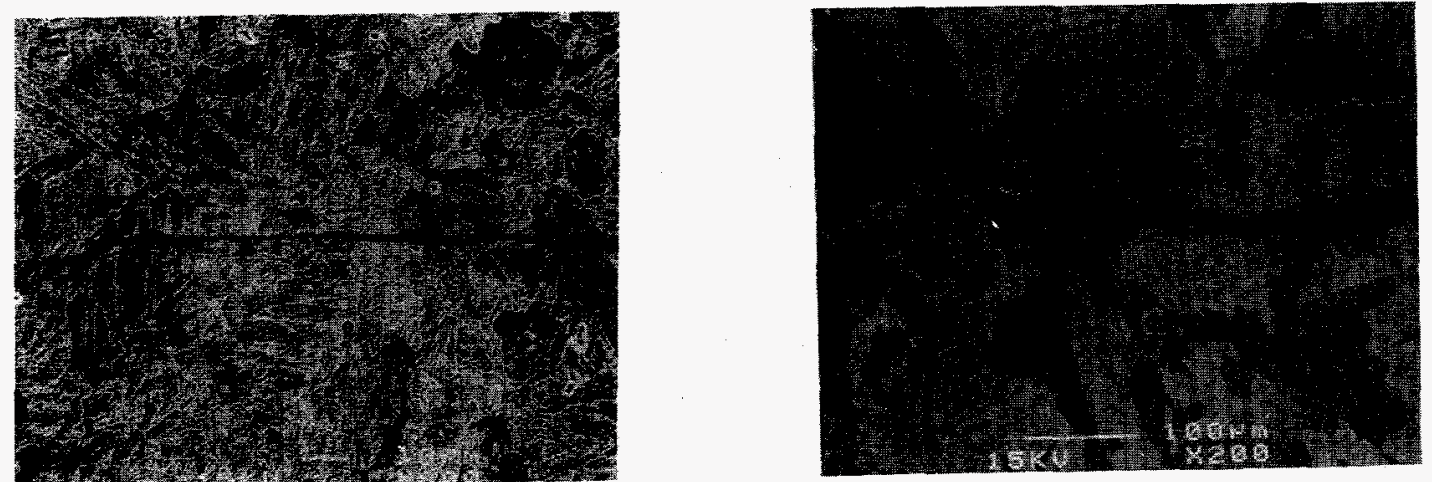

Water with $\approx 0.7 \mathrm{ppm}$ DO

Figure 14. Photomicrographs of surface cracks along longitudinal sections of A533-Gr B LAS and A106-Gr B CS in air, high-DO water, and simulated PWR environments

The results from the present study indicate that the decrease in fatigue life of CSs and LASs in high-DO water is primarily caused by the effects of environment on the growth of short cracks. Crack growth rates are nearly two orders of magnitude higher in high-DO water than in air during the initial stages of fatigue damage (for cracks $<100 \mu \mathrm{m}$ ), and one order of magnitude higher for cracks $>100 \mu \mathrm{m}$. Metallographic examination of the test specimens indicate that, in high-DO water, surface cracks grow entirely as tensile cracks normal to the stress. In air and low-DO water, surface crack growth occurs initially as shear cracks $\approx 45^{\circ}$ to 

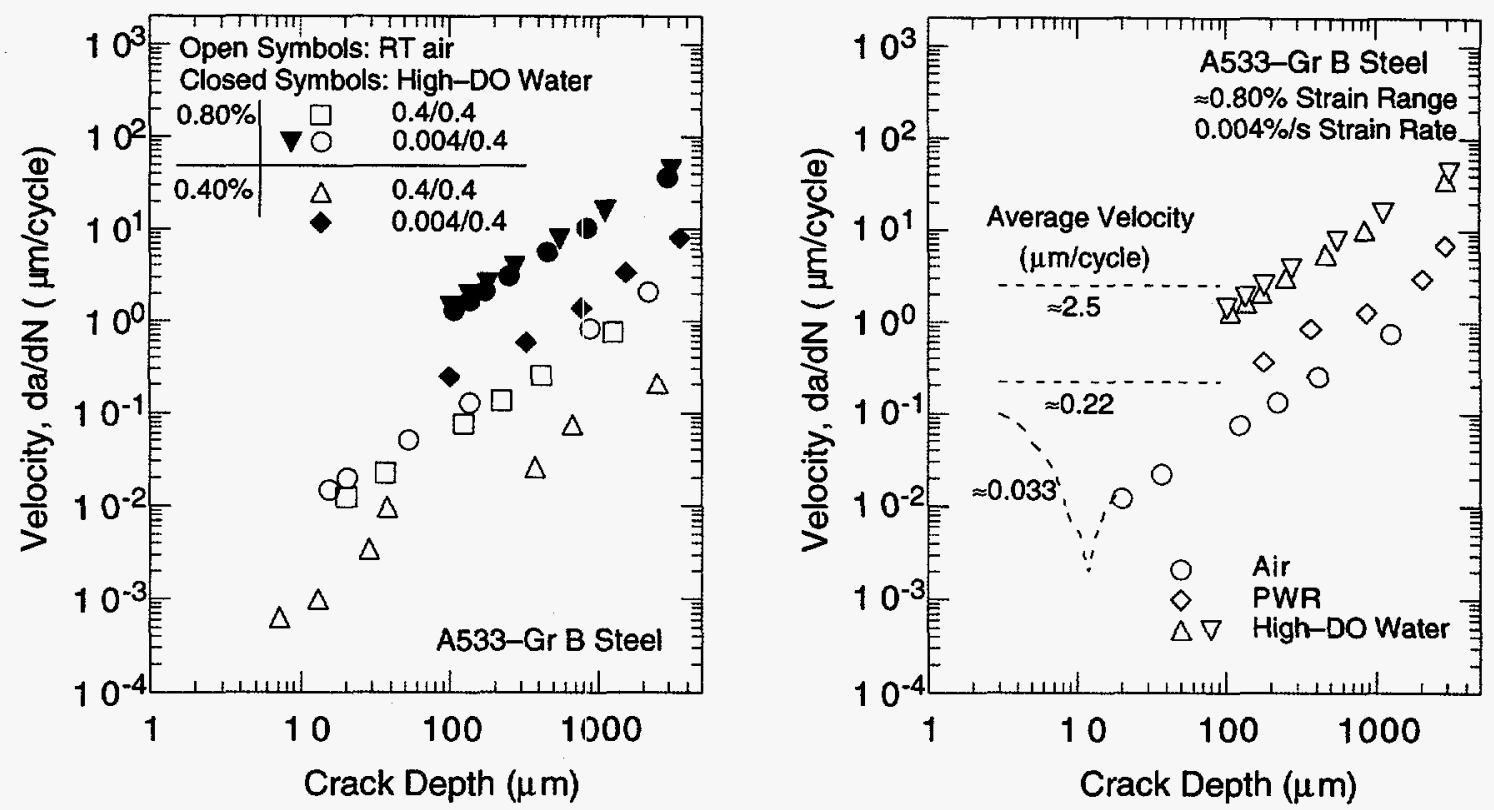

Figure 15. Crack growth rates as a function of crack depth for A533-Gr B LAS tested in air and water environments. Dotted lines show the probable growth rates during the early stage of fatigue damage in air and low- and high-DO.

the stress axis, and then as tensile cracks normal to the stress axis when slip is no longer confined to planes at $45^{\circ}$ to the stress axis.

These results suggest that, in LWR environments, the growth of MSCs occurs by anodic dissolution; the growth rates depend on the DO in water and on the sulfur content of the steel. When the applied strain is greater than the threshold strain required to rupture the passive oxide film, crack extension occurs by anodic dissolution of freshly exposed surfaces and depends on the oxidation characteristics. Studies of the effects of strain rate change on fatigue life of CSs and LASs in high-DO water also show that the applied strain must exceed a threshold value to rupture the passive surface film for environmental effects to occur.8,9,16,17 The crack tip strain rate is used to describe oxide rupture at the crack tip during crack advance. The critical crack tip velocity depends on sulfur content in the steel and sulfide ion diffusion away from the crack tip in water. The relationship of environmentally assisted crack growth rate $V\left(\mathrm{~cm} \cdot \mathrm{s}^{-1}\right)$ to the crack tip strain rate $\dot{\varepsilon}_{\mathrm{ct}}\left(\mathrm{s}^{-1}\right)$ is

$$
V=A\left(\dot{\varepsilon}_{c t}\right)^{n}
$$

where constants $\mathrm{A}$ and $\mathbf{n}$ depend on the material and environmental conditions at the crack tip. There is a lower limit on the crack propagation rate associated with either blunting (when the crack tip cannot keep up with general corrosion rate of the crack sides) or the fact that a critical level of sulfide ions cannot be maintained at the crack tip. The crack propagation rate at which this transition occurs will depend on DO level, flow rate, etc. Based on these factors, the maximum and minimum environmentally controlled crack propagation rates have been defined. 40 For crack-tip sulfide ion concentrations above the critical level,

$$
V=2.25 \times 10^{-4} \dot{\varepsilon}_{c t}^{0.35}
$$


and for crack tip sulfide ion concentrations below the critical level,

$$
V=10^{-2} \dot{\varepsilon}_{c t}^{1.0}
$$

Assuming that the crack tip strain rate $\dot{\varepsilon}_{c t}$ is the same as the applied strain rate $\dot{\varepsilon}_{\text {app }}$ and crack advance due to mechanical fatigue is insignificant during the initial stages of fatigue damage, the crack advance (in $\mathrm{cm}$ ) per cycle is given by

$$
\Delta a_{r}=2.25 \times 10^{-4}\left(\Delta \varepsilon-\varepsilon_{f}\right)\left(\dot{\varepsilon}_{a p p}\right)^{-0.65},
$$

where $\varepsilon_{f}$ is the threshold strain increment needed to rupture the oxide film. For A533-Gr B steel, the threshold strain range for environmentally assisted reduction in fatigue life is $\approx 0.36 \% .8,9$ For an applied tensile strain rate of $0.004 \% / \mathrm{s}$, from Eq. 8, the crack growth during the initial stage of fatigue damage (for cracks $<100 \mu \mathrm{m}$ ) is $\approx 7$ and $0.65 \mu \mathrm{m} /$ cycle at 0.8 and $0.4 \%$ strain ranges, respectively. These values are higher than the measured average CGRs by a factor of 2 to 3 (Fig. 15).

In Fig. 16, the measured CGRs are presented with the current and proposed 46 ASME Section XI reference crack growth curves for CSs and LASs. Data for A333-Gr 6 CS in $288^{\circ} \mathrm{C}$ water with 1 or $0.005 \mathrm{ppm} \mathrm{DO*}$ are also included in the figure. For the cylindrical fatigue specimens, the stress intensity ranges $\Delta \mathrm{K}$ were determined from the values of $\Delta \mathrm{J}$, which, for a small half-circular surface crack, 45 are given by

$$
J=3.2\left(\frac{\sigma^{2}}{2 E}\right) a+5.0\left(\frac{\sigma \varepsilon_{p}}{1+n}\right) a
$$

where $\mathrm{E}$ is the elastic modulus, $\varepsilon_{p}$ is nominal plastic strain, and a is crack depth. The stress intensities associated with conventional cylindrical fatigue specimens were modified on the basis of rigorous finite-element models. ${ }^{47}$ The cyclic stress $\sigma$ and strain $\varepsilon$ is defined as

$$
\varepsilon=\frac{\sigma}{E}+\left(\frac{\sigma}{A}\right)^{n}
$$

where the constant $\mathrm{A}$ and the exponent $\mathrm{n}$ were determined from experimental data.8,9.16,17 The results show good agreement with the proposed reference curves. The growth rates for the A333-Gr 6 steel in low-DO water seem to be significantly higher than the ANL data on A533 Gr B steel tested under similar conditions. The results also suggest that, for smooth cylindrical specimens, the threshold value of $\Delta \mathrm{K}$ below which environment affects growth rates is either very low or does not exist.

\footnotetext{
* M. Higuchi, presented at the joint meeting of the working groups on Evaluation Methods and S/N Data Analysis, Pressure Vessel Research Council, April 1996, Orlando, FL.
} 


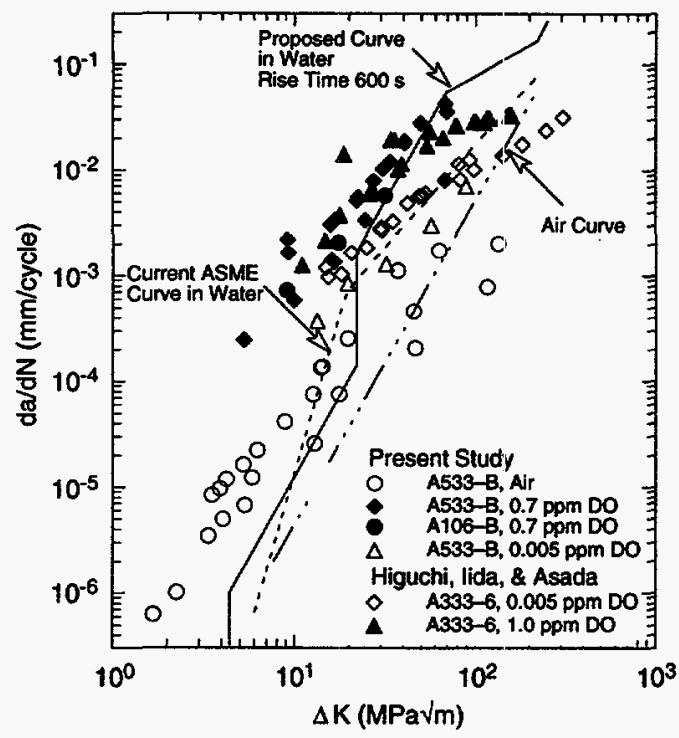

Figure 16.

Crack growth rates determined from smooth cylindrical fatigue test specimens and ASME Section $X I$ reference curves for CSs and LASs in air and water environments

\subsection{Austenitic Stainless Steels (D. J. Gavenda and O. K. Chopra)}

Fatigue tests have been conducted on Types 304 and 316 NG SS in air and LWR environments to evaluate the effects of material and loading variables, such as steel type, strain rate, DO, and strain range, on the fatigue lives of these steels. The composition of the SSs used for the fatigue tests is listed in Table 4. Experimental results have been compared with estimates of fatigue life based on a statistical model. The formation and growth of fatigue cracks in austenitic SSs in air and LWR environments are discussed. Details about the test facility and procedure have been described in Section 2.1.2. The fatigue test data from the present study and those obtained previously ${ }^{11}$ on Type 316NG SS in air and high-DO water are listed in Tables 5 and 6.

Table 4. Composition (wt.\%) of austenitic SSs used for fatigue tests

\begin{tabular}{ccccccccccccc}
\hline Material & Heat & Source & C & P & S & Si & Cr & Ni & Mn & Mo & Or & N \\
\hline Type 316NG a & \multirow{2}{*}{ D432804 } & Vendor & 0.011 & 0.020 & 0.001 & 0.52 & 17.55 & 13.00 & 1.76 & 2.49 & 0.10 & 0.108 \\
& & ANL & 0.013 & 0.020 & 0.002 & 0.49 & 17.54 & 13.69 & 1.69 & 2.45 & 0.10 & 0.105 \\
Type 304 b & \multirow{2}{*}{30956} & Vendor & 0.060 & 0.019 & 0.007 & 0.48 & 18.99 & 8.00 & 1.54 & 0.44 & - & 0.100
\end{tabular}

aASME SA312 seamless SS pipe (hot finished), $610 \mathrm{~mm}$ O.D. and $30.9 \mathrm{~mm}$ wall, fabricated by Sumitomo Metal Industries, Ltd. Solution annealed at $1038-1093^{\circ} \mathrm{C}$ for $0.5 \mathrm{~h}$ and water quenched.

bsolution annealed at $1050^{\circ} \mathrm{C}$ for $0.5 \mathrm{~h}$.

\subsubsection{Air Environment}

Existing fatigue S-N data indicate that the fatigue lives of austenitic SSs in air is independent of temperature in the range from room temperature to $427^{\circ} \mathrm{C}$. Fatigue lives of Types 304 and 316 SS are similar and those of Type 316NG SS are superior. The effects of strain rate on fatigue life cannot be established from existing $\mathbf{S}-\mathrm{N}$ data. Limited results suggest that some heats are sensitive to strain rate; fatigue life may decrease up to $30 \%$ with decreasing strain rate. 
Table 5. Fatigue test results for Type 316NG SS

\begin{tabular}{|c|c|c|c|c|c|c|c|c|c|}
\hline \multirow{2}{*}{$\begin{array}{c}\text { Temp. } \\
\text { and } \\
\text { Test No. }\end{array}$} & \multirow[b]{2}{*}{ Environ. ${ }^{a}$} & \multirow{2}{*}{$\begin{array}{c}\text { DO } \\
\text { (ppb) }\end{array}$} & \multirow{2}{*}{$\begin{array}{c}\mathrm{pH} \\
\text { at } \mathrm{RT}\end{array}$} & \multirow{2}{*}{$\begin{array}{c}\text { Conduc- } \\
\text { tivity } \\
(\mu \mathrm{S} / \mathrm{cm})\end{array}$} & \multicolumn{2}{|c|}{$\begin{array}{c}\text { Strain Rate } \\
(\% / \mathrm{s})\end{array}$} & \multirow{2}{*}{$\begin{array}{l}\text { Stress } \\
\text { Range } \\
\text { (MPa) }\end{array}$} & \multirow{2}{*}{$\begin{array}{c}\text { Strain } \\
\text { Range } \\
(\%)\end{array}$} & \multirow{2}{*}{$\begin{array}{c}\text { Life } \\
\mathrm{N}_{25} \\
\text { (Cycles) }\end{array}$} \\
\hline & & & & & Ten. & Comp. & & & \\
\hline \multicolumn{10}{|c|}{ Room Temp. } \\
\hline 1394 & Air & - & - & - & 0.50 & 0.50 & 694.7 & 1.51 & 4,649 \\
\hline 1391 & Air & - & - & - & 0.50 & 0.50 & 554.8 & 1.00 & 13,561 \\
\hline 1390 & Air & - & - & - & 0.50 & 0.50 & 518.1 & 0.75 & 25,736 \\
\hline 1396 & Air & - & - & - & 0.50 & 0.50 & 506.7 & 0.76 & 30,000 \\
\hline 1420 & Air & - & - & - & 0.49 & 0.49 & 495.3 & 0.49 & 54,249 \\
\hline 1392 & Air & - & - & - & 0.50 & 0.50 & 475.9 & 0.51 & 60,741 \\
\hline 1393 & Air & - & - & - & 0.50 & 0.50 & 464.7 & 0.41 & 127,386 \\
\hline 1395 & Air & - & - & - & 0.50 & 0.50 & 456.7 & 0.35 & 183,979 \\
\hline 1397 & Air & - & - & - & 0.50 & 0.50 & 446.0 & 0.30 & 347,991 \\
\hline 1398 & Air & - & - & - & 0.50 & 0.50 & 436.7 & 0.27 & 666,000 \\
\hline 1399 & Air & - & - & - & 0.50 & 0.50 & 431.8 & 0.25 & $>1,900,000$ \\
\hline 1400 & Air & - & - & - & 0.50 & 0.50 & 427.4 & 0.25 & $1,775,000$ \\
\hline \multicolumn{10}{|c|}{$288^{\circ} \mathrm{C}$} \\
\hline 1408 & Air & - & - & - & 0.50 & 0.50 & 416.6 & 0.76 & 21,548 \\
\hline 1790 & Air & - & - & - & 0.005 & 0.50 & 452.8 & 0.75 & 16,765 \\
\hline 1409 & Air & - & - & - & 0.50 & 0.50 & 377.2 & 0.50 & 53,144 \\
\hline 1410 & Air & - & - & - & 0.50 & 0.50 & 377.6 & 0.50 & 51,194 \\
\hline 1792 & Air & & & & 0.005 & 0.50 & 413.4 & 0.51 & 35,710 \\
\hline 1407 & Air & - & - & - & 0.50 & 0.50 & 364.4 & 0.40 & 82,691 \\
\hline 1430 & Air & - & - & - & 0.50 & 0.50 & 348.3 & 0.30 & 168,852 \\
\hline 1435 & Air & - & - & - & 0.50 & 0.50 & 342.0 & 0.25 & 314,352 \\
\hline 1480 & Air & - & - & - & 0.49 & 0.49 & 340.1 & 0.25 & 319,308 \\
\hline 1485 & Air & - & - & - & 0.51 & 0.51 & 340.4 & 0.25 & 369,206 \\
\hline \multicolumn{10}{|c|}{$320^{\circ} \mathrm{C}$} \\
\hline 1405 & Air & - & - & - & 0.50 & 0.50 & 426.0 & 0.75 & 20,425 \\
\hline 1404 & Air & - & - & - & 0.50 & 0.50 & 387.4 & 0.50 & 47,011 \\
\hline 1406 & Air & - & - & - & 0.50 & 0.50 & 371.6 & 0.40 & 82,691 \\
\hline \multicolumn{10}{|c|}{$288^{\circ} \mathrm{C}$} \\
\hline 1426 & Hi DO & $>200$ & - & - & 0.80 & 0.80 & 405.1 & 0.80 & 12,069 \\
\hline 1427 & Hi DO & $>200$ & - & - & 0.082 & 0.082 & 421.7 & 0.82 & 6,679 \\
\hline 1428 & Hi DO & $>200$ & - & - & 0.0074 & 0.0074 & 441.4 & 0.74 & 5,897 \\
\hline 1797 & Hi DO & 750 & 5.9 & 0.076 & 0.005 & 0.50 & 437.3 & 0.78 & 4,520 \\
\hline 1414 & Hi DO & $>200$ & - & - & 0.50 & 0.50 & 375.3 & 0.50 & 26,230 \\
\hline 1418 & Hi DO & $>200$ & - & - & 0.50 & 0.50 & 375.5 & 0.50 & 25,714 \\
\hline 1423 & Hi DO & $>200$ & - & - & 0.05 & 0.05 & 378.8 & 0.50 & 17,812 \\
\hline 1425 & Hi DO & $>200$ & - & - & 0.0049 & 0.0049 & 393.2 & 0.49 & 13,684 \\
\hline 1431 & Hi DO & $>200$ & - & - & 0.29 & 0.29 & 356.5 & 0.29 & 116,754 \\
\hline 1434 & Hi DO & $>200$ & - & - & 0.029 & 0.029 & 350.0 & 0.29 & 40,643 \\
\hline 1436 & Hi DO & $>200$ & - & - & 0.025 & 0.025 & 354.0 & 0.25 & $>1,719,851$ \\
\hline 1512 & Hi DO & $>200$ & - & - & 0.24 & 0.24 & 361.2 & 0.24 & $2,633,954$ \\
\hline 1796 & PWR & 5 & 6.4 & 20.20 & 0.50 & 0.50 & 403.6 & 0.80 & 12,500 \\
\hline 1812 & PWR & 2 & 6.5 & 20.00 & 0.05 & 0.50 & 413.9 & 0.80 & 6,375 \\
\hline 1791 & PWR & 4 & 6.5 & 19.23 & 0.005 & 0.50 & 441.9 & 0.77 & 3,040 \\
\hline 1793 & PWR & 4 & 6.4 & 19.23 & 0.005 & 0.50 & 434.3 & 0.80 & 3,020 \\
\hline 1794 & PWR & 4 & 6.4 & 20.00 & 0.005 & 0.50 & 390.9 & 0.50 & 7,370 \\
\hline 1814 & PWR & 1 & 6.5 & 20.00 & 0.05 & 0.50 & 348.7 & 0.29 & 33,200 \\
\hline
\end{tabular}


Table 6. Fatigue test results for Type 304 SS

\begin{tabular}{|c|c|c|c|c|c|c|c|c|c|}
\hline \multirow{2}{*}{$\begin{array}{c}\text { Temp. } \\
\text { and } \\
\text { Test No. }\end{array}$} & \multirow[b]{2}{*}{ Environ. ${ }^{a}$} & \multirow{2}{*}{$\begin{array}{c}\text { DO } \\
(\mathrm{ppb})\end{array}$} & \multirow{2}{*}{$\begin{array}{l}\mathrm{pH} \\
\text { at } \mathrm{RT}\end{array}$} & \multirow{2}{*}{$\begin{array}{l}\text { Conduc- } \\
\text { tivity } \\
(\mu \mathrm{S} / \mathrm{cm})\end{array}$} & \multicolumn{2}{|c|}{$\begin{array}{c}\text { Strain Rate } \\
(\% / \mathrm{s})\end{array}$} & \multirow{2}{*}{$\begin{array}{l}\text { Stress } \\
\text { Range } \\
\text { (MPa) }\end{array}$} & \multirow{2}{*}{$\begin{array}{c}\text { Strain } \\
\text { Range } \\
(\%)\end{array}$} & \multirow{2}{*}{$\begin{array}{c}\text { Life } \\
\mathrm{N}_{25} \\
\text { (Cycles) }\end{array}$} \\
\hline & & & & & Ten. & Comp. & & & \\
\hline \multicolumn{10}{|c|}{$288^{\circ} \mathrm{C}$} \\
\hline 1801 & Air & - & - & - & 0.4 & 0.4 & 419.2 & 0.76 & 24,500 \\
\hline 1805 & Air & - & - & - & 0.004 & 0.4 & 467.9 & 0.76 & 14,410 \\
\hline 1804 & Air & - & - & - & 0.4 & 0.4 & 382.8 & 0.51 & 61,680 \\
\hline 1817 & Air & - & - & - & 0.004 & 0.4 & 421.7 & 0.51 & 42,180 \\
\hline 1806 & PWR & 4 & 6.0 & 18.87 & 0.4 & 0.4 & 428.9 & 0.73 & 11,500 \\
\hline 1810 & PWR & 5 & 6.4 & 18.89 & 0.04 & 0.4 & 447.6 & 0.77 & 5,800 \\
\hline 1808 & PWR & 4 & 6.4 & 18.87 & 0.004 & 0.4 & 468.3 & 0.77 & 2,850 \\
\hline 1821 & PWR & 2 & 6.5 & 22.22 & 0.004 & 0.4 & 474.3 & 0.76 & 2,420 \\
\hline 1807 & PWR & 4 & 6.5 & 18.87 & 0.4 & 0.4 & 374.6 & 0.51 & 25,900 \\
\hline 1823 & PWR & 3 & 6.6 & 23.06 & 0.004 & 0.4 & 408.2 & 0.51 & 6,900 \\
\hline
\end{tabular}

a PWR = simulated PWR water that contains $2 \mathrm{ppm}$ lithium and $1000 \mathrm{ppm}$ boron.

Statistical models have been developed for estimating the effects of material and loading conditions on the fatigue lives of austenitic SSs. ${ }^{21,22}$ These models are based on the JNUFAD* data base for "Fatigue Strength of Nuclear Plant Components" from Japan, the data compiled by Jaske and O'Donnell ${ }^{48}$ for developing fatigue design criteria for pressure vessel alloys, and the tests conducted by Conway et al., 49 Keller, ${ }^{50}$ and by ANL. ${ }^{11}$ In air, the fatigue life $\mathrm{N}$ of Types 304 and 316 SS is expressed as

$$
\ln (\mathrm{N})=6.690-1.980 \ln \left(\varepsilon_{\mathrm{a}}-0.12\right)
$$

and that of Type 316NG SS as

$$
\ln (\mathrm{N})=7.072-1.980 \ln \left(\varepsilon_{\mathrm{a}}-0.12\right),
$$

where $\varepsilon_{\mathrm{a}}$ is the applied strain amplitude (\%). The fatigue lives of Types 304,316 , and $316 \mathrm{NG}$ $\mathrm{SS}$ in air at various temperatures are presented in Fig. 17, with the values estimated from Eqs. $11 \mathrm{a}$ and $11 \mathrm{~b}$. At temperatures of $25-450^{\circ} \mathrm{C}$, the fatigue lives of Types 304 and $316 \mathrm{SS}$ in air show no dependence on temperature. For Type $316 \mathrm{NG}$ SS, the results at room temperature show good agreement with estimates from the statistical model or the Jaske and O'Donnell 48 curve, but the data at $288^{\circ} \mathrm{C}$ are lower than the estimated values at strain amplitudes $<0.2 \%$.

Also, the ASME mean curve is not consistent with the existing fatigue $\mathrm{S}-\mathrm{N}$ data for austenitic SSs. At strain amplitudes $<0.5 \%$, the mean curve predicts significantly longer fatigue lives than those observed experimentally; the fatigue lives at $288^{\circ} \mathrm{C}$ and $\approx 0.25 \%$ strain range fall very close to the ASME Code design curve. When the Code fatigue S-N curve for austenitic SSs was extended to $10^{8}$ cycles, this discrepancy was taken into account, but no change was made to the curve for $<10^{6}$ cycles. The statistical model is in good agreement with the Jaske and O'Donnell ${ }^{48}$ average curve.

The fatigue S-N data from the present study and those obtained previously on Type 316NG SSll in air are shown in Fig. 18. Also shown are the S-N curves estimated from the

\footnotetext{
* Private communication from M. Higuchi, Ishikawajima-Harima Heavy Industries Co., Japan, to M. Prager of the Pressure Vessel Research Council, 1992. The old data base "FADAL" has been revised and renamed "JNUFAD."
} 

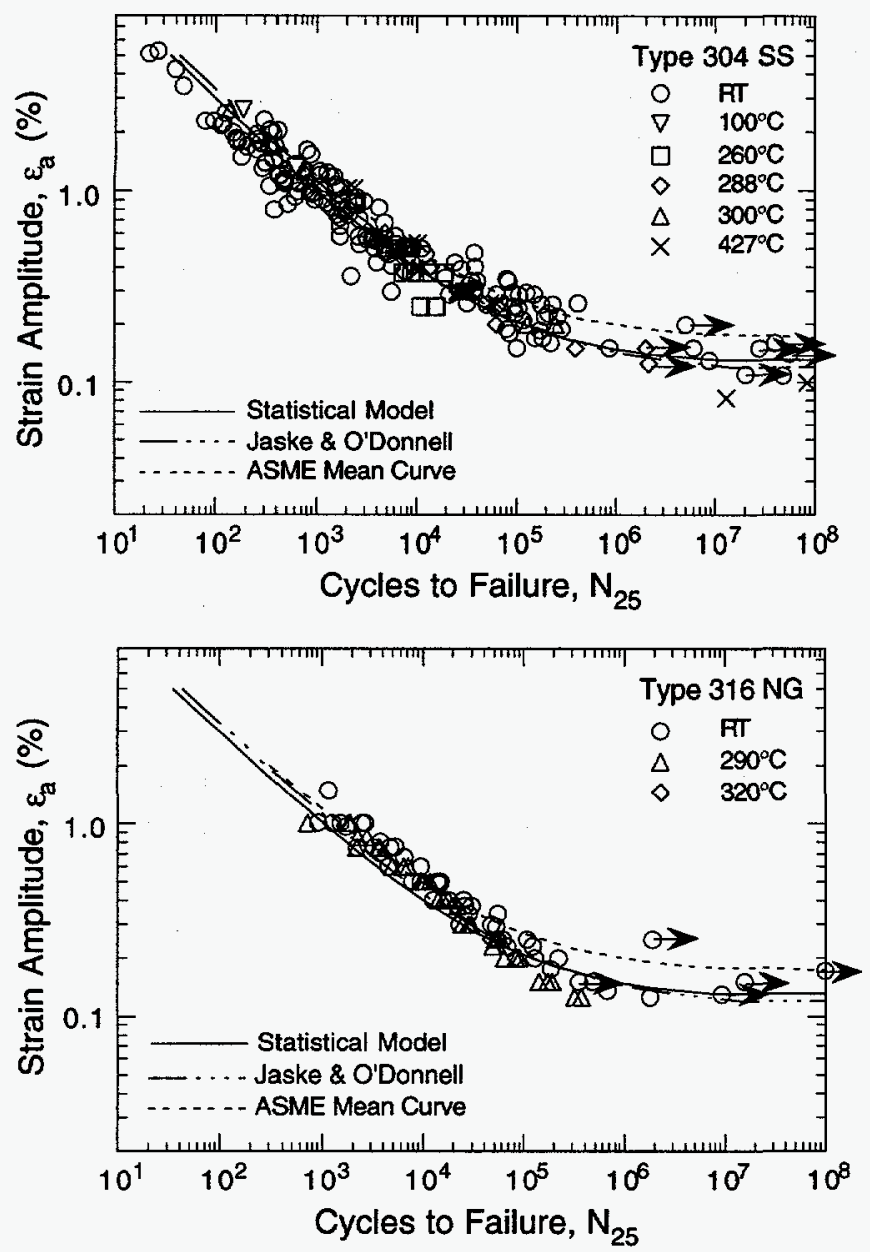

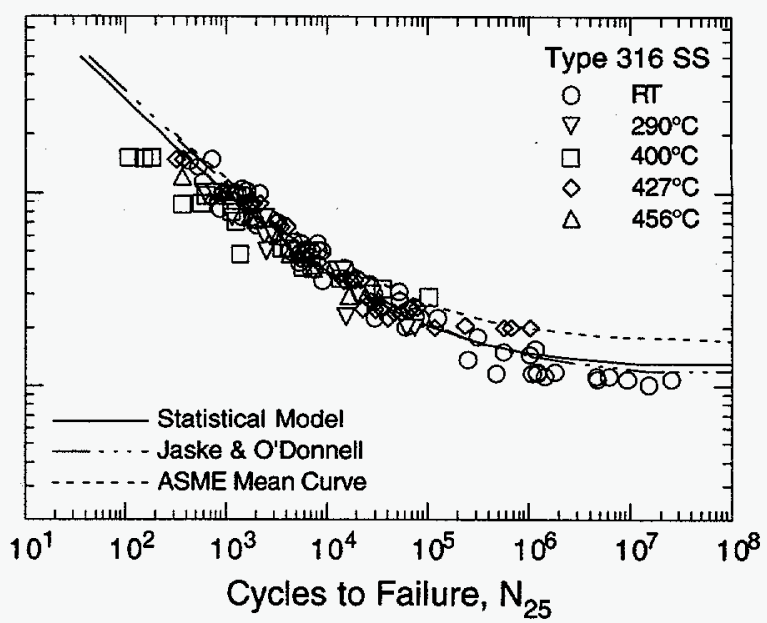

Figure 17.

Fatigue S-N behavior for Types 304, 316 , and $316 N G$ SS in air at various temperatures
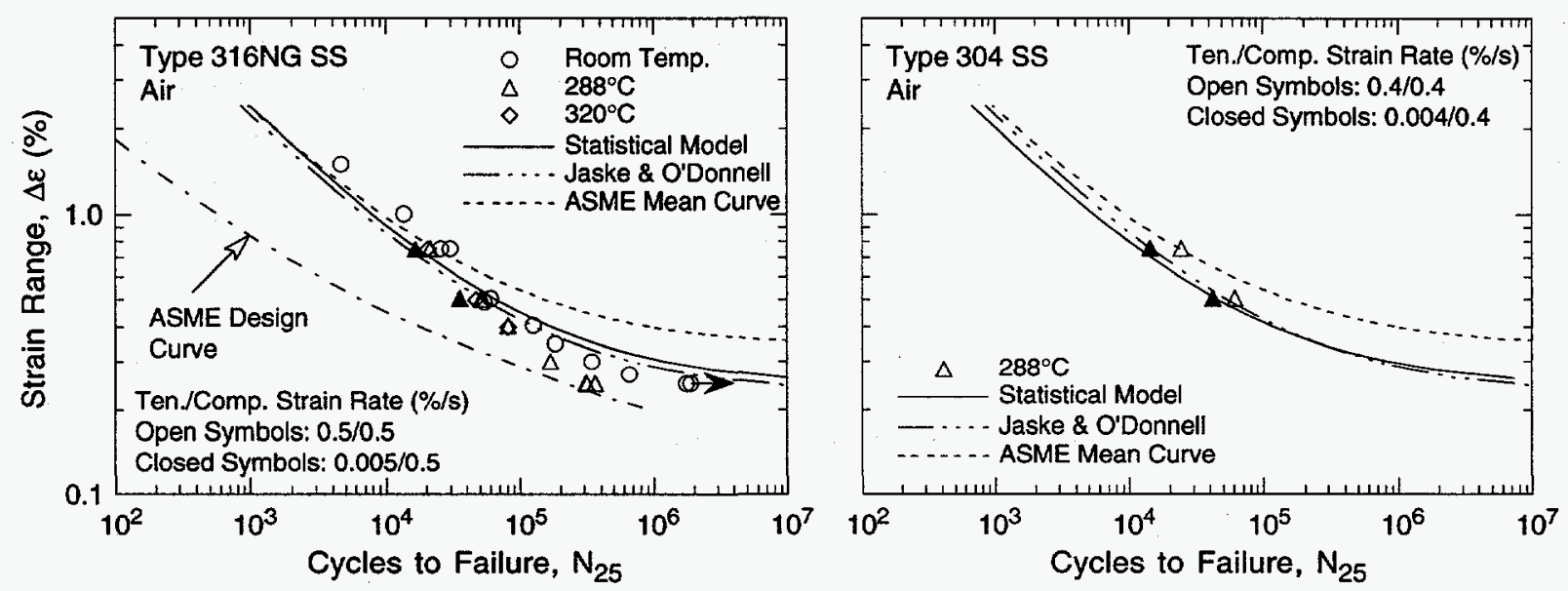

Figure 18. Total-strain-range versus fatigue-life data for Types $316 N G$ and 304 SS in air

statistical model, best-fit curve proposed by Jaske and O'Donnell, 48 and the ASME mean curve. The results show good agreement with estimates from the statistical model or Jaske and O'Donnell curve. 48 
The cyclic strain hardening and cyclic stress-versus-strain curves for Types 316NG and $304 \mathrm{SS}$ at room temperature and $288^{\circ} \mathrm{C}$ have been presented earlier. 19 At both temperatures, the steels exhibit rapid hardening during the first 50-100 cycles of fatigue life. The extent of hardening increases with applied strain range and is greater at room temperature than at $288^{\circ} \mathrm{C}$. The initial hardening is followed by softening and a saturation stage at $288^{\circ} \mathrm{C}$ and by continuous softening at room temperature. The results also indicate that, at $288-430^{\circ} \mathrm{C}$, cyclic stresses increase with decreasing strain rate.

\subsubsection{Water Environment}

\section{Fatigue Life}

The fatigue S-N data on austenitic SSs indicate a significant decrease in fatigue life in water; the effect of environment on fatigue life increases with decreases in strain rate. The fatigue lives of austenitic SSs in LWR coolant environments can be estimated from statistical models. 21,22 These models are based on the JNUFAD data base and the tests conducted by General Electric Corporation in a test loop at the Dresden 1 reactor 51,52 and by ANL. 1 However, most of the data used in developing the models were obtained in water that contained $0.2 \mathrm{ppm}$ or more of $\mathrm{DO}$ and at temperatures in the range of $288-320^{\circ} \mathrm{C}$. Consequently, the models do not consider the effects of temperature or DO content on the fatigue lives of these steels. In LWR environments, the fatigue life N of Types 304 and 316 SS is expressed as

$$
\ln (\mathrm{N})=6.331-1.980 \ln \left(\varepsilon_{\mathrm{a}}-0.12\right)+0.134 \dot{\varepsilon}^{*}
$$

and that of Type $316 \mathrm{NG}$, as

$$
\ln (\mathrm{N})=6.713-1.980 \ln \left(\varepsilon_{\mathrm{a}}-0.12\right)+0.134 \dot{\varepsilon}^{*}
$$

where $\varepsilon_{\mathrm{a}}$ is applied strain amplitude (\%) and $\dot{\varepsilon}^{*}$ is transformed strain rate defined as

$$
\begin{array}{ll}
\dot{\varepsilon}^{*}=0 & (\dot{\varepsilon}>1 \% / \mathrm{s}) \\
\dot{\varepsilon}^{*}=\ln (\dot{\varepsilon}) & (0.001 \leq \dot{\varepsilon} \leq 1 \% / \mathrm{s}) \\
\dot{\varepsilon}^{*}=\ln (0.001) & (\dot{\varepsilon}<0.001 \% / \mathrm{s}) .
\end{array}
$$

The statistical model is recommended for predicting fatigue lives $\leq 10^{6}$ cycles. The lower bound value of $0.001 \% / \mathrm{s}$ on the strain rate effect was based on the results for CSs and LASs. 8,9

The fatigue S-N data for Types $316 \mathrm{NG}$ and $304 \mathrm{SS}$ in water at $288^{\circ} \mathrm{C}$ are shown in Fig. 19 , which also shows the ASME Code fatigue design curve. The results indicate a significant decrease in fatigue life in water relative to that in air; the reduction in life depends on both strain rate and DO content of the water. The fatigue lives of Types 316NG and 304 SS in air, simulated PWR, and high-DO water are plotted as a function of strain rate in Fig. 20. In all environments, the fatigue lives of these steels decrease with decreasing strain rate. The effect of strain rate is smallest in air and largest in a low-DO PWR environment. In a simulated PWR environment, a decrease in strain rate from 0.4 to $0.004 \% / \mathrm{s}$ decreases fatigue life by a factor of $\approx 8$. The decrease in life is lower at low strain ranges, e.g., a factor of $\approx 8$ at $0.75 \%$ and $\approx 5$ at $0.3 \%$ strain range. 

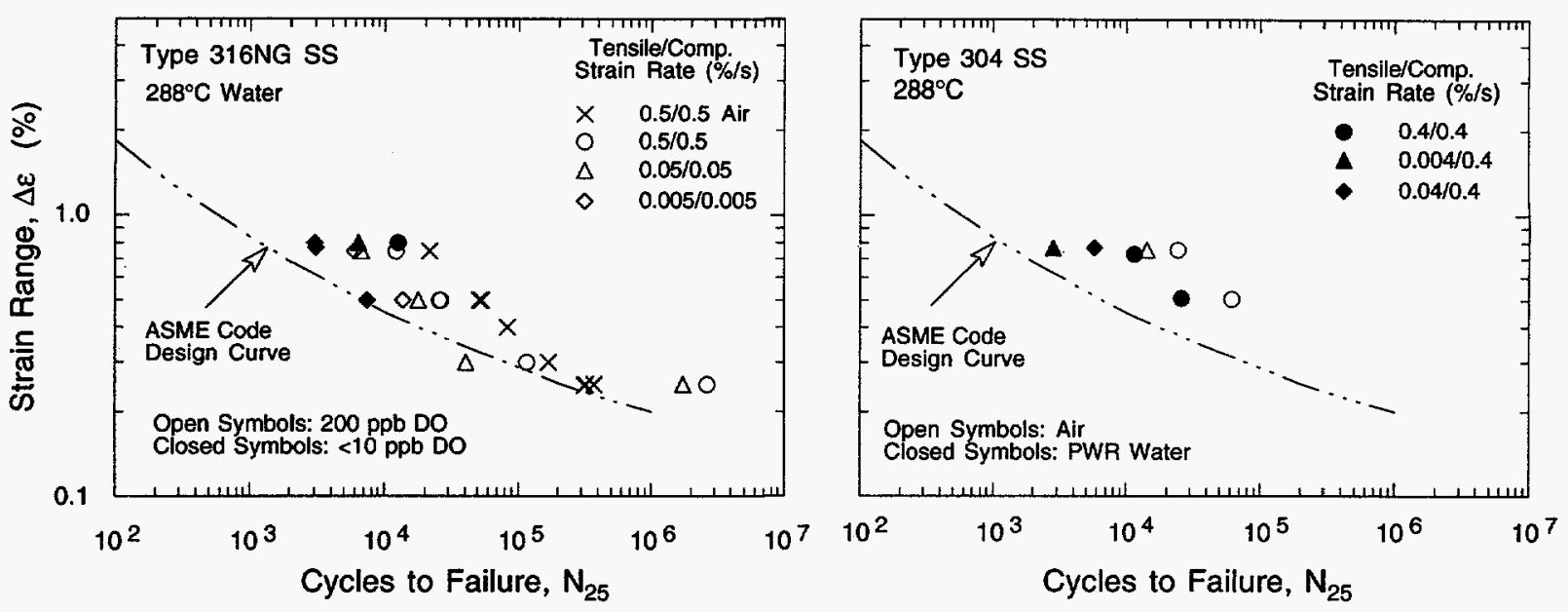

Figure 19. Total-strain-range-versus-fatigue-life data for Types 316NG and 304 SS in air and water

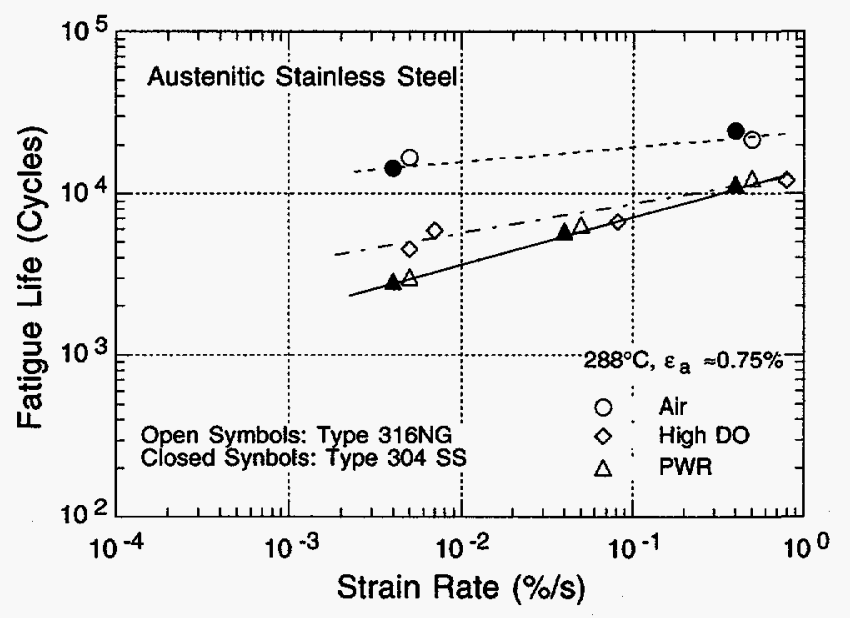

Figure 20.

Effect of strain rate on fatigue lives of austenitic SSs in air and in simulated $P W R$ and high-DO water environments

The results also indicate that environmental effects on the fatigue lives of austenitic SSs are more pronounced in low-DO than in high-DO water. At slow strain rates, e.g., $\approx 0.004 \% / s$, the reduction in fatigue life in a simulated PWR environment $(<10 \mathrm{ppb} D O)$ is greater by a factor of $\approx 2$ than in high-DO water $(\geq 200 \mathrm{ppb} D O$ ). Such a dependence of fatigue life on DO content is quite different from that of ferritic steels. For CSs and LASs, environmental effects on fatigue life increase with increasing DO content above a minimum threshold value of 0.05 ppm. ${ }^{8,9}$ Also, environmental effects on the fatigue life of CSs and LASs are modest at DO levels below $0.05 \mathrm{ppm}$, i.e., fatigue life is lower by a factor of $<2$ than it is in air. In view of these results, the statistical models for austenitic SSs (Eqs. 12a-12c) will be updated to incorporate the effects of $\mathrm{DO}$ and strain rate on fatigue life.

\section{Metallographic Examination}

A detailed examination of the fatigue test specimens was conducted to investigate the role of high-temperature oxygenated water on fatigue cracking. In general, the specimens tested in air show slight discoloration, whereas the specimens tested in oxygenated water developed a gray/black corrosion scale. Photomicrographs of the gage surface of Type 316NG SS 
specimens tested in air, simulated PWR, and high-DO water environments are shown in Fig. 21. Crystalline oxides and a thin gray corrosion scale are present on specimens tested in water. X-ray diffraction analyses of specimens tested in water indicate that the corrosion scale primarily consists of magnetite $\left(\mathrm{Fe}_{3} \mathrm{O}_{4}\right)$ or ferroferric oxide $\left(\mathrm{FeFe}_{2} \mathrm{O}_{4}\right)$, chromium oxide $(\mathrm{CrO})$, and maghemite $\left(\gamma-\mathrm{Fe}_{2} \mathrm{O}_{3}\right)$. In addition to these phases, a specimen tested in high-DO water also contained hematite (ferric oxide or $\alpha-\mathrm{Fe}_{2} \mathrm{O}_{3}$ ).

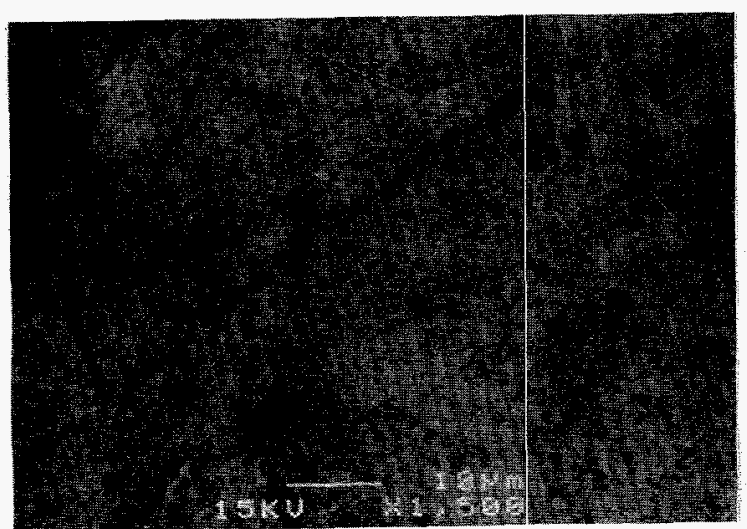

(a)

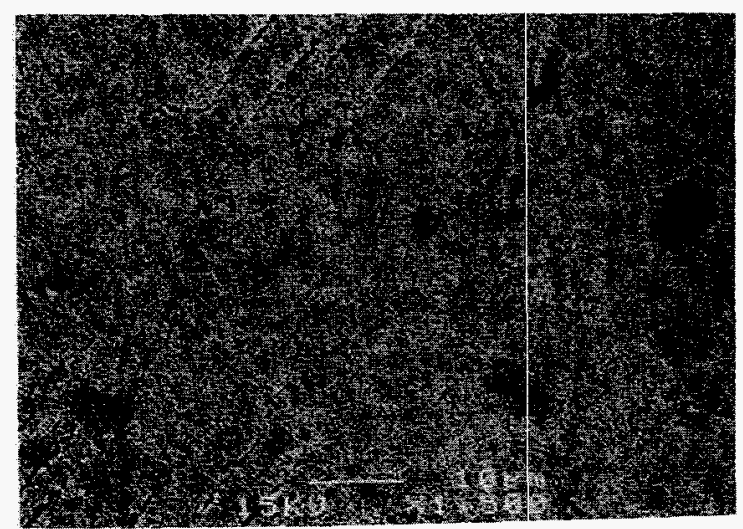

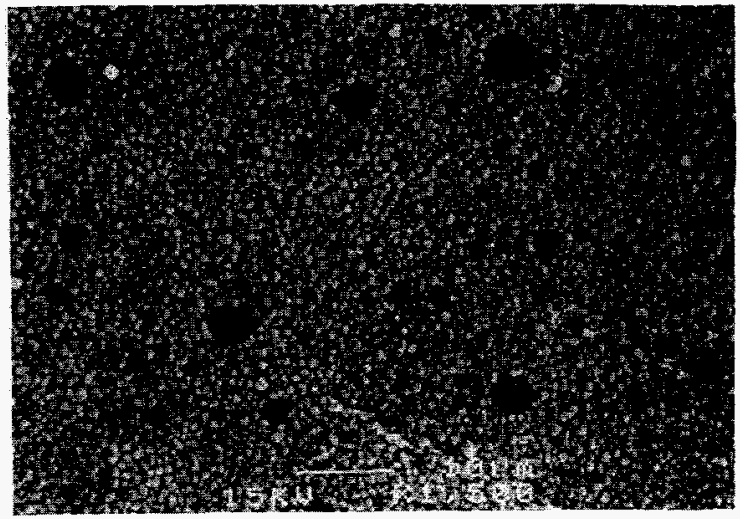

(b)

Figure 21.

SEM photomicrographs of gage surface of Type 316NG SS specimens tested in (a) air, (b) simulated $P W R$, and (c) high-DO-water environments

(c)

Figure 22 shows photomicrographs of the fracture surface at approximately the same crack length for Type 316NG SS specimens tested in air, high-DO water, and low-DO PWR water. Fatigue striations can be seen clearly on all specimens. The spacing between striations indicates that crack growth rates increase in the following sequence: air, high-DO water, and low-DO PWR water.

The crack frequency, i.e., number of cracks per unit length of the specimen gage surface, was measured along longitudinal sections of specimens tested in various environments. Preliminary results indicate that crack frequency is lower in high-DO water than in air or the simulated PWR environment. For Type $316 \mathrm{NG}$ SS tested at $288^{\circ} \mathrm{C}, \approx 0.75 \%$ strain range, and $0.005 \% / \mathrm{s}$ strain rate, the number of cracks longer than $20 \mu \mathrm{m}$ along a $7-\mathrm{mm}$ gage length was 16,14 , and 8 in air, simulated PWR, and high-DO water, respectively. 


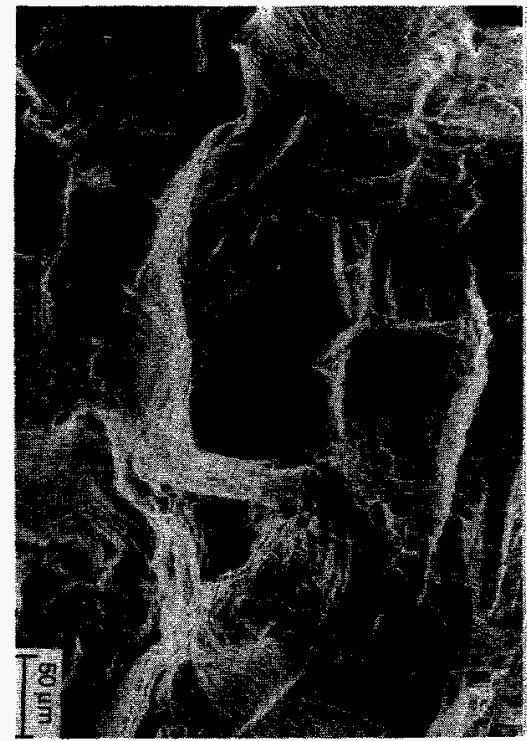

(a)

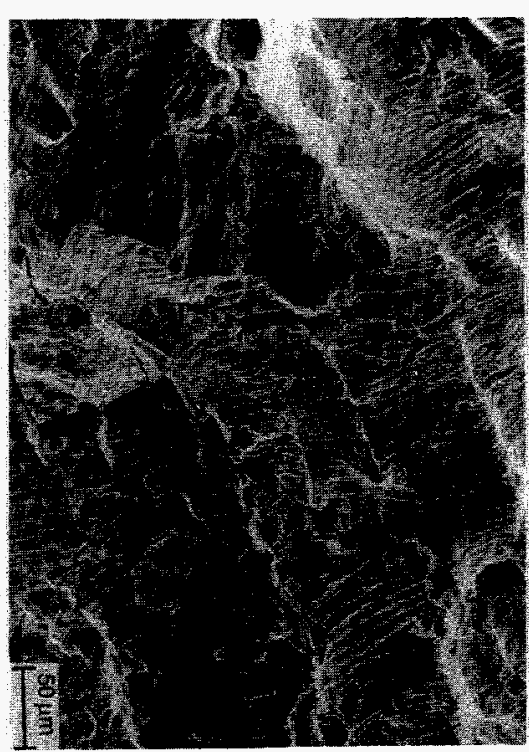

(b)

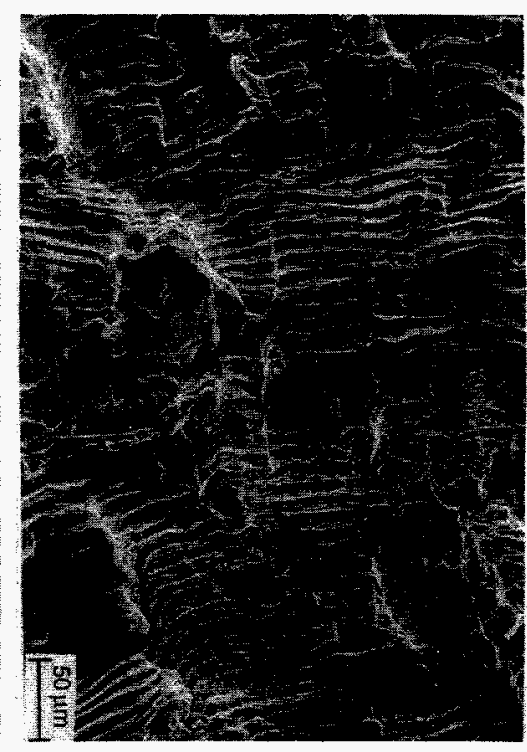

(c)

Figure 22. Photomicrographs of fracture surface of Type $316 N G$ SS specimens tested at $288^{\circ} \mathrm{C}$ and $0.75 \%$ strain range in (a) air, (b) high-DO water, and (c) simulated low-DO PWR water

The formation and growth of surface cracks appears to be different in simulated PWR water from that in air, although the crack frequency is the same in all of the environments (Fig. 23). Metallographic examination of the test specimens indicates that, in all of the environments, cracks primarily form within PSBs. During cyclic straining, strain localization in PSBs results in the formation of extrusions and intrusions at the surface; ultimately, with continued cycling, microcracks develop in these PSBs. Once a microcrack is formed, it continues to grow along its slip plane or a PSB as a Mode II (shear) crack in Stage I growth. The orientation of the crack is usually $45^{\circ}$ to the stress axis. The Stage I crack may extend across several grains before the increasing stress intensity of the crack promotes slip on systems other than the primary slip. Because slip is no longer confined to planes at $45^{\circ}$ to the stress axis, the crack begins to propagate as a Mode I (tensile) crack, normal to the stress axis as Stage II growth. This behavior was observed in all of the specimens that were tested in air and, in most instances, for specimens that were tested in high-DO water. In a simulated PWR environment ( $<10 \mathrm{ppb}$ DO), the surface cracks appear to grow entirely as Mode I tensile cracks normal to the stress axis; this suggests that factors other than mechanical fatigue control the growth of surface microcracks in PWR water.

The formation and growth of surface cracks in PWR water are consistent with both the slip dissolution 40,41 and hydrogen-induced cracking mechanisms. 42 However, lower fatigue lives in low-DO water than in high-DO water can not be reconciled in terms of the slip dissolution mechanism. If slip dissolution alone was responsible for enhanced CGRs in water, similar growth behavior (growth of surface cracks entirely as Mode I tensile cracks) and reduction in fatigue lives should also be observed in high-DO water. It is likely that hydrogeninduced cracking is important in PWR water with low-DO. Fatigue tests are in progress on austenitic SSs to characterize the formation and growth of surface cracks in LWR environments. 
Strain Rate: $0.4 \%$ /s
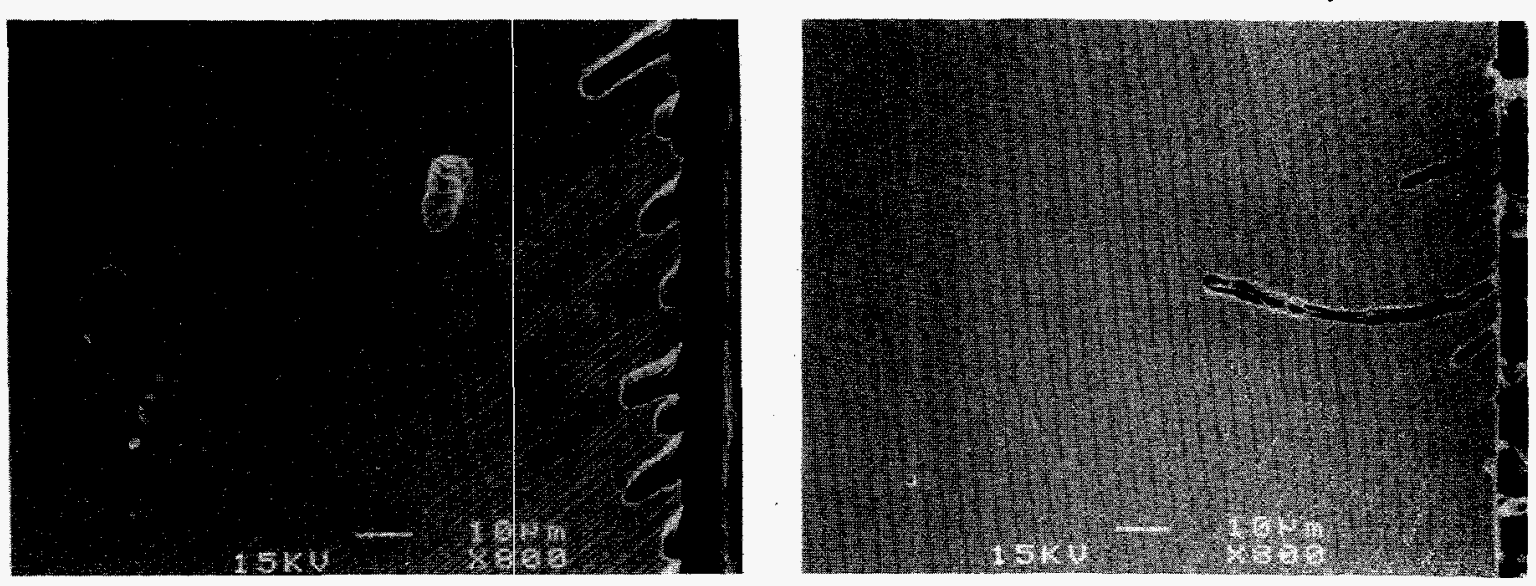

Air
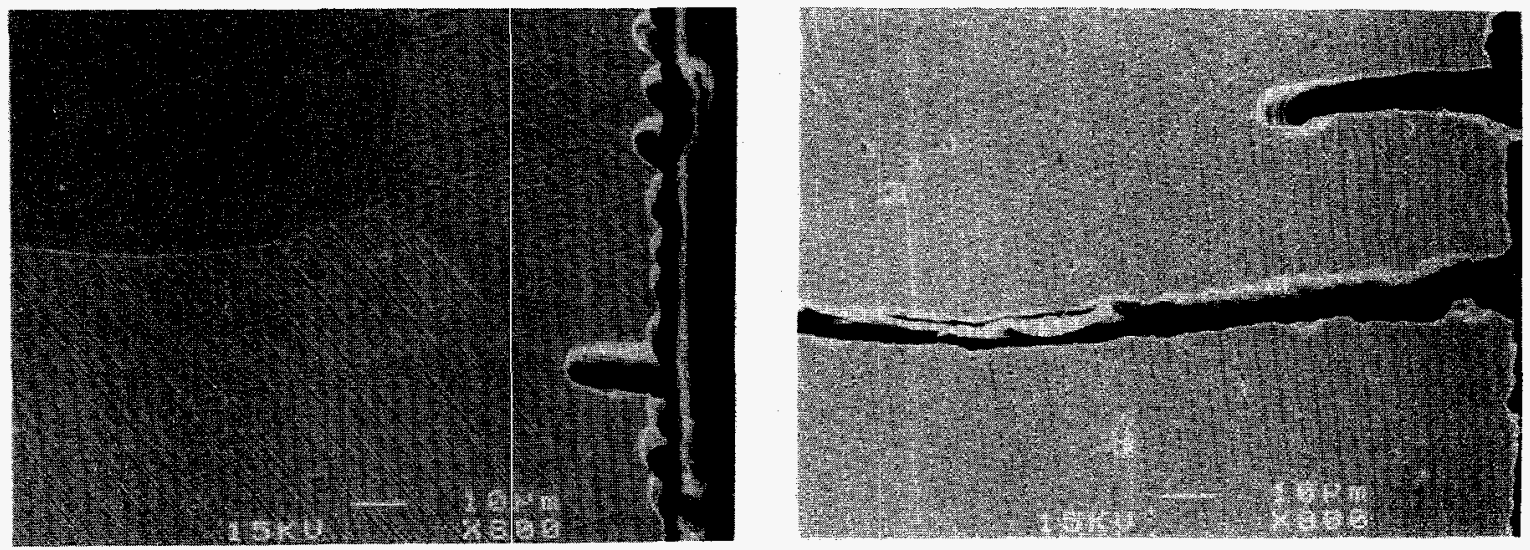

Simulated PWR Water
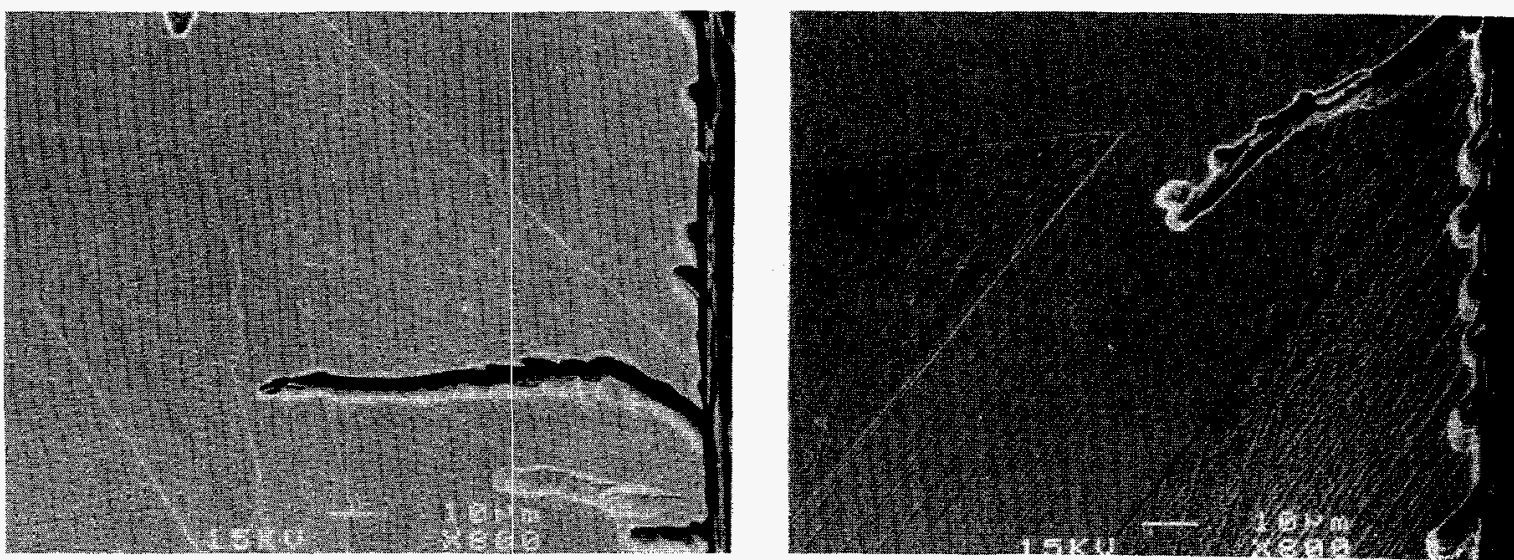

water with $\approx 0.7 \overline{\mathrm{ppm}}$ DO

Figure 23. Photomicrographs of surface cracks along longitudinal sections of Type 316NG SS in air and water environments at strain rates of 0.4 and $0.004 \% / \mathrm{s}$ 


\section{Irradiation-Assisted Stress Corrosion Cracking of Austenitic SS}

In recent years, failures of reactor-core internal components in both BWRs and PWRs have increased after accumulation of relatively high fluence $\left(>5 \times 10^{20} \mathrm{n} \cdot \mathrm{cm}^{-2}, \mathrm{E}>1 \mathrm{MeV}\right)$. The general pattern of the observed failures indicates that, as nuclear plants age and neutron fluence increases, various apparently nonsensitized austenitic SSs become susceptible to intergranular failure. Some components (e.g., BWR core shroud, control-blade handle and sheath) are known to have cracked under minimal applied stress. Although most failed components can be replaced, some safety-significant structural components (e.g., BWR top guide, shroud, and core plate) would be very difficult or impractical to replace. Therefore, to understand this type of degradation, which is commonly known as IASCC, the structural integrity of these components after accumulation of high fluence has been a subject of concern and extensive research.

The primary effects of irradiation include alteration of microchemistry, microstructure, and mechanical properties of structural materials, which are usually fabricated from ASTM Type 304,316 , or 348 SSs. Irradiation produces defects and defect clusters in grain matrices, and alters the dislocation network, dislocation loop, and dislocation channel structures, leading to radiation-induced hardening. Irradiation also leads to changes in the stability of second-phase precipitates and the local alloy chemistry near grain boundaries, precipitates, and defect clusters. Grain-boundary microchemistry that differs significantly from that of the bulk composition can be produced in association with not only radiation-induced segregation (RIS) but also thermally driven equilibrium and nonequilibrium segregation of alloying and impurity elements. Neutron irradiation also alters the water chemistry, in particular, near the grain-boundary surfaces in a crack-tip region.

For many years, irradiation-induced grain-boundary depletion of chromium has been considered as the primary metallurgical process that causes IASCC. One of the most important factors that has been considered by many investigators to support the chromiumdepletion mechanism is the observation that the dependence of IGSCC of nonirradiated thermally sensitized material and of IASCC of BWR-irradiated solution-annealed material on water chemistry (i.e., oxidizing potential) is similar. Recently, attention has also focused on the effects of fabrication-related variables, i.e., grain-boundary segregation and depletion of alloying and impurity elements by thermal processes, the effect of final thermomechanical treatment, hardening by cold work, the use of recycled scrap metals, uptake of minor impurities during iron- and steelmaking, and contamination by minor impurities during welding of field components such as BWR core shrouds.

In this reporting period, our effort has focused on: (a) SSRT testing of model SS alloys irradiated in the Halden reactor, (b) characterization of deleterious impurities from contamination during welding of core internal components, (c) hardness and grain size distribution in weld HAZs, and (d) analysis of fluorine and oxygen in the materials. Preliminary results obtained on base-metal components, such as neutron-absorber tubes and control-blade sheath irradiated in several BWRs, indicated that inadvertent contamination by impurities such as fluorine and oxygen can be deleterious. Consistent with this, significant fluorine and oxygen contamination was observed in a BWR core shroud weld specimen and in nonirradiated weld specimens of Type 304 SS prepared by a shielded-metal-arc (SMA) process. 


\subsection{Slow-Strain-Rate-Tensile Tests of Austenitic Stainless Steels Irradiated in the Halden Reactor (H. M. Chung, W. E. Ruther, and R. V. Strain)}

Additional results from SSRT: tests were obtained for model SS alloy specimens irradiated to a fluence of $\approx 0.45 \times 10^{21} \mathrm{n} \cdot \mathrm{cm}^{-2}\left(\mathrm{E}>1 \mathrm{MeV}\right.$ ) at $\approx 288^{\circ} \mathrm{C}$ in a helium environment in the Halden reactor. Companion tests on archive materials were also conducted in HP water that contained $\approx 8 \mathrm{ppm}$ DO. The alloy composition and updated test results are given in Tables 7 and 8 , respectively.

Heats L7 (high in oxygen and sulfur) and L2 (high in phosphorus and sulfur) exhibited unusually low ductility in water even in the nonirradiated state, i.e., only $8.4-9.1 \%$, versus $19-47 \%$ for other steels listed in Table 8 . Heat L7, which contains $\approx 274$ wppm oxygen and $\approx 380 \mathrm{wppm}$ sulfur, exhibited high ductility $(45.2 \%)$ when tested in air, whereas ductility was only $\approx 8.4 \%$ when tested in water (see Fig. 24). This indicates a significant effect of oxygen and sulfur, or both, dissolved in the material on SSRT properties in oxygenated water. Sulfur content was also high $(\approx 340 \mathrm{wppm})$ in Type 304 SS Heat L2, which also exhibited unusually low ductility in water.

An unusual brittle morphology was observed on $\approx 20 \%$ of the fracture surface of the nonirradiated specimen from Heat L7. The brittle morphology was associated with dense aggregates of precipitates that are tetrahedral in shape and $10-20 \mathrm{~mm}$ in size. It is not clear whether the precipitates formed in the material before fracture during the SSRT test, or after fracture during exposure to water. Nevertheless, no intergranular fracture morphology was observed in this specimen. Further analysis of microchemical and microstructural characteristics of the fracture surfaces of Heats L7 and L2 is being conducted by scanning electron microscopy energy-dispersive spectroscopy (SEM-EDS) and Auger electron spectroscopy (AES).

Table 7. Composition (in wt.\%) of model SS alloys used for SSRT tests in simulated BWR water at $\approx 288^{\circ} \mathrm{C}$

\begin{tabular}{cccccccccccc}
\hline Alloy ID & Ni & Si & P & S & Mn & C & N & Cr & Mo or Nb & O & Remarks \\
\hline L23 & 12.04 & 0.68 & 0.030 & 0.047 & 0.96 & 0.043 & 0.092 & 17.30 & Nb 1.06 & 0.093 & CP 348 \\
L7 & 10.60 & 0.18 & 0.040 & 0.038 & 1.02 & 0.007 & 0.111 & 15.40 & - & 0.274 & high O, N. S; low Si. C \\
L14 & 7.93 & 1.49 & 0.080 & 0.002 & 1.76 & 0.107 & 0.028 & 15.00 & - & 0.045 & high Si, P. C; low S, N \\
L17 & 8.00 & 0.66 & 0.090 & 0.009 & 0.48 & 0.061 & 0.078 & 15.30 & - & 0.090 & high P: low S \\
L6 & 10.00 & 1.90 & 0.020 & 0.005 & 1.13 & 0.096 & 0.087 & 17.10 & - & 0.058 & high Si, C, Cr; low S \\
L27 & 10.30 & 0.96 & 0.040 & 0.002 & 0.97 & 0.057 & 0.019 & 15.30 & Mo 2.01 & - & CP 316, B 0.030 \\
L26 & 8.09 & 0.79 & 0.004 & 0.002 & 0.91 & 0.070 & 0.089 & 17.20 & - & 0.080 & low P.S S \\
L2 & 10.50 & 0.82 & 0.080 & 0.034 & 1.58 & 0.074 & 0.102 & 17.02 & - & 0.066 & high P, S, N \\
L25 & 8.93 & 0.92 & 0.020 & 0.008 & 1.54 & 0.019 & 0.095 & 17.20 & - & 0.085 & B 0.010 \\
C1 & 8.12 & 0.50 & 0.038 & 0.002 & 1.00 & 0.060 & 0.060 & 18.11 & - & - & CP 304 \\
L5 & 9.66 & 0.90 & 0.113 & 0.028 & 0.47 & 0.006 & 0.033 & 21.00 & - & - & high P. Cr: low Si, C \\
L22 & 13.30 & 0.24 & 0.015 & 0.004 & 0.40 & 0.003 & 0.001 & 16.10 & Mo 2.04 & - & HP 316 \\
C3 & 8.91 & 0.46 & 0.019 & 0.004 & 1.81 & 0.016 & 0.083 & 18.55 & - & - & CP 304L \\
C16 & 12.90 & 0.38 & 0.014 & 0.002 & 1.66 & 0.020 & 0.011 & 16.92 & - & - & high Ni: low S. N \\
L4 & 10.20 & 0.94 & 0.031 & 0.010 & 1.75 & 0.110 & 0.002 & 15.80 & - & - & high Mn. C: low N \\
L18 & 8.13 & 0.14 & 0.016 & 0.033 & 1.13 & 0.080 & 0.001 & 18.00 & - & - & low Si, N \\
\hline
\end{tabular}


Table 8. SSRTa test and SEM fractography results for specimens of austenitic SSs irradiated in helium at $288^{\circ} \mathrm{C}$ in Halden reactor

\begin{tabular}{|c|c|c|c|c|c|c|c|c|c|c|c|}
\hline \multirow[b]{2}{*}{$\begin{array}{r}\text { Alloy } \\
\text { Ident. } \\
\text { No. }\end{array}$} & \multirow{2}{*}{$\begin{array}{c}\text { Fast- } \\
\text { Neutron } \\
\text { Fluence } \\
\left(\mathrm{n} \cdot \mathrm{cm}^{-2}\right)\end{array}$} & \multirow[b]{2}{*}{$\begin{array}{c}\text { SSRT } \\
\text { No. }\end{array}$} & \multicolumn{4}{|c|}{ Feedwater Chemistry } & \multicolumn{3}{|c|}{ SSRT Parameters } & \multicolumn{2}{|c|}{ Fracture Behavior } \\
\hline & & & $\begin{array}{c}\text { Oxygen } \\
\text { Conc. } \\
\text { (ppm) }\end{array}$ & $\begin{array}{c}\text { Average } \\
\text { ECP } \\
\text { (mV SHE) }\end{array}$ & $\begin{array}{c}\text { Cond. } \\
\text { at } 25^{\circ} \mathrm{C} \\
\left(\mu \mathrm{S} \cdot \mathrm{cm}^{-1}\right)\end{array}$ & $\begin{array}{c}\mathrm{pH} \\
\text { at } 25^{\circ} \mathrm{C}\end{array}$ & $\begin{array}{c}\text { Failure } \\
\text { Time } \\
\text { (h) }\end{array}$ & $\begin{array}{c}\text { Max. } \\
\text { Stress } \\
(\mathrm{MPa})\end{array}$ & $\begin{array}{c}\text { Total } \\
\text { Elong. } \\
(\%)\end{array}$ & $\begin{array}{c}\text { TGSCC } \\
(\%)\end{array}$ & $\begin{array}{c}\text { IGSCC } \\
(\%)\end{array}$ \\
\hline L23 & 0 & CHR-1 & 8.6 & +228 & 0.07 & 6.65 & 240.3 & 480 & 18.6 & - & - \\
\hline L7 & 0 & CHR-2 & 8.0 & +217 & 0.07 & 7.37 & 141.2 & 370 & 8.4 & $20^{b}$ & 0 \\
\hline L7 & 0 & \multicolumn{2}{|c|}{ CHR-7test in air } & - & - & - & 761.0 & 572 & 45.2 & 0 & 0 \\
\hline L14 & 0 & CHR-3 & 8.6 & +208 & 0.07 & 7.37 & 794.4 & 474 & 47.2 & 0 & 0 \\
\hline L17 & 0 & CHR-4. & 7.5 & +262 & 0.06 & 7.09 & 236.1 & 412 & 14.0 & - & - \\
\hline L6 & 0 & CHR-5 & 7.9 & +286 & 0.08 & 6.85 & 773.4 & 545 & 45.9 & 0 & 0 \\
\hline L27 & 0 & CHR-6 & 8.0 & +247 & 0.08 & 6.96 & 405.0 & 483 & 24.1 & 0 & 0 \\
\hline L26 & 0 & CHR-8 & 9.4 & +223 & 0.07 & 6.65 & 703.9 & 596 & 41.8 & 0 & 0 \\
\hline $\mathbf{L 2}$ & 0 & CHR-9 & 8.6 & +292 & 0.06 & 6.55 & 152.6 & 348 & 9.1 & - & - \\
\hline L25 & 0 & CHR-10 & 8.2 & +239 & 0.06 & 6.42 & 479.5 & 458 & 28.4 & - & - \\
\hline $\mathrm{Cl}$ & $0.45 \times 1021$ & HR-1 & 8.3 & +184 & 0.07 & 7.03 & 299.9 & 680 & 17.8 & 4 & 0 \\
\hline LS & $0.45 \times 10^{21}$ & HR-2 & 9.7 & +208 & 0.07 & 6.89 & 552.9 & 539 & 32.8 & 2 & 2 \\
\hline L22 & $0.45 \times 10^{21}$ & HR-3 & 8.0 & +236 & 0.07 & 6.80 & 160.4 & 596 & 9.5 & 50 & 15 \\
\hline C3 & $0.45 \times 10^{21}$ & HR-4 & 8.7 & +161 & 0.07 & 6.68 & 552.0 & 491 & 32.8 & 5 & 0 \\
\hline $\mathrm{C} 16$ & $0.45 \times 10^{21}$ & HR-5 & 8.3 & +204 & 0.08 & 6.74 & 368.6 & 527 & 21.9 & 2 & 0 \\
\hline L4 & $0.45 \times 10^{21}$ & HR-6 & 9.0 & +202 & 0.08 & 6.70 & 400.4 & 542 & 23.8 & 46 & 0 \\
\hline L18 & $0.45 \times 10^{21}$ & HR-7 & 9.0 & +203 & 0.08 & 6.33 & 156.7 & 572 & 9.3 & 54 & 0 \\
\hline
\end{tabular}

aStrain rate of $1.65 \times 10^{-7} \mathrm{~s}^{-1}$ (strain rate for Test CHR-1 was $2.15 \times 10^{-7} \mathrm{~s}^{-1}$ ).

${ }^{b}$ Brittle crack morphology on $\approx 20 \%$ of the fracture surface in association with dense aggregates of internal oxides that are tetrahedral in shape and $10-20 \mathrm{~mm}$ in size.

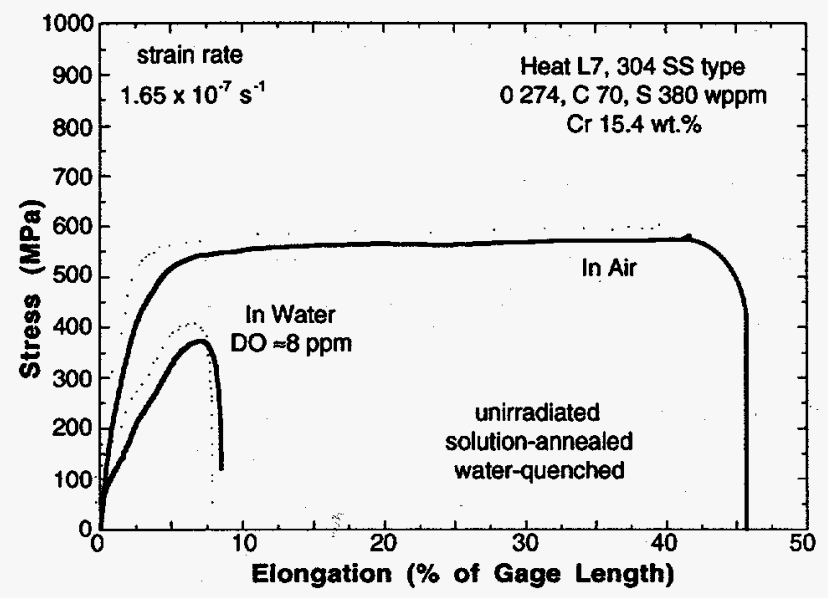

Figure 24.

Stress-versus-elongation behavior of laboratory Heat L7 of Type 304 SS in air and water that contained $\approx 8 \mathrm{ppm} D O$

Fracture surface morphology of several Halden-reactor-irradiated SSRT specimens was characterized by SEM; the results are summarized in Table 8 and the percent IGSCC is shown in Fig. 25 for specimens from seven heats that have been tested and characterized thus far. Data obtained from BWR neutron-absorber tubes and a control-blade sheath are also shown in the figure for comparison. Figures 26 and 27 show similar data in terms of percent transgranular stress corrosion cracking (TGSCC) and combined IGSCC and TGSCC, respectively.

Preliminary observations indicate that unusually high oxygen and sulfur dissolved in the material is deleterious to SSRT behavior in water, even at low fluence. In previous studies 

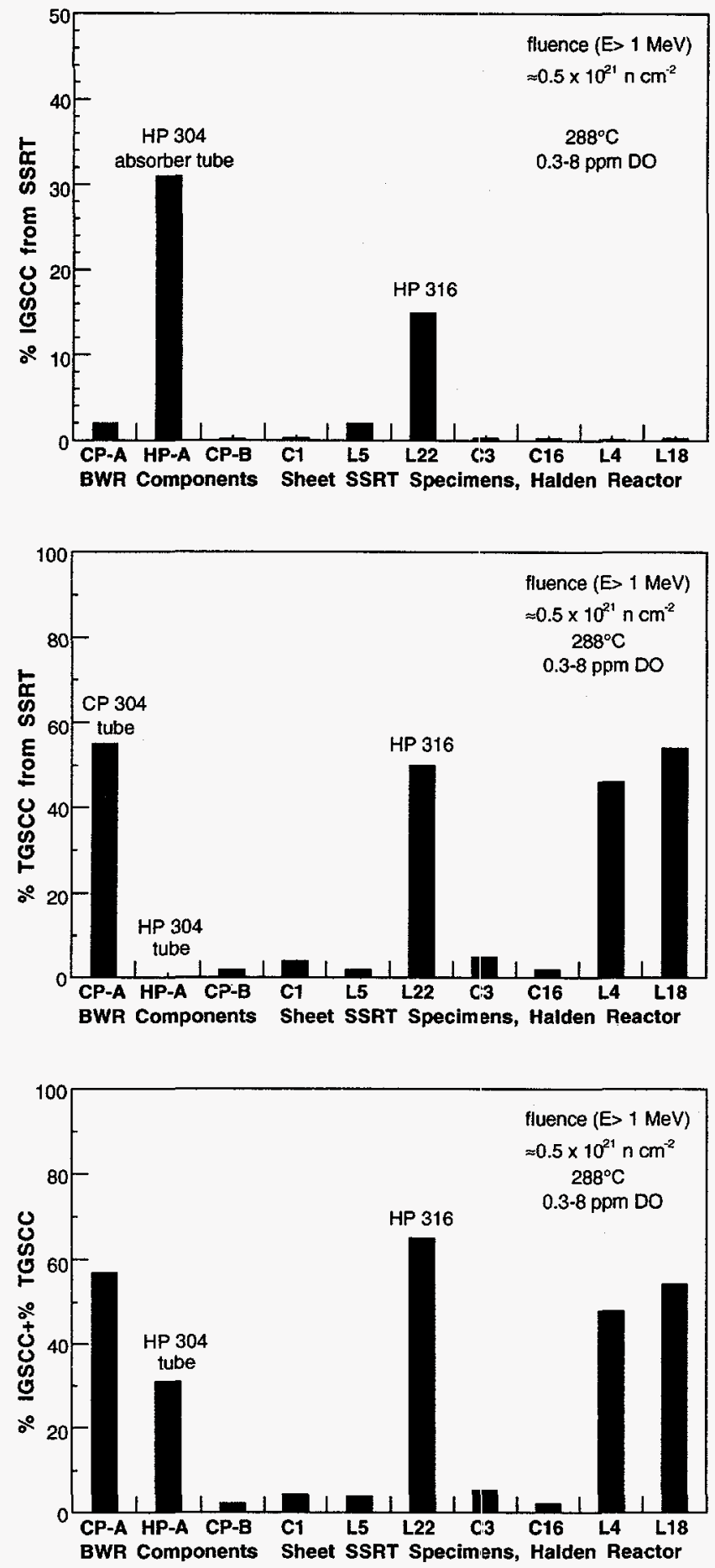

Figure 25.

Percent IGSCC of SS heats irradiated in helium in Halden reactor to fluence of $\approx 0.45 \times 10^{21} \mathrm{n} \cdot \mathrm{cm}^{-2}$ (E > $1 \mathrm{MeV}$. Similar results from BWR neutronabsorber tubes and control-blade sheath irradiated to $\approx 0.6 \times 10^{21} \mathrm{n} \cdot \mathrm{cm}^{-2}(\mathrm{E}>1$ $\mathrm{MeV}$ ) are shown for comparison. HP = high purity; $\mathrm{CP}=$ commercial purity.

Figure 26.

Percent TGSCC of SS heats irradiated in Halden reactor to fluence of $\approx 0.45 x$ $10^{21} \mathrm{n} \cdot \mathrm{cm}^{-2}(\mathrm{E}>1 \mathrm{MeV})$. Similar results from BWR neutron-absorber tubes and control-blade sheath are shown for comparison. $H P=$ high purity; $C P=$ commercial purity .

Figure 27.

Combined percent IGSCC and TGSCC of SS heats irradiated in Halden reactor to fluence of $\approx 0.45 \times 10^{21} \mathrm{n} \cdot \mathrm{cm}^{-2}(E>1$ $\mathrm{MeV})$. Similar results from BWR neutron-absorber tubes and controlblade sheath are shown for comparison. $H P=$ high purity; $C P=$ commercial purity.

on BWR neutron-absorber tubes and a control blade sheath, we observed that susceptibility to IGSCC increased significantly for higher oxygen content in the irradiated materials. It is necessary, however, to obtain more conclusive evidence that is based on results from the entire test matrix of the Halden irradiation experiment for low-, medium-, and high-fluence levels, i.e., $\approx 0.45, \approx 1.1$, and $\approx 3.0 \times 10^{21} \mathrm{n} \cdot \mathrm{cm}^{-2}$, respectively. 
Results on Heats CP-A, LA, and L18 in Figs. 25 and 26 are consistent with a trend wherein susceptibility of high-carbon Type 304 SS to TGSCC is high, whereas susceptibility to IGSCC is low. However, Type 316 SS Heat L22 exhibited high susceptibility to TGSCC as well as IGSCC despite of its low carbon content of $\approx 0.003 \mathrm{wt} . \%$.

\subsection{Properties of Stainless Steel Welds (J.-H. Park and H. M. Chung)}

Most large components, such as BWR core shrouds, are welded in the field by either SMA or submerged-arc (SA) procedures. These procedures include the use of welding electrodes that are coated with a welding flux. Consequently, contamination by impurities can occur in the fusion zones and HAZs, and the microchemistry and microstructure of these regions differ from those of the base metal; factors that can influence IGSCC and IASCC behavior. The structure and properties of weld HAZs of three commercial heats of Types 304, 304L, and 316 (Table 9) were investigated further in this reporting period.

Table 9. Composition (in wt.\%) of commercial heats of Types 304, 304L, and 316 SS that were used to investigate SCC and IASCC behavior of welds with respect to $B W R$ core shroud cracking

\begin{tabular}{ccccccccccc}
\hline ANL ID & Type & $\mathrm{Ni}$ & $\mathrm{Si}$ & $\mathrm{P}$ & $\mathrm{S}$ & $\mathrm{Mn}$ & $\mathrm{C}$ & $\mathrm{N}$ & $\mathrm{Cr}$ & Mo \\
\hline $\mathrm{C} 1$ & 304 & 8.12 & 0.50 & 0.038 & 0.002 & 1.00 & 0.060 & 0.060 & 18.11 & - \\
$\mathrm{C} 3$ & $304 \mathrm{~L}$ & 8.91 & 0.46 & 0.019 & 0.004 & 1.81 & 0.016 & 0.083 & 18.55 & - \\
$\mathrm{C} 21$ & 316 & 10.24 & 0.51 & 0.034 & 0.001 & 1.19 & 0.060 & 0.020 & 16.28 & 2.08 \\
\hline
\end{tabular}

\subsubsection{Chemical Composition of HAZ}

Weldments of 12.7-mm-thick plates of the commercial-grade heats were prepared by SMA and gas-tungsten-arc (GTA) procedures. The compositions of the HAZ of the SMA weld and base metal of Type 304 SS Heat C1 and Type 316 SS Heat C21, determined by bulk chemical analysis, 53 are summarized in Tables 10 and 11 , respectively. Similar results for GTA welds of the same heats are given in Tables 12 and 13, respectively. Significant contamination or depletion of elements in HAZ relative to those in base metal is denoted by bold face in the tables.

Only the fluorine content was analyzed for the SMA weld of Heat C1; results for other heats are not available. Based on the results in Tables 10-13, the following trends are evident:

(a) Chemical composition of the HAZ in the GTA weld is similar to that of the base metal.

(b) Welding by the SMA procedure leads to significant contamination of the HAZ by oxygen, fluorine, and sulfur. These impurities are conducive to higher susceptibility to IASCC. The major sources of contamination are the weld electrode coating and air.

(c) The weld HAZ of Type 304 SS picks up some molybdenum during SMA welding.

(d) The weld HAZ of Type 316 loses a significant amount of molybdenum during welding by either the SMA or GTA procedure. 
Table 10. Composition of SMA weld $H A Z$ and base metal of commercial heat $\mathrm{C} 1$ of Type 304 SS

\begin{tabular}{ccc}
\hline Element & SMA HAZ & Base Metal \\
\hline In wt.\% & & \\
$\mathrm{Cr}$ & 19.91 & 13.11 \\
$\mathrm{Ni}$ & 9.36 & 8.12 \\
$\mathrm{Mn}$ & 1.18 & 1.00 \\
$\mathrm{Mo}$ & $\mathbf{0 . 2 7}$ & $<\mathbf{0 . 0 5}$ \\
$\mathrm{Cu}$ & 0.07 & 0.05 \\
$\mathrm{Si}$ & 0.56 & 0.50 \\
In ppm & & \\
$\mathrm{C}$ & 600 & 600 \\
O & $\mathbf{6 4 0}$ & $\mathbf{8 0}$ \\
$\mathrm{P}$ & $\mathbf{3 1 0}$ & 380 \\
$\mathrm{~S}$ & $\mathbf{5 0}$ & $\mathbf{2 0}$ \\
$\mathrm{F}$ & $\mathbf{3 0}$ & 0 \\
\hline
\end{tabular}

Table 12. Composition of GTA weld $H A Z$ and base metal of commercial heat $\mathrm{C} 1$ of Type 304 SS

\begin{tabular}{crr}
\hline Element & SMA HAZ & Base Metal \\
\hline In wt.\% & & \\
$\mathrm{Cr}$ & 18.88 & 18.11 \\
$\mathrm{Ni}$ & 9.60 & 8.12 \\
$\mathrm{Mn}$ & 1.30 & 1.00 \\
$\mathrm{Mo}$ & 0.06 & $<0.05$ \\
$\mathrm{Cu}$ & 0.05 & 0.05 \\
$\mathrm{Si}$ & 0.47 & 0.50 \\
In ppm & & \\
$\mathrm{C}$ & 600 & 600 \\
$\mathrm{O}$ & 97 & 80 \\
$\mathrm{P}$ & 330 & 380 \\
$\mathrm{~S}$ & 20 & 20 \\
\hline
\end{tabular}

Table 11. Composition of SMA weld $H A Z$ and base metal of commercial heat $\mathrm{C} 21$ of Type 316 SS

\begin{tabular}{ccc}
\hline Element & SMA HAZ & Base Metal \\
\hline In wt.\% & & \\
$\mathrm{Cr}$ & 19.19 & 16.28 \\
$\mathrm{Ni}$ & 10.10 & 10.24 \\
$\mathrm{Mn}$ & 1.21 & 1.19 \\
$\mathrm{Mo}$ & $\mathbf{0 . 8 1}$ & 2.08 \\
$\mathrm{Si}$ & 0.56 & 0.51 \\
In ppm & & \\
$\mathrm{C}$ & 600 & 600 \\
$\mathrm{O}$ & 420 & 70 \\
$\mathrm{P}$ & 280 & 340 \\
$\mathrm{~S}$ & 60 & 10 \\
\hline
\end{tabular}

Table 13. Composition of GTA weld $H A Z$ and base metal of commercial heat $\mathrm{C} 21$ of Type 316 SS

\begin{tabular}{ccc}
\hline Element & SMA HAZ & Base Metal \\
\hline In wt.\% & & \\
$\mathrm{Cr}$ & 17.74 & 16.28 \\
$\mathrm{Ni}$ & $\mathbf{1 9 . 2 4}$ & 10.24 \\
$\mathrm{Mn}$ & 1.42 & 1.19 \\
$\mathrm{Mo}$ & 1.45 & 2.08 \\
$\mathrm{Si}$ & 0.53 & 0.51 \\
In ppm & & \\
$\mathrm{C}$ & 500 & 600 \\
$\mathrm{O}$ & 51 & 70 \\
P & 310 & 340 \\
$\mathrm{~S}$ & 20 & 10 \\
\hline
\end{tabular}

\subsubsection{Characterization of Grain Size and Hardening in HAZ}

Grain size distribution in the HAZ of the SMA weld of Type 304 SS Heat C1 was measured and is shown in Fig. 28. Grain size was measured as a function of distance from the boundary between the fusion zone and the HAZ (see Arrow B in Fig. 29). Grain size decreases from $\approx 65 \mu \mathrm{m}$ at the boundary and reaches a nearly constant value of $\approx 30 \mu \mathrm{m}$ at $>1 \mathrm{~mm}$ from the fusion zone. As indicated in Fig. 29, small inclusions were observed occasionally in the fusion zone. The ellipsoidal inclusion in the figure was $\approx 0.8 \mathrm{~mm}$ long and $\approx 0.4 \mathrm{~mm}$ wide. Analysis by SEM-EDS indicates that the inclusion was rich in oxygen, sodium, aluminum, silicon, potassium, calcium, titanium, chromium, and manganese, elements that are abundant in the coating of the ES08-16 weld electrode that was used to produce the SMA 

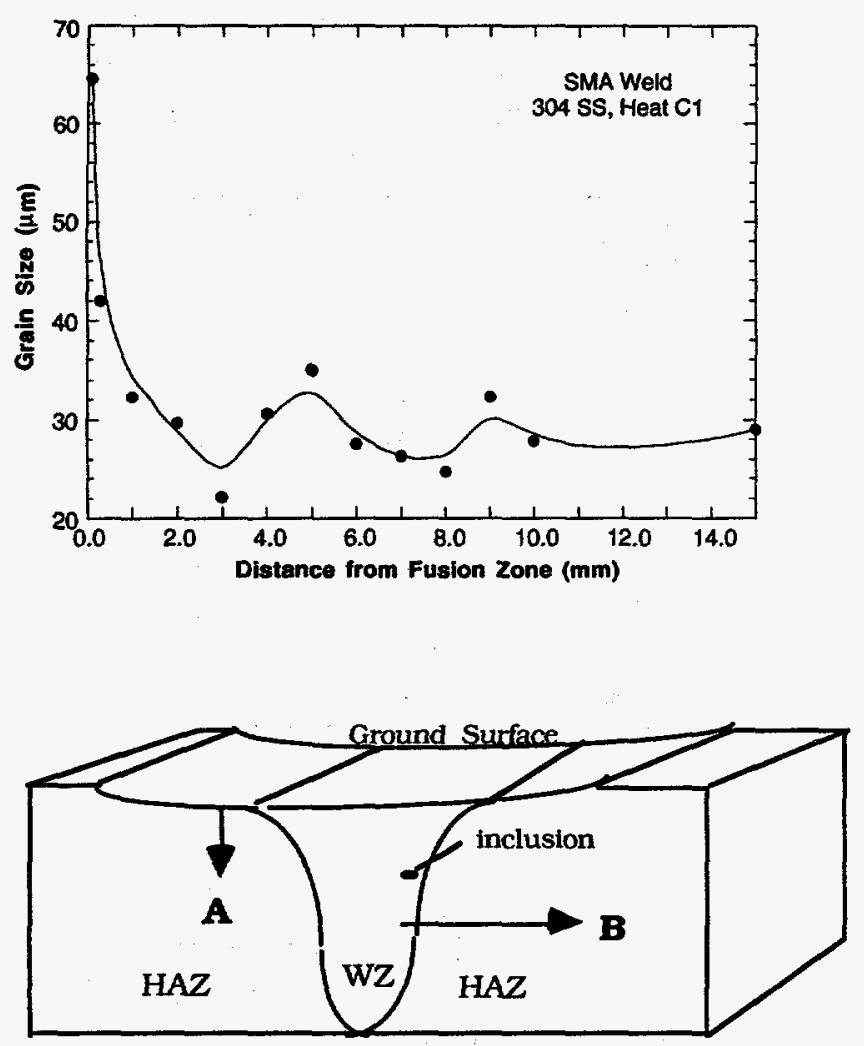

Figure 28.

Grain size of HAZ in SMA weld of Type 304 SS, Heat C1, as function of distance from fusion zone
Figure 29.

Schematic representation of SMA weld of Type 304 SS Heat C. WZ and HAZ denote, respectively, fusion and heataffected zone. Top surface was smoothed with a grinding wheel.

weld. This finding indicates that the inclusion was a small piece from the weld electrode coating.

To characterize local hardening of the SMA weld HAZ, Vickers microhardness was measured as a function of distance from the boundary between the fusion zone and the HAZ (in the direction of Arrow B in Fig. 29); the results are shown in Fig. 30. Hardness at $\approx 0.5 \mathrm{~mm}$ from the fusion zone is low and close to the base metal hardness of $\approx 220-230$ VHN. However, hardness is relatively high (280-310 VHN) at $0.8-2.5 \mathrm{~mm}$ away from the fusion zone. Hardening in $\mathrm{HAZ}$ is influenced by several factors: (a) local oxygen contamination, (b) grain size, (c) dislocations and defects produced during welding, and (d) local annealing and recovery during cooling.

Most cracking in BWR core shroud welds occurs at 1-4 mm away from the fusion zone; a distance not much different from the region of relatively high microhardness shown in Fig. 30. This indicates that local hardening plays an important role in SCC of the HAZ in components such as BWR core shrouds.

Rough surfaces of welded components are frequently smoothed in the field by grinding. During this procedure, the surface region is locally heated and is subject to significant cold work. To simulate the effect of this practice, the free surface of an SMA weld of Type 304 SS Heat $\mathrm{Cl}$ was smoothed with a grinding wheel. The microhardness measurements in Fig. 31 show that the grinding procedure introduces a hard subsurface layer $\approx 0.4 \mathrm{~mm}$ thick. 

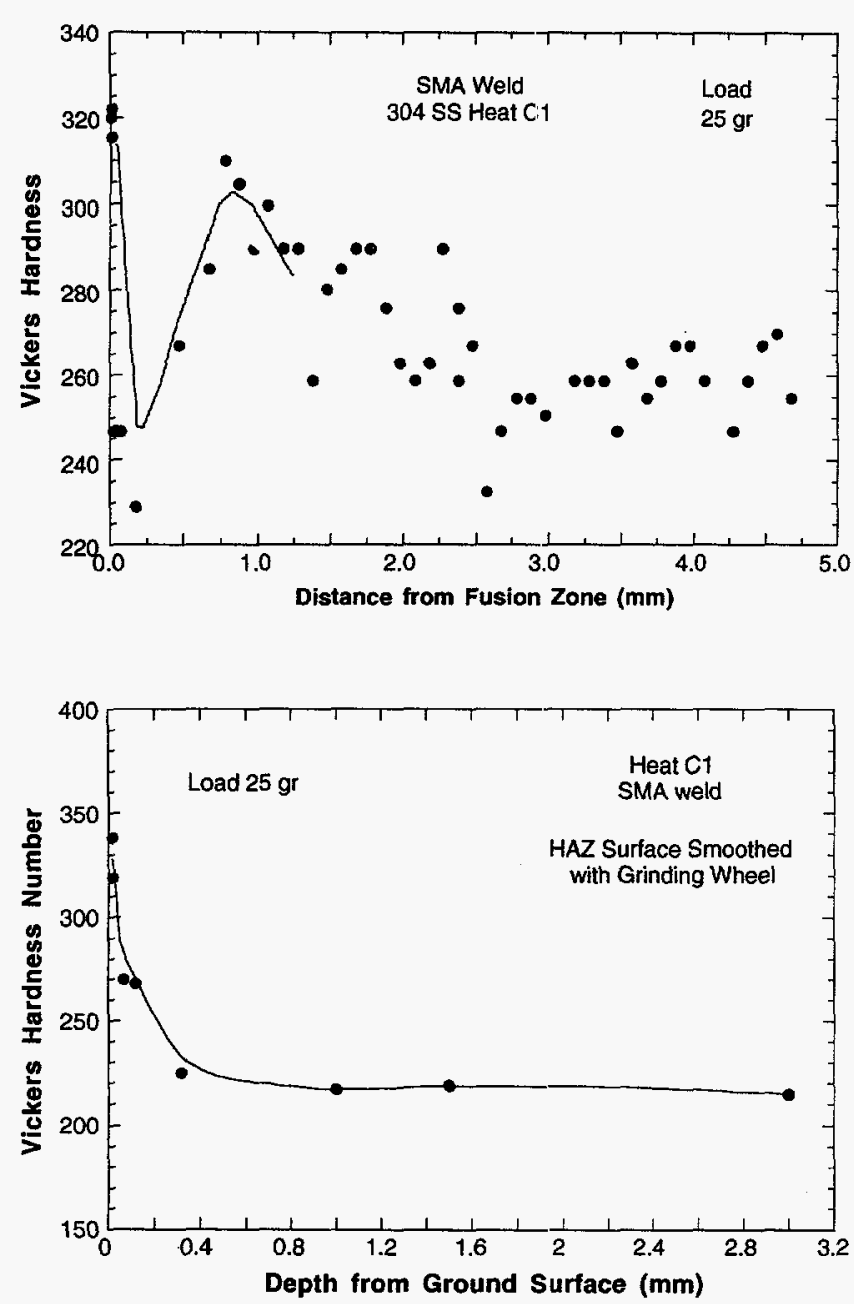

Figure 30.

Microhardness of SMA weld HAZ of Type 304 SS Heat CI as function of distance from fusion zone (Arrow $B$, Fig. 29). Note hardness maximum at 0.7-1.5 mm.
Figure 31.

Microhardness of HAZ in SMA weld of Type 304 SS, Heat C1, as function of distance (Arrow A, Fig. 29) from weld surface smoothed with a grinding wheel to simulate BWR core shroud weld surface finish

Figure 32 shows the hardening behavior of the ground specimen of the SMA weld of Type 304 SS Heat $\mathrm{Cl}$ and of the HAZs of two core shroud weld specimens, i.e., specimens of Type 304 SS from irradiated core shrouds in BWR-Q and -D. Information on the type of steel and approximate fluence level is somewhat limited and the chemical composition of the core shroud materials is not known. The hardness profile of the ground SMA weld of Heat $\mathrm{Cl}$ is similar to that of the H5 core shroud weld of the BWR-Q. However, the cold-worked layer of the H5 core shroud weld from BWR-D is significantly thicker, i.e., 0.4 versus $1.3 \mathrm{~mm}$.

Based on the results shown in Figs. 30 and 31, a three-dimensional (3-D) local hardness profile of the ground HAZ of the SMA weld of Heat $\mathrm{Cl}$ was constructed (see Fig. 33). The hardness results depicted in the figure suggest that a crack mostly likely would nucleate at the ground surface and propagate parallel to and 1-3 mm away from the boundary between the fusion zone and the HAZ.

\subsubsection{Secondary-Ion Mass Spectroscopy of Fluorine and Oxygen in Laboratory Welds}

The detection limit of fluorine in the SMA weld of Type $304 \mathrm{SS}$, Heat $\mathrm{C} 1$, by the wetchemistry method was $<\approx 30$ wppm when several grams of material were available for analysis, but only $\approx 120 \mathrm{wppm}(\approx 360 \mathrm{appm})$ when the sample mass was $<1 \mathrm{mg}$. Therefore, fluorine and 


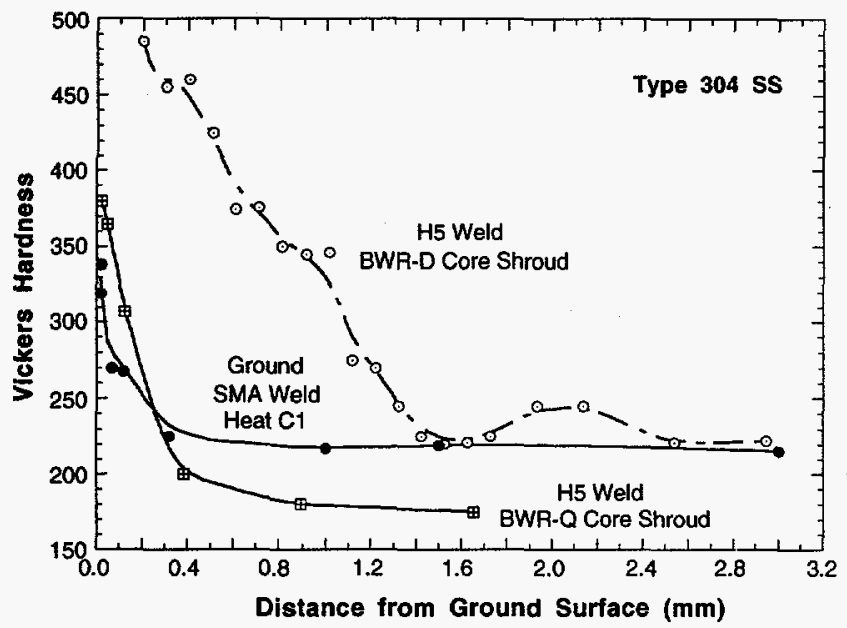

Figure 32.

Microhardness profiles of cold-worked HAZs of Type 304 SS, Heat C1, and $B W R$ core shroud welds as function of distance from ground surface

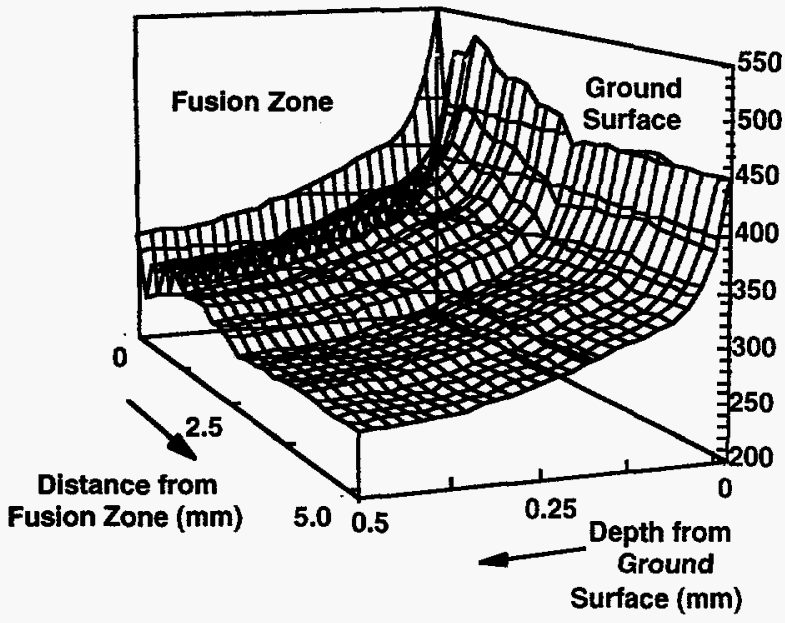

Figure 33.

Vickers microhardness of HAZ in SMA weld of Type 304 SS, Heat C1, as function of distance from ground surface and fusion zone. Note hardness maximum at $\approx 1 \mathrm{~mm}$ from fusion zone.

oxygen contamination in the specimen was analyzed by secondary-ion mass spectroscopy (SIMS). 53 The SMA weld specimen that contained the fusion zone and the HAZ was polished, etched in a dilute oxalic acid solution, and ultrasonically cleaned in alcohol before SIMS analysis. Secondary ions of fluorine that were ejected from the weld fusion zone and the HAZ were analyzed by using cesium primary ions in one case and oxygen ions in another.

Figure 34 shows distribution maps of fluorine and oxygen secondary ions obtained with cesium primary ions. The figure provides direct evidence that local regions high in oxygen concentration are also high in fluorine concentration. Although the solubility of fluorine and oxygen in steels is very low or negligible, the arc in the weld fumes may promote dissolution of atomic fluorine and oxygen in the fusion zone and the HAZ. This observation is consistent with the results of AES analyses of BWR core shrouds and neutron-absorber tubes, which showed a high fluorine content in oxide or spinel precipitates. ${ }^{54}$ It also seems to be consistent with the observation by Ward et al. that a visible oxide film promotes fluorine-assisted IGSCC. 55 

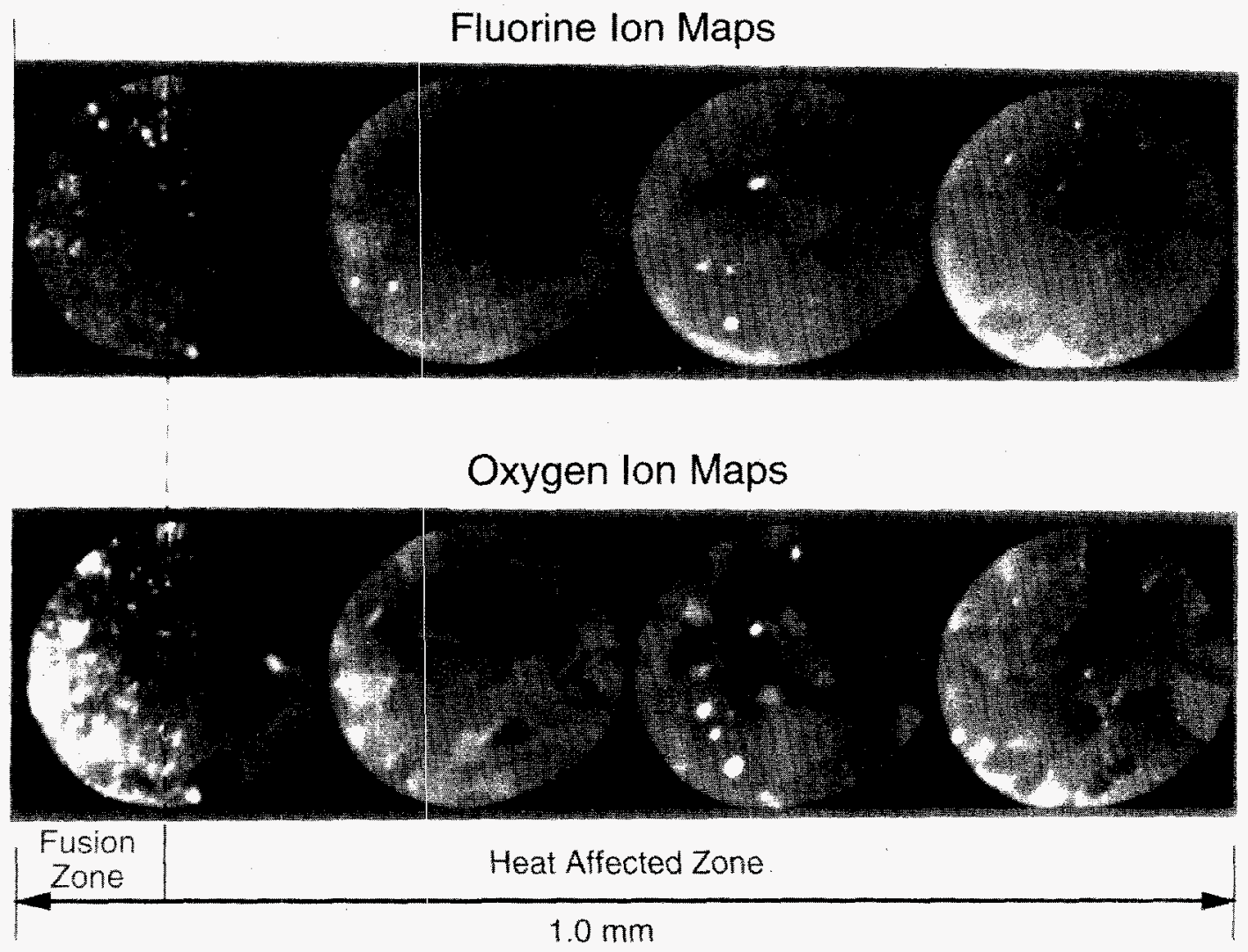

Figure 34. Fluorine (top) and oxygen (bottom) ion maps of SMA weld of Type 304 SS, Heat C1, determined by SIMS analysis

\subsubsection{Summary of Characterization of Simulated Core Shroud Weld}

In summary, we believe the following factors exacerbate the susceptibility of the HAZ of a core shroud weld to SCC:

(a) Oxygen, fluorine, and sulfur contamination that occurs during welding

(b) Hardening at a maximum distance of $\approx 1-3 \mathrm{~mm}$ from the fusion zone

(c) Hardened surface layers that are a result of postweld grinding

(d) Hardening by neutron irradiation that is compounded by hardening effects of (b) and (c)

(e) Thermal sensitization during welding

(f) Irradiation-induced grain-boundary depletion of chromium, which is compounded by thermal sensitization.

These factors may be more significant in some materials than in others, e.g., Type 304 versus Type 304L SSs. Additional results after irradiation of the laboratory-produced weld specimens and microstructural and microchemical analyses of BWR core shroud specimens will provide more definitive evidence of the above factors and a more quantitative understanding of the cracking mechanism. Initial results of grain-boundary segregation of fluorine in BWR neutron-absorber tubes and a core shroud weld are given below. 


\subsection{Analysis of Fluorine in BWR Components (H. M. Chung and J. E. Sanecki)}

To explore the role of fluorine in IASCC of SS, the segregation behavior of fluorine to grain boundaries in BWR neutron-absorber tubes and a core shroud weld was analyzed with a scanning Auger microscope (SAM). The composition and fast-neutron fluence of the BWR components are given in Table 14. Auger specimens were charged with hydrogen and fractured in situ in the ultrahigh vacuum of the SAM. Auger electron spectroscopy appeared to be superior to other techniques for determining grain-boundary compositions of most nonmetallic impurities at low concentrations. Derivative AES signals were obtained with a focused electron beam $\approx 1 \mu \mathrm{m}$ in diameter. The grain-boundary profile of a core shroud weld specimen was determined by an automated depth-profiling technique, i.e., repeated argon ion sputtering and acquisition of an AES fluorine signal at $625 \mathrm{eV} .54$

Table 14. Material type, composition (in wt.\%), and fluence of BWR components

\begin{tabular}{|c|c|c|c|c|c|c|c|c|c|c|c|}
\hline \multirow[b]{2}{*}{ Heat $\mathbb{D}$} & \multicolumn{9}{|c|}{ Composition (wt.\%) } & Source & \multirow{2}{*}{$\begin{array}{c}\text { Fluence } \\
\left(10^{21} \mathrm{n} \cdot \mathrm{cm}^{-2}\right)\end{array}$} \\
\hline & $\mathrm{Cr}$ & $\mathrm{NI}$ & Mn & $\mathrm{C}$ & $\mathbf{N}$ & B & Si & $\mathrm{P}$ & $\mathrm{S}$ & BWR & \\
\hline HP304-A & 18.50 & 9.45 & 1.53 & 0.018 & 0.100 & $<0.001$ & $<0.03$ & 0.005 & 0.003 & BWR-Pa & $0.2-1.4$ \\
\hline HP304-B & 18.30 & 9.75 & 1.32 & 0.015 & 0.080 & $<0.001$ & 0.05 & 0.005 & 0.005 & BWR-Pa & $0.2-1.4$ \\
\hline HP304-CD & 18.58 & 9.44 & 1.22 & 0.017 & 0.037 & 0.001 & 0.02 & 0.002 & 0.003 & BWR-Pa & $0.2-2.0$ \\
\hline CP304-A & 16.80 & 8.77 & 1.65 & $0.08^{b}$ & 0.052 & - & 1.55 & $0.045^{b}$ & $0.030^{\mathrm{b}}$ & BWR-V & $0.2-2.0$ \\
\hline CP304-B & $18-20$ & 8-10 & $2.00^{b}$ & $0.08^{b}$ & - & - & $1.00^{\mathrm{b}}$ & $0.045^{\mathrm{b}}$ & $0.030^{\mathrm{b}}$ & BWR-L ${ }^{d}$ & $0.5-2.6$ \\
\hline CP348A & 17.4 & 11.5 & 1.56 & 0.074 & 0.042 & - & 0.34 & 0.007 & 0.009 & BWR-Ke & $\approx 1.5$ \\
\hline HP348B & 17.7 & 11.1 & 1.65 & 0.041 & 0.008 & - & 0.19 & 0.002 & 0.007 & $B W R-K^{e}$ & $\approx 3.5$ \\
\hline 507-B & & & shrou & weld, & pe 3041 & compo & Ion unk & lown & & BWR-C & 0.05 \\
\hline CSW-D & & & e shr & I weld, & 304 & ompos & on unk & own & & BWR-D & $\approx 0.1$ \\
\hline CSW-Q & & & e shrot & d weld, & pe 304 & composit & on unkr & own & & BWR-Q & $\approx 0.00003$ \\
\hline
\end{tabular}

aHigh-purity neutron absorber tubes, $\mathrm{OD}=4.78 \mathrm{~mm}$, wall thickness $=0.63 \mathrm{~mm}$, composition before service.

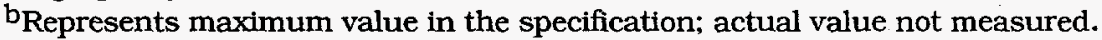

cCommercial-purity absorber tubes, $\mathrm{OD}=4.78 \mathrm{~mm}$, wall thickness $=0.79 \mathrm{~mm}$, composition after service.

d Commercial-purity control blade sheath, thickness $1.22 \mathrm{~mm}$, actual composition not measured.

eswelling mandrel tube irradiated in $7 \times 7$ fuel assembly in BWR KKP-1.

Initial results indicated that fluorine concentration is higher on grain boundaries than in grain matrices. 54 Therefore, further analysis was conducted on specimens from neutronabsorber tubes and a core shroud weld. Figure 35 shows the relative intensities of the fluorine signal at $625 \mathrm{eV}$ from ductile and intergranular fracture surfaces of the neutron-absorber tubes. The CP and HP Type 304 SS absorber tubes were fabricated from Heat CP304-A and HP304-A, respectively, and were irradiated to fluence of $\approx 2.0 \times 10^{21} \mathrm{n} \mathrm{cm}^{-2}$ in a BWR. In Fig. 35 , average concentrations of fluorine are significantly higher on grain boundaries than in grain matrices, however, absolute concentrations on grain boundaries could not be determined.

Auger electron spectroscopy analysis of grain-boundary distribution of fluorine was also conducted on the Type 304L SS BWR core shroud weld (Specimen 507-B, Table 14). The HAZ of the weld specimen was fractured in situ in the ultrahigh vacuum environment of the SAM, and one of the grain boundaries was selected and analyzed by means of a depth-profiling technique. The fluorine signal (at $625 \mathrm{eV}$ ) as a function of distance beneath the grain boundary was plotted in Fig. 36, which shows that fluorine content is significantly higher on grain boundaries than in grain matrices, probably as a result of thermal segregation during cooling of the HAZ. Because of its very low solubility in SSs, fluorine will segregate by a thermal process to local sites such as matrix/precipitate interfaces, grain boundaries, and stacking faults; however, irradiation-induced segregation cannot be ruled out and further investigation will be needed to clarify this point. 

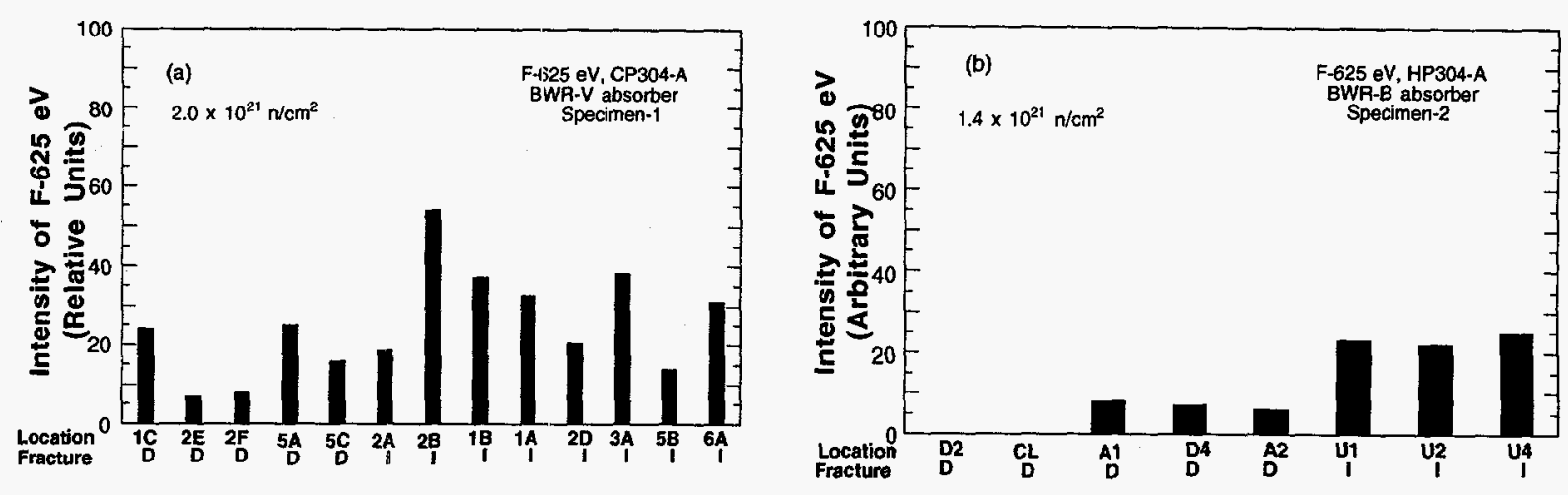

Figure 35. Fluorine 625-eV intensities from spots on ductile (grain matrix, denoted " $D$ ") and intergranular (grain boundary, denoted " $\mathrm{I}$ ) fracture surfaces in (a)CP and (b) HP BWR neutron-absorber tubes

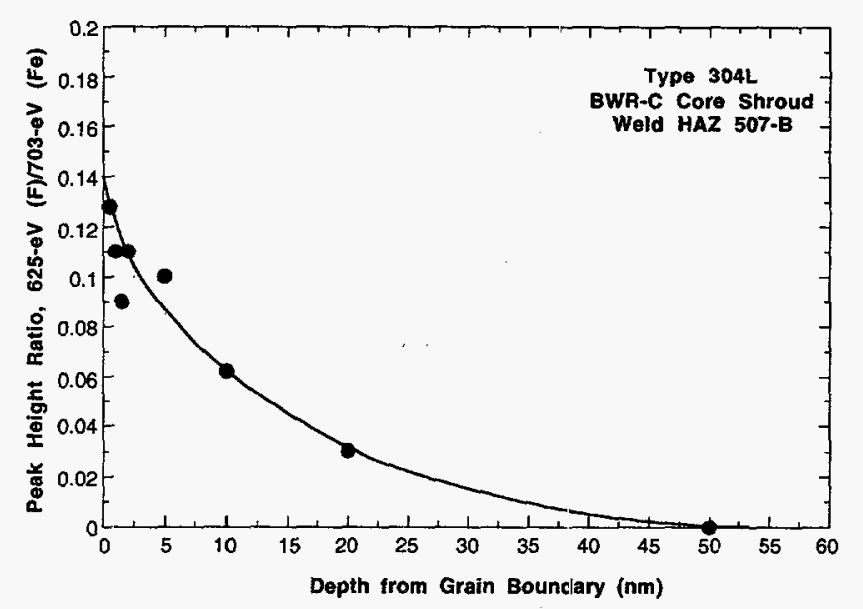

Figure 36.

Intensity of fluorine AES signal as function of sputter distance from grain boundary surface in Type $304 \mathrm{~L}$ coreshroud weld HAZ, Specimen 507-B

\subsection{Development of Hot-Cell J-R Test Facility (T. H. Hughes and E. E. Gruber)}

\subsubsection{Introduction}

The equipment for fracture toughness $J-R$ testing of irradiated compact-tension (CT) specimens in a hot cell has been assembled. The design of the test train has been modified to reduce the heat loss from the furnace and to minimize thermal gradients near the specimen. As part of the preliminary checkout of the equipment, a series of out-of-cell fracture toughness $\mathrm{J}-\mathrm{R}$ tests has been conducted on annealed and nonirradiated Type 304 SS specimens according to the "Standard Test Method for J-integral Characterization of Fracture Toughness," which is currently under consideration within the ASTM technical committee. This procedure is a merger of ASTM Specifications E 813 (Standard Test Method for $\mathrm{J}_{\mathrm{IC}}$, a Measure of Fracture Toughness) and E 1152 (Standard Test Method for Determining J-R Curve). In this method, the J-R curve characterizes the resistance of the material to slow stable crack growth after initiation from a preexisting fatigue crack. The $J_{I C}$ value characterizes the toughness of the material near the onset of stable crack extension. The parameter $\mathrm{J}_{\mathrm{C}}$ represents a measure of fracture toughness at instability prior to the onset of significant stable crack extension. 
The method involves pin loading of precracked fatigue specimens and determination of $\mathrm{J}$ as a function of crack growth. Load-versus-load-line displacement is recorded to calculate the $\mathrm{J}$-integral. The calculated J-integral is plotted against estimated or physical crack growth $\Delta$ a, within specified limits of crack growth. The crack length and crack growth are determined from either elastic compliance measurements or direct current DC electric potential (EP) technique.

\subsubsection{Equipment}

The test system is designed for in-cell testing with the test train, furnace, and other equipment mounted on a portable, wheeled cart that can be rolled into the cell. A schematic representation of the system is shown in Fig. 37. If required, a small autoclave can be installed inside the furnace for conducting tests in simulated LWR environments. The hydraulic actuator is mounted on top of the frame, with the test train components suspended beneath it. An enlarged drawing and photograph of the actuator, load cell, test train, and furnace are shown in Figs. 38 and 39, respectively. The $22.24 \mathrm{kN}$ (5 kip) load cell is at the top of the pull rod. A "trim" heater has been fitted to the lower end of the pull rod to compensate for axial heat loss from the specimen chamber. This heater is a small 125-watt band heater clamped around an aluminum cylinder that surrounds the pull rod, just above the upper clevis holder. The furnace is mounted on a pneumatic cylinder and can be raised to enclose the load cage and the specimen during the test.

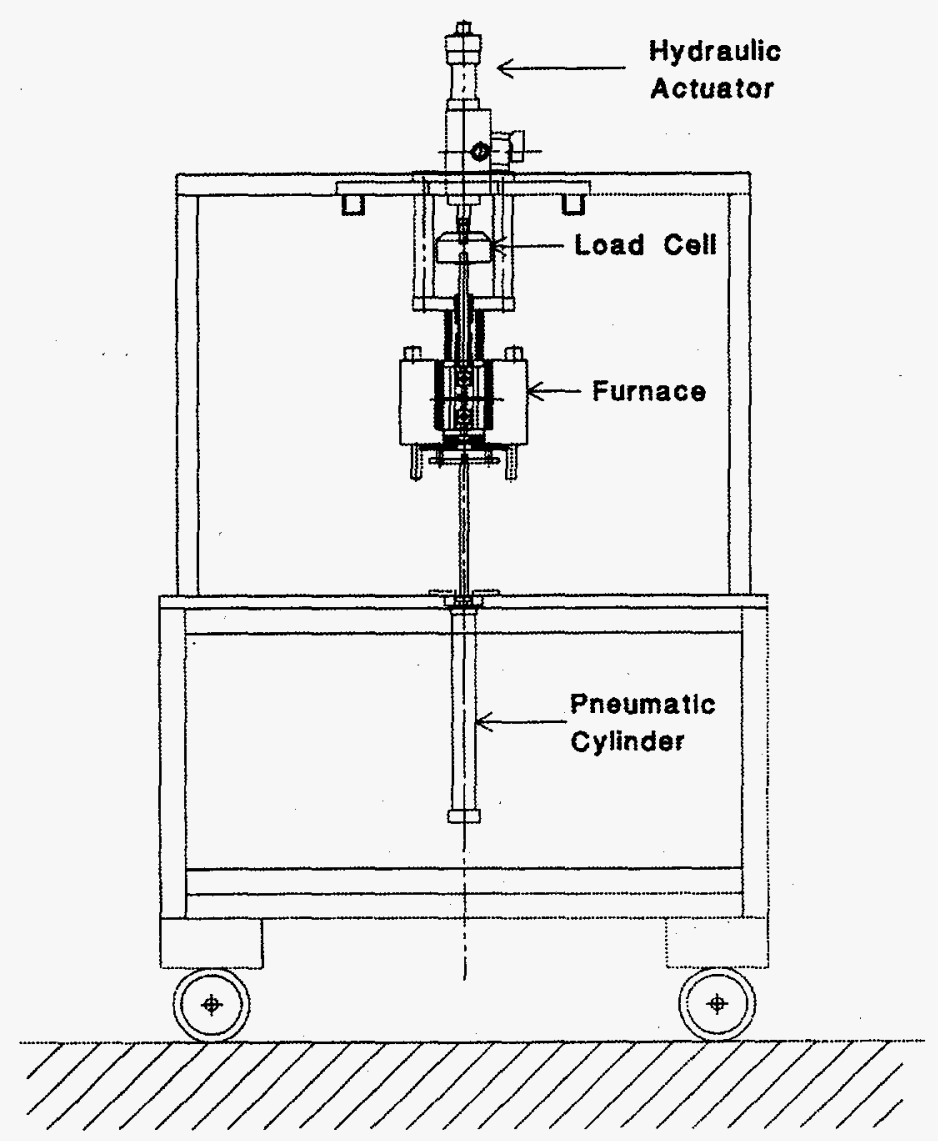

Figure 37. Schematic representation of hot-cell $J-R$ test facility 
A detailed drawing of the specimen load cage is shown in Fig. 40. The load cage that contains the specimen consists of two $12.7-\mathrm{mm}(0.5$-in.)-thick plates separated by four compression rods. The lower two-piece clevis assembly is fastened at the bottom of this rigid cage, with the two sections connected by an oxidized Zircaloy pin that is electrically insulated with mica washers. The same arrangement is used for the upper clevice assembly that is connected to the pull rod. The CT specimen is mounted in the clevises with Inconel pins. Current is passed through the specimen for resistance measurements by means of a ceramic current clip. This spring-loaded clip incorporates platinum contacts that are accurately positioned on the specimen by locating pins inserted in holes in the specimens. Potential leads are secured by short SS pins that are inserted into threaded holes in the specimens. Jigs have been designed and fabricated to facilitate this procedure.

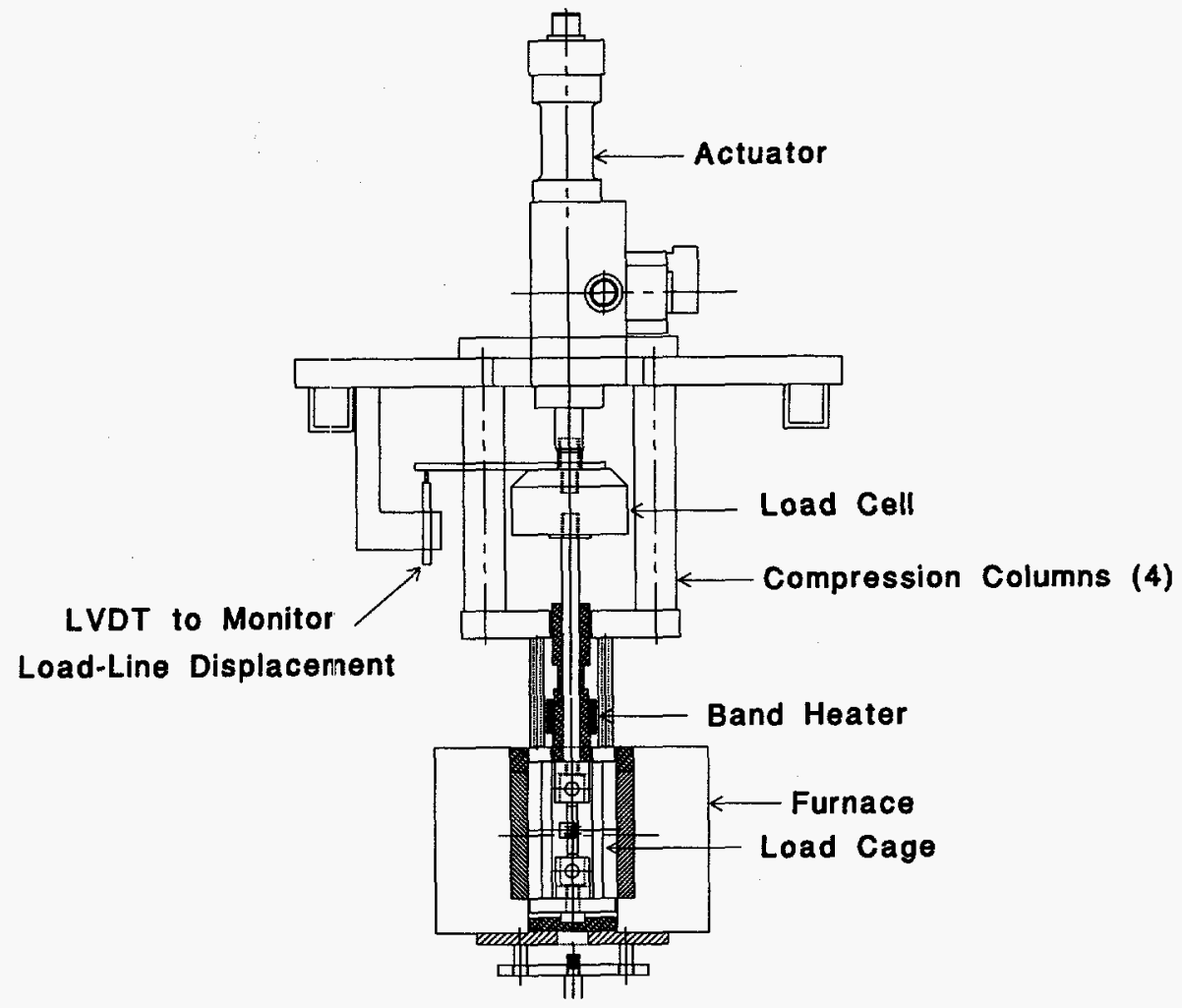

Figure 38. Schematic representation of actuator, load cell, load train, and furnace

\subsubsection{Specimen Dimensions and Configuration}

The configuration of the SS specimens that are being irradiated in the Halden reactor is shown in Fig. 41. The designs for CT)and disk-shaped compact-tension (DCT) specimens that have been used successfully and recommended in ASTM Standards are shown in Fig. 42. Both CT and DCT specimen designs are single-edge-notched fatigue precracked plates loaded in tension. Figure 41 shows that, although the Halden specimens are rectangular, their dimensions are similar to those of the DCT specimen. For example, the span of the load points (center of the pin holes) is $0.275 \mathrm{~W}$, where $\mathrm{W}$ is the specimen width given by the distance from the load line to the back edge of the specimen. However, the specimen height and thickness (side-to-side dimension) are 0.583 and $0.54 \mathrm{~W}$, respectively, instead of the 0.675 and $0.5 \mathrm{~W}$ recommended for the DCT specimen design. 


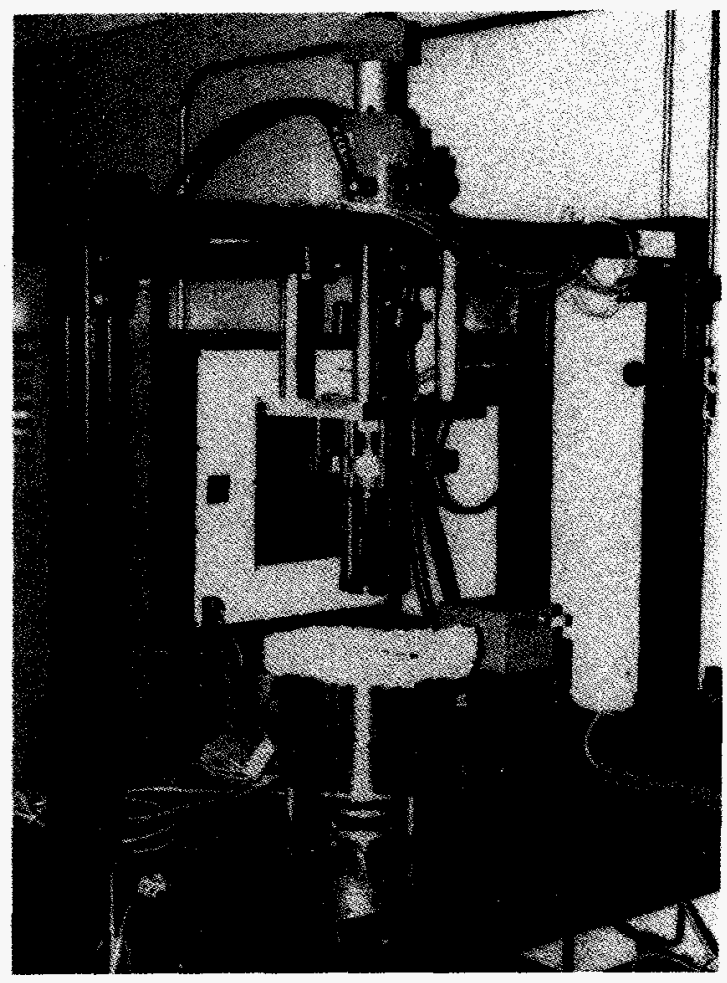

Figure 39. Photograph of actuator, load cell, load train, and furnace

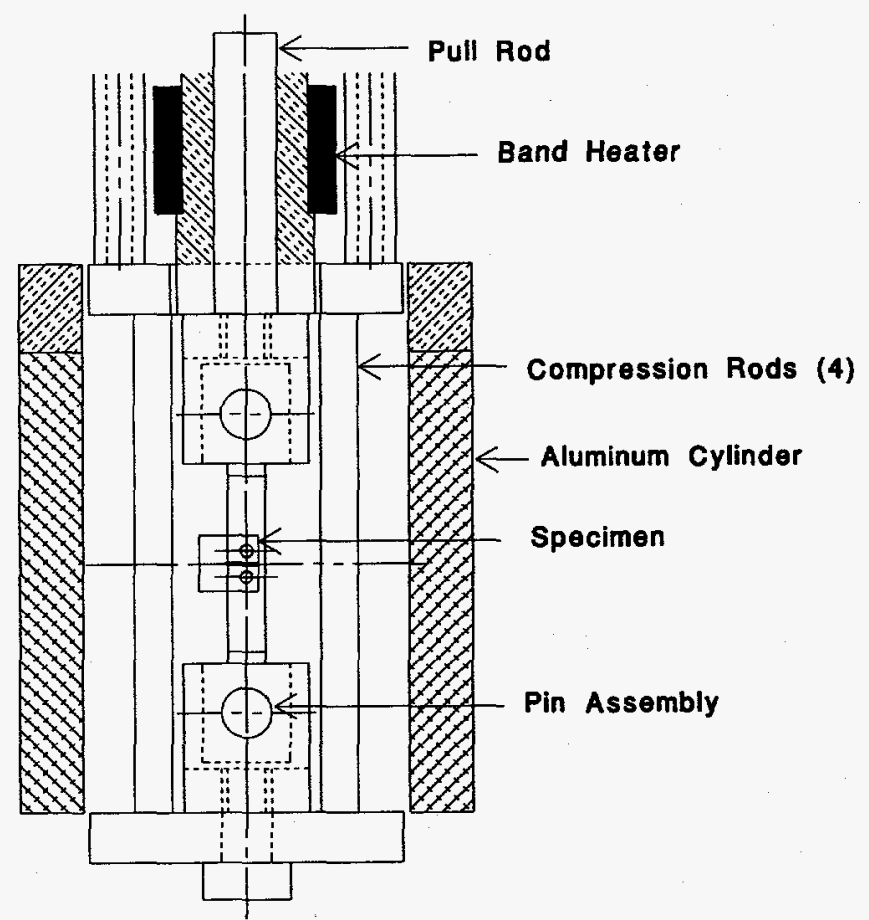

Figure 40. Detailed drawing of specimen load cage

Calculations to determine crack length and J-integral were performed with the correlations recommended for DCT specimens. The applicability of the procedure to a rectangular specimen geometry used in the present study will be evaluated. 


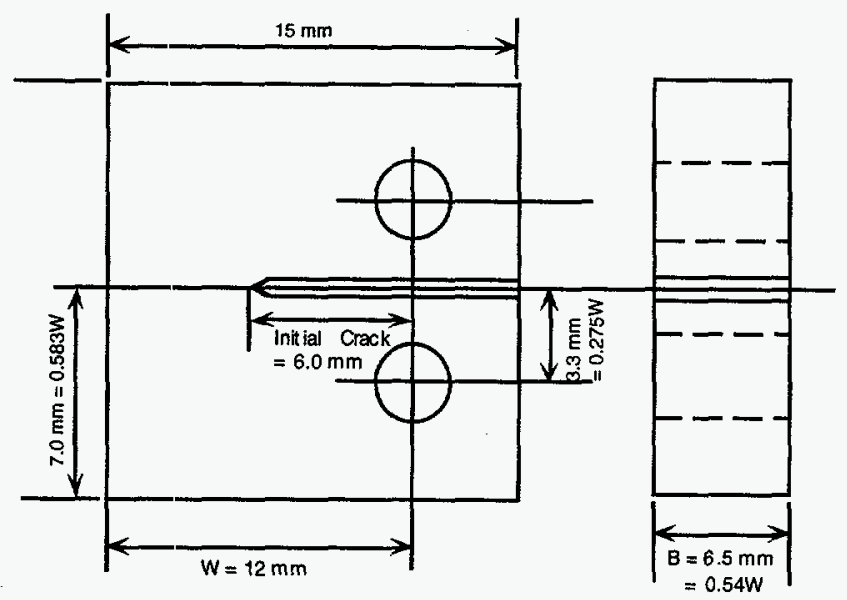

Figure 41. Configuration of compact-tension specimen in this study
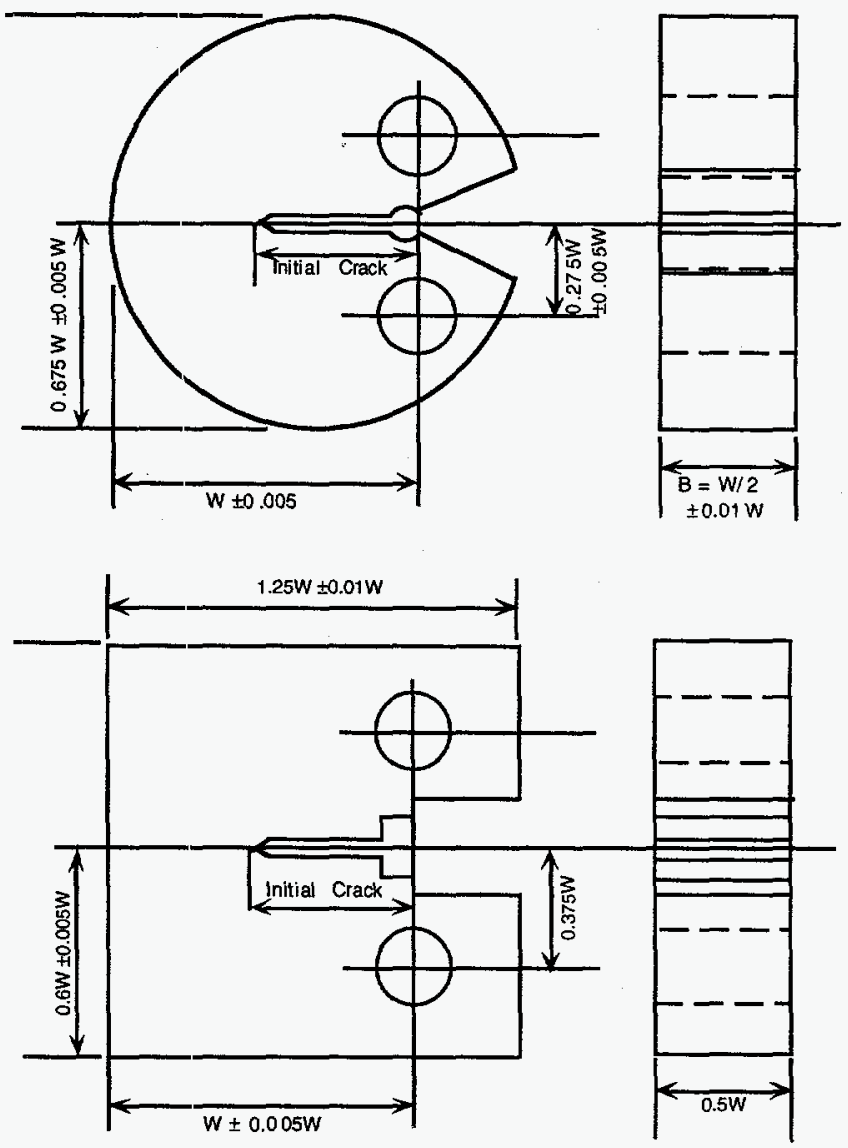

Figure 42. DCT and CT specimen designs from other investigations

\subsubsection{Calculations of Crack Length}

Results of crack length measurements by the potential drop method have been presented previously.56 For a single specimen method that uses the elastic compliance technique on DCT specimens with crack opening displacements measured at the load line, the crack length ai is given by 


$$
\begin{aligned}
a_{i} / W= & 0.998193-3.88087 u_{x}+0.187106 u_{x}^{2}+20.3714 u_{x}^{3} \\
& -45.2125 u_{x}^{4}+44.527 u_{x}^{5}
\end{aligned}
$$

where

$$
\begin{aligned}
& u_{x}=\frac{1}{\left[\left(B_{e f} E_{e f} C_{c i}\right)^{1 / 2}+1\right]}, \\
& B_{e f}=B-\left(B-B_{N}\right)^{2} / B, \\
& E_{e f}=E /\left(1-v^{2}\right),
\end{aligned}
$$

$\mathrm{W}$ is specimen width, $\mathrm{B}$ is specimen thickness, $\mathrm{B}_{\mathrm{N}}$ is net specimen thickness (distance between roots of the side grooves), $E$ is elastic modulus, $v$ is Poisson's ratio, and $C_{c i}$ is the corrected specimen elastic compliance. The measured compliance is corrected for rotation of the crack centerline by applying the expression

$$
C_{c i}=\frac{C_{i}}{\left[\frac{H^{*}}{R} \sin \theta-\cos \theta\right]\left[\frac{D}{R} \sin \theta-\cos \theta\right]},
$$

where

$$
\theta=\sin ^{-1}\left[\frac{\left(\frac{d_{m}}{2}+D\right)}{\left(D^{2}+R^{2}\right)^{1 / 2}}\right]-\tan ^{-1}\left(\frac{D}{R}\right)
$$

$\mathrm{C}_{\mathrm{i}}$ is the measured specimen elastic compliance at the load line, $\mathrm{H}^{*}$ is the initial half-span of the load points (i.e., center of the pin holes), $\mathrm{R}$ is the radius of rotation of the crack centerline (Fig. 43), given by $\left(\mathrm{W}+\mathrm{a}_{\mathrm{i}}\right) / 2 ; \mathrm{D}$ is one-half the initial distance between the displacement measuring points, $d_{m}$ is the total measured load-line displacement; and $\theta$ is the angle of rotation of a rigid body element about the unbroken midsection line.

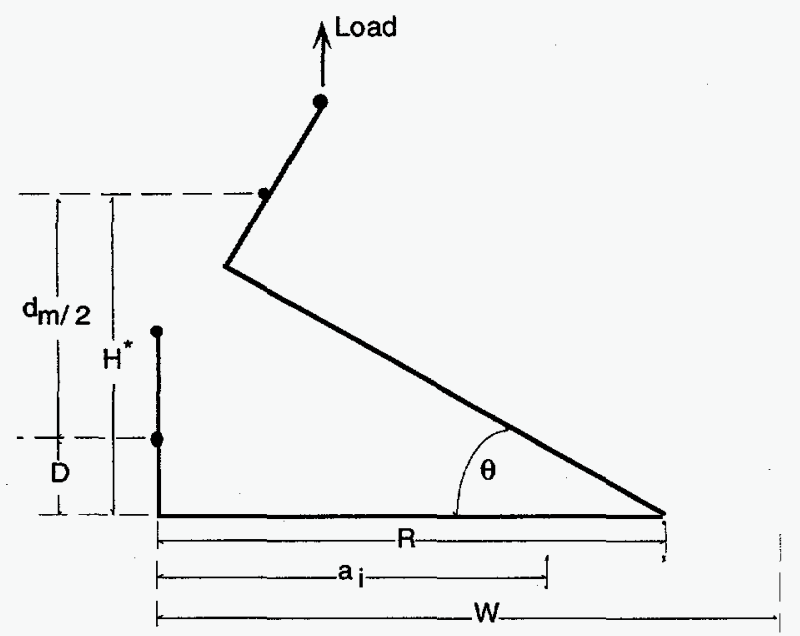

Figure 43.

Elastic compliance correction for specimen rotation 


\subsubsection{Calculations of J-Integral}

The J-integral is calculated from the load and load-line displacement curves. The total value of $J$ is the sum of the elastic and plastic components $J_{e l}$ and $J_{p l}$,

$$
J=J_{e l}+J_{p l}
$$

The total area and plastic component of the area $A_{p l(i)}$ at each recorded deflection are computed during the test by summation of the increase in areas for each increment in deflection; the elastic component of deflection is calculated from specimen load-line elastic compliance at each step and subtracted from the total deflection to obtain plastic deflection. The elastic component of $J$, at a point corresponding to $a_{i}, V_{i}, P_{i}$ on the specimen load-versusload-line displacement record, is given by

$$
J_{e l(i)}=\frac{\left(K_{(i)}\right)^{2}\left(1-v^{2}\right)}{E_{e f}}
$$

where the stress intensity $\mathrm{K}_{(\mathbf{i})}$ is expressed as

$$
\begin{gathered}
K_{(i)}=\left[\frac{P_{i}}{\left(B B_{N} W\right)^{1 / 2}}\right] f\left(\frac{a_{i}}{W}\right), \\
f\left(\frac{a_{i}}{W}\right)=\left[\frac{\left(2+\frac{a_{i}}{W}\right)}{\left(1-\frac{a_{i}}{W}\right)^{3 / 2}}\right]\left\{0.76+4.8\left(\frac{a_{i}}{W}\right)-11.58\left(\frac{a_{i}}{W}\right)^{2}+11.43\left(\frac{a_{i}}{W}\right)^{3}-4.08\left(\frac{a_{i}}{W}\right)^{4}\right\},
\end{gathered}
$$

and $P_{i}$ is the load. The plastic component of $J$ is given by

$$
J_{p l(i)}=\left[J_{p l(i-1)}+\left(\frac{\eta_{(i-1)}}{b_{(i-1)}}\right) \frac{A_{p l(i)}-A_{p l(i-1)}}{B_{N}}\right]\left[1-\gamma_{(i-1)} \frac{a_{(i)}-a_{(i-1)}}{b_{(i-1)}}\right]
$$

where the factors that account for limited crack growth $\gamma_{(i)}$ and for the tensile component of the load $\eta_{(i)}$ are expressed as

$$
\begin{aligned}
& \eta_{(i-1)}=2.0+0.552 \frac{b_{(i-1)}}{W}, \\
& \gamma_{(i-1)}=1.0+0.76 \frac{b_{(i-1)}}{W},
\end{aligned}
$$

and $\mathrm{B}_{(\mathrm{i}-1)}$ is the remaining ligament (distance from the physical crack front to the back edge of the specimen) at a point $\mathrm{i}-1$.

The quantity $A_{p l(i)}-A_{p l(i-1)}$ is the increment of plastic area under the load-versus-loadline displacement record between lines of constant displacement at points $i-1$ and $i$. The 
quantity $\mathrm{J}_{\mathrm{pl}(\mathrm{i})}$ represents the total crack-growth-corrected plastic $\mathrm{J}$ at point $\mathrm{i}$ and is obtained by first incrementing the existing $\mathrm{J}_{\mathrm{pl}(\mathrm{i}-1)}$ and then modifying the total accumulated result to account for the crack growth increment. Accurate evaluations of $J_{p 1(i)}$ require small uniform crack-growth increments. The plastic area under the load-versus-load-line displacement record is given by

$$
A_{p l(i)}=A_{p l(i-1)}+\frac{\left[P_{i}+P_{i-1}\right]\left[V_{p l(i)}-V_{p l(i-1)}\right]}{2}
$$

where the total and plastic component of load-line displacement $V_{(i)}$ and $V_{p l(i)}$ are expressed as

$$
V_{p l(i)}=V_{(i)}-P_{i} C_{c i}
$$

\subsubsection{Fracture Toughness J-R Tests}

Two fracture toughness J-R tests have been completed on solution-annealed Type 304 SS at room temperature and at $288^{\circ} \mathrm{C}$. The specimens were precracked at loads based on the maximum allowable load $\mathrm{P}_{\mathrm{m}}$ given by the relationship

$$
P_{m}=\left(0.4 \sigma_{f} B b^{2}\right) /(2 W+a)
$$

where the flow stress $\sigma_{\mathrm{f}}$ is the mean of the yield and ultimate stress. The final fatigue precrack extension $(\approx 1 \mathrm{~mm})$ was carried out at loads $\leq \mathrm{P}_{\mathrm{m}}$ or at a load such that the ratio of the maximum stress intensity applied during fatigue precracking to the elastic modulus $\left(\mathrm{K}_{\max } / \mathrm{E}\right)$ was $\leq 1.6 \times 10^{-4} \mathrm{~m}^{1 / 2}\left(\leq 0.001 \mathrm{in.}^{1 / 2}\right)$.

The fatigue precracked specimens were loaded at a constant extension rate and the tests were interrupted periodically to determine crack length. For crack length measurements, the specimen was either held at constant extension to measure crack length by the EP technique, or was unloaded up to $0.5 \mathrm{P}_{\mathrm{m}}$ and then reloaded to measure crack length by the elastic compliance method. For most steels, load relaxation occurs during the hold period or during unloading, which causes a time dependent nonlinearity in the unloading curve. Consequently, prior to unloading or EP measurements, the specimen was held for $\approx 1 \mathrm{~min}$ to allow for load relaxation. Furthermore, because specimen extension was monitored and controlled away from the specimen in the present method, the specimen was strained during the hold period because of load relaxation. Figure $44 \mathrm{a}$ shows that, for a load relaxation of $\approx 0.1 \mathrm{kN}(\approx 22 \mathrm{lbs})$, the specimen will extend $\approx 0.01 \mathrm{~mm}$. The load-line displacement was recorded to calculate the $\mathrm{J}$-integral according to the procedure described in the previous section.

The specimen extension was monitored and controlled outside of the high-temperature zone. The displacement of load points (center of the loading pins) was determined by subtracting the machine compliance from the measured extension. The curves for machine compliance, expressed in terms of load-versus-displacement (of the loading points) at room temperature and $288^{\circ} \mathrm{C}$, are shown in Fig. 44a. The displacement consists of elastic and some plastic extension. The latter most likely occurred in and around the pin holes. The plastic component of the machine compliance at $288^{\circ} \mathrm{C}$ is shown in Fig. $44 \mathrm{~b}$. Because of plastic deformation, machine compliance during unloading was different from the loading compliance. 


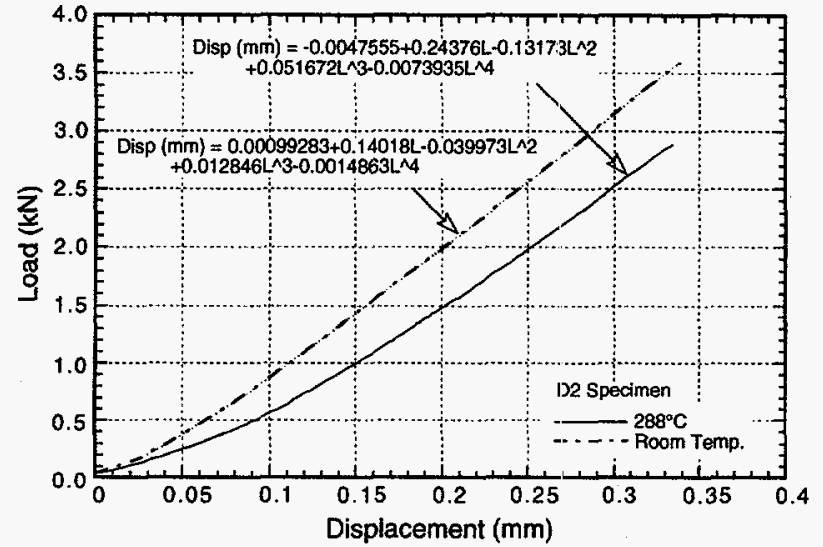

(a)

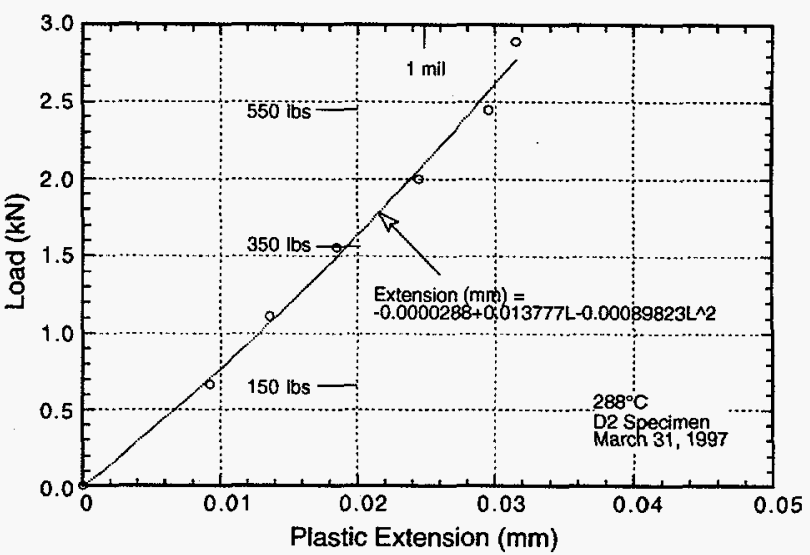

(b)

Figure 44. (a) Machine compliance expressed in terms of load-versus-displacement of loading points at room temperature and $288^{\circ} \mathrm{C}$ and (b) plastic component of machine compliance at $288^{\circ} \mathrm{C}$

The results indicate that, at both room temperature and $288^{\circ} \mathrm{C}$, the unloading compliance curve varies with the maximum applied load. The unloading compliance curves at $288^{\circ} \mathrm{C}$ and maximum loads of 667 and $2891 \mathrm{~N}$ (150 and $650 \mathrm{lbs}$ ) are shown in Fig. 45.

The actual displacement of load points was measured optically and compared with the estimated load-line displacement. The measured and estimated values of load-line displacement for the room-temperature J-R tests (Fig. 46) show very good agreement. For load-line displacements up to $2 \mathrm{~mm}$, the error in the estimated values is $<0.02 \mathrm{~mm}$.

Both DC potential-drop and elastic unloading compliance techniques were used to determine crack length and extension. The measured and estimated crack lengths during precracking of one of the Type 304 SS specimens are shown in Fig. 47. Both methods yield very good estimates of fatigue crack length.

The load-versus-load-line displacement curves and fracture toughness $\mathrm{J}-\mathrm{R}$ curves from the two tests are shown in Figs. 48 and 49, respectively. The specimens were broken after the test and the initial crack length and physical crack extension were determined by the $9 / 8$ averaging technique, i.e., the two near-surface measurements were averaged and the resultant value was averaged with the rernaining seven measurements. For one of the specimens, the final crack size was marked by heat tinting and for the other, it was marked by fatigue cycling. The elastic compliance was corrected by using the measured initial crack size.

At room temperature and $288^{\circ} \mathrm{C}$, the $\mathrm{J}-\mathrm{R}$ curves determined by the elastic compliance method show good agreement with the data obtained from 1T CT specimens; the data points follow the $4 \sigma_{\mathrm{f}}$ blunting line. However, at both temperatures, the estimated final crack length is significantly lower than the optically measured crack length. The difference most likely arises from the effects of crack closure during unloading. For relatively tough materials, such as solution-annealed Type 304 SS, crack extension occurs by ductile tearing. Small misalignment in the specimen loading would cause the fracture surfaces to touch each other during unloading, which results in lower apparent crack lengths. 

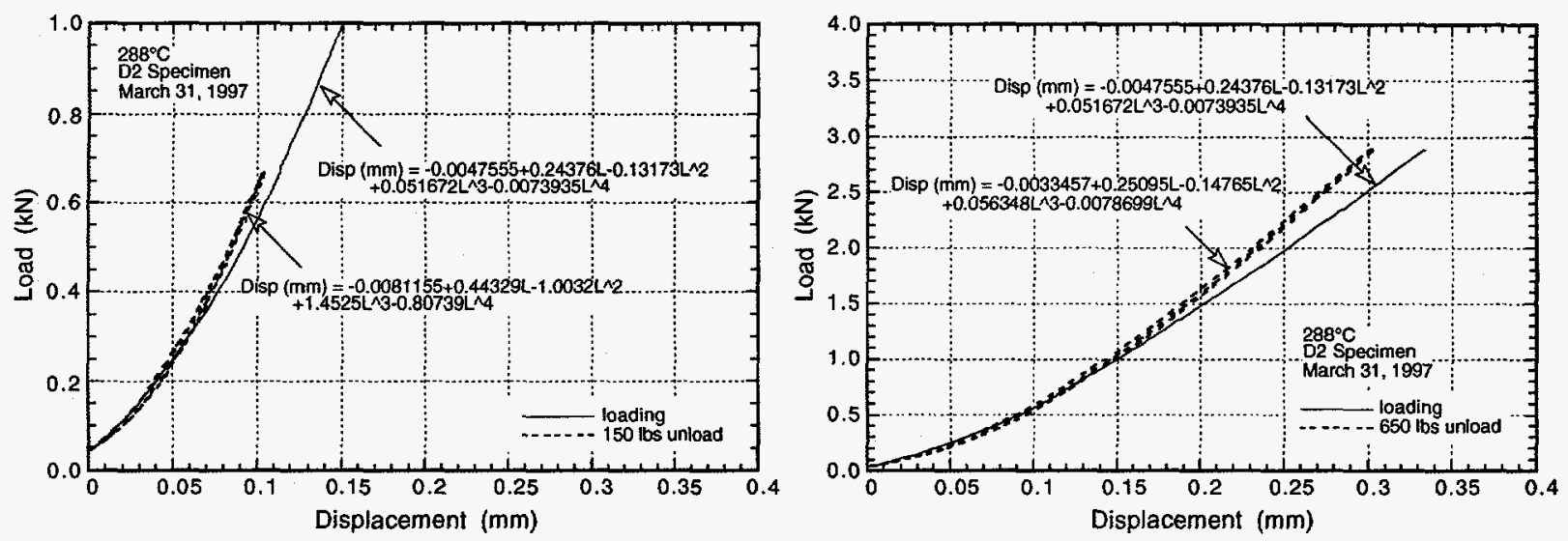

Figure 45. Unloading machine compliance at $288^{\circ} \mathrm{C}$ for maximum loads of 667 and $2981 \mathrm{~N}$
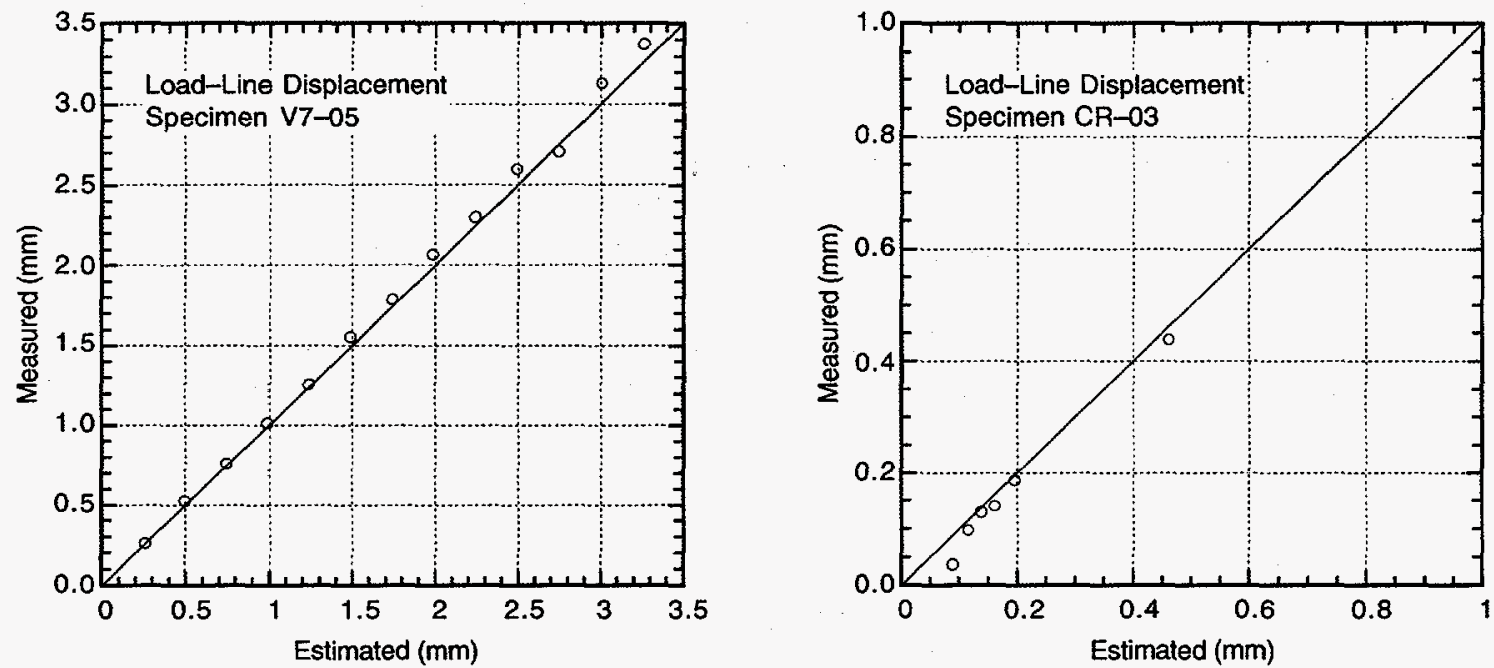

Figure 46. Measured and estimated values of load-line displacement for solution-annealed and 50\% cold-worked Type 304 SS tested at room temperature

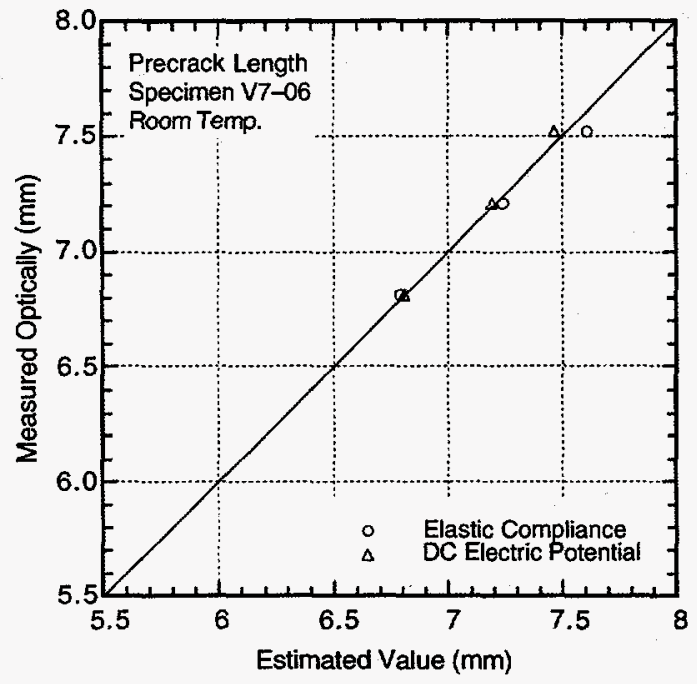

Figure 47.

Measured and estimated values of crack length of solution-annealed Type 304 SS specimen precracked at room temperature 

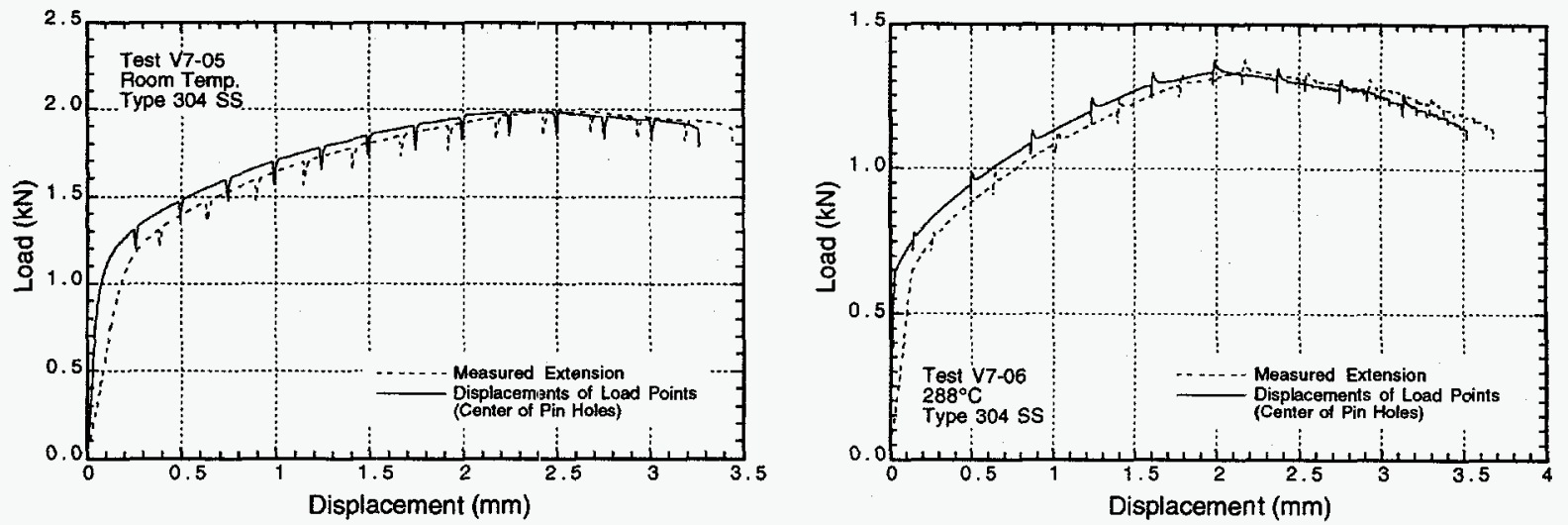

Figure 48. Load-versus-load-line displacement curves for solution-annealed Type 304 SS at room temperature and $288^{\circ} \mathrm{C}$
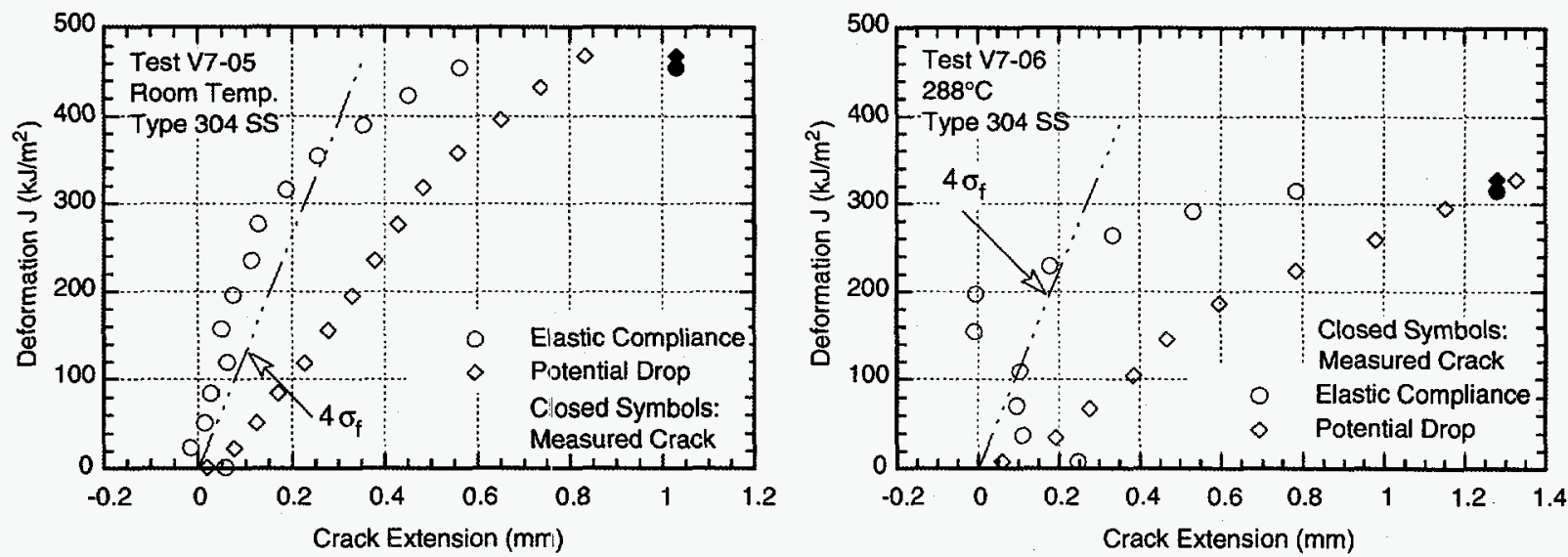

Figure 49. Fracture toughness J-R curves for solution-annealed Type 304 SS at room temperature and $288^{\circ} \mathrm{C}$

Although the final crack lengths estimated by the potential-drop technique agree with the optically measured crack lengths, the $J-R$ curves do not follow the blunting line. The results show significant crack extension during the initial stages of loading that is typically characterized by crack blunting in SSs. Crack extensions estimated by either the elastic compliance or the EP techniques can be adjusted so they agree with the measured physical crack size. The results will be validated by conducting fracture toughness J-R curve tests at room temperature and $288^{\circ} \mathrm{C}$ on two heats of thermally aged $\mathrm{CF}-8 \mathrm{M}$ cast SS and on $50 \%$ coldworked Type $316 \mathrm{NG}$ SS, and performing fatigue crack growth studies on the same three materials at $288^{\circ} \mathrm{C}$ in air.

\section{Environmentally Assisted Cracking of Alloys 600 and 690 in Simulated LWR Water (W. E. Ruther, W. K. Soppet, and T. F. Kassner)}

The objective of this work is to evaluate the resistance of Alloys 600 and 690 to EAC in simulated LWR coolant environments. High-nickel alloys have experienced general corrosion 
(tube wall thinning), localized intergranular attack (IGA), and SCC in LWRs. Secondary-side IGA* and axial and circumferential $\mathrm{SCC}^{* *}$ have occurred in Alloy 600 tubes at tube support plates in many steam generators. Primary-water SCC of Alloy 600 steam generator tubes in PWRs at roll transitions and U-bends and in tube plugs ${ }^{* * *}$ is a widespread problem that has been studied intensively. Cracking has also occurred in Alloy 600 and other high-nickel alloys (e.g., Inconel-82 and -182 and Alloy X750) that are used in applications such as instrument nozzles and heater thermal sleeves in the pressurizer ${ }^{\dagger}$ and the penetrations for control-rod drive mechanisms in reactor vessel closure heads in the primary system of PWRs; ${ }^{\dagger \dagger}$ in dissimilar-metal welds between SS piping and low-alloy steel nozzles, in jet pump hold-down beams, ${ }^{\dagger \dagger}$ and in shroud-support-access-hole covers $\$$ in BWRs. Alloy 600, in general, undergoes differing thermomechanical processing for applications other than those used for steam generator tubes. Because environmental degradation of the alloys in many cases is very sensitive to processing, further evaluation of even SCC is needed. In addition, experience strongly suggests that materials that are susceptible to SCC are also susceptible to environmental degradation of fatigue life and fatigue-crack growth properties. In this investigation, we have obtained information on the effect of temperature, load ratio $\mathrm{R}$, and stress intensity (K) on EAC of Alloys 600 and 690 in simulated BWR and PWR water.

\subsection{Experimental Methods for Measuring CGR in Alloy 600}

The experimental procedures relevant to our mechanical loading systems are similar to those in ASTM E647. The tests are performed under controlled loading conditions with closed-loop servo-controlled machines (MTS ${ }^{\mathrm{TM}}$ systems). The contribution to the load that arises from the pressure difference between the inside and the outside of the autoclave is taken into consideration. Additional mechanical contributions that arise from friction between the pull rod in the load train and the autoclave pressure seal are typically $<0.4 \%$ of the mechanical loading force under autoclave operating pressure and temperature.

The tests in air are performed in a system that is also used for tests in simulated reactor coolant environments. Air is circulated at a slow rate through the autoclave at atmospheric pressure to help maintain a uniform temperature within the autoclave. For tests in air, there is no mechanical contribution from pressure differences between the inside and the outside of

* USNRC Information Notice No. 91-67, "Problems with the Reliable Detection of Intergranular Attack (IGA) of Steam Generator Tubing," Oct. 1991.

** USNRC Information Notice No. 90-49, "Stress Corrosion Cracking in PWR Steam Generator Tubes," Aug. 1990; Notice No. 91-43, "Recent Incidents Involving Rapid Increases in Primary-to-Secondary Leak Rate," July 1991; Notice No. 92-80, "Operation with Steam Generator Tubes Seriously Degraded," Dec. 1992; Notice No. 94-05, "Potential Failure of Steam Generator Tubes with Kinetically Welded Sleeves," Jan. 1994.

*** USNRC Information Notice No. 89-33, "Potential Failure of Westinghouse Steam Generator Tube Mechanical Plugs," March 1989; Notice No. 89-65, "Potential for Stress Corrosion Cracking in Steam Generator Tube Plugs Supplied by Babcock and Wilcox," Sept. 1989; Notice No. 94-87, "Unanticipated Crack in a Particular Heat of Alloy 600 Used for Westinghouse Mechanical Plugs for Steam Generator Tubes," Dec. 1994.

$\dagger$ USNRC Information Notice No. 90-10, "Primary Water Stress Corrosion Cracking (PWSCC) of Inconel 600," Feb. 1990.

t+ USNRC Generic Letter 97-01: "Degradation of Control Rod Drive Mechanism and Other Vessel Closure Head Penetrations," Apr. 1, 1997; USNRC Information Notice No. 96-11, "Ingress of Demineralizer Resins Increases Potential for Stress Corrosion Cracking of Control Rod Drive Mechanism Penetrations," Feb. 1996; INPO Document SER 20-93 "Intergranular Stress Corrosion Cracking of Control Rod Drive Mechanism Penetrations," Sept. 1993.

$+\dagger \dagger$ USNRC Information Notice No. 93-101, "Jet Pump Hold-Down Beam Failure," Dec. 1993.

$\S$ USNRC Information Notice No. 92-57. "Radial Cracking of Shroud Support Access Hole Cover Welds," Aug. 1992. 
the autoclave or from friction in the load train, because there is no seal between the pull rod and the autoclave.

A DC potential-drop measurement system is used for both the tests in air and those in an HP water environment. The specimens in the load train are electrically insulated from the autoclave and each other by using oxidized Zircaloy 705 pins (oxidized by heating at $550^{\circ} \mathrm{C}$ for 4-8 h) to attach the specimens to the load train. The resistance across the crack is measured by the potential drop for each specimen as a computer automatically controls a programmable DC power supply to direct the electrical current first in one direction and then in the reverse direction. The DC and drops in potential are measured by high-accuracy, stable, scanning multimeters that are controlled by the computer over an IEEE-488 interface. Hundreds of measurements are averaged for one reading, which is transformed to a crack length by a software algorithm that is integral to the control computer. Corrosion-fatigue specimens are held at operating conditions without mechanical loading until the resistance of the specimens stabilizes, typically one week, before the initial fatigue loading at $R=0.4$ is applied. Resolution of the crack length varies somewhat from one specimen to another and depends on the alloy composition and uniform crack length; a typical value is $\pm 0.05 \mathrm{~mm}(0.002 \mathrm{in}$.) for Alloy 600 or 690 .

When tests are conducted in a simulated PWR environment (boric acid, lithium hydroxide and a hydrogen overpressure), the DC potential-drop system, which indicates negative CGRs, fails shortly after the cracks begin to grow. Our best explanation at present is that hydrogen enters the metal matrix and changes the intrinsic resistance of the specimen. For CGR tests in simulated PWR water, a compliance technique that was used previously, was upgraded to perform measurements without interrupting the corrosion-fatigue test.

The compliance measurement system is composed of MTS ${ }^{\text {TM }}$ Model 632.10 hermetically sealed crack-opening-displacement (COD) gages that are interfaced to a computer data acquisition system along with a conditioned load cell signal. The COD gages are calibrated to an accuracy of $\pm 1 \%$ at the desired test temperature prior to each test with a micrometer fixture traceable to a National Institute Standard. The resulting typical COD gage output transfer function is $0.075 \mathrm{~mm} / \mathrm{V}$. Experience with compliance measurements with MTS ${ }^{\mathrm{TM}}$ clip gages indicates that the resolution is $\pm 0.025 \mathrm{~mm}(0.001 \mathrm{in}$.). The computer data acquisition system accepts the multiplexed load and COD voltage signals with a resolution of $\pm 0.05 \%$ of the applied voltage range. Compliance data from the load cell and COD gages are acquired during the unloading phase of the ramp waveform. Initially, the load-versus-COD data are graphically analyzed to select the region of the waveform with the steepest linear slope to optimize the data acquisition period. The compliance value for a test cycle is computed by a least-squares linear-regression analysis of 250 data samples. The computer software monitors the fit of the linear regression curve for a minimum correlation coefficient of 0.999 . During a corrosion-fatigue test, ten successive load-line compliance values are recorded at 1 - $\mathrm{h}$ time intervals, averaged, and applied to a subroutine that calculates crack length by means of a polynomial elastic compliance expression derived for CT and wedge-opening-load specimens. ${ }^{\mathbf{5 7}}$ However, for conditions of accelerated crack growth, the measurement time interval can be reduced to $10 \mathrm{~min}$.

Both the initial crack length. and the crack length and shape at the end of the test are determined from the fracture surface for comparison with measurements inferred from COD or DC potential-drop measurements. The specimen is cut into two pieces along the midplane of 
the thickness and the crack in one piece is extended by fracturing at a cryogenic temperature. One of these segments is used to examine the fracture surface by SEM. Excess metal in the noncracked region the other piece is removed with a cutoff wheel and a transverse section is prepared and polished for metallographic evaluation of the region that contains the corrosionfatigue crack to confirm the nature of the crack path and determine whether crack branching had occurred.

Water for the CGR test systems is obtained from a reverse osmosis purification system and is passed through a demineralizer with mixed-bed ion-exchange resins; the conductivity

is $<0.1 \mu \mathrm{S} \cdot \mathrm{cm}^{-1}$. To avoid contamination by nonionic organic contaminants, the water flows though a final water purification system (e.g., a Millipore Super-Q Ultrapure Water System ${ }^{\mathrm{TM}}$ coupled with an Ultra Dynamics UV Purifier ${ }^{\mathrm{TM}}$ ) that contains a bed of activated charcoal, an Organex bed, a resin bed, and a $0.2-\mu \mathrm{m}$ filter. The purified water is stored in 135-liter SS feedwater tanks that are refilled weekly. The feedwater tanks are connected to the autoclave systems with SS tubing. Whenever the conductivity of the stored feedwater solution increases to $\geq 0.1 \mu \mathrm{S} \cdot \mathrm{cm}^{-1}$ during the storage period, the tanks are spray sterilized/passivated with a $10 \%$ hydrogen peroxide solution and thoroughly rinsed with deionized water prior to refilling. The DO level is adjusted by vacuum sparging of the filled tanks; nitrogen or hydrogen is used for low-DO tests and oxygen-nitrogen gas mixtures are used to establish predetermined DO levels. Final adjustment of the effluent DO in the latter tests is achieved by slightly varying the storage tank pressure and/or the flow rate of water in the autoclave. The DO concentration in the effluent stream from the autoclaves is monitored by Chemetrics ${ }^{\mathrm{TM}}$ ampoules and/or by an Orbisphere ${ }^{\mathrm{TM}} \mathrm{DO}$ monitor. The electrochemical potential of platinum and SS electrodes is measured versus a room-temperature $0.1 \mathrm{~N} \mathrm{KCl} / \mathrm{Ag} / \mathrm{AgCl}$ reference electrode located in the high-temperature effluent stream $\left(289^{\circ} \mathrm{C}\right)$ from the autoclave. The platinum potential, in particular, responds rapidly to changes in DO concentrations in simulated LWR coolant water.

\subsection{Tensile Properties of Solution-Annealed and Thermally Treated Alloy 600}

The composition, microstructure, and tensile properties of heats of Alloys 600 and 690 that have been used in the fatigue-crack-growth investigation were reported previously. 58,59 A heat of Alloy 600 (NX9244G) with a low-carbon content (0.03 wt.\%) was obtained for CGR measurements in simulated LWR environments. The alloy was produced by INCO Alloys International, Huntington, WV, for the Kobe Material Testing Laboratory Co. Ltd., Hyogo, Japan. The plates were heat treated at the Kobe Material Testing Laboratory and cut into small blocks ( $\approx 32 \times 65 \times 140 \mathrm{~mm}$ ) for distribution to various laboratories that are participating in the International Crack Growth-EAC investigation of Alloy 600 in simulated BWR and PWR environments. The composition of the material is given in Table 15. Compact-tension specimens were fabricated in which the orientation of the crack plane in the specimens corresponds to the identification code T-L for plates in ASTM Specification E399. In our previous CGR experiments on other heats of Alloys 600 and 690 , the CT specimens were in the L-T orientation.

Tensile specimens were also obtained from the blocks and from several of the CT specimens after the CGR tests were completed. The tensile properties of the material at 25, 290 , and $320^{\circ} \mathrm{C}$ in four heat-treatment conditions, hardness at room temperature, and grain size are given in Table 16. Two blocks of material were solution annealed at 1025 and $1115^{\circ} \mathrm{C}$ for $2 \mathrm{~h}$ and two blocks that had been subjected to these solution heat treatments were 
thermally treated at $600^{\circ} \mathrm{C}$ for $24 \mathrm{~h}$. Solution heat treatments at 1025 and $1115^{\circ} \mathrm{C}$ produced ASTM grain sizes of $\approx 1.0-1.5$ and $0.2-0.4$, respectively, which correspond to average grain diameters of $\approx 250-210$ and $340-310 \mu \mathrm{m}$ (Fig. 50). The ultimate tensile strengths at $290^{\circ} \mathrm{C}$ for materials that were solution annealed at 1025 and $1115^{\circ} \mathrm{C}$ are $\approx 550$ and $513 \mathrm{MPa}$, respectively. The yield strength was $156 \mathrm{MPa}$ for three heat-treatment conditions and was slightly higher (173 MPa) for material that was solution annealed at $1025^{\circ} \mathrm{C}$ and thermally treated. Because of the low carbon content and relatively high solution annealing temperatures, intergranular carbides were not observed in the specimens by optical microscopy and SEM.

Figure 51 shows the dependence of yield stress on grain size for Heat NX9244G $\Leftrightarrow 0.03$ wt.\% carbon) in the solution-annealed and solution-annealed and thermally treated conditions and Heat NX8844 (0.08 wt.\% carbon) in the solution-annealed condition. The latter heat was used in corrosion-fatigue experiments that were reported previously. 60 Heat treatment at $600^{\circ} \mathrm{C}$ for $24 \mathrm{~h}$ has virtually no effect on the tensile properties when compared with material that was solution-annealed at the two temperatures. The data follow a Petch relationship, i.e., $\sigma_{\mathrm{y}}=\sigma_{\mathrm{i}}+\mathrm{k} \cdot \mathrm{d}^{-1 / 2}$, where $\sigma_{\mathrm{y}}$ is the yield stress; $\mathrm{d}$ is the grain diameter; $\mathrm{k}$, an empirical constant; and $\sigma_{i}$, the "friction" stress, which is a measure of intrinsic resistance of the material for dislocation motion. The dependence in Fig. 51 may be somewhat fortuitous because the decrease in tensile stress for the material with the large grain size (Heat NX9244G), in part, may be caused by the low carbon content of the material.
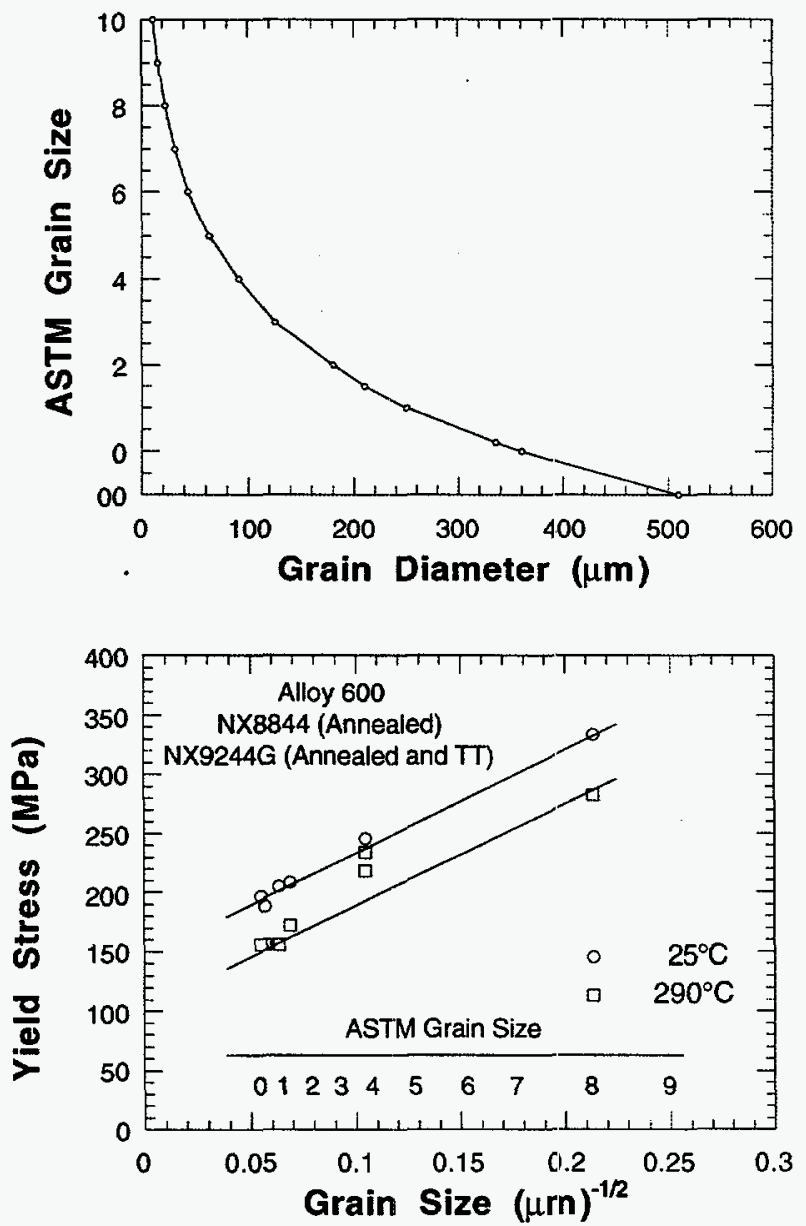

Figure 50.

Relationship between ASTM grain size number and average grain diameter
Figure 51.

Dependence of $0.2 \%$ yield stress at 25 and $290^{\circ} \mathrm{C}$ on grain size of solutionannealed and thermally treated Alloy 600 specimens 


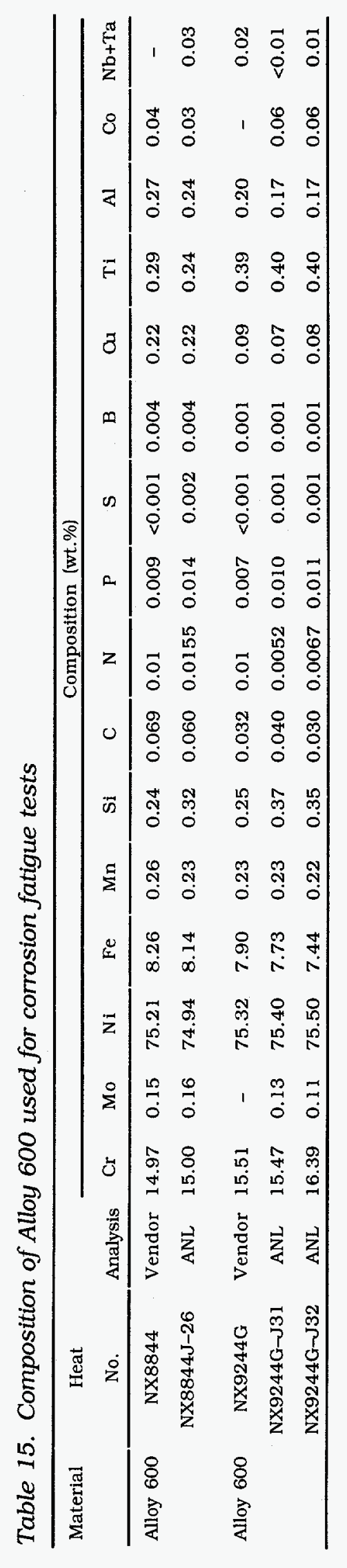


Table 16. Tensile properties of Alloy 600 under various heat-treatment conditions

\begin{tabular}{|c|c|c|c|c|c|c|c|c|c|c|c|c|}
\hline $\begin{array}{l}\text { Alloy } 600 \\
\text { Heat No. }\end{array}$ & Material Condition & $\begin{array}{l}\text { Test } \\
\text { No. }\end{array}$ & $\begin{array}{l}\text { Spec. } \\
\text { No. }\end{array}$ & & $\begin{array}{l}\text { Temp. } \\
\left({ }^{\circ} \mathrm{C}\right)\end{array}$ & $\begin{array}{c}\sigma_{u} \\
(\mathrm{MPa})\end{array}$ & $\begin{array}{c}\sigma_{y} \\
(\mathrm{MPa})\end{array}$ & $\begin{array}{c}\varepsilon_{\tau} \\
(\%)\end{array}$ & $\begin{array}{l}\mathrm{RA} \\
(\%)\end{array}$ & $\begin{array}{l}\text { Hardness }^{a} \\
\text { (VN) }\end{array}$ & $\begin{array}{l}\text { Hardness } \\
\qquad\left(\mathrm{R}_{\mathrm{b}}\right)\end{array}$ & $\begin{array}{c}\text { ASTM } \\
\text { Grain Size }\end{array}$ \\
\hline NX8844B-33 & Annealed $872^{\circ} \mathrm{C} / 1 \mathrm{~h}$ & $-b$ & $-b$ & & 25 & 748.8 & 339.9 & 35.5 & - & - & 90 & 7.5 \\
\hline NX8844B-33 & Annealed $872^{\circ} \mathrm{C} / 1 \mathrm{~h}$ & $\mathrm{~T} 19$ & B33-05 & & 25 & 714.9 & 333.2 & 39.6 & 66.9 & 190 & 91 & 8 \\
\hline NX8844B-33 & Annealed $872^{\circ} \mathrm{C} / \mathrm{I} \mathrm{h}$ & $\mathrm{T} 8$ & B33-03 & & 290 & 686.1 & 282.6 & 38.6 & 61.1 & - & - & - \\
\hline NX8844B-33 & Annealed $872^{\circ} \mathrm{C} / 1 \mathrm{~h}$ & $\mathrm{~T} 10$ & B33-04 & & 320 & 680.6 & 282.6 & 39.1 & 55.5 & - & - & - \\
\hline NX8844J J-26 & Annealed $1038^{\circ} \mathrm{C} / 1 \mathrm{~h}$ & $-\mathrm{b}$ & $-\mathrm{b}$ & & 25 & 694.3 & 298.6 & 41.0 & - & - & 86 & 4 \\
\hline $\mathrm{NX} 8844 \mathrm{~J}-26$ & Annealed $1038^{\circ} \mathrm{C} / 1 \mathrm{~h}$ & $\mathrm{~T} 21$ & $\mathrm{~J} 26-05$ & & 25 & 653.5 & 245.5 & 49.2 & 61.1 & 173 & 87 & 4 \\
\hline NX8844J-26 & Annealed $1038^{\circ} \mathrm{C} / 1 \mathrm{~h}$ & T23 & J26-06 & & 290 & 637.8 & 234.0 & 45.2 & 53.3 & - & - & - \\
\hline $\mathrm{NX8844J-26}$ & Annealed $1038^{\circ} \mathrm{C} / 1 \mathrm{~h}$ & $\mathrm{~T} 44$ & J26-08 & & 290 & 626.5 & 218.0 & 48.7 & 57.2 & - & - & - \\
\hline$N X 8844 J-26$ & Annealed $1038^{\circ} \mathrm{C} / 1 \mathrm{~h}$ & $\mathrm{~T} 25$ & J26-07 & & 320 & 639.4 & 246.8 & 45.8 & 48.9 & - & - & - \\
\hline $\mathrm{NX9244G}$ & Mill Annealed & $-\mathrm{b}$ & $-b$ & & 25 & 657.0 & 300.0 & 43.9 & 60.6 & - & 83 & - \\
\hline NX9244G-J320 & Annealed $1025^{\circ} \mathrm{C} / 2 \mathrm{~h}$ & T43J: & $320-04$ & $\mathrm{c}$ & 25 & 580.6 & 205.1 & 62.7 & 82.0 & 145 & 78 & 1.0 \\
\hline NX9244G-J320 & Annealed $1025^{\circ} \mathrm{C} / 2 \mathrm{~h}$ & T38d: & $320-02$ & c & 290 & 547.9 & 155.7 & 68.4 & 72.2 & - & - & - \\
\hline NX9244G-J320 & Annealed $1025^{\circ} \mathrm{C} / 2 \mathrm{~h}$ & T39J: & $320-03$ & $\mathrm{c}$ & 320 & 551.9 & 154.5 & 69.9 & 70.1 & - & - & - \\
\hline NX9244G-J32 1 & $\begin{array}{l}\text { Annealed } 1025^{\circ} \mathrm{C} / 2 \mathrm{~h} \\
+600^{\circ} \mathrm{C} / 24 \mathrm{~h}\end{array}$ & T32. & $321-03$ & c & 25 & 582.0 & 208.4 & 59.5 & 66.1 & 148 & 79 & 1.5 \\
\hline NX9244G-J321 & $\begin{array}{l}\text { Annealed } 1025^{\circ} \mathrm{C} / 2 \mathrm{~h} \\
+600^{\circ} \mathrm{C} / 24 \mathrm{~h}\end{array}$ & T35s & $321-05$ & c & 290 & 552.1 & 172.5 & 65.2 & 59.8 & - & - & - \\
\hline NX9244G-J321 & $\begin{array}{l}\text { Annealed } 1025^{\circ} \mathrm{C} / 2 \mathrm{~h} \\
+600^{\circ} \mathrm{C} / 24 \mathrm{~h}\end{array}$ & T34. & $321-04$ & c & 320 & 551.6 & 166.9 & 67.0 & 64.4 & - & - & - \\
\hline NX9244G-J310 & Annealed $1115^{\circ} \mathrm{C} / 2 \mathrm{~h}$ & T40J: & $310-01$ & c & 25 & 551.7 & 188.7 & 58.7 & 77.5 & 144 & 78 & 0.4 \\
\hline NX9244G-J310 & Annealed $1115^{\circ} \mathrm{C} / 2 \mathrm{~h}$ & T41JS & $310-02$ & c & 290 & 508.9 & 155.7 & 65.5 & 68.8 & - & - & - \\
\hline$N X 9244 G-J 310$ & Annealed $1115^{\circ} \mathrm{C} / 2 \mathrm{~h}$ & T42J & $310-03$ & c & 320 & 507.5 & 146.1 & 67.7 & 69.5 & - & - & - \\
\hline NX9244G-J31 1 & $\begin{array}{l}\text { Annealed } 1115^{\circ} \mathrm{C} / 2 \mathrm{~h} \\
+600^{\circ} \mathrm{C} / 24 \mathrm{~h}\end{array}$ & T30J: & $311-03$ & d & 25 & 545.7 & 194.5 & 57.2 & 61.5 & - & - & - \\
\hline NX9244G-J311 & $\begin{array}{l}\text { Annealed } 1115^{\circ} \mathrm{C} / 2 \mathrm{~h} \\
+600^{\circ} \mathrm{C} / 24 \mathrm{~h}\end{array}$ & T31JS & $311-04$ & c & 25 & 553.1 & 196.4 & 56.8 & 63.0 & 142 & 77 & 0.2 \\
\hline NX9244G-J311 & $\begin{array}{l}\text { Annealed } 1115^{\circ} \mathrm{C} / 2 \mathrm{~h} \\
+600^{\circ} \mathrm{C} / 24 \mathrm{~h}\end{array}$ & T33d & $311-05$ & c & 290 & 517.0 & 155.7 & 66.7 & 65.9 & - & - & - \\
\hline NX9244G-J311 & $\begin{array}{l}\text { Annealed } 1115^{\circ} \mathrm{C} / 2 \mathrm{~h} \\
+600^{\circ} \mathrm{C} / 24 \mathrm{~h}\end{array}$ & T36. 3 & $311-06$ & c & 320 & 514.9 & 155.7 & 65.3 & 60.6 & - & - & - \\
\hline
\end{tabular}

aVickers hardness at room temperature, 500 gf, $15 \mathrm{~s}$.

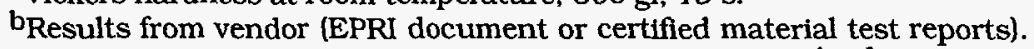

cTensile tests conducted in air at a strain rate of $1.0 \times 10^{-4} \mathrm{~s}^{-1}$.

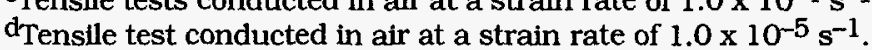




\subsection{Crack Growth Rates of Low-Carbon Alloy 600 in $\mathrm{HP}$ Oxygenated Water at $289^{\circ} \mathrm{C}$}

Corrosion-fatigue experiments were conducted on Alloy 600 specimens in HP oxygenated $(\approx 300 \mathrm{ppb} \mathrm{DO})$ water at $289^{\circ} \mathrm{C}$ to determine the effects of heat treatment conditions, load ratio, and stress intensity on CGRs. Two specimens from a heat of low-carbon Alloy 600 (NX9244G), both solution-annealed at $1025^{\circ} \mathrm{C}$ for $2 \mathrm{~h}$ and one thermally treated at $600^{\circ} \mathrm{C}$ for $24 \mathrm{~h}$, were tested in one autoclave system; another autoclave contained two specimens from this heat, both of which were solution annealed at $1115^{\circ} \mathrm{C}$ for $2 \mathrm{~h}$ and one that was also thermally treated at $600^{\circ} \mathrm{C}$ for $24 \mathrm{~h}$. The experimental conditions and results from $14 \mathrm{CGR}$ tests on each set of specimens are given in Tables 17 and 18. Crack growth was determined by the DC potential-drop method. The experiments were conducted at load ratios $R$ between 0.2 and 0.95 and maximum stress intensity values $K_{\max }$ between $\approx 30$ and $39 \mathrm{MPa} \cdot \mathrm{m}^{1 / 2}$. The frequency and rise time $T_{\mathrm{r}}$ of the positive sawtooth waveform were $8 \times 10^{-2} \mathrm{~Hz}$ and $12 \mathrm{~s}$, respectively. This range of $R$ and $K_{\max }$ values produced $\Delta K=K_{\max }(1-R)$ values of $\approx 1.6-31 \mathrm{MPa} \cdot \mathrm{m}^{1 / 2}$ and CGRs between $\approx 1 \times 10^{-11}$ and $2 \times 10^{-8} \mathrm{~m} \cdot \mathrm{s}^{-1}$. The dependence of the CGRs on $\Delta K$ from the results in Tables 17 and 18 is shown in Figs. 52 and 53, respectively. The dependence on $\Delta \mathrm{K}$ of the CGR for each specimen is given by a power-law relationship; the coefficient-of-fit indicated on the figures is quite good.
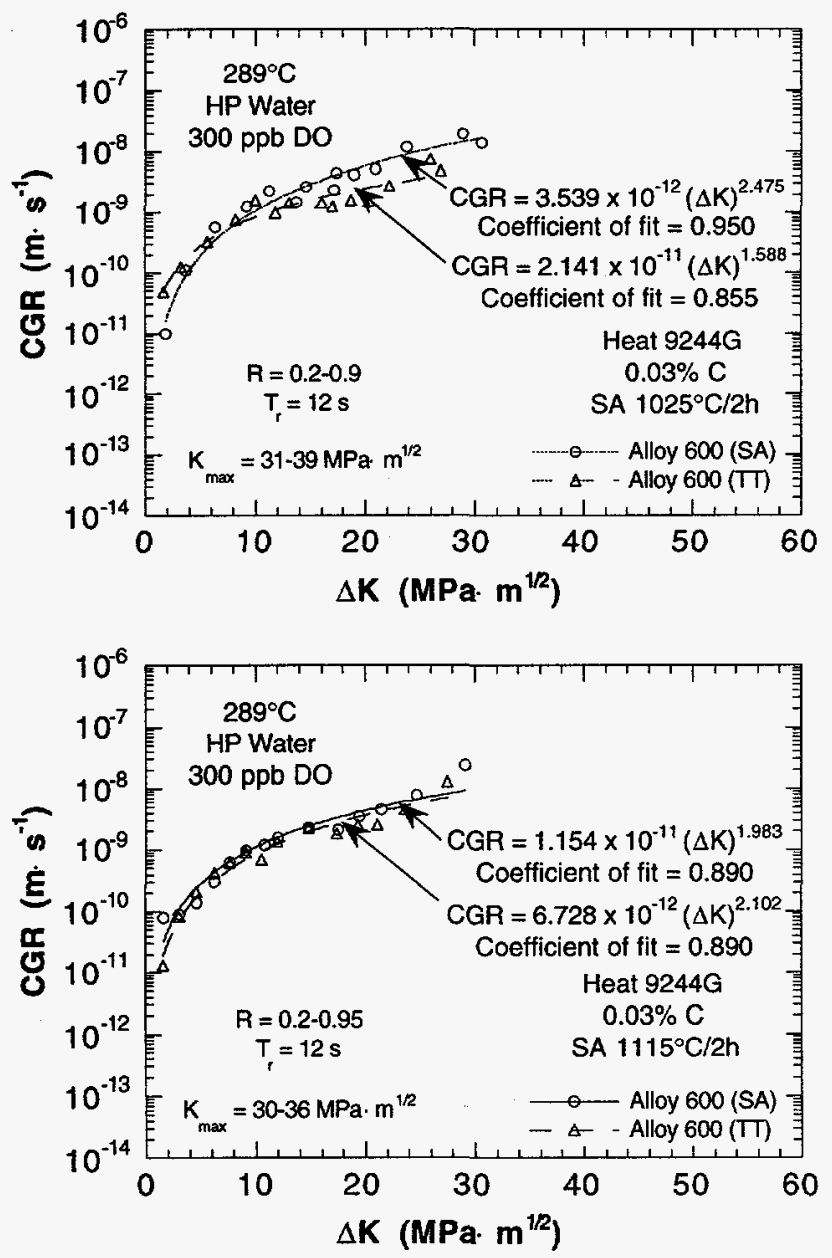

Figure 52.

Dependence of CGRs in oxygenated HP water at $289^{\circ} \mathrm{C}$ on $\Delta \mathrm{K}$ of Alloy 600 specimens solution-annealed at $1025^{\circ} \mathrm{C}$ and solution-annealed at this temperature and thermally treated at $600^{\circ} \mathrm{C}$ for $24 \mathrm{~h}$

Figure 53.

Dependence of CGRs in oxygenated HP water at $289^{\circ} \mathrm{C}$ on $\Delta K$ of Alloy 600 specimens solution-annealed at $1115^{\circ} \mathrm{C}$ and solution-annealed at this temperature and thermally treated at $600^{\circ} \mathrm{C}$ for $24 \mathrm{~h}$ 
Table 17. Crack growth results at $289^{\circ} \mathrm{C}$ in $\mathrm{HP}$ water with $\approx 300$ ppb DO for Alloy 600 specimens annealed at $1025^{\circ} \mathrm{C}$

\begin{tabular}{|c|c|c|c|c|c|c|c|c|c|c|c|c|c|}
\hline \multirow{3}{*}{$\begin{array}{l}\text { Test } \\
\text { No. }\end{array}$} & \multirow{3}{*}{$\begin{array}{c}\text { Test } \\
\text { Time } \\
\text { (h) }\end{array}$} & \multicolumn{3}{|c|}{ Water Chemistry } & \multirow[b]{2}{*}{ Electrode } & \multirow[b]{2}{*}{ Potential } & \multirow{3}{*}{$\begin{array}{l}\text { Load } \\
\text { Ratioc }\end{array}$} & \multirow{2}{*}{\multicolumn{3}{|c|}{$\begin{array}{l}\text { Alloy } 600 \text { (Annealed) } \\
\text { Specimen No. J320-02 }\end{array}$}} & \multirow{2}{*}{\multicolumn{3}{|c|}{$\begin{array}{c}\text { Alloy } 600 \text { (TT) } \\
\text { Specimen No. J321-02 }\end{array}$}} \\
\hline & & \multirow{2}{*}{$\begin{array}{c}\mathrm{O}_{2}^{b} \\
\text { Conc. } \\
\text { (ppb) }\end{array}$} & \multirow{2}{*}{$\begin{array}{l}\text { Cond. } \\
\text { at } 25^{\circ} \mathrm{C} \\
\left(\mu \mathrm{S} \cdot \mathrm{cm}^{-1}\right)\end{array}$} & \multirow{2}{*}{$\begin{array}{l}\mathrm{pH} \text { at } \\
25^{\circ} \mathrm{C}\end{array}$} & & & & & & & & & \\
\hline & & & & & $\begin{array}{l}304 \mathrm{SS} \\
\mathrm{mV}(\mathrm{SHE})\end{array}$ & $\begin{array}{c}\mathrm{Pt} \\
\text { (@) } 289^{\circ} \mathrm{C}\end{array}$ & & $\begin{array}{l}\mathrm{K}_{\max }{ }^{\mathrm{d}} \\
(\mathrm{MPa} .\end{array}$ & $\begin{array}{l}\Delta \mathrm{Ke} \\
1 / 2)\end{array}$ & $\begin{array}{l}\text { Rate } \\
\left(10^{-10} \mathrm{~m} \cdot \mathrm{s}^{-1}\right)\end{array}$ & $\begin{array}{r}\mathrm{K}_{\max }{ }^{\mathrm{d}} \\
(\mathrm{MPa}\end{array}$ & $\begin{array}{l}\Delta \mathrm{K}^{\mathrm{e}} \\
1 / 2 \mathrm{~J}\end{array}$ & $\begin{array}{l}\text { Rate } \\
\left(10^{-10} \mathrm{~m} \cdot \mathrm{s}^{-1}\right)\end{array}$ \\
\hline 1 & $\begin{array}{l}836- \\
868\end{array}$ & 310 & 0.07 & 6.90 & 118 & 117 & 0.45 & 31.2 & 17.16 & 23.3 & 31.0 & 17.05 & 12.6 \\
\hline 2 & $\begin{array}{l}870- \\
888\end{array}$ & 310 & 0.07 & 6.94 & 123 & 118 & 0.40 & 31.7 & 19.02 & 41.8 & 31.2 & 18.72 & 15.6 \\
\hline 3 & $\begin{array}{l}890- \\
908\end{array}$ & 230 & 0.07 & 6.94 & 123 & 118 & 0.35 & 32.3 & 20.99 & 51.6 & 31.3 & 20.37 & 15.3 \\
\hline 4 & $\begin{array}{l}1028- \\
1051\end{array}$ & 300 & 0.07 & 6.86 & - & - & 0.30 & 34.1 & 23.84 & 117.5 & 31.8 & 22.23 & 27.2 \\
\hline 5 & $\begin{array}{l}1052- \\
1075\end{array}$ & 310 & 0.07 & 6.86 & - & - & 0.50 & 34.8 & 17.42 & 44.2 & 32.0 & 16.00 & 14.3 \\
\hline 6 & $\begin{array}{l}1218- \\
1228\end{array}$ & 260 & 0.06 & 6.55 & 118 & 111 & 0.20 & 36.2 & 28.95 & 194.4 & 32.4 & 25.95 & 75.1 \\
\hline 7 & $\begin{array}{l}1228- \\
1245\end{array}$ & 280 & 0.06 & 6.55 & 124 & 118 & 0.60 & 36.5 & 14.60 & 26.7 & 32.6 & 13.03 & 14.0 \\
\hline 8 & $\begin{array}{l}1250- \\
1272\end{array}$ & 300 & 0.06 & 6.55 & 135 & 127 & 0.75 & 36.8 & 9.21 & 12.4 & 32.7 & 8.19 & 7.45 \\
\hline 9 & $\begin{array}{l}1272- \\
1417\end{array}$ & 300 & 0.06 & 6.55 & 146 & 140 & 0.90 & 37.0 & 3.70 & 1.12 & 32.9 & 3.29 & 1.25 \\
\hline 10 & $\begin{array}{l}1417- \\
1682\end{array}$ & 290 & 0.06 & 6.55 & 152 & 143 & 0.95 & 37.1 & 1.85 & 0.10 & 33.0 & 1.65 & 0,48 \\
\hline 11 & $\begin{array}{l}1682- \\
1701\end{array}$ & 260 & 0.06 & 6.55 & 152 & 140 & 0.70 & 37.3 & 11.19 & 22.4 & 33.2 & 9.95 & 15.5 \\
\hline 12 & $\begin{array}{l}1701- \\
1746\end{array}$ & 270 & 0.06 & 6.55 & 155 & 143 & 0.83 & 37.5 & 6.38 & 5.64 & 33.3 & 5.66 & 3.21 \\
\hline 13 & $\begin{array}{l}1746- \\
1755\end{array}$ & 290 & 0.06 & 6.55 & 158 & 146 & 0.20 & 38.3 & 30.64 & 140.7 & 33.6 & 26.88 & 49.8 \\
\hline 14 & $\begin{array}{l}1756- \\
1772\end{array}$ & 320 & 0.06 & 6.55 & 166 & 155 & 0.65 & 39.0 & 13.67 & 14.4 & 33.8 & 11.83 & 9.81 \\
\hline
\end{tabular}

a Compact tension specimens (ITCT) of Alloy 600, Heat No. NX9244G. The specimens (Nos. J320-02 and J321-02) were tested in the solution-

annealed $\left(1025^{\circ} \mathrm{C}\right.$ for $\left.2 \mathrm{~h}\right)$ and solution-annealed $\left(1025^{\circ} \mathrm{C}\right.$ for $\left.2 \mathrm{~h}\right)$ and thermally treated $\left(600^{\circ} \mathrm{C}\right.$ for $\left.24 \mathrm{~h}\right)$ conditions, respectively. Yield stresses of the materials at $289^{\circ} \mathrm{C}$ for these heat-treatment conditions are 156 and $173 \mathrm{MPa}$, respectively.

b Effluent DO concentration was determined with Chemetrics ampules and an Orbisphere Oxygen meter.

c Frequency and rise time of the positive sawtooth waveform were $8 \times 10^{-2} \mathrm{~Hz}$ and $12 \mathrm{~s}$, respectively.

d Stress intensity, $K_{\max }$, values at the end of the time period.

$\mathrm{e} \Delta \mathrm{K}=\mathrm{K}_{\max }(1-\mathrm{R})$, where load ratio $\mathrm{R}=\mathrm{K}_{\min } / \mathrm{K}_{\max }$. 
Table 18. Crack growth results at $289^{\circ} \mathrm{C}$ in $\mathrm{HP}$ water with $\approx 300$ ppb DO for Alloy 600 specimens a annealed at $1115^{\circ} \mathrm{C}$

\begin{tabular}{|c|c|c|c|c|c|c|c|c|c|c|c|c|c|}
\hline \multirow{3}{*}{$\begin{array}{l}\text { Test } \\
\text { No. }\end{array}$} & \multirow{3}{*}{$\begin{array}{c}\text { Test } \\
\text { Time } \\
\text { (h) }\end{array}$} & \multicolumn{3}{|c|}{ Water Chemistry } & \multirow{3}{*}{$\begin{array}{c}\text { Electrode } \\
304 \text { SS } \\
\text { mV(SHE) }\end{array}$} & \multirow[b]{2}{*}{ Potential } & \multirow{3}{*}{$\begin{array}{l}\text { Load } \\
\text { Ratioc }\end{array}$} & \multirow{2}{*}{\multicolumn{3}{|c|}{$\begin{array}{c}\text { Alloy } 600 \text { (Annealed) } \\
\text { Specimen No. J310-02 }\end{array}$}} & \multirow{2}{*}{\multicolumn{3}{|c|}{$\begin{aligned} \text { Alloy } 600 \text { (TT) } \\
\text { Specimen No. J311-02 }\end{aligned}$}} \\
\hline & & \multirow{2}{*}{$\begin{array}{c}\mathrm{O}_{2}^{b} \\
\text { Conc. } \\
\text { (ppb) }\end{array}$} & \multirow{2}{*}{$\begin{array}{c}\text { Cond. } \\
\text { at } 25^{\circ} \mathrm{C} \\
\left(\mu \mathrm{S} \cdot \mathrm{cm}^{-1}\right)\end{array}$} & \multirow{2}{*}{$\begin{array}{l}\mathrm{pH} \text { at } \\
25^{\circ} \mathrm{C}\end{array}$} & & & & & & & & & \\
\hline & & & & & & $\begin{array}{c}\mathrm{Pt} \\
\text { (a) } 289^{\circ} \mathrm{C}\end{array}$ & & $\begin{array}{r}\mathrm{K}_{\max }{ }^{\mathrm{d}} \\
(\mathrm{MPa}\end{array}$ & $\Delta \mathrm{Ke}$ & $\begin{array}{l}\text { Rate } \\
\left(10^{-10} \mathrm{~m} \cdot \mathrm{s}^{-1}\right)\end{array}$ & $\begin{array}{r}\mathrm{K}_{\max }{ }^{\mathrm{d}} \\
(\mathrm{MPa}\end{array}$ & $\Delta \mathrm{Ke}$ & $\begin{array}{l}\text { Rate } \\
\left(10^{-10} \mathrm{~m} \cdot \mathrm{s}^{-1}\right)\end{array}$ \\
\hline 1 & $2^{1-}$ & 300 & 0.09 & 6.30 & 145 & 112 & 0.50 & 29.6 & 14.80 & 22.9 & 29.6 & 14.80 & 22.4 \\
\hline 2 & $\begin{array}{l}30- \\
70\end{array}$ & 300 & 0.09 & 6.30 & 150 & 122 & 0.60 & 30.0 & 12.00 & 15.7 & 29.9 & 11.90 & 13.6 \\
\hline 3 & $\begin{array}{c}70- \\
143\end{array}$ & 310 & 0.09 & 6.30 & 151 & 124 & 0.70 & 30.4 & 9.12 & 9.87 & 30.2 & 9.07 & 9.18 \\
\hline 4 & $\begin{array}{l}143- \\
191\end{array}$ & 325 & 0.09 & 6.30 & 152 & 124 & 0.75 & 30.5 & 7.63 & 6.34 & 30.4 & 7.60 & 6.07 \\
\hline 5 & $\begin{array}{l}395- \\
480\end{array}$ & 300 & 0.07 & 6.25 & 151 & 129 & 0.90 & 31.1 & 3.11 & 0.89 & 31.0 & 3.10 & 0.82 \\
\hline 6 & $\begin{array}{l}482- \\
574\end{array}$ & 290 & 0.07 & 6.25 & 151 & 129 & 0.85 & 31.2 & 4.67 & 1.37 & 31.1 & 4.67 & 2.08 \\
\hline 7 & $\begin{array}{l}575- \\
646\end{array}$ & 310 & 0.07 & 6.25 & 155 & 134 & 0.80 & 31.3 & 6.26 & 3.05 & 31.3 & 6.26 & 4.18 \\
\hline 8 & $\begin{array}{l}1200- \\
1230\end{array}$ & 300 & 0.12 & 6.76 & 153 & 142 & 0.45 & 31.8 & 17.49 & 20.9 & 31.6 & 17.38 & 18.2 \\
\hline 9 & $\begin{array}{l}1367- \\
1392\end{array}$ & 300 & 0.12 & 6.76 & 154 & 137 & 0.40 & 32.4 & 19.44 & 35.3 & 32.1 & 19.26 & 25.4 \\
\hline 10 & $\begin{array}{l}1393- \\
1414\end{array}$ & 305 & 0.12 & 6.76 & 153 & 147 & 0.35 & 33.0 & 21.45 & 46.3 & 32.4 & 21.06 & 25.3 \\
\hline 11 & $\begin{array}{l}1415- \\
1484\end{array}$ & 300 & 0.12 & 6.76 & 156 & 144 & 0.68 & 33.7 & 10.78 & 11.8 & 32.7 & 10.46 & 6.92 \\
\hline 12 & $\begin{array}{l}1585- \\
2208\end{array}$ & 320 & 0.07 & 6.78 & 149 & 140 & 0.95 & 33.8 & 1.69 & 0.78 & 32.8 & 1.64 & 0.13 \\
\hline 13 & $\begin{array}{l}2208- \\
2236\end{array}$ & 300 & 0.07 & 6.78 & 158 & 133 & 0.30 & 35.2 & 24.64 & 78.8 & 33.7 & 23.59 & 46.3 \\
\hline 14 & $\begin{array}{l}2237- \\
2244\end{array}$ & 280 & 0.07 & 6.78 & 150 & 131 & 0.20 & 36.4 & 29.12 & 236.0 & 34.4 & 27.52 & 132.0 \\
\hline
\end{tabular}

a Compact tension specimens (1TCT) of Alloy 600, Heat No. NX9244G. The specimens (Nos. J310-02 and J311-02) were tested in the solutionannealed $\left(1115^{\circ} \mathrm{C}\right.$ for $\left.2 \mathrm{~h}\right)$ and solution-annealed $\left(115^{\circ} \mathrm{C}\right.$ for $\left.2 \mathrm{~h}\right)$ and thermally treated $\left(600^{\circ} \mathrm{C}\right.$ for $\left.24 \mathrm{~h}\right)$ conditions, respectively. Yield stress of the material at $289^{\circ} \mathrm{C}$ for both heat-treatment conditions is $156 \mathrm{MPa}$.

b Effluent dissolved -oxygen concentration was determined with Chemetrics ampules and an Orbisphere Oxygen meter.

c Frequency and rise time of the positive sawtooth waveform were $8 \times 10^{-2} \mathrm{~Hz}$ and $12 \mathrm{~s}$, respectively.

d Stress intensity, $K_{\max }$, values at the end of the time period.

e $\Delta K=K_{\max }(1-R)$, where load ratio $R=K_{\min } / K_{\max }$. 
Although the crack growth behavior of the specimens appears quite similar, the results for the solution-annealed and thermally treated specimens from the two experiments are shown in Figs. 54 and 55, respectively. Figures 52-55 indicate that different solution annealing temperatures $\left(1025\right.$ versus $1115^{\circ} \mathrm{C}$ ) and thermal treatment at $600^{\circ} \mathrm{C}$ for $24 \mathrm{~h}$ do not produce large variations in CGRs of this heat of low-carbon, large-grain-size material in oxygenated water at $289^{\circ} \mathrm{C}$. The combined data from the four specimens in the two experiments are shown in Fig. 56. Differences in the rates mainly occur at $\Delta \mathrm{K}$ values $>20 \mathrm{MPa} \cdot \mathrm{m}^{1 / 2}$, which correspond to tests at low load ratios $(\mathrm{R}<0.4)$.
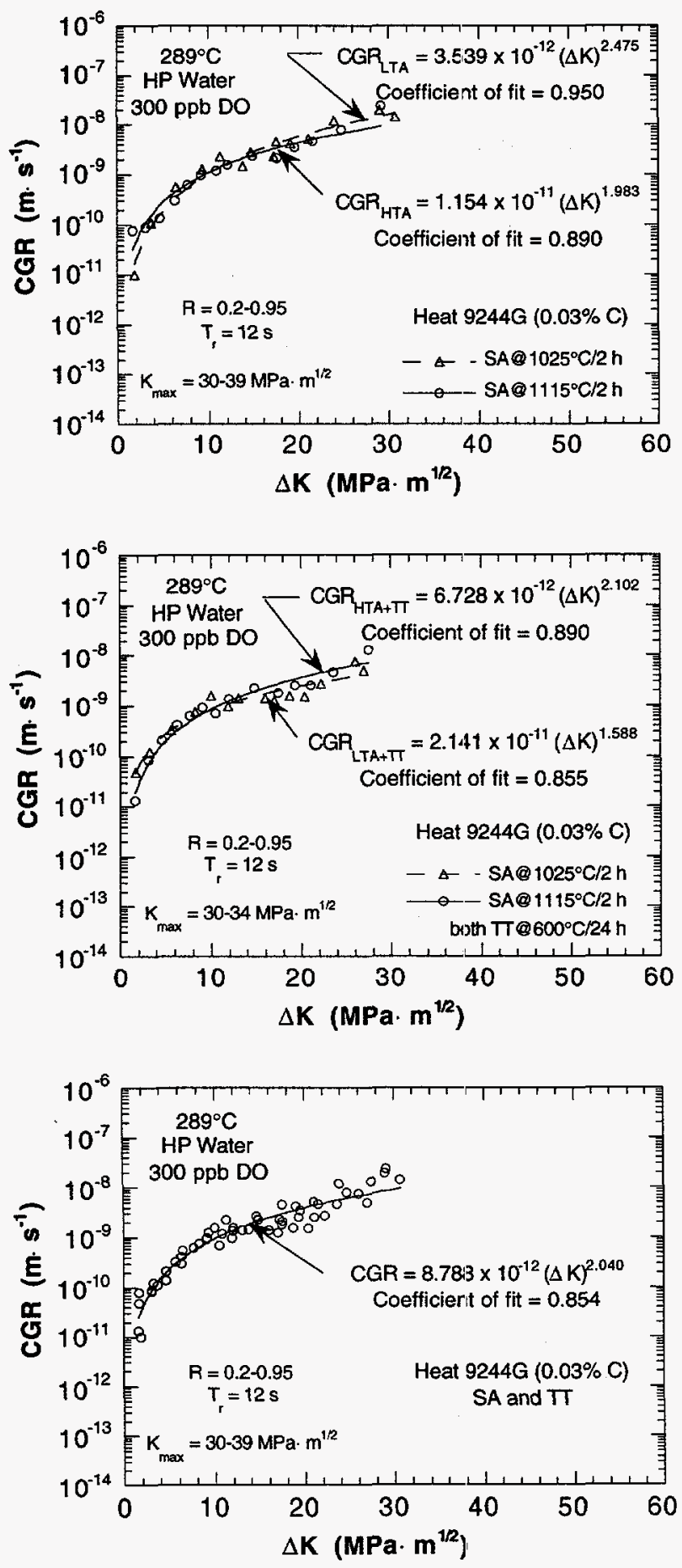

Figure 54.

Dependence of CGRs in oxygenated HP water at $289^{\circ} \mathrm{C}$ on $\Delta K$ of solutionannealed Alloy 600 specimens
Figure 55.

Dependence of CGRs in oxygenated HP water at $289^{\circ} \mathrm{C}$ on $\Delta K$ of thermally treated Alloy 600 specimens
Figure 56.

Combined data for dependence on $\Delta K$ of CGR of low-carbon heat of Alloy 600 in $\mathrm{HP}$ oxygenated water at $289^{\circ} \mathrm{C}$ 


\subsection{Comparison of CGRs of Alloy 600 in HP Oxygenated Water and Air}

The CGRs in HP oxygenated water of specimens from Heat NX9244G with different heattreatment conditions can be compared with CGRs in air from another heat of Alloy 600 (NX8197), which were reported previously (Fig. 57).60 The most useful comparison would be for rates in water and in air, determined from the same heat of material with the same heat treatment; however, the present results preclude such a comparison. Nevertheless, a ratio of the CGRs for each specimen in water to those in air, or from the combined data from several specimens with differing heat treatments to those in air can be obtained from the "best-fit" correlations for the CGR-versus- $\Delta \mathrm{K}$ data. The results of several such comparisons in water (Figs. 52, 53, and 56) and in air (Fig. 57) are shown in Figs. 58-60, respectively.

The ratios of the CGRs for Alloy 600 in water and air at $289^{\circ} \mathrm{C}$ (Figs. 58-60) indicate that the rates are higher in water than in air (ratio $>1$ ) at $\Delta \mathrm{K}$ values $<18 \mathrm{MPa} \cdot \mathrm{m}^{1 / 2}$ and are lower in water than in air (ratio $<1$ ) at higher values of $\Delta \mathrm{K}$. For high load ratios (i.e., $\mathrm{R} \geq 0.95$ ) and a $\mathrm{K}_{\max }$ of $\approx 40 \mathrm{MPa} \cdot \mathrm{m}^{1 / 2}$, which correspond to $\Delta \mathrm{K}$ values of $\leq 2 \mathrm{MPa} \cdot \mathrm{m}^{1 / 2}$, the rates in water are higher than in air by a factor of $\approx 10$. Extrapolation of the curves to lower $\Delta K$ values, i.e., higher load ratios that approach constant load $(R=1.0)$, implies even greater enhancement of the rates in water; however, this extrapolation leads to considerable uncertainty because the measured rates in both water and air approach the sensitivity of the crack length measurement system under these loading conditions, even in long-term tests $(\approx 1000 \mathrm{~h})$.
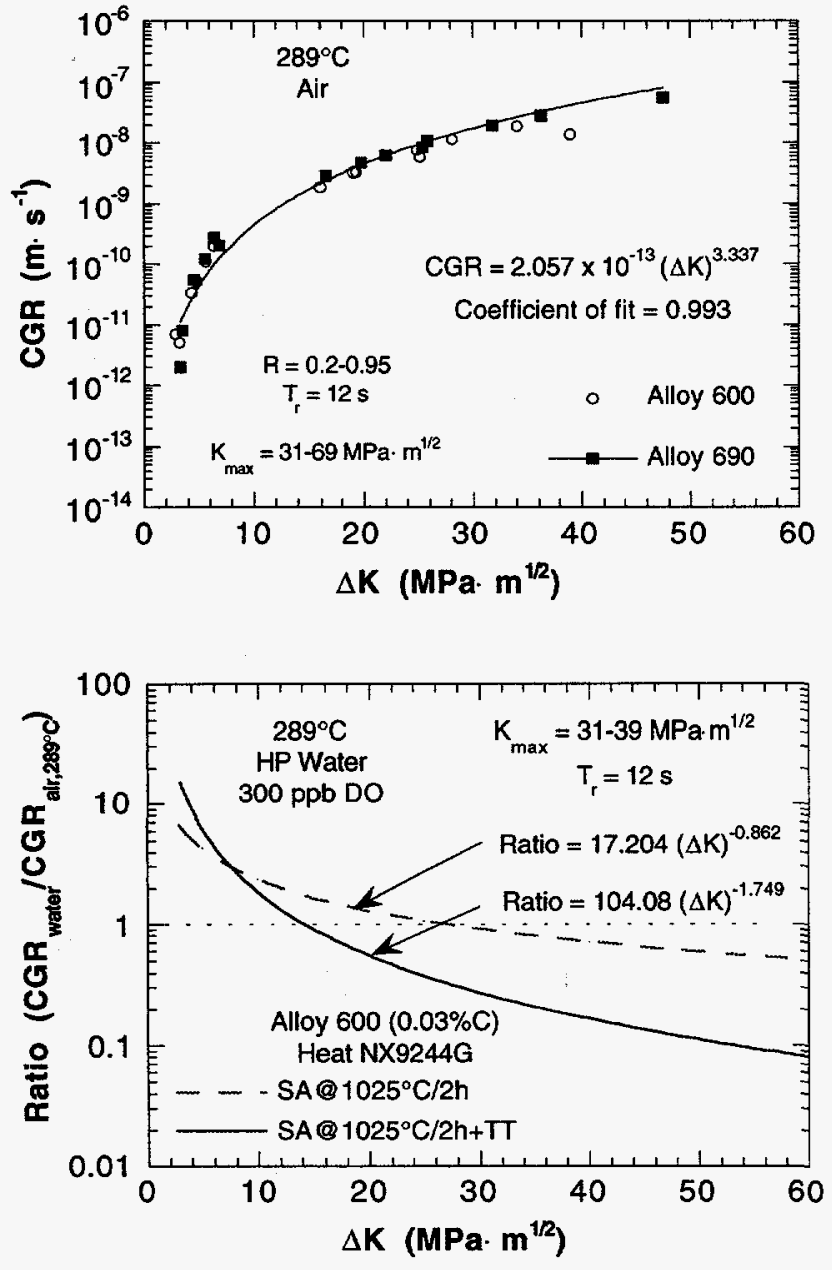

Figure 57.

Dependence on $\triangle K$ of CGR of Alloys 600 and 690 in air at $289^{\circ} \mathrm{C}$
Figure 58.

Dependence on $\triangle K$ of ratio of CGRs of solution-annealed $\left(1025^{\circ} \mathrm{C}\right)$ and thermally treated Alloy 600 in HP oxygenated water to CGRs of millannealed Alloy 600 in air at $289^{\circ} \mathrm{C}$ 

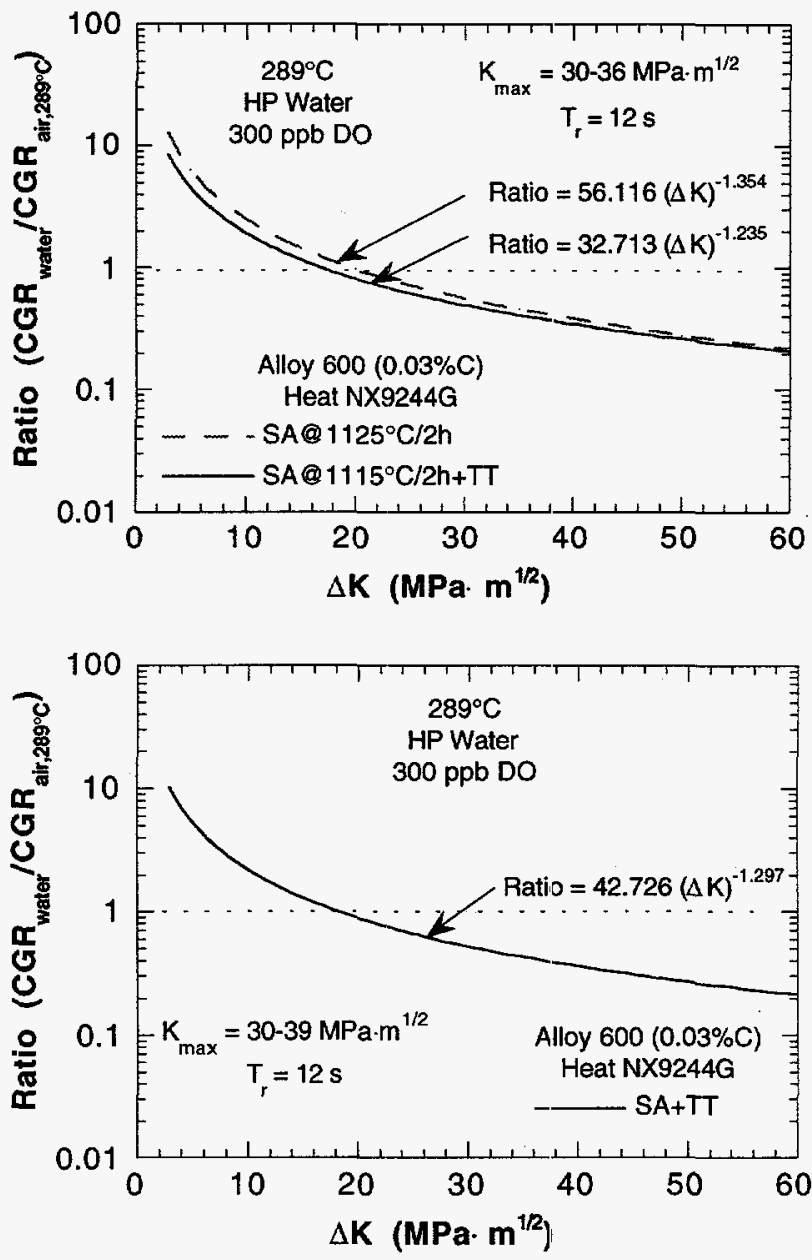

Figure 59.

Dependence on $\Delta K$ of ratio of CGRs of solution-annealed $\left(1115^{\circ} \mathrm{C}\right)$ and thermally treated Alloy 600 in HP oxygenated water to CGRs of millannealed Alloy 600 in air at $289^{\circ} \mathrm{C}$
Figure 60.

Dependence on $\Delta K$ of ratio of CGRs in HP oxygenated water of a low-carbon heat of Alloy 600 with differing heat treatments to CGRs in air of millannealed Alloy 600 at $289^{\circ} \mathrm{C}$

Crack growth experiments are being conducted in HP oxygenated water under constant load at $\mathrm{K}_{\max }$ of $<40 \mathrm{MPa} \cdot \mathrm{m}^{1 / 2}$ to determine the degree of rate enhancement as $\Delta \mathrm{K}$ approaches zero.

In Fig. 60 , as $\Delta \mathrm{K}$ increases from $\approx 18 \mathrm{MPa} \cdot \mathrm{m}^{1 / 2}$, the ratio of the CGRs in water and air is $<1$, and at a $\Delta \mathrm{K}$ of $40 \mathrm{MPa} \cdot \mathrm{m}^{1 / 2}$, the rate in water is lower than in air by a factor of $\approx 3$, based on the combined data from the four specimens. This behavior was observed for Alloy 600 specimens in $\mathrm{HP}$ deoxygenated water $(<5 \mathrm{ppb} \mathrm{DO})$ at $289^{\circ} \mathrm{C}$, as shown in Fig. 61.60 The CGRs of Alloy 600 are lower in deoxygenated water than in air at $\Delta \mathrm{K}$ values $>6 \mathrm{MPa} \cdot \mathrm{m}^{1 / 2}$, and at lower $\Delta \mathrm{K}$, the rates in water are higher than in air by, at most, a factor of $\approx 2$, in contrast to a factor of $\approx 10$ in water that contains $\approx 300 \mathrm{ppb}$ DO. The results in Figs. 60 and 61 show the interdependence of loading conditions and DO in HP water and CGRs of Alloy 600, albeit for different heats of material with differing carbon contents and heat treatments. These figures also illustrate that generalization of CGR results from a single loading condition and DO level in water to other loading and/or DO conditions can be misleading. For example, at a $\Delta \mathrm{K}$ of $18 \mathrm{MPa} \cdot \mathrm{m}^{1 / 2}$, the CGRs of Alloy 600 are the same in air as in water that contains $300 \mathrm{ppb}$ DO at $289^{\circ} \mathrm{C}$, whereas at this $\Delta \mathrm{K}$, the rate is higher by a factor of 2 in air than in water that contains $<5 \mathrm{ppb} D O$. Similarly, at a $\Delta \mathrm{K}$ of $6 \mathrm{MPa} \cdot \mathrm{m}^{1 / 2}$, the CGRs are the same in air and in water that contains $\approx 5 \mathrm{ppb} \mathrm{DO}$ at $289^{\circ} \mathrm{C}$, although the rate in water that contains $\approx 300 \mathrm{ppb}$ $\mathrm{DO}$ is higher by a factor of 5 than air at this $\Delta \mathrm{K}$. 


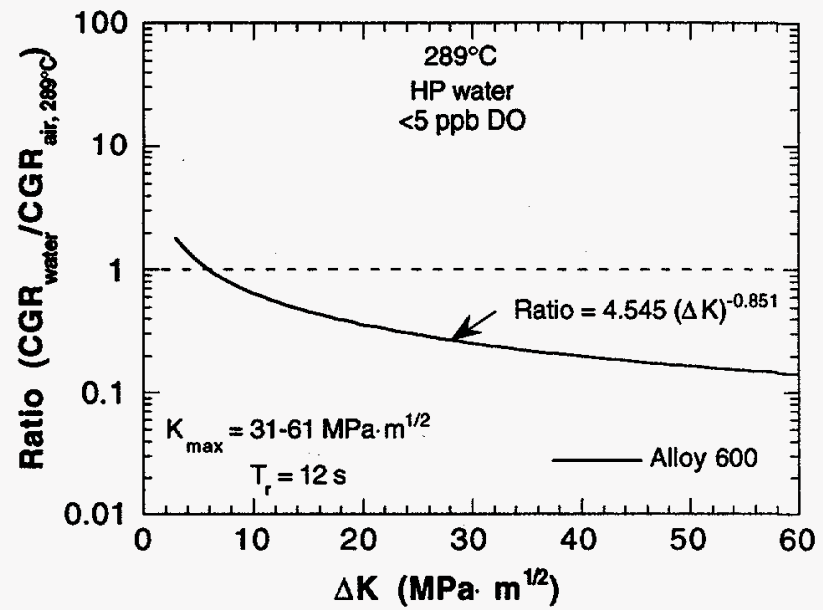

Figure 61.

Dependence on $\triangle K$ of ratio of CGRs in HP deoxygenated water of Alloy 600 with 0.08 wt.\% carbon and differing heat treatments to CGRs in air of millannealed Alloy 600 at $289^{\circ} \mathrm{C}$

\subsection{Morphology of Crack Path and Fracture Surface of Alloy 600 Specimens}

Figures 62-65 show the fracture surface, fracture morphology, and crack path in the crack-tip region of the specimens listed in Tables 17 and 18. The 1TCT specimens were sectioned vertically, and one-half of each specimen was split in the plane of the crack in liquid nitrogen. Corrosion-product films were removed from the fracture surface by a chemical process to reveal the morphology of the underlying material. The intact portion of the specimen that encompassed the crack was polished and etched to corroborate the mode of crack propagation and also to determine if crack branching had occurred during the test. The total crack lengths at the end of the test were consistent with values obtained by the DC potential-drop technique and no branching of the cracks had occurred.

\begin{tabular}{|c|c|c|c|}
\hline ALLOY 600 & HEAT TREATMENT & LOAD CONDITIONS & ENVIRONMENT \\
Spec. No. J320-02 & Solution Annealed & $K_{\max }=31-39 \mathrm{MPa} \cdot \mathrm{m}^{1 / 2}$ & $300 \mathrm{ppb}$ DO \\
Heat No. NX9244G & $1025{ }^{\circ} \mathrm{C} / 2 \mathrm{~h}$ & $\mathbf{R}=0.20-0.95$ & $0.06-0.07 \mu \mathrm{S} \cdot \mathrm{cm}^{-1}$ \\
& & Freq. $=0.077 \mathrm{~Hz}$ & \\
\hline
\end{tabular}

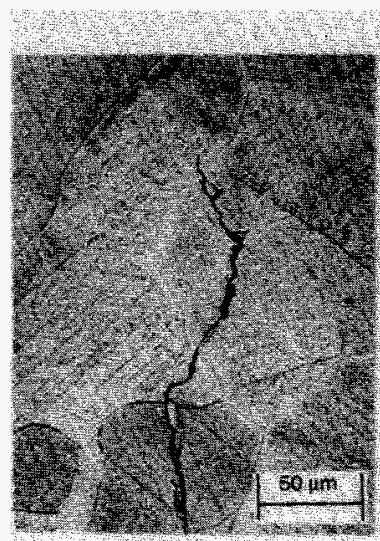

ORACK-TIP REGION

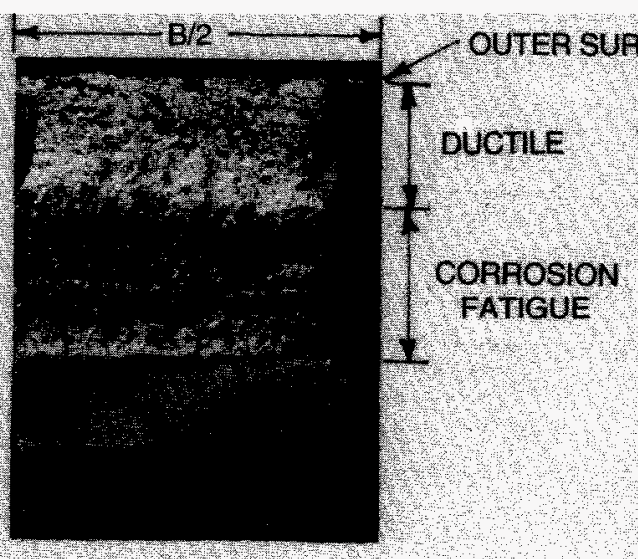

FRACTURE SURFACE

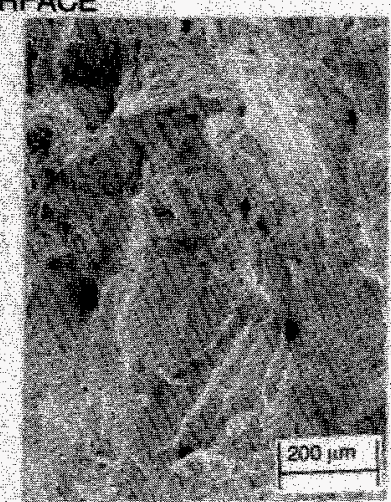

FRACTURE MORPHOLOGY

Figure 62. Crack path, fracture surface, and fracture morphology of 1TCT solutionannealed $\left(1025^{\circ} \mathrm{C}\right.$ for $2 \mathrm{~h}$ ) specimen of Alloy 600 (No. J320-02) after crack growth experiment in HP oxygenated water at $289^{\circ} \mathrm{C}$ 


\begin{tabular}{|c|c|c|c|}
\hline ALLOY 600 & HEAT TREATMENT & LOAD CONDITIONS & ENVIRONMENT \\
Spec. No. J321-02 & Solution Annealed & $\mathrm{K}_{\max }=31-34 \mathrm{MPa} \cdot \mathrm{m}^{\mathrm{l} / 2}$ & $300 \mathrm{ppb}$ DO \\
Heat No. NX9244G & $1025^{\circ} \mathrm{C} / 2 \mathrm{~h}$ and & $\mathrm{R}=0.20-0.95$ & $0.06-0.07 \mu \mathrm{S} \cdot \mathrm{cm}^{-1}$ \\
& Theimally Treated & Freq. $=0.077 \mathrm{~Hz}$ & \\
& $600^{\circ} \mathrm{C} / 24 \mathrm{~h}$ & & \\
\hline
\end{tabular}

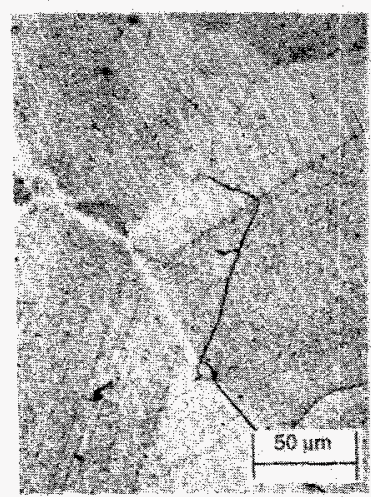

CRACK-TIP REGION

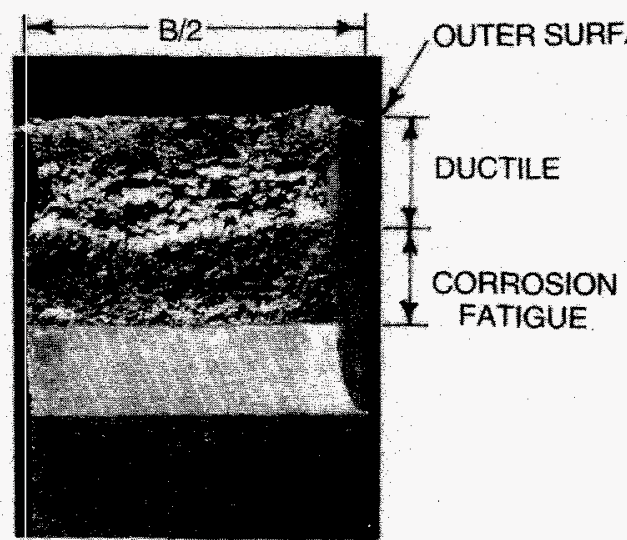

FRACTURE SURFACE

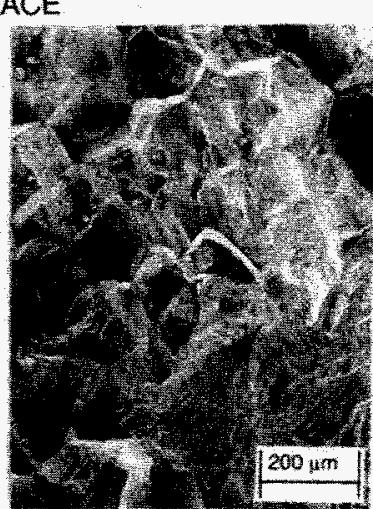

FRACTURE MORPHOLOGY

Figure 63. Crack path, fracture surface, and fracture morphology of 1TCT solutionannealed and thermally treated $\left(1025^{\circ} \mathrm{C}\right.$ for $2 \mathrm{~h}$ and $600^{\circ} \mathrm{C}$ for $24 \mathrm{~h}$ ) specimen of Alloy 600 (No. J321-02) after crack growth experiment in HP oxygenated water at $289^{\circ} \mathrm{C}$

\begin{tabular}{|c|c|c|c|}
\hline $\begin{array}{c}\text { ALLOY } 600 \\
\text { Spec. No. J310-02 } \\
\text { Heat No. NX9244G }\end{array}$ & $\begin{array}{l}\text { HEAT TIEEATMENT } \\
\text { Solution Annealed } \\
1115^{\circ} \mathrm{C} / 2 \mathrm{~h}\end{array}$ & $\begin{array}{c}\text { LOAD CONDITIONS } \\
\begin{aligned} \mathrm{K}_{\max }=30-36 \mathrm{MPa} \cdot \mathrm{m}^{1 / 2} \\
\mathrm{R}=0.20-0.95 \\
\mathrm{~F}=0.077 \mathrm{~Hz}\end{aligned}\end{array}$ & $\begin{array}{l}\text { ENVIRONMENT } \\
300 \mathrm{ppb} \text { DO } \\
0.07-0.12 \mu \mathrm{s} \cdot \mathrm{cm}^{-1}\end{array}$ \\
\hline
\end{tabular}

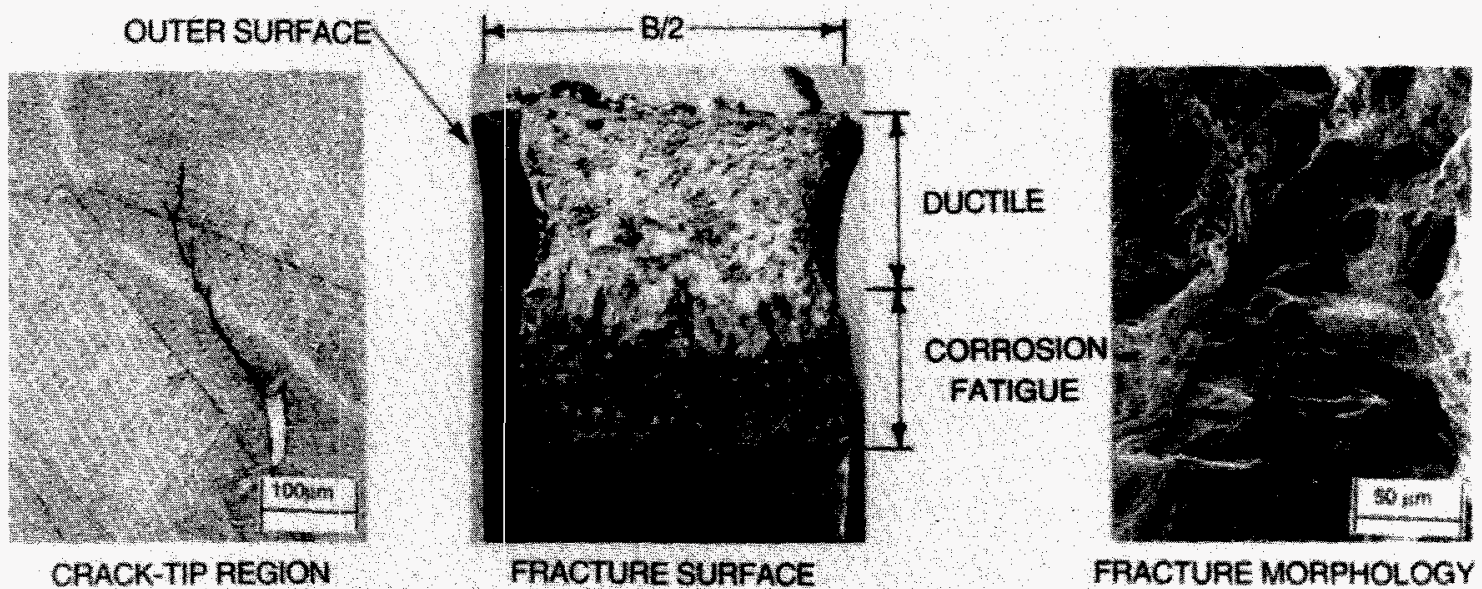

Figure 64. Crack path, fracture surface, and fracture morphology of 1TCT solutionannealed $\left(1115^{\circ} \mathrm{C}\right.$ for $2 \mathrm{~h}$ ) specimen of Alloy 600 (No. J310-02) after crack growth experiment in $\mathrm{HP}$ oxygenated water at $289^{\circ} \mathrm{C}$ 


\begin{tabular}{|c|c|c|c|}
\hline ALLOY 600 & HEAT TREATMENT & LOAD CONDITIONS & ENVIRONMENT \\
Spec. No. J311-02 & Solution Annealed & $K_{\max }=30-34 \mathrm{MPa} \cdot \mathrm{m}^{1 / 2}$ & $300 \mathrm{ppb}$ DO \\
Heat No. NX9244G & $1115^{\circ} \mathrm{C} / 2$ h and & $\mathbf{R}=0.20-0.95$ & $0.07-0.12 \mu \mathrm{s} \cdot \mathrm{cm}^{-1}$ \\
& Thermally Treated & Freq. $=0.077 \mathrm{~Hz}$ & \\
& $600^{\circ} \mathrm{C} / 24 \mathrm{~h}$ & & \\
\hline
\end{tabular}

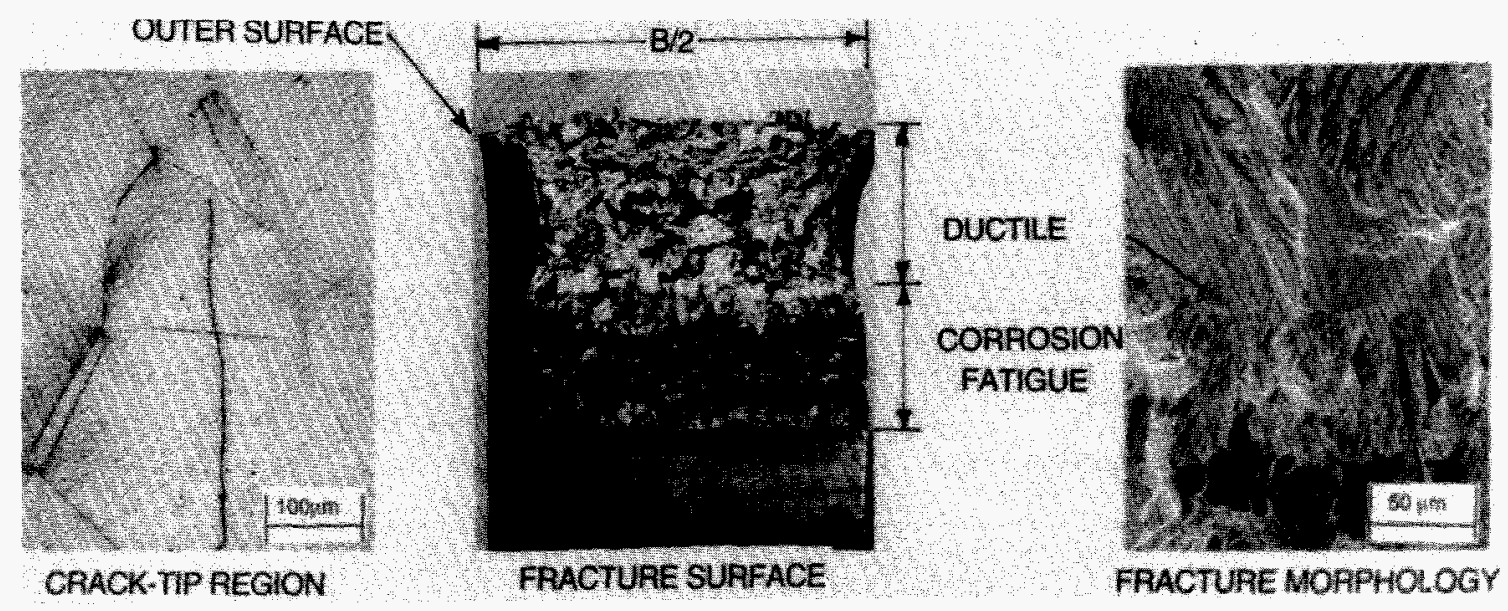

Figure 65. Crack path, fracture surface, and fracture morphology of 1TCT solutionannealed and thermally treated $\left(1115^{\circ} \mathrm{C}\right.$ for $2 \mathrm{~h}$ and $600^{\circ} \mathrm{C}$ for $\left.24 \mathrm{~h}\right)$ specimen of Alloy 600 (No. J311-02) after crack growth experiment in HP oxygenated water at $289^{\circ} \mathrm{C}$

The Alloy 600 specimens from the CGR experiments in HP oxygenated water exhibited a transgranular mode of crack propagation. This mode of crack propagation can be attributed to the strong contribution of mechanical cyclic loading in tests at $R$ of $0.2-0.8$ and the relatively small degree of crack extension that occurred in tests at $R>0.8$.

\section{Modeling of Residual Stresses in Core Shroud Structures (J. Zhang, P. Dong, F. W. Brust, Battelle Columbus Laboratories; and W. J. Shack, ANL)}

Under contract to ANL, Battelle Columbus Laboratories (BCL) has used numerical models to characterize weld residual stresses and the associated stress intensity factors at BWR core shroud welds. A detailed description of the weld residual stresses has been obtained for the $\mathrm{H} 4$ weld. The multipass welding process was simulated by an axisymmetric solid element model. A shell element analysis was also performed to quantify the effects of specimen removal on residual stress measurements. Based on the residual stress results, stress intensity factors were calculated.

\subsection{Core Shroud Weld Geometry and Calculation of Residual Stress Distributions}

The H4 weld is a multipass SA weld that joins two Type 304 SS cylinders. The geometry of the cylinder and the $\mathrm{H} 4$ weld is shown in Fig. 66. The inner radius and thickness of the cylinder are $2.23 \mathrm{~m}$ (88 in.) and $31.1 \mathrm{~mm}$ (1.5 in.), respectively. The $\mathrm{H} 4$ weld groove is a symmetrical "double- $J$ " type. The sides of the groove are $22.5^{\circ}$ from the normal and the root regions have a $6.3-\mathrm{mm}(0.25-\mathrm{in}$.) radius. The specified welding parameters for the $\mathrm{H} 4$ weld are 


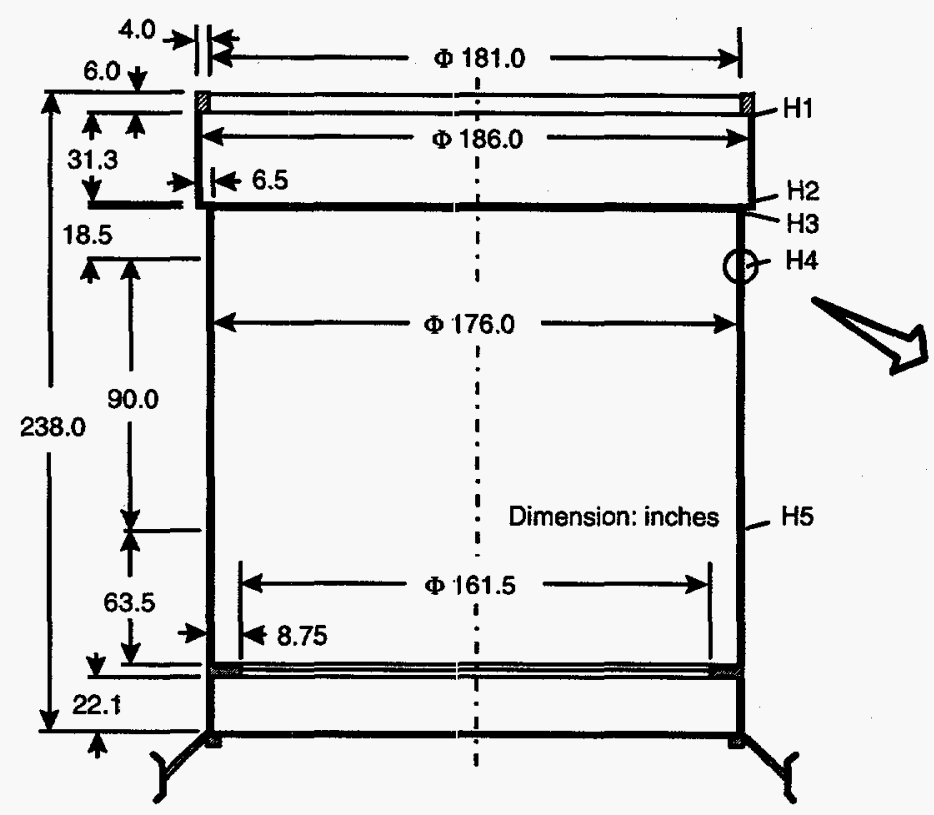

(a) Shroud Section View

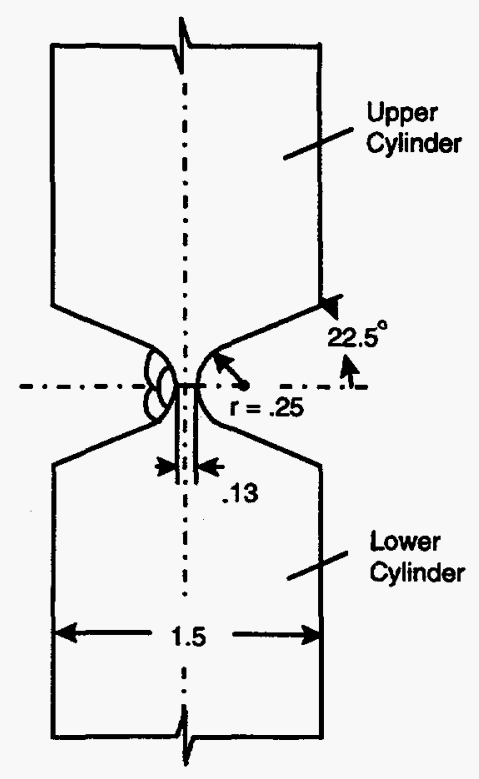

(b) Details of $\mathrm{H} 4$ Weld Geometry

Figure 66. Core shroud structure and H4 weld geometry

Table 19. Welding parameters for $\mathrm{H} 4$ weld

\begin{tabular}{lccc}
\hline Passes & $\begin{array}{c}\text { Current } \\
(\mathrm{A})\end{array}$ & $\begin{array}{c}\text { Voltage } \\
(\mathrm{V})\end{array}$ & $\begin{array}{c}\text { Travel Speed } \\
(\mathrm{mm} / \mathrm{s})\end{array}$ \\
\hline Root & 285 & 28 & 6.3 \\
Balance & 510 & 30 & 7.6 \\
\hline
\end{tabular}

listed in Table 19. An arc efficiency of $70 \%$ is assumed. The root passes on the inner side of the cylinder were made first. Additional passes were used to fill the entire inner groove. Then, the outer groove was back-chipped, and the root passes on the outer side of the cylinder were then made. The outer groove was finally filled during additional passes.

Based on the $\mathrm{H} 4$ weld geometry and pass sequence, an axisymmetric finite-element model was generated, as shown in Fig. 67. The finite-element model consists of 2952 elements and 3145 nodes. A refined mesh is used in and near the weld region. In the weld region, 18 lumped weld passes are assumed, as indicated in Fig. 67b, where Passes 1 and 10 are the root passes on the inner and outer sides of the cylinder. A weld cap is assumed for the weld profile on both sides of the cylinder. Because the $\mathrm{H} 4$ weld was made after the H1-H3 welds, the radial and axial displacements were fixed at the $\mathrm{H} 3$ end of the model to simulate the restraints by the remainder of the shroud structure. The $\mathrm{H} 5$ end of the model was left free.

A sequentially coupled thermal mechanical analysis approach was used. A thermal analysis was performed, and the temperature solutions obtained from the thermal analysis were then used as the input for the structural analysis. The thermal analysis was performed with the TEMPER code developed at BCL. The mechanical analysis was performed with the ABAQUS finite-element code. Currently, almost all general-purpose commercial finite-element codes, 


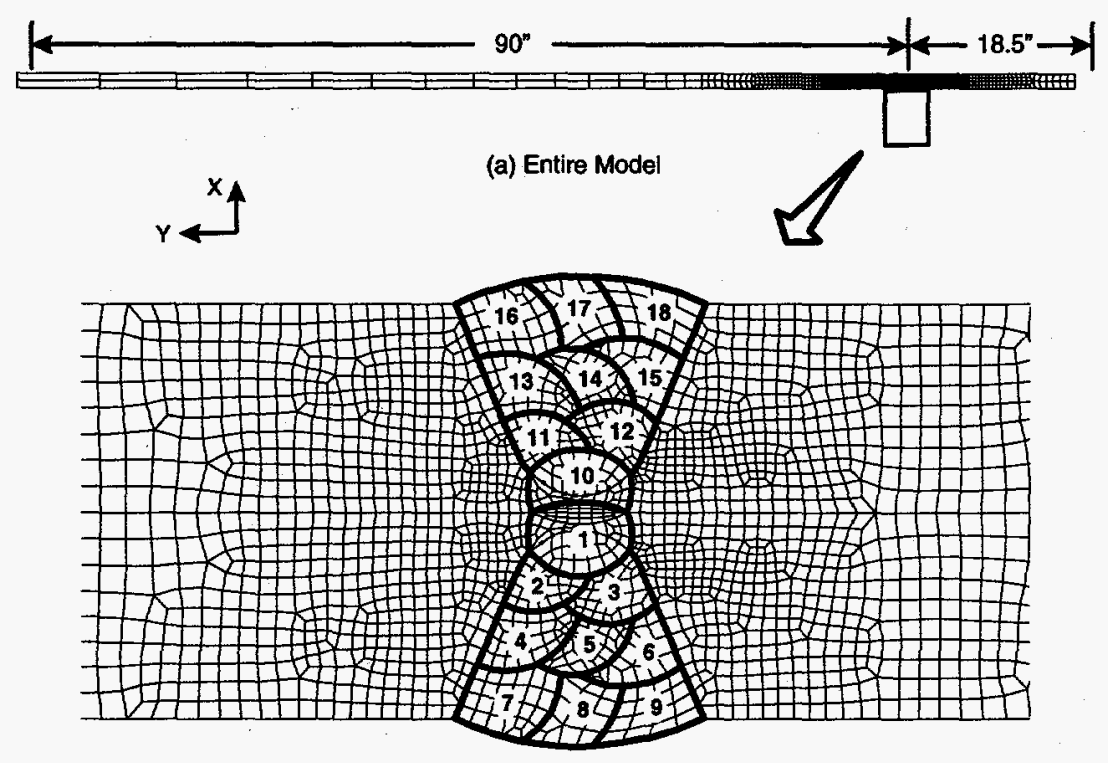

Figure 67.

Axisymmetric finite-element

model for $\mathrm{H} 4$ weld analysis

(b) View of Weld Region and Lumped Weld Pass Sequence

including ABAQUS, are incapable of directly modeling important welding phenomenon such as material melting and metal deposition. Effective modeling of these phenomena is especially important for multipass welds, and a special user-material subroutine was developed at BCL to model the material behavior during welding.

The H4 weld temperature history generated by TEMPER was read into ABAQUS as a field variable by a user subroutine. This field variable was then passed to the special material subroutine to calculate the driving force for the mechanical analysis. The strain components and material yielding status were calculated by the special user-material routine as solutiondependent state variables. The sequential metal deposition effects associated with multiple passes were simulated by assigning a negligible material stiffness (comparable to the stiffness at melting temperature) to those filler elements that are not yet deposited. Once a filler element is deposited, its virgin stress state is restored. Temperature-dependent material properties with nonlinear hardening behavior were used for the analysis.

Figure 68a shows the resulting axial residual stress distributions through the thickness of shroud wall at the weld centerline $(Y=0)$ and HAZs $(Y=-19-\mathrm{mm}[-0.75-\mathrm{in}],. 19-\mathrm{mm}[0.75-\mathrm{in}$.]). The axial residual stresses show a "thick-shell" type of distribution. In the middle of the wall, the axial residual stresses are compressive, whereas, at both inner and outer surfaces of the pipe, tensile stresses were present, except at the weld centerline, where a small-amplitude compressive stress is present on the outer surface. This compressive axial stress was primarily due to axial bending of the wall caused by radial shrinkage of the weld and the presence of a weld cap. At the HAZs (19-mm [0.75-in.] away from the weld centerline), tensile stresses occur at both the inner and outer surfaces. The stress distributions at the two HAZ locations are very similar except near the outer surface. The difference near the outer surface was primarily due to the effects of the weld pass sequence in the last weld layer (Passes 16, 17 and 18). At these cross sections, the maximum tensile axial stresses are at the inner surface of the shroud wall.

Figure $68 \mathrm{~b}$ shows the corresponding throughwall hoop residual stress distributions. As expected, the hoop stresses are tensile almost everywhere at these cross sections. The maximum tensile hoop stress occurs at the weld centerline, between the midthickness and outer 


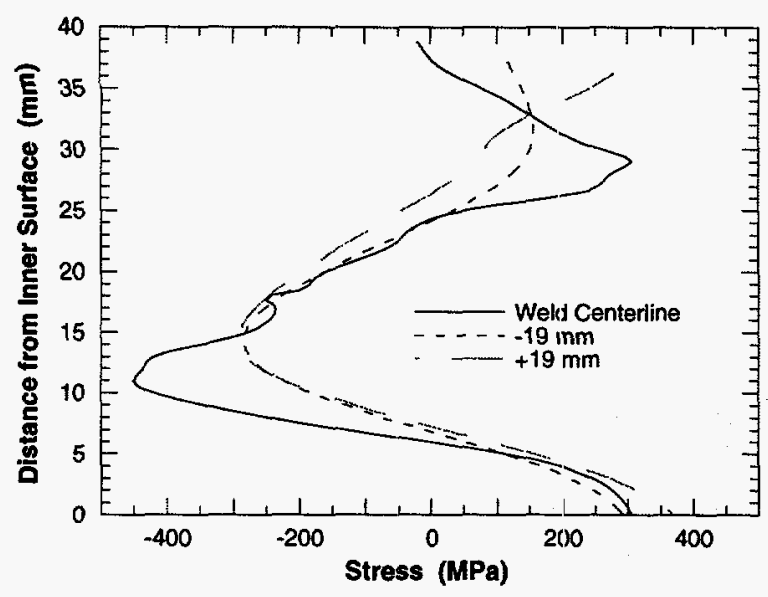

(a)

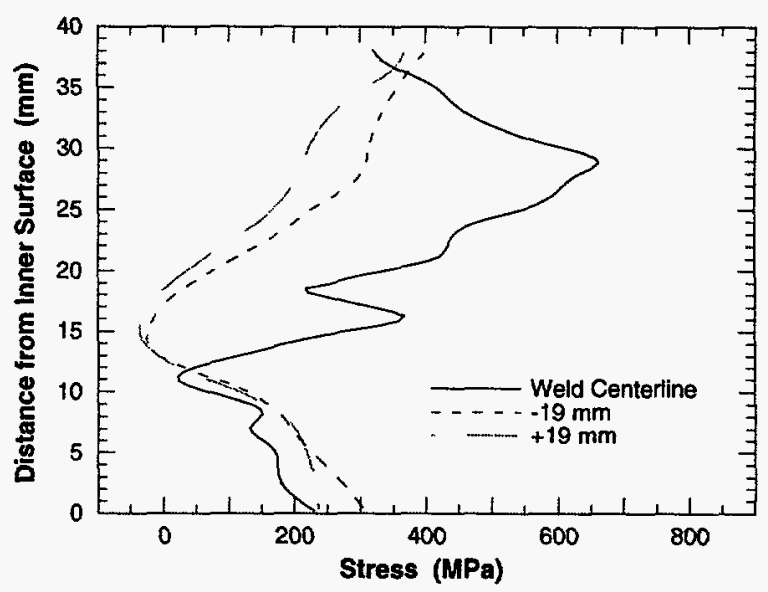

(b)

Figure 68. Throughwall residual stress distribution in $H 4$ Weld (a) axial stress, (b) hoop stress

surfaces. At the HAZs, the tensile stresses peak at the inner and outer surfaces; however, their magnitudes are much smaller than the peak value at the weld centerline.

Figures $69 \mathrm{a}$ and $69 \mathrm{~b}$ show contour plots of the axial and hoop residual stresses in the weld area. For clarity, zones of tensile and compressive stresses are also indicated. Fig. 70 a shows the axial residual stress distributions along the outer and inner surfaces of the shroud. Again, the axial residual stress at the inner surface of the weld centerline is compressive. Rapid variations of the axial stresses occur within a region of 50-mm (2-in.) from the weld centerline. As shown in Fig. 70b, the hoop residual stress distributions at the inner and outer surfaces are very similar. The hoop stresses are tensile within the weld area and become compressive immediately outside this area. The hoop stresses decay more quickly with distance from the weld than do the axial stresses. The residual stress distributions (Fig. 70) obtained from the current analysis are quite similar to those determined experimentally by neutron diffraction for a similar H4 weld. ${ }^{61}$

To better understand the mechanism of residual stress evolution in the $\mathrm{H} 4$ weld, the residual stress states at the end of various weld passes were determined. These stress states are shown in Fig. 71 (axial stress) and 72 (hoop stress). Eight residual stress states were plotted, corresponding to states after a layer of weld passes was deposited.

Both axial and hoop stresses exhibited a drastic change from Pass 9 to Pass 10. After Pass 9, the inner groove was filled, and at Pass 10 the root passes in the outer groove were started. After Pass 9, the axial stress distributions are more like a "thin-shell" type of bending distribution in which the magnitudes gradually increase from Pass 1 to Pass 9. At Pass 10, the compressive axial stress zone was pushed from the midsurface toward the inner surface, but a tensile stress zone remained at the inner surface. Thus, the characteristic, doubly curved "thick-shell" type of axial stress distribution was developed. This pattern was further established at Pass 12, where the second weld layer was made in the outer groove, and maintained throughout the rest of the passes until the outer groove was filled. The same observation can also be made for the hoop stress evolution, except that tensile stresses occurred at all stages. 

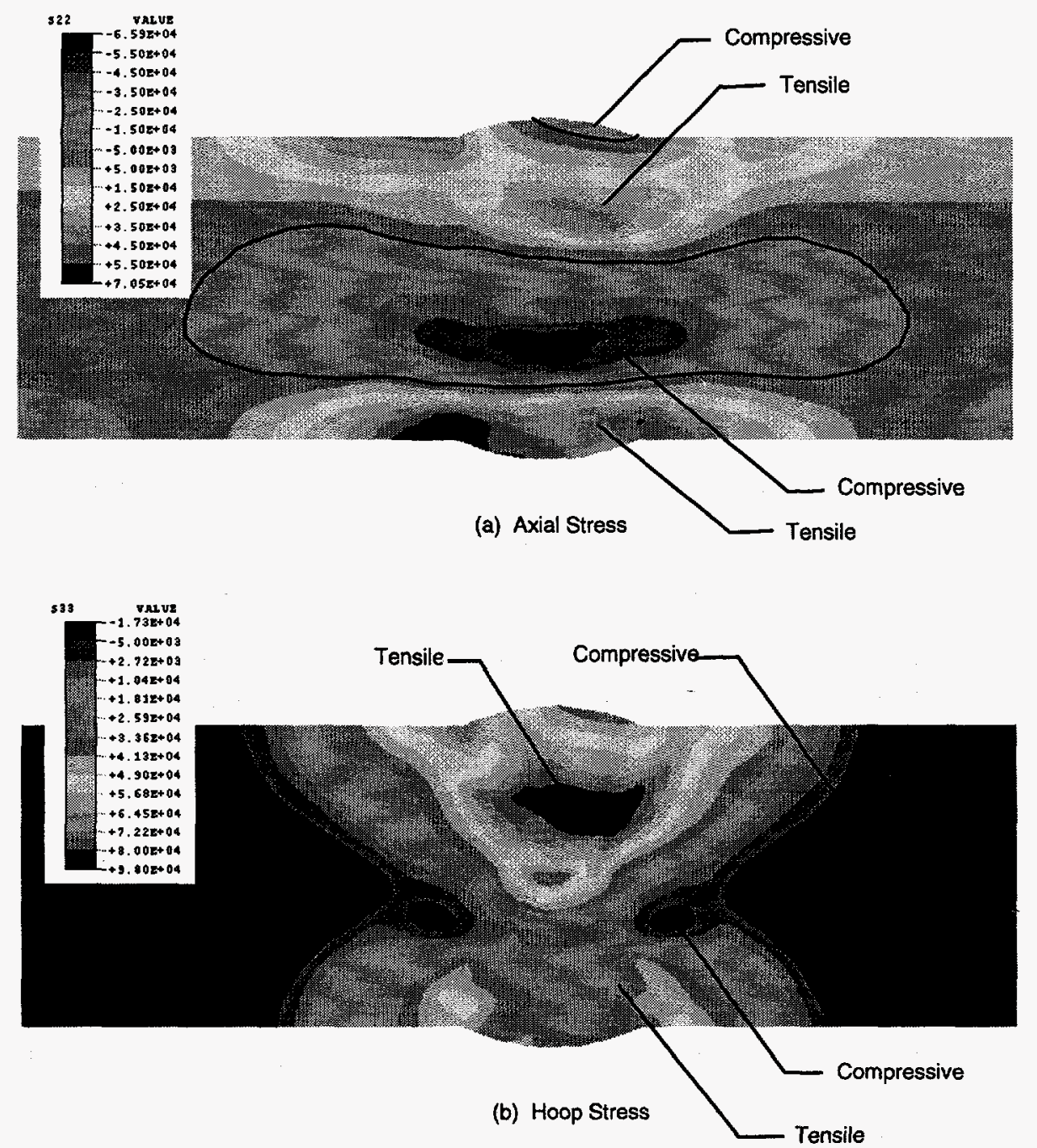

Figure 69. Contour plots of residual stress distributions in $\mathrm{H} 4$ weld

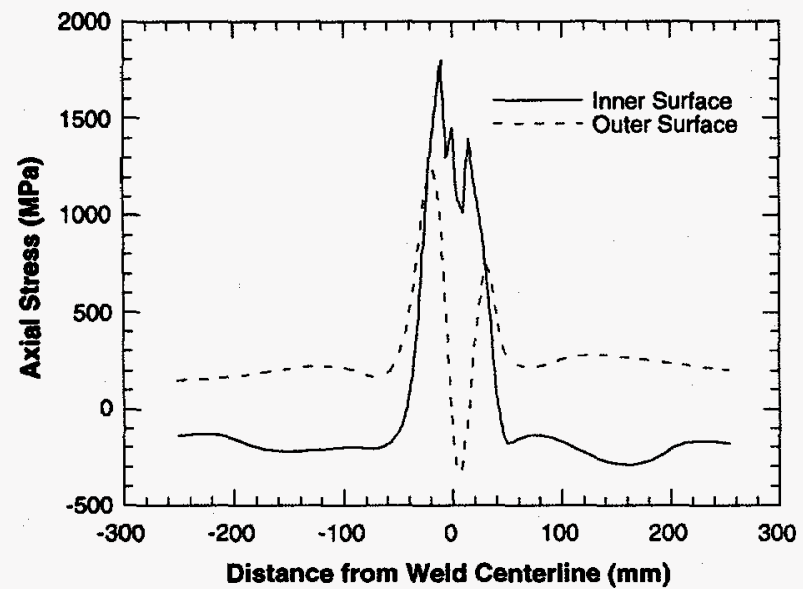

(a)

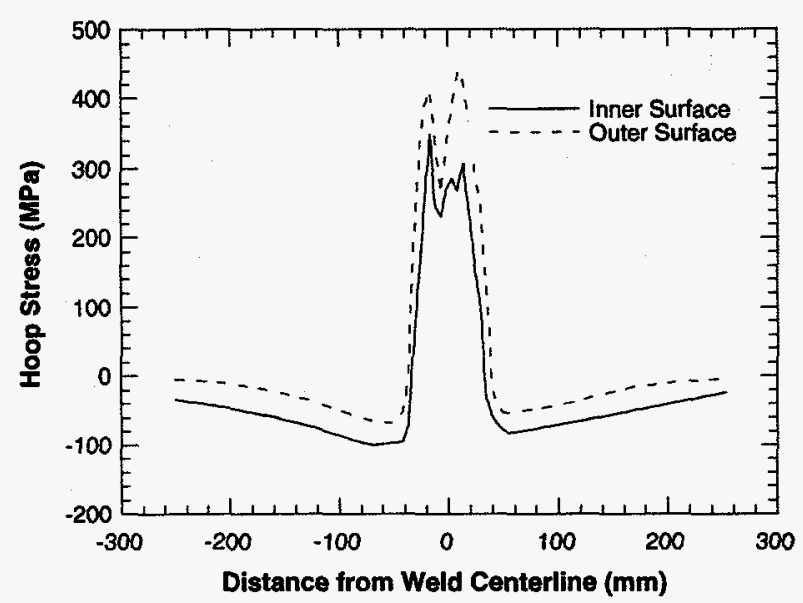

(b)

Figure 70. Residual stress distributions along inner and outer surfaces of core shroud: (a) axial stress, (b) hoop stress 


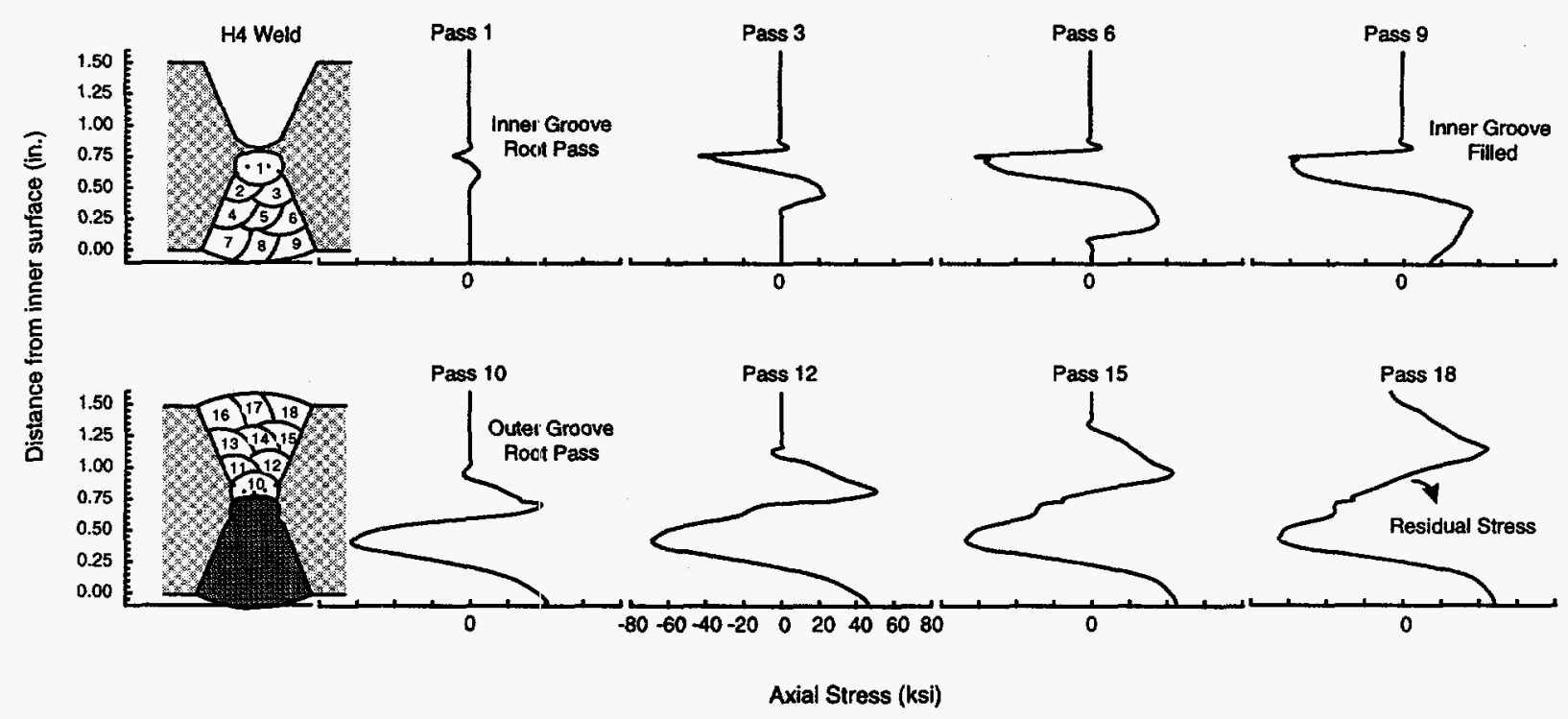

Figure 71. Evolution of axial residual stress through shroud wall at $\mathrm{H} 4$ weld centerline

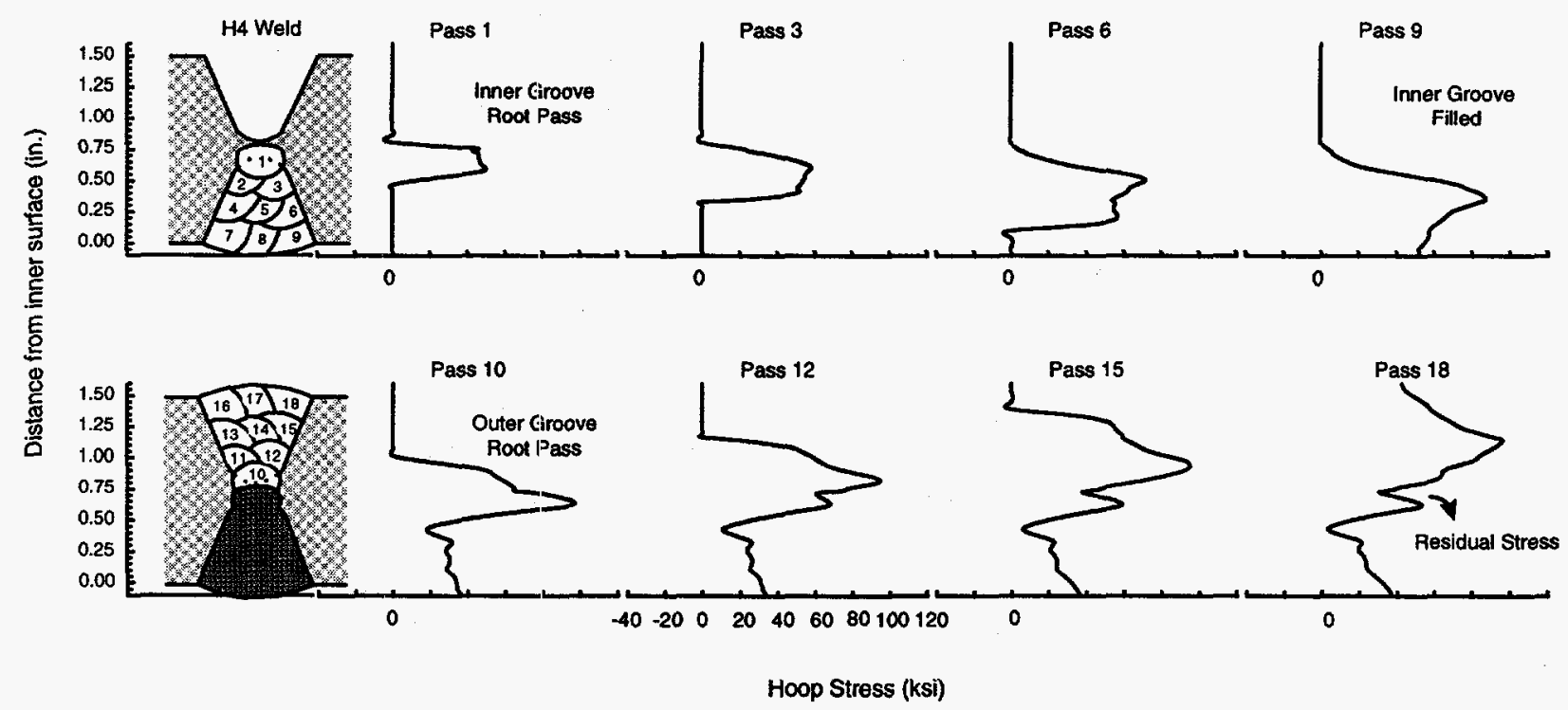

Figure 72. Evolution of hoop residual stress through shroud wall at $\mathrm{H} 4$ weld centerline

\subsection{Effects of Specimen Removal on Residual Stress Distributions}

Residual stress measurements of core shroud welds generally require that a portion of the shroud wall which contains the weld be removed from the structure. The process of specimen removal may alter the in-situ residual stress field. The degree of relaxation depends on the size of the specimen and on the characteristics of the surrounding residual stress field. To better quantify the effects of specimen removal, the removal process was analyzed with a 3-D shell element model.

Figure 73 shows the finite-element mesh for the shell element model used in this analysis. Only one-eighth of the entire core shroud was modeled due to size limitations of the finite- 


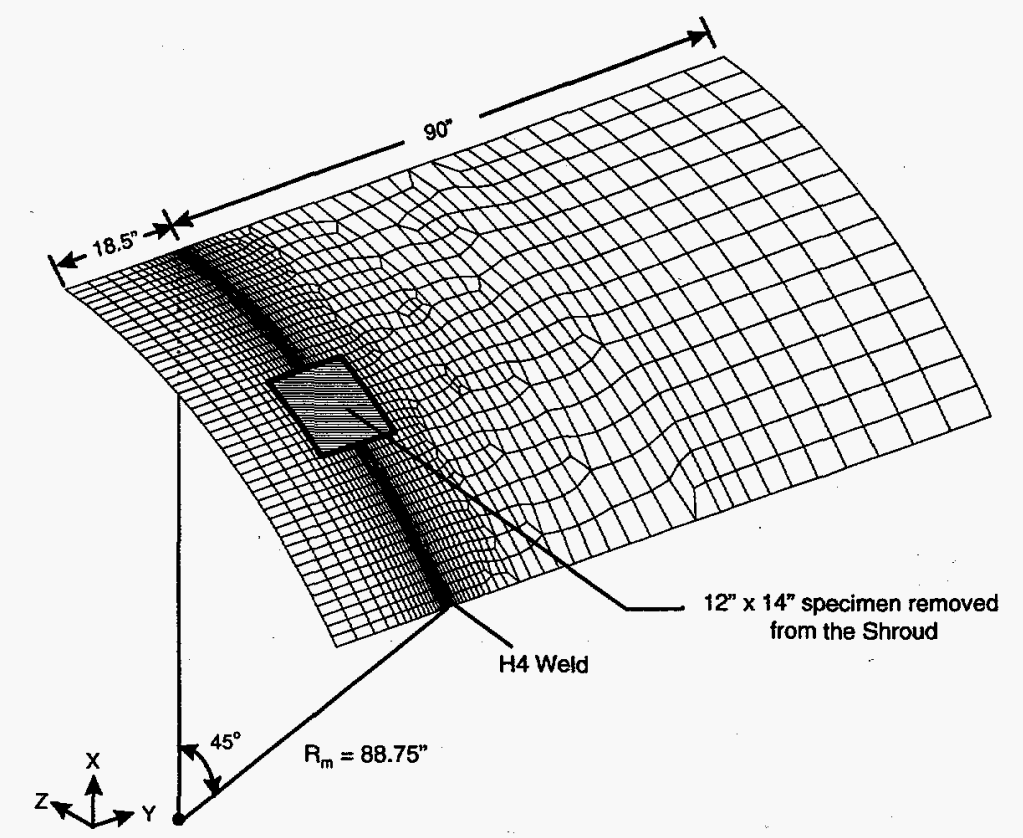

Figure 73.

3-D shell element model used to evaluate effect of specimen

removal on residual stress

distribution in $\mathrm{H} 4$ weld

element model. The finite-element mesh consists of 2001 shell elements and 2086 nodes. As in the axisymmetrical model, a refined mesh was used in and around the weld area. Eleven sectional integration points were used through the shell thickness to accurately capture through-wall stress variations. The $0.3-\mathrm{m} \times 0.4-\mathrm{m}(12-\mathrm{in} . \mathrm{x} 14-\mathrm{in}$.) shroud specimen that was removed was located at the center of the shell model, as indicated in Fig. 73.

Symmetrical displacement boundary conditions were imposed in the circumferential direction at the nodes along the two edges at $\theta=0^{\circ}$ and $\theta=45^{\circ}$ As in the axisymmetric model, all of the nodal displacements at the $\mathrm{H} 3$ end were fixed; those at the $\mathrm{H} 5$ end were left free. The shell element analysis was also performed with ABAQUS, along with some utility programs developed at $\mathrm{BCL}$. The detailed residual stress field obtained from the axisymmetrical model was mapped onto the 3-D shell element model as an initial stress field, and equilibrium iterations for the mapped residual stresses on the shell model were performed. The specimen was then removed from the model (i.e., stresses equal and opposite to those exerted on the specimen by the surrounding material were applied to obtain stress-free boundary conditions), and the resulting changes in the stress fields were computed.

Figures $74 \mathrm{a}$ and $74 \mathrm{~b}$ show the contour plots of axial stress distributions at the inner surface of the shroud before and after specimen removal. Note that the axial stresses are plotted with the same contour scale. After removal, the compressive axial residual stresses at the inner surface were released along two cutting edges in the hoop direction to achieve stress-free surface conditions, but the tensile axial stress at the center of specimen (in the weld) was increased (a darker color). Figures $75 \mathrm{a}$ and $75 \mathrm{~b}$ show the through-thickness distributions of both axial and hoop stresses at the center of specimen before and after removal. For the axial component, both the tensile stress at the inner surface and the compressive stress at the outer surface increased. For the hoop component, however, the tensile stress at the outer surface decreased, and the tensile stress at the inner surface increased slightly. The overall changes were fairly small. 


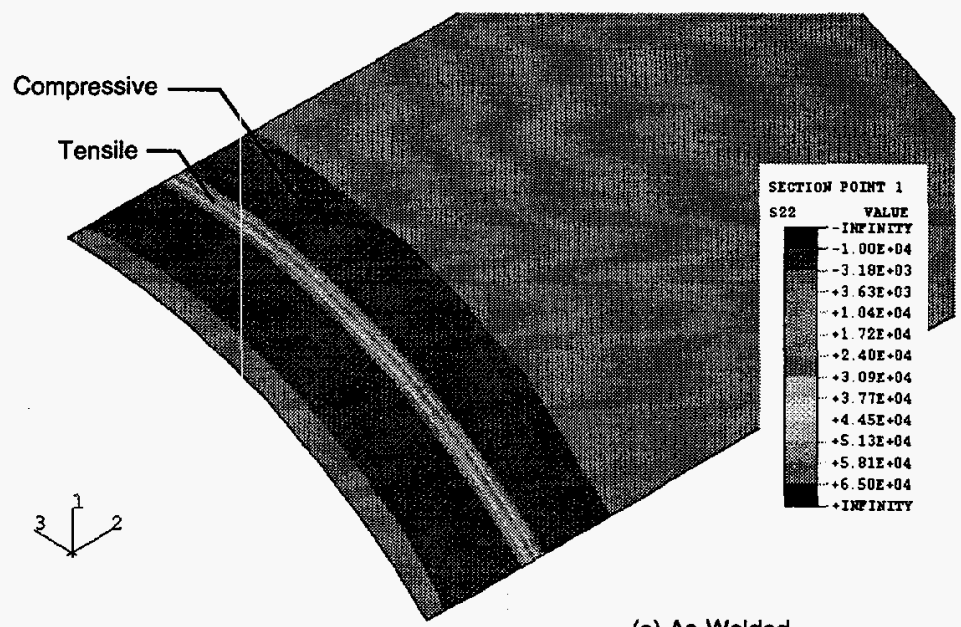

(a) As-Welded

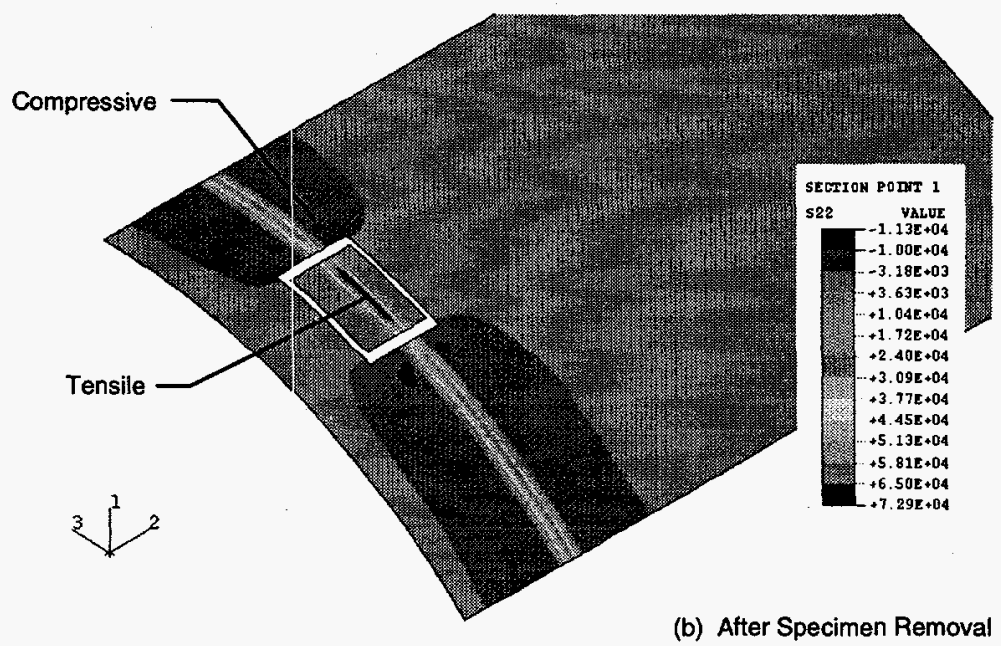

Figure 74. Axial residual stress distribution at inner surface of core shroud

The effects of specimen removal on the residual stress redistribution may be explained by the free-body diagram shown in Fig. 76. The effects of cutting along the specimen boundary can be approximately represented by equivalent sectional moments or forces obtained from the residual stress field and acting in a reversed direction. At the two circumferential cutting edges, sectional bending moments are present due to tensile axial residual stresses at the outer surface and compressive axial residual stresses at the inner surface (Fig. 70a). Along the other two edges (longitudinal cuts), sectional normal forces are present in the hoop direction and their distributions are similar to those of the hoop stresses in Fig. 70b. From the free-body diagram, 


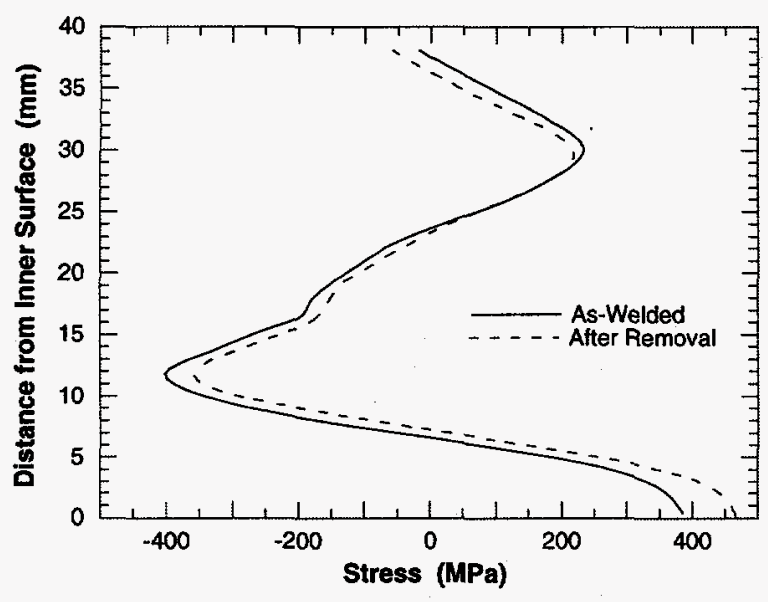

(a)

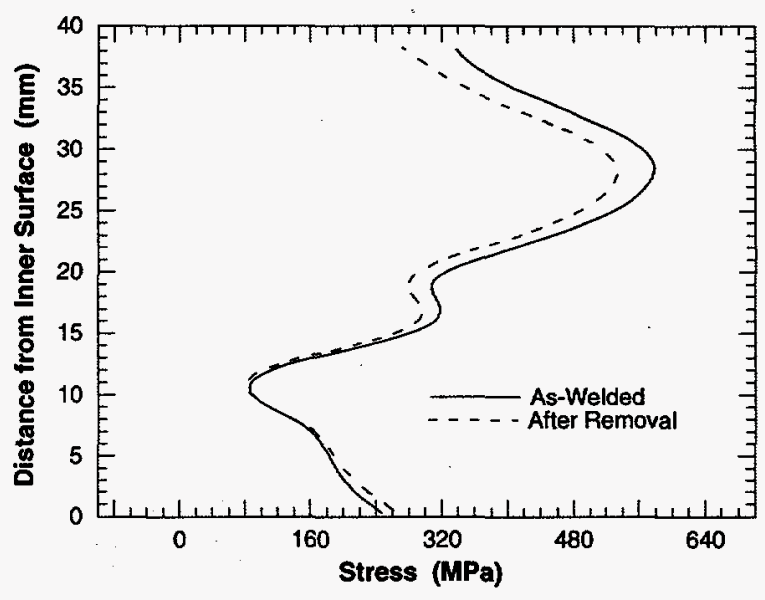

(b)

Figure 75. Throughwall residual stresses at center of a specimen removed from core shroud

it is clear that additional tensile and compressive axial stresses are introduced at the inner and outer surfaces, respectively (due to the equivalent bending moments at the circumferential cutting edges). The equivalent normal forces at the longitudinal cuts also produce a resultant bending moment at the specimen center due to the specimen curvature. This resultant bending moment causes a decrease in tensile hoop residual stress at the outer surface. Because of this relaxation, the radius of curvature of the specimen is increased after removal, as was observed experimentally for a specimen from a core shroud $\mathrm{H} 4$ weld. 61

\subsection{Calculation of Stress Intensity Factors for Welds with Flaws}

After the residual stress distributions in the uncracked weldment were determined, the finite-element alternating method (FEAM) ${ }^{62-66}$ was used to obtain stress intensity factors for weldments that contained flaws. FEAM methods have been verified for many different crack problems, loading conditions, etc. The major advantage of the method is that only a finiteelement mesh of the uncracked geometry is needed to obtain stress intensity factors (or the $\mathrm{J}$ Integral, displacements, stresses, etc). More important, the same mesh can be used to obtain solutions for cracks of many different sizes and geometries. Because the finite-element stiffness matrix needs to be reduced only once, regardless of the crack size, crack location, crack orientation, crack number, etc., the method is extremely efficient (mixed-mode conditions can be handled as well).

The stress intensity factors due the weld residual stresses for an internal circumferential crack on the H3 side of the weld in the HAZ obtained with the FEAM are shown in Fig. 77 as a function of crack depth. The crack location (19-mm [0.75-in.]) from the weld centerline on the H3 side is shown in Fig. 78, which also illustrates the redistribution of axial residual stresses associated with a 10.4-mm (0.41-in.) crack. The crack faces are stress-free. The stress directly ahead of the crack tip decreased to $\approx 138 \mathrm{Mpa}(20 \mathrm{ksi})$. The tensile stresses at the outer surface decreased somewhat as well.

In Fig. 77, in addition to the FEAM solution, two other solutions are plotted. One solution was obtained using the NASA FLAGRO program, 67 which uses a weight function method with the crack plane residual stresses serving as the initial stress state. Another was calculated with 


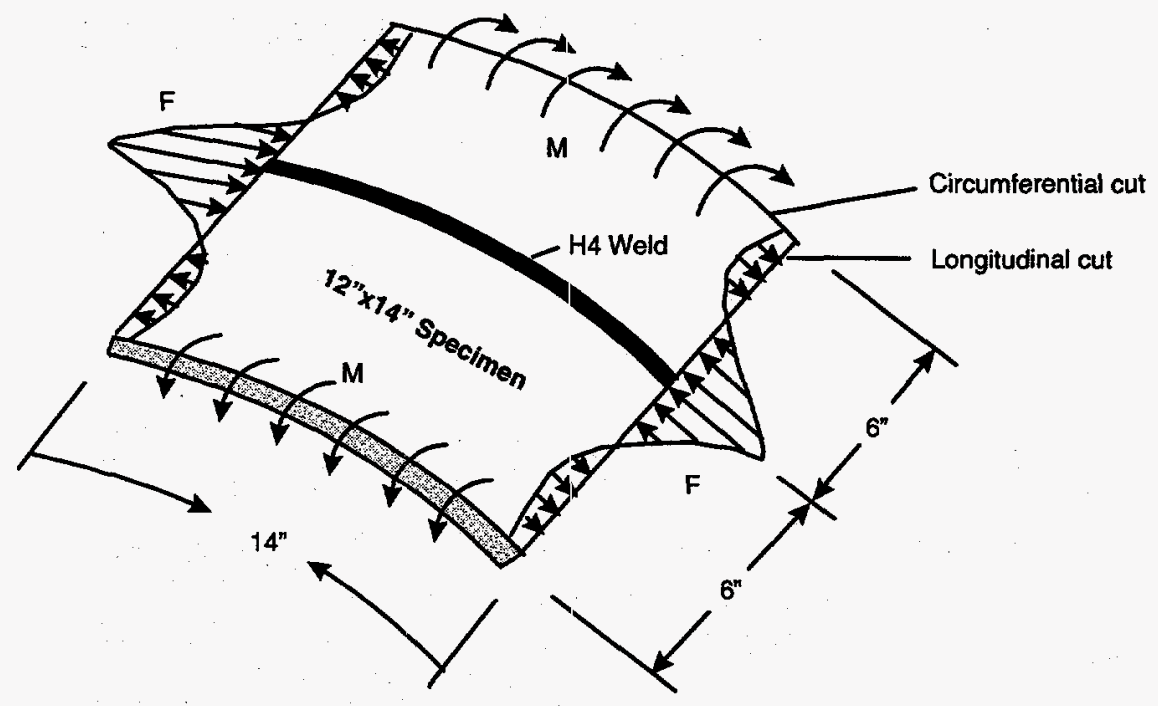

Figure 76.

Equivalent boundary forces and moments on removed specimen

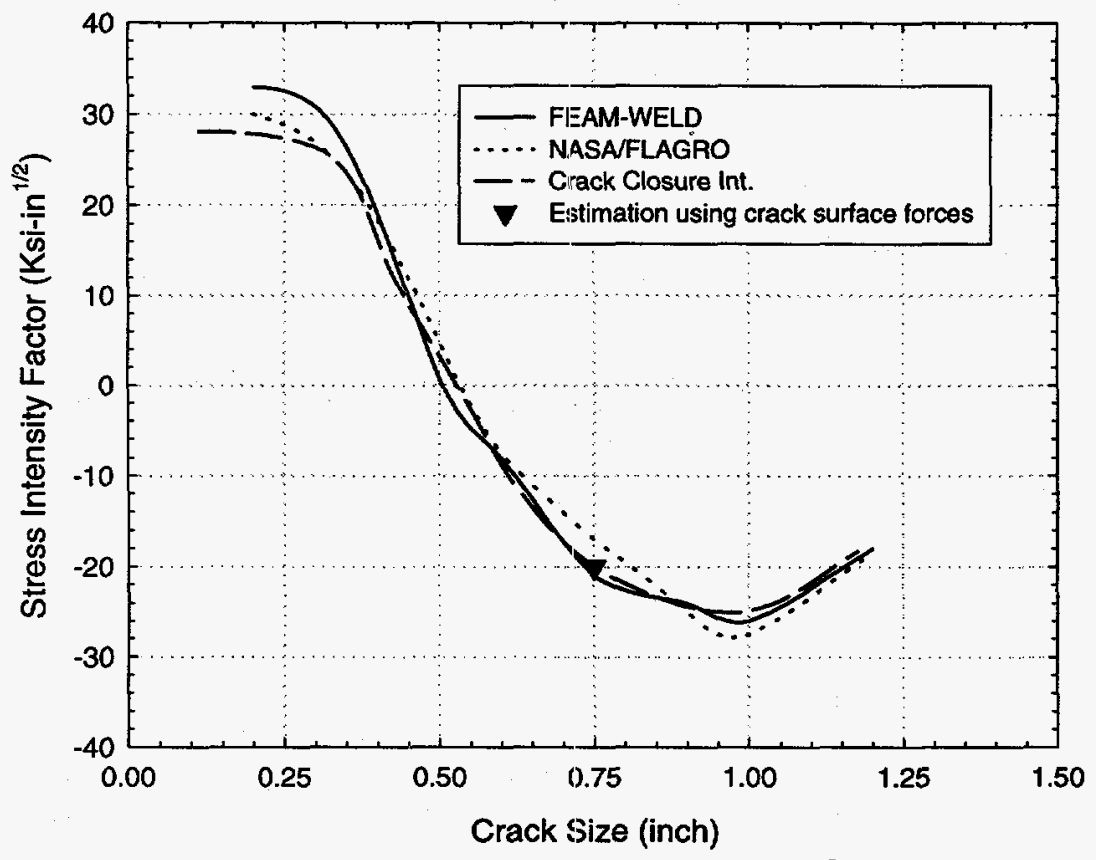

Figure 77.

Stress intensity factor solutions for complete circumferential cracks in $\mathrm{H} 4$ weld growing from the inner surface on $H 3$ side $H A Z$ (19mm [0.75-in.] from weld centerline) as function of crack depth

the original crack closure integral technique. ${ }^{68}$ This required a reanalysis in which double nodes were placed along the crack plane and released to obtain the energy release rate, and subsequently, $\mathrm{K}$. This method is quite tedious compared with the FEAM method. The FEAM solution is probably the most accurate, although the three methods give comparable results. The stress intensity factor decreases as the crack depth increases until it reaches negative values for crack depths $>\approx 15-\mathrm{mm}$. This is consistent with the results shown in Fig. 78 , where the stresses at the crack tip for a crack depth of 10.4-mm (0.41-in.) are decreasing and the stresses a small distance ahead of the crack tip are negative.

The stress intensity factors for external cracks at the same axial location on the $\mathrm{H} 3$ side of the weld are plotted versus crack depth in Fig. 79. The variation of $K$ with crack depth is similar to that for internal cracks both in magnitude and shape. However, the $\mathrm{K}$ values approach zero for a crack depth of $\approx 22.9-\mathrm{mm}(0.9-\mathrm{in}$.) for the external cracks versus $15.2-\mathrm{mm}(0.6-\mathrm{in}$.) for the internal cracks. 


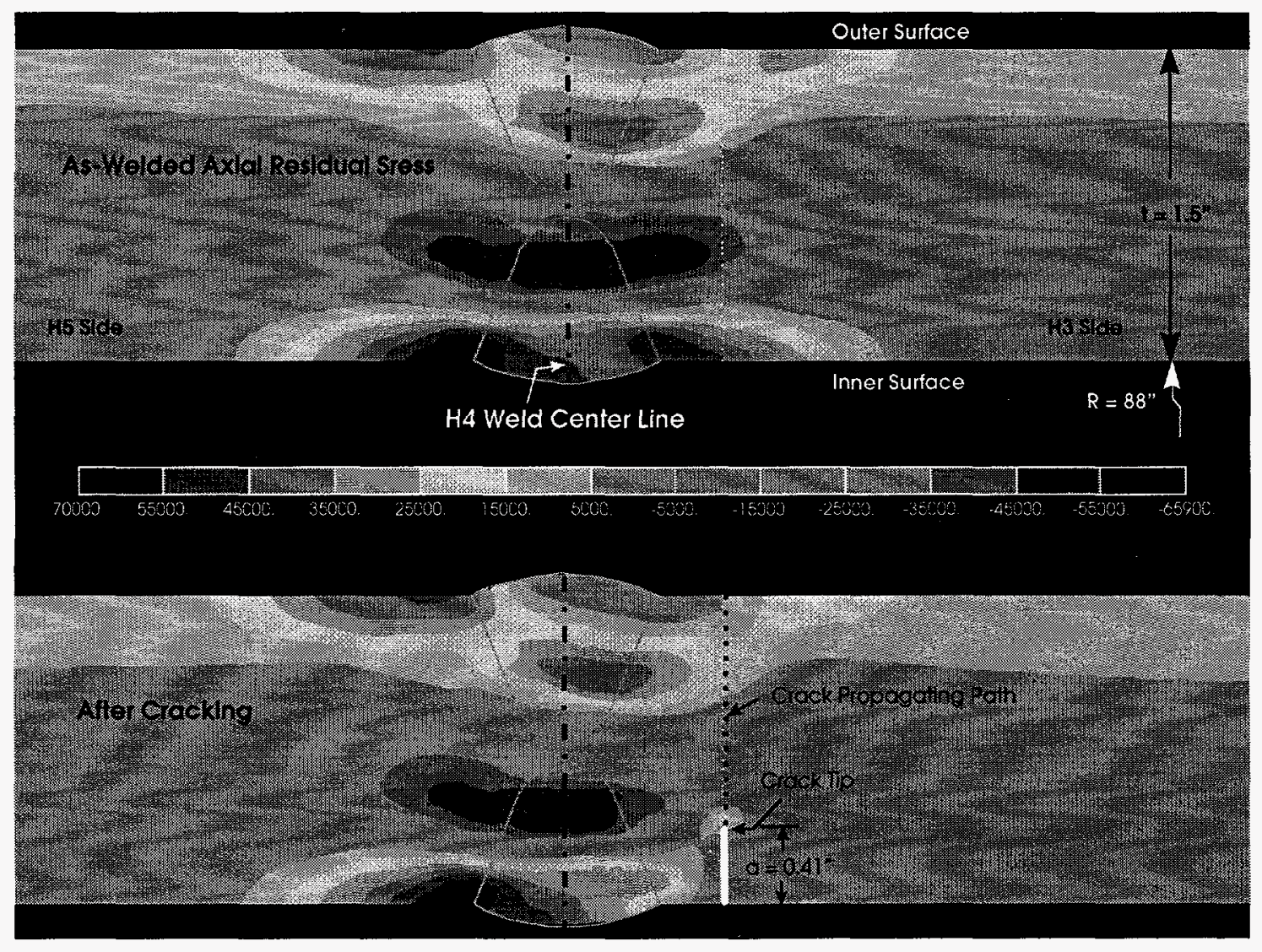

Figure 78. Redistribution of residual stress due to crack growth

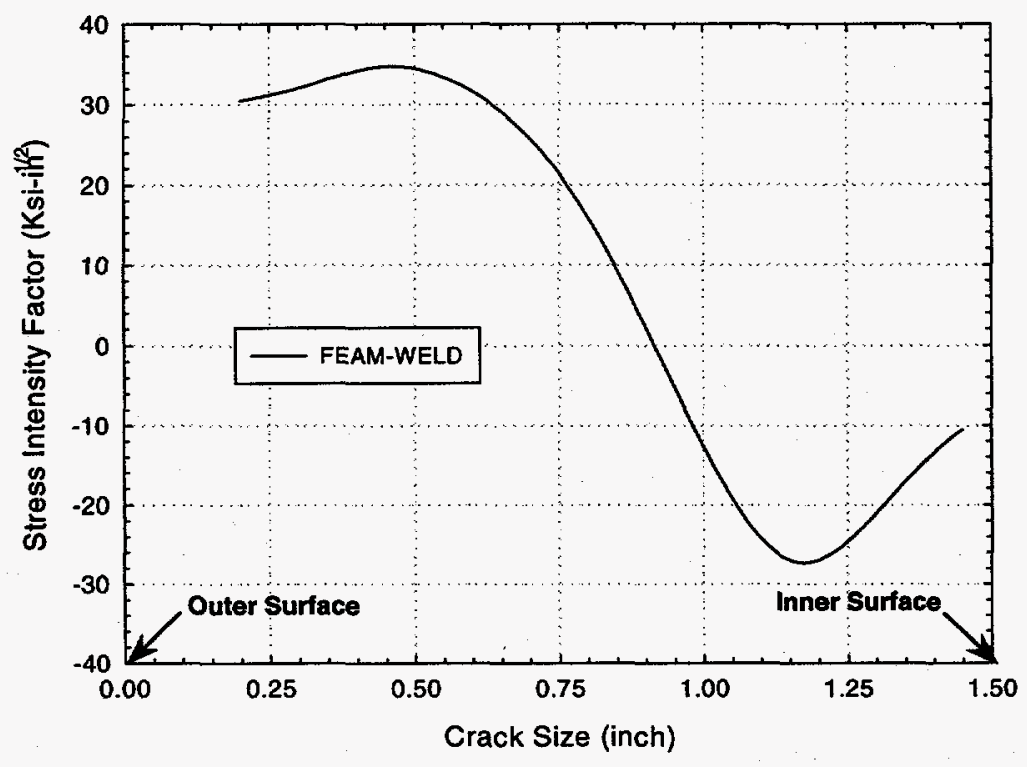

Figure 79.

Stress intensity factor solutions for complete circumferential cracks in $\mathrm{H} 4$ weld growing from the outer surface on the H5 side HAZ (15.5$\mathrm{mm}[0.61-i n$.$] from weld$ centerline) as function of crack depth 


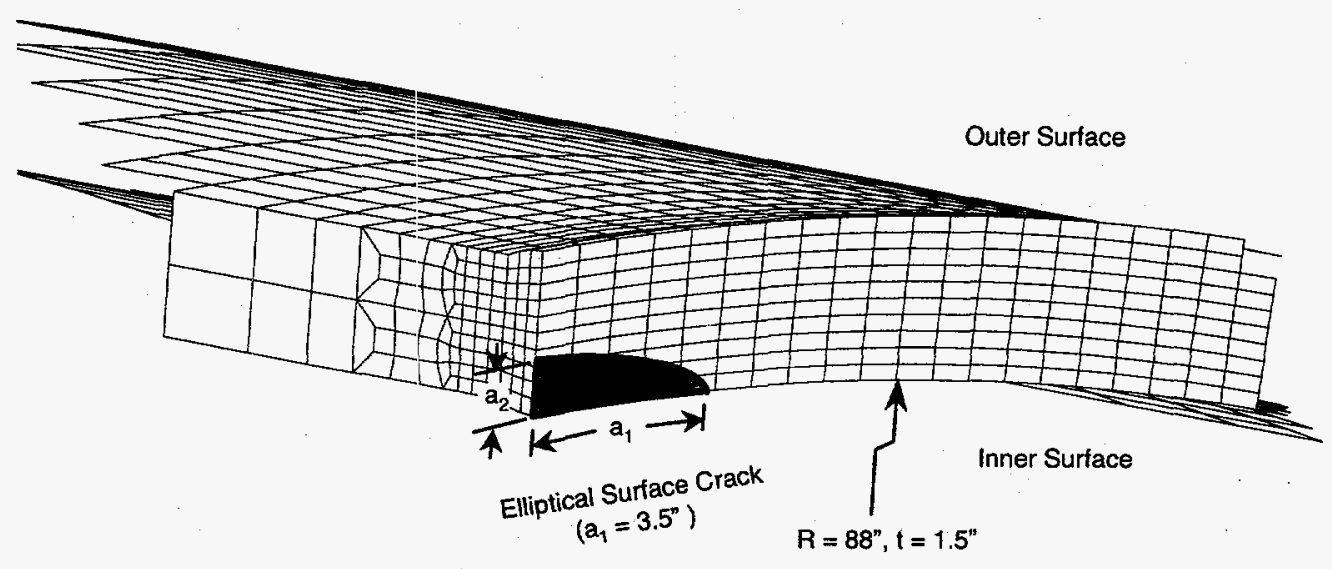

$\mathrm{r}_{\mathrm{z}}^{\mathrm{x}}$

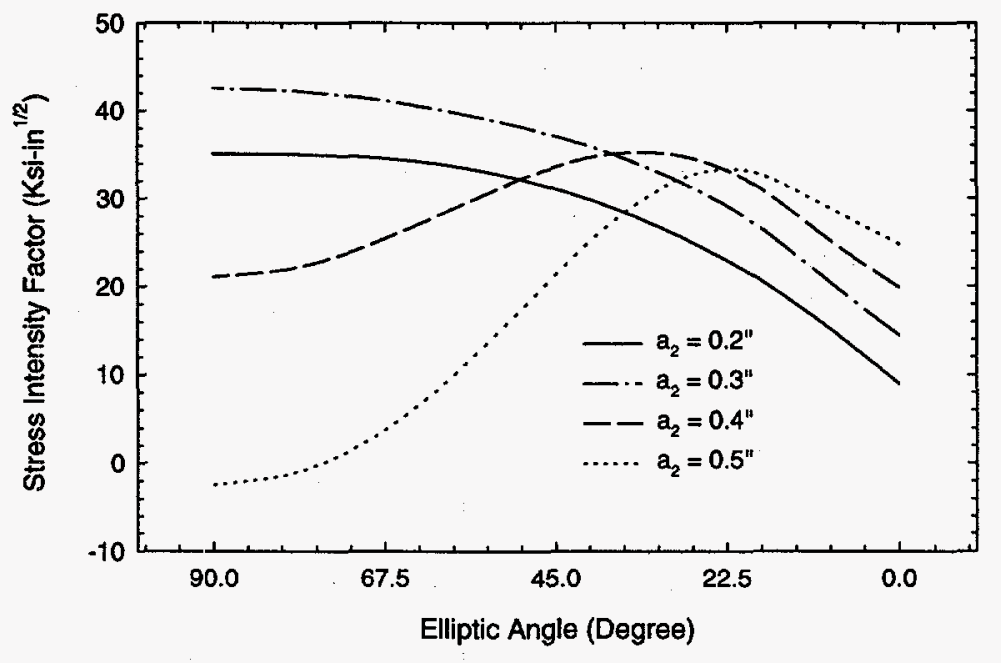

Figure 80. Stress iniensity factors for surface cracks in weld centerline of H4 weld

To analyze the case of a surface crack of length $a_{1}$, the residual stress state from the axisymmetrical case (Fig. 67) was mapped onto a 3-D model. The 3-D mesh is shown at the top of Fig. 80. For this analysis, the stresses were also assumed to be symmetrical about the weld centerline. The stresses on the $\mathrm{H3}$ side of the weld were used for the symmetrical distribution. The mesh refinement in the radial and axial directions for the axisymmetrical model was greater than for the 3-D model. Hence, the mapped stresses in the 3-D model represent averages of the stresses over several elements in the axisymmetrical model, and the 3-D solution is expected to be somewhat less accurate than the solution for the axisymmetrical model. The surface crack was then introduced into the model (at the weld centerline) as illustrated in the upper portion of Fig. 80. The crack length was fixed at $88.9-\mathrm{mm}(3.5-\mathrm{in}$.$) and the crack depth, a_{2}$ was varied. The FEAM approach was used to obtain stress intensity factors as a function of elliptic crack 
angle, as illustrated at the bottom of Fig. 80. Although the stress state in the uncracked case was axisymmetric, the stress redistribution that occurs when the surface crack is introduced is not axisymmetric. Hence, $\mathrm{K}$ varies with the elliptic crack angle. An elliptical angle of $90^{\circ}$ indicates the deepest point of the crack $\left(a_{t} a_{2}\right)$ and an angle of $0^{\circ}$ corresponds to the inner surface of the pipe (at location $a_{1}$ ). The $K$ values are larger here at the deepest point of the crack are larger than those in Fig. 78 (note that a very long $a_{1}$ would represent an axisymmetric crack). This is expected because the stresses at the weld centerline are larger than those at the H3-side HAZ crack.

The $\mathrm{K}$ values at the deepest point of the crack decrease as the crack depth increases (recall that the crack length $a_{1}$ is kept constant in these calculations). However, as the crack depth increases, $\mathrm{K}$ increases at elliptic angles of $\approx 40^{\circ}$ or less. For crack depths of $10-13 \mathrm{~mm}$ (0.4-0.5 in.), the $\mathrm{K}$ at the deepest point of the crack is markedly smaller than the $\mathrm{K}$ near the surface of the pipe. These results suggest that cracks, if driven by corrosion mechanisms that depend on $\mathrm{K}$, will tend to increase in length in the angular direction much more rapidly than they grow throughwall. Indeed, there will be a tendency for full $360^{\circ}$ cracks to develop. For the axisymmetrical case with a complete $360^{\circ}$ crack, the results indicate that a crack that grows from the inside to the outside of the vessel surface, or vice versa, would be likely to stop approximately midwall, because $\mathrm{K}$ becomes negative for deeper cracks.

Several other issues should be addressed before definitive conclusions can be reached. The effect of elastic-plastic crack growth was not considered here. The welding process induces significant plastic deformation in the vessel, and, as stress corrosion cracks grow in the vessel, the crack-opening stresses at the tip will cause additional plasticity near the crack tip. The size of this plastic zone will determine whether nonlinear effects will be significant in the analysis. However, elastic effects should dominate as the cracks get deeper, and the crack opening stresses become small. In addition, the effect of 3-D variations in the residual stress fields, e.g., those associated with the start/stop positions, on the growth of the surface crack is unknown. Finally, the effect on crack growth of the additional constraint caused by other welds in the vessel after full fabrication should be considered.

\section{Summary of Results}

\subsection{Environmental Effects on Fatigue S-N Behavior of Primary Pressure Boundary Materials}

Fatigue tests have been conducted to determine the crack initiation and crack growth characteristics of A533-Gr B LAS and A106-Gr B CS in air and LWR environments. Crack length as a function of fatigue cycles was determined in air and water environments. The significant results are summarized below.

(a) In air, fatigue cracks, $10 \mu \mathrm{m}$ or longer, form quite early during fatigue $(<10 \%$ of life) even at low strain ranges $(\approx 0.4 \%)$. The largest crack is $<100 \mu \mathrm{m}$ at half life. The results suggest that linear damage summation should be valid for strain or stress ranges above the fatigue limit, e.g., the crack-depth-versus-life-fraction plots are approximately the same over a wide range of strain or stress. 
(b) The decrease in fatigue life of CSs and LASs in high-DO water is primarily caused by the effects of environment on the growth of short cracks. During the initial stages of fatigue damage (for cracks $<100 \mu \mathrm{m}$ ), crack growth rates in high-DO water are nearly two orders of magnitude higher than in air. For crack sizes $>100 \mu \mathrm{m}$, the growth rate is one order of magnitude higher in high-DO water than in air.

(c) In high-DO water, the surface cracks appear to grow entirely as Mode I tensile cracks normal to the stress axis. In air or low-DO water, growth of surface cracks initially occurs as a shear crack at $\approx 45^{\circ}$ to the stress axis.

(d) The results from the present study are consistent with the slip-dissolution model for enhanced crack growth rates in LWR environments.

Fatigue tests have also been conducted on Types $316 \mathrm{NG}$ and 304 SS to establish the effects of LWR coolant environments on fatigue lives of these steels. The results indicate significant decrease in fatigue life in water when compare with that in air; the decrease in life depends both on strain rate and DO content of the water. Environmental effects on fatigue life are the same for Types 304 and 316NG SS. However, unlike CSs and LASs, environmental effects are more pronounced in low-DO than in high-DO water. At $\approx 0.004 \% / \mathrm{s}$ strain rate, reduction in fatigue life in water that contains $<10 \mathrm{ppb} D O$ is greater by a factor of $\approx 2$ than in water with $\geq 200 \mathrm{ppb}$ DO. In a simulated PWR environment, a decrease in strain rate from 0.4 to $0.004 \% / \mathrm{s}$ decreases fatigue life by a factor of $\approx 8$. Experimental results have been compared with estimates of fatigue life that are based on a statistical model.

A detailed examination of the fatigue test specimens was conducted to investigate the role of high-temperature oxygenated water in fatigue cracking. The formation and growth of surface cracks in simulated PWR water and air differ. In a simulated PWR environment $(<10 \mathrm{ppb} \mathrm{DO})$, the surface cracks appear to grow entirely as tensile cracks in Stage II growth normal to the stress axis. In air and, for most cases, in high-DO water, surface cracks initially grow along slip planes as shear cracks in Stage I growth along planes at $45^{\circ}$ to the stress axis. In all environments, cracks primarily formed within PSBs. Additional tests are in progress to characterize the formation and growth of surface cracks in LWR environments. Fatigue tests are also being conducted to define a threshold strain amplitude below which environmental effects on fatigue life do not occur, and the threshold strain rate below which effects of environment saturate.

\subsection{Irradiation Assisted Stress Corrosion Cracking}

Slow-strain-rate-tensile tests were conducted in simulated BWR water at $288^{\circ} \mathrm{C}$ on model SS alloys that were irradiated at $288^{\circ} \mathrm{C}$. in helium to a fluence of $\approx 0.45 \times 10^{21} \mathrm{n} \cdot \mathrm{cm}^{-2}$ $(\mathrm{E}>1 \mathrm{MeV}$ ) in the Halden reactor. Initial results indicate that the ductility of irradiated $\mathrm{CP}$ Type 304 SS sheet specimens is higher than that of BWR neutron-absorber tubes at a comparable fluence level. High-purity Type 316 SS was more susceptible to IGSCC. This behavior is similar to that observed for HP heats of Type 304 SS. Type 304 SS heats high in carbon content were more susceptible to TGSCC but less susceptible to IGSCC. Unusually high levels of oxygen and sulfur in SS appear to have a deleterious effect on SCC of Type 304 SS, even in the nonirradiated state, during SSRT tests in HP oxygenated water at $288^{\circ} \mathrm{C}$. 
Shielded-metal-arc welds were prepared from Types 304, 304L, and 316 SS to simulate BWR core-shroud welds. Significant contamination by oxygen, sulfur, and fluorine was observed in the HAZ of the SMA welds. The source of this contamination is the coating on the welding electrode and the air atmosphere. In contrast, contamination in GTA welds was insignificant.

Microhardness profiles of the fusion zone and HAZ of an SMA weld of Type 304 SS were determined. A region of maximum hardness was observed in the $H A Z$ at $\approx 0.8-3 \mathrm{~mm}$ away from the fusion zone. This region coincides with the region where cracking occurs in BWR core shroud welds. When the surface of the weld was smoothed with a grinding wheel, the hardness near the ground surface was significantly higher, indicating that a cold-worked surface layer can promote crack nucleation. The local hardening characteristics, together with contamination by oxygen, fluorine, and sulfur, may be important factors that increase susceptibility to SCC of core shroud welds in BWRs.

Auger electron spectroscopy analyses show that fluorine atoms segregate to grain boundaries in BWR neutron-absorber, tubes and in a core shroud weld; however, the mechanism of the segregation (i.e., thermal, irradiation-induced, or both) is not understood. Because the solubility of both fluorine and oxygen in steel is very low, it is likely that these elements will segregate by a thermal process to local sites such as matrix/precipitate interfaces, grain boundaries, and stacking faults; however, irradiation-induced segregation cannot be ruled out and further investigation is needed.

Equipment for fracture toughness $\mathrm{J}-\mathrm{R}$ testing of irradiated CT specimens in a hot cell has been assembled. Results of preliminary fracture toughness $J-R$ tests indicate that an elastic compliance method can be used to estimate crack length during $\mathrm{J}-\mathrm{R}$ tests or fatigue crack growth in LWR environments. These findings will be validated by (a) conducting fracture toughness $\mathrm{J}-\mathrm{R}$ curve tests at room temperature and $288^{\circ} \mathrm{C}$ on two heats of thermally aged CF$8 \mathrm{M}$ cast SS and on $50 \%$ cold-worked Type $316 \mathrm{NG}$ SS, and (b) performing fatigue crack growth studies on the same three materials at $288^{\circ} \mathrm{C}$ in air.

\subsection{Environmentally Assisted Cracking of Low-Carbon Alloy 600 in Simulated LWR Water}

Corrosion-fatigue experiments were conducted on CT specimens of a low-carbon content $(0.03 \mathrm{wt} . \%)$ heat of Alloy 600 in HP oxygenated water to investigate the effects of load ratio and heat treatment conditions on CGRs at $289^{\circ} \mathrm{C}$. The specimens were fabricated from blocks of material that were solution-annealed at 1025 and $1115^{\circ} \mathrm{C}$ for $2 \mathrm{~h}$ and heat treated at $600^{\circ} \mathrm{C}$ for $24 \mathrm{~h}$ after solution annealing at the two temperatures. Solution annealing at 1025 and $1115^{\circ} \mathrm{C}$ produced ASTM grain sizes of $\approx 1.0-1.5$ and 0.2 , respectively, which correspond to large average grain diameters of $\approx 250-210$ and $340 \mu \mathrm{m}$. Based on results from four specimens, these heat treatment conditions did not have a significant effect on the CGRs in HP oxygenated water. Other heats of material with differing carbon content and heat treatment conditions could produce a wider variation in the results.

"Best-fit" correlations for the CGRs in water that contained $\approx 300 \mathrm{ppb}$ DO versus $\Delta \mathrm{K}$ were obtained for each specimen and for the combined data from the four specimens of the same material with different heat treatments. The effect of HP oxygenated water on the CGRs 
relative to that in air was determined from a ratio of the CGRs at $289^{\circ} \mathrm{C}$ in water to the CGRs of another heat of Alloy 600 in air at $289^{\circ} \mathrm{C}$, and from a ratio of the CGRs from the combined data in water for all of the heat treatment conditions to that in air at $289^{\circ} \mathrm{C}$. The results indicate that the rates for Alloy 600 are higher in water than in air at $\Delta K$ values $<18 \mathrm{MPa} \cdot \mathrm{m}^{1 / 2}$ and are lower in water than in air at higher values of $\Delta \mathrm{K}$. At a $\Delta \mathrm{K}$ of $\approx 2 \mathrm{MPa} \cdot \mathrm{m}^{1 / 2}$, the rate is higher by a factor of $\approx 10$ in water than in air. At this $\Delta \mathrm{K}$, CGRs for specimens from other heats of Alloy 600 in HP water that contained $<5 \mathrm{ppb}$ DO were higher by a factor of $\approx 2$ than they were in air.

The morphology of corrosion-fatigue cracks in the Alloy 600 specimens was determined. Transgranular cracking occurred in air and HP oxygenated water because of the strong contribution of mechanical cyclic loading in tests at $R$ values of $0.2-0.8$ and the relatively small degree of crack extension that occurred in tests at $\mathrm{R}>0.8$.

\subsection{Modeling of Residual Stresses in Core Shroud Structures}

Under a subcontract to ANL, BCL has used numerical models to characterize weld residual stresses and the associated stress intensity factors at BWR core shroud welds. A detailed description of the weld residual stresses has been obtained for the $\mathrm{H} 4$ weld. Based on the residual stress results that were obtained, stress intensity factors were calculated.

The H4 weld is a multipass SA weld that joins two Type 304 SS cylinders. The axial residual stresses for this weld show a "thick-shell" type of distribution. In the middle of the wall, the axial residual stresses are compressive, whereas, at both inner and outer surfaces of the pipe, tensile stresses were present, except at the weld centerline, where a small-amplitude compressive stress is present on the outer surface. The stresses are tensile in the HAZs on the inner and outer surfaces. At these cross sections, the maximum tensile axial stresses are at the inner surface of the shroud wall.

After residual stress distributions in the uncracked weldment were determined, stress intensity factors $\mathrm{K}$ for weldments that contained flaws were determined. Complete $360^{\circ}$ cracks, as well as a surface crack extending over only a portion of circumference, were considered. For the axisymmetrical case with a complete $360^{\circ} \mathrm{crack}$, the results indicate that a crack growing from the inside to the outside vessel surface, or vice versa, would be likely to stop growing about midwall, because $\mathrm{K}$ becomes negative for deeper cracks. For the surface crack that extends over only a portion of the circumference, the $K$ values at the deepest point of the crack decrease as the crack depth increases. However, the $K$ values along the crack front near the surface remain positive, and in fact, increase as the crack grows deeper. These results suggest that cracks, if driven by corrosion mechanisms that depend on $K$, will tend to increase in length in the angular direction much more rapidly than they grow throughwall. Indeed, there will be a tendency for full $360^{\circ}$ cracks to develop; the average depth of the cracks is expected to be $\approx 50 \%$ of the wall thickness, although local perturbations in the stress distributions could produce localized regions of deeper cracking. 


\section{References}

1. ASME Boiler and Pressure Vessel Code Section III - Rules for Construction of Nuclear Power Plant Components, The American Society of Mechanical Engineers, New York, 1992 Ed.

2. B. F. Langer, Design of Pressure Vessels for Low-Cycle Fatigue, ASME J. Basic Eng. 84, 389-402 (1962).

3. Tentative Structural Design Basis for Reactor Pressure Vessels and Directly Associated Components (Pressurized, Water Cooled Systems), PB 151987, U.S. Dept. of Commerce, Office of Technical Service, 1 Dec. 1958 Revision.

4. S. Ranganath, J. N. Kass, and J. D. Heald, Fatigue Behavior of Carbon Steel Components in High-Temperature Water Environments, in BWR Environmental Cracking Margins for Carbon Steel Piping, EPRI NP-2406, Electric Power Research Institute, Palo Alto, CA, Appendix 3 (May 1982).

5. W. A. Van Der Sluys, Evaluation of the Available Data on the Effect of the Environment on the Low Cycle Fatigue Properties in Light Water Reactor Environments, in Proc. 6th Int. Symp. on Environmental Degradation of Materials in Nuclear Power Systems - Water Reactors, R. E. Gold and E. P. Simonen, eds., The Metallurgical Society, Warrendale, PA, pp. 1-4 (1993).

6. M. Higuchi and K. Iida, Fatigue Strength Correction Factors for Carbon and Low-Alloy Steels in Oxygen-Containing High-Temperature Water, Nucl. Eng. Des. 129, 293-306 (1991).

7. M. Higuchi, K. Iida, and Y. Asada, Effects of Strain Rate Change on Fatigue Life of Carbon Steel in High-Temperature Water, in Fatigue and Crack Growth: Environmental Effects, Modeling Studies, and Design Considerations, PVP Vol. 306, S. Yukawa, ed., American Society of Mechanical Engineers, New York, pp. 111-116 (1995).

8. O. K. Chopra and W. J. Shack, Effects of LWR Environments on Fatigue Life of Carbon and Low-Alloy Steels, in Fatigue and Crack Growth: Environmental Effects, Modeling Studies, and Design Considerations, PVP Vol. 306, S. Yukawa, ed., American Society of Mechanical Engineers, New York, pp. 95-109 (1995).

9. O. K. Chopra and W. J. Shack, Evaluation of Effects of LWR Coolant Environments on Fatigue Life of Carbon and Low-Alloy Steels, in Proc. of Symp. on Effects of the Environment on the Initiation of Crack Growth, ASTM STP 1298, W. A. Van Der Sluys, R. S. Piascik, and R. Zawierucha, eds., American Society for Testing and Materials, Philadelphia, pp. 247-266 (1997).

10. P. D. Hicks, Fatigue of Ferritic Steels, in Environmentally Assisted Cracking in Light Water Reactors: Semiannual Report October 1990-March 1991, NUREG/CR-4667 Vol. 12, ANL-91/24, pp. 3-18 (Aug. 1991). 
11. W. J. Shack and W. F. Burke, Fatigue of Type 316NG SS, in Environmentally Assisted Cracking in Light Water Reactors, Semiannual Report, October 1989-March 1990, NUREG/CR-4667 Vol. 10, ANL-91/5, pp. 3-19 (March 1991).

12. K. Iida, A Review of Fatigue Failures in LWR Plants in Japan, Nucl. Eng. Des. 138, 297-312 (1992).

13. O. K. Chopra, W. F. Michaud, and W. J. Shack, Fatigue of Ferritic Steels, in Environmentally Assisted Cracking in Light Water Reactors, Semiannual Report, October 1992-March 1993, NUREG/CR-4667 Vol. 16, ANL-93/27, pp. 3-19 (Sept. 1993).

14. O. K. Chopra, W. F. Michaud, W. J. Shack, and W. K. Soppet, Fatigue of Ferritic Steels, in Environmentally Assisted Cracking in Light Water Reactors, Semiannual Report, AprilSeptember 1993, NUREG/CR-4667 Vol. 17, ANL-94/16, pp. 1-22 (June 1994).

15. O. K. Chopra, W. F. Michaud, and W. J. Shack, Fatigue of Ferritic Steels, in Environmentally Assisted Cracking in Light Water Reactors, Semiannual Report, October 1993-March 1994, NUREG/CR-4667 Vol. 18, ANL-95/2, pp. 3-10 (March 1995).

16. O. K. Chopra, D. J. Gavenda, and W. J. Shack, Fatigue of Ferritic Steels, in Environmentally Assisted Cracking in Light Water Reactors, Semiannual Report, AprilSeptember 1994, NUREG/CR-4667 Vol. 19, ANL-95/25, pp. 1-19 (Sept. 1995).

17. O. K. Chopra, D. J. Gavenda, and W. J. Shack, Fatigue of Ferritic Steels, in Environmentally Assisted Cracking in Light Water Reactors, Semiannual Report, October 1994-March 1995, NUREG/CR-4667 Vol. 20, ANL-95/41, pp. 1-19 (Jan. 1996).

18. O. K. Chopra and W. J. Shack, Fatigue of Ferritic Steels, in Environmentally Assisted Cracking in Light Water Reactors, Semiannual Report, April-December 1995, NUREG/CR-4667 Vol. 21, ANL-96/1, pp. 1-27 (July 1996).

19. O. K. Chopra et al, Environmental Effects on Fatigue Strain-versus-Life (S-N) Behavior of Primary Pressure Boundary Materials, in Environmentally Assisted Cracking in Light Water Reactors, Semiannual Report, January 1996-June 1996, NUREG/CR-4667 Vol. 22, ANL-97/9, pp. 2-39 (May 1997).

20. S. Majumdar, O. K. Chopra, and W. J. Shack, Interim Fatigue Design Curves for Carbon, Low-Alloy, and Austenitic Stainless Steels in LWR Environments, NUREG/CR-5999, ANL-93/3 (April 1993).

21. J. Keisler, O. K. Chopra, and W. J. Shack, Fatigue Strain-Life Behavior of Carbon and Low-Alloy Steels, Austenitic Stainless Steels, and Alloy 600 in LWR Environments, NUREG/CR-6335, ANL-95/15 (Aug. 1995).

22. J. Keisler, O. K. Chopra, and W. J. Shack, Statistical Models for Estimating Fatigue StrainLife Behavior of Pressure Boundary Materials in Light Water Reactor Environments, Nucl. Eng. Des. 167, 129-154 (1996). 
23. W. A. Van Der Sluys and S. Yukawa, Status of PVRC Evaluation of LWR Coolant Environmental Effects on the S-N Fatigue Properties of Pressure Boundary Materials, in Fatigue and Crack Growth: Environmental Effects, Modeling Studies, and Design Considerations, S. Yukawa, ed., American Society of Mechanical Engineers, New York, pp. 47-58 (1995).

24. A. G. Ware, D. K. Morton, and M. E. Nitzel, Application of NUREG/CR-5999 Interim Design Curves to Selected Nuclear Power Plant Components, NUREG/CR-6260, INEL-95/0045 (March 1995).

25. A. F. Deardorff and J. K. Smith, Evaluation of Conservatisms and Environmental Effects in ASME Code, Section III, Class 1 Fatigue Analysis, SAND94-0187, prepared by Structural Integrity Associates, San Jose, CA, under contract to Sandia National Laboratories, Albuquerque, NM (August 1994).

26. M. E. Mayfield, E. C. Rodabaugh, and R. J. Eiber, A Comparison of Fatigue Test Data on Piping with the ASME Code Fatigue Evaluation Procedure, ASME paper 79-PVP-92, American Society of Mechanical Engineers, New York (1979).

27. L. F. Kooistra, E. A. Lange, and A. G. Pickett, Full-Size Pressure Vessel Testing and Its Application to Design, J. Eng. Power 86, 419-428 (1964).

28. K. J. Miller, Initiation and Growth Rates of Short Cracks, in Fundamentals of Deformation and Fracture, B. A. Bilby, K. J. Miller, and J. R. Willis, eds., Cambridge United Press, pp. 476-500 (1984).

29. K. J. Miller, Damage in Fatigue: A New Outlook, in International; Pressure Vessels and Piping Codes and Standard: Volume 1 - Current Applications, PVP Vol. 313-1, K. R. Rao and Y. Asada, eds., American Society of Mechanical Engineers, New York, pp. 191-192 (1995).

30. K. Tokaji, T. Ogawa, and Y. Harada, The Growth of Small Fatigue Cracks in a Low Carbon Steel; The Effect of Microstructure and Limitations of Linear Elastic Fracture Mechanics, Fatigue Fract. Eng. Mater. Struct. 9, 205-217 (1986).

31. K. Tokaji and T. Ogawa. The Growth of Microstructurally Small Fatigue Cracks in Metals, in Short Fatigue Cracks, ESIS 13, M. J. Miller and E. R. de los Rios, eds., Mechanical Engineering Publication, London, pp. 85-99 (1992).

32. K. Tokaji, T. Ogawa, and S. Osako, The Growth of Microstructurally Small Fatigue Cracks in a Ferritic-Pearlitic Steel, Fatigue Fract. Eng. Mater. Struct. 11, 331-342 (1988).

33. E. R. de los Rios, A. Navarro, and K. Hussain, Microstructural Variations in Short Fatigue Crack Propagation of a C-Mn Steel, in Short Fatigue Cracks, ESIS 13, M. J. Miller and E. R. de los Rios, eds., Mechanical Engineering Publication, London, pp. 115-132 (1992).

34. G. L. Wire and Y. Y. Li, Initiation of Environmentally-Assisted Cracking in Low-Alloy Steels, in Fatigue and Fracture - 1996 - Volume 1, PVP Vol. 323, H. S. Mehta, ed., American Society of Mechanical Engineers, New York, pp. 269-289 (1996). 
35. W. H. Cullen, M. Kemppainen, H. Hänninen, and K. Törrönen, The Effects of Sulfur Chemistry and Flow Rate on Fatigue Crack Growth Rates in LWR Environments, NUREG/CR-4121 (1985).

36. J. H. Bulloch, Environmentclly Assisted Cracking Phenomena in Reactor Pressure Vessel Steel - The Role of Manganese Sulphide Segregation, in Proc. 3rd Int. Symp. on Environmental Degradation of Materials in Nuclear Power Systems - Water Reactors, G. J. Theus and J. R. Weeks, eds., The Metallurgical Society, Warrendale, PA, pp. 261-267 (1988).

37. W. A. Van Der Sluys and R. H. Emanuelson, Environmental Acceleration of Fatigue Crack Growth in Reactor Pressure. Vessel Materials and Environments, in Environmentally Assisted Cracking: Science and Engineering, ASTM STP 1049, W. B. Lisagor, T. W. Crooker, and B. N. Leis, eds., American Society for Testing and Materials, Philadelphia, PA, pp. 117-135 (1990).

38. T. A. Auten, S. Z. Hayden, and R. H. Emanuelson, Fatigue Crack Growth Rate Studies of Medium Sulfur Low Alloy Steels Tested in High Temperature Water, in Proc. 6th Int. Symp. on Environmental Degradation of Materials in Nuclear Power Systems - Water Reactors, R. E. Gold and E. P. Simonen, eds., The Metallurgical Society, Warrendale, PA, pp. 35-40 (1993).

39. J. D. Atkinson, J. Yu, and Z.-Y. Chen, An Analysis of the Effects of Sulfur Content and Potential on Corrosion Fatigue Crack Growth in Reactor Pressure Vessel Steels, Corros. Sci. 38 (5), 755-765 (1996).

40. F. P. Ford, S. Ranganath, and D. Weinstein, Environmentally Assisted Fatigue Crack Initiation in Low-Alloy Steels - A Review of the Literature and the ASME Code Design Requirements, EPRI Report TR-102765 (Aug. 1993).

41. F. P. Ford, Overview of Collaborative Research into the Mechanisms of Environmentally Controlled Cracking in the Low Alloy Pressure Vessel Steel/Water System, in Proc. 2nd Int. Atomic Energy Agency Specialists' Meeting on Subcritical Crack Growth, NUREG/CP0067, MEA-2090, Vol. 2, pp. 3-71 (April 1986).

42. H. Hänninen, K. Törrönen, and W. H. Cullen, Comparison of Proposed Cyclic Crack Growth Mechanisms of Low Alloy Steels in LWR Environments, in Proc. 2nd Int. Atomic Energy Agency Specialists' Meeting on Subcritical Crack Growth, NUREG/CP-0067, MEA-2090, Vol. 2, pp. 73-97 (April 1986).

43. J. H. Bulloch, A Review of the Fatigue Crack Extension Behavior of Ferritic Pressure Vessel Materials in Pressurized Water Reactor Environments, Res. Mechanica 26, 95-172 (1989).

44. C. M. Suh, R. Yuuki, and H. Kitagawa, Fatigue Microcracks in a Low Carbon Steel, Fatigue Fract. Eng. Mater. Struct. 8, 193-203 (1985).

45. N. E. Dowling, Crack Growth During Low-Cycle Fatigue of Smooth Axial Specimens, in Cyclic Stress-Strain and Plastic Deformation Aspects of Fatigue Crack Growth, ASTM STP 637, American Society for Testing and Materials, Philadelphia, PA, pp. 97-121 (1977). 
46. E. D. Eason, E. E. Nelson, and J. D. Gilman, Modeling of Fatigue Crack Growth Rate for Ferritic Steels in Light Water Reactor Environments, PVP-Vol. 286, Changing Priorities of Code and Standards, American Society of Mechanical Engineers, New York, pp. 131-142 (1994).

47. T. P. O'Donnell and W. J. O'Donnell, Stress Intensity Values in Conventional S-N Fatigue Specimens, in Fatigue and Crack Growth: International Pressure Vessels and Piping Codes and Standards: Volume 1 - Current Applications, PVP Vol. 313-1, K. R. Rao and Y. Asada, eds., American Society of Mechanical Engineers, New York, pp. 195-197 (1995).

48. C. E. Jaske and W. J. O'Donnell, Fatigue Design Criteria for Pressure Vessel Alloys, Trans. ASME J. Pressure Vessel Technol. 99, 584-592 (1977).

49. J. B. Conway, R. H. Stentz, and J. T. Berling, Fatigue, Tensile, and Relaxation Behavior of Stainless Steels, TID-26135, U.S. Atomic Energy Commission, Washington, DC (1975).

50. D. L. Keller, Progress on LMFBR Cladding, Structural, and Component Materials Studies During July, 1971 through June, 1972, Final Report, Task 32, Battelle-Columbus Laboratories, BMI-1928 (1977).

51. D. A. Hale, S. A. Wilson, E. Kiss, and A. J. Gianuzzi, Low Cycle Fatigue Evaluation of Primary Piping Materials in a BWR Environment, GEAP-20244, U.S. Nuclear Regulatory Commission (Sept. 1977).

52. D. A. Hale, S. A. Wilson, J. N. Kass, and E. Kiss, Low Cycle Fatigue Behavior of Commercial Piping Materials in a BWR Environment, J. Eng. Mater. Technol. 103, 15-25 (1981).

53. J.-H. Park and H. M. Chung, Properties of Stainless Steel Welds, in Environmentally Assisted Cracking in Light Water Reactors, Semiannual Report, January 1996-June 1996 , NUREG/CR-4667 Vol. 22, ANL-97/9, pp. 44-48 (June 1997).

54. H. M. Chung, W. E. Ruther, J. E. Sanecki, A. G. Hins, N. J. Zaluzec, and T. F. Kassner, Irradiation-Assisted Stress Corrosion Cracking of Austenitic Stainless Steels: Recent Progress and New Approaches, J. Nucl. Mater. 23961 (1996).

55. C. T. Ward, D. L. Mathis, and R. W. Staehle, Intergranular Attack of Sensitized Austenitic Stainless Steels by Water Containing Fluoride Ions, Corrosion 25394 (1969) .

56. E. E. Gruber, and T. H. Hughes, Development of Hot-Cell $J-R$ Testing Facility, in Environmentally Assisted Cracking in Light Water Reactors, Semiannual Report, April 1995-December 1995, NUREG/CR-4667 Vol. 21, ANL-96/1, pp. 56-59 (July. 1996).

57. A. Saxena and S. J. Hudak, Review and Extension of Compliance Information for Common Crack Growth Specimens, Int. J. Fracture 14, 453-468 (1978). 
58. W. E. Ruther, W. K. Soppet, D. J. Gavenda, and T. F. Kassner, Environmentally Assisted Cracking of Alloys 600 and 690 in Simulated LWR Water, in Environmentally Assisted Cracking in Light Water Reactors, Semiannual Report, October 1994-March 1995 , NUREG/CR-4667 Vol. 20, ANL-95/41, pp. 20-30 (Jan. 1996).

59. W. E. Ruther, W. K. Soppet, and T. F. Kassner, Corrosion Fatigue of Alloys 600 and 690 in Simulated LWR Environments, NUREG/CR-6383, ANL-95/37 (April 1996).

60. W. E. Ruther, W. K. Soppet, and T. F. Kassner, Environmentally Assisted Cracking of Alloys 600 and 690 in Simulated LWR Water, in Environmentally Assisted Cracking in Light Water Reactors, Semiannual Report, January 1996-June 1996, NUREG/CR-4667 Vol. 22, ANL-97/9, pp. 49-68 (June 1997).

61. E. A. Payzant, S. Spooner, X. Zhu, C. R. Hubbard, S. T. Rosinski, and J. Dowicki, Experimental Determination of Residual Stress by Neutron Diffraction in a Boiling Water Reactor Core Shroud, Proc. of ASME PVP Conf., Vol. 322, American Society of Mechanical Engineers, New York, pp. 55-61 (1996).

62. T. Nishioka and S. N. Atluri, Analytical Solutions for Embedded Elliptical Cracks, and Finite Element Alternating Method for Elliptical Surface Cracks Subjected to Arbitrary Loadings, Eng. Fracture Mechanics, 17 (3), pp. 247-268 (1983).

63. R. B. Stonesifer, F. W. Brust, and B. N. Leis, Mixed-Mode Stress Intensity Factors for Interacting Semi-Elliptical Surface Cracks in a Plate, Eng. Fracture Mechanics 45 (3), pp. 357-380 (1993).

64. R. B. Stonesifer, F. W. Brust, and B. N. Leis, Stress Intensity Factors for Long Axial OD Surface Cracks in Large R/t Pipes, ASTM STP 1131, American Society for Testing and Materials, Philadelphia, PA, pp. 29-45 (1992).

65. T. Nishioka and S. N. Atluri, Analysis of Surface Flaw in Pressure Vessels by a New 3 Dimensional Alternating Method, J. Pressure Vessel Technol. 104, pp. 299-307 (Nov. 1992).

66. S. N. Atluri, Energetic Approaches and Path Independent Integrals in Fracture, in Computational Methods in Mechanics of Fracture, ed. S. N. Atluri, North-Holland (1968).

67. NASA FLAGRO-Version 2.0, Developed by R. Forman, National Aeronautical and Space Agency, Dayton, OH, (1993).

68. F. G. Buchholtz, Improved Formulae for the Finite Element Calculation of the Strain Energy Release Rate by the Modified Crack Closure Integral Method, in Accuracy Reliability and Training in FEM Technology, J. Robinson, ed., Robinson and Associates, Dorset, pp. 650-659 (1984). 
NRC FORM 335

(2-89)

NRCM 1102

3201,3202
U.S. NUCLEAR REGULATORY COMMISSION

\section{BIBLIOGRAPHIC DATA SHEET}

(See instructions on the reverse)

2. TIRLE AND SUBTITLE

Environmentally Assisted Cracking in Light Water Reactors.

Semiannual Report July 1996-December 1996
1. REPORT NUMBER

(Assigned by NRC. Add Vol., Supp., Rev.,

and Addendum Numbers, if any.)

NUREG/CR-4667, Vol. 23

ANL-97/10

3. DATE REPORT PUBLISHED

\begin{tabular}{l|l} 
MONTH & YEAR
\end{tabular}

October

1997

4. FIN OR GRANT NUMBER

W6610

5. AUTHOR(S)

O. K. Chopra, H. M. Chung, D. J. Gavenda, E. E. Gruber, T. H. Hughes, a

T. F. Kassner, P. R. Luebbers, J.-H. Park, W. E. Ruther, a

W. J. Shack, W. K. Soppet, R. V. Strain, J. Zhang, P. Dong, and F. W. Brust

6. TYPE OF REPORT

Technical; Semiannual

7. PERIOD COVERED (Inclusive Dates)

July 1996-December 1996

8. PERFORMING ORGANIZATION - NAME AND ADDRESS (If NRC, provide Division, Office or Region, U.S. Nuclear Regulatory Commission, and mailing address; if contractor, provide name and mailing address.)

a Argonne National Laboratory

bBattelle Columbus Laboratories

9700 South Cass Avenue

505 King Avenue

Argonne, IL 60439

Columbus, $\mathrm{OH} 43201$

9. SPONSORING ORGANIZATION - NAME AND ADDRESS (If NRC, type "Same as above"; if contractor, provide NRC Division, Office or Region, U.S. Nuclear Regulatory Commission, and mailing address.)

Division of Engineering Technology

Office of Nuclear Regulatory Research

U.S. Nuclear Regulatory Commission

Washington, DC 20555-0001

10. SUPPLEMENTARY NOTES

\section{MCNei 1, NRC Project Manager}

11. ABSTRACT (200 words or less)

This report summarizes work performed by Argonne National Laboratory on fatigue and environmentally assisted cracking (EAC) in light water reactors from July 1996 to December 1996. Topics that have been investigated include (a) fatigue of carbon, lowalloy, and austenitic stainless steels (SSs) used in reactor piping and pressure vessels, (b) irradiation-assisted stress corrosion cracking of Type 304 SS, (c) EAC of Alloy 600, and (d) characterization of residual stresses in welds of boiling water reactor (BWR) core shrouds by numerical models. Fatigue tests were conducted on ferritic and austenitic SSs in water that contained various concentrations of dissolved oxygen to determine whether a slow strain rate applied during various portions of a tensile-loading cycle are equally effective in decreasing fatigue life. Slow-strain-rate-tensile tests were conducted in simulated BWR water at $288^{\circ} \mathrm{C}$ on SS specimens irradiated to a low fluence in the Halden reactor and the results were compared with similar data from a control-blade sheath and neutron-absorber tubes irradiated in BWRs to the same fluence level. Crack-growth-rate tests were conducted on compact-tension specimens from a low-carbon content heat of Alloy 600 in high-purity oxygenated water at $289^{\circ} \mathrm{C}$.

Residual stresses and stress intensity factors were calculated for BWR core shroud welds.

12. KEY WORDS/DESCAIPTORS (List words or phrases that will assist researchers in locating this report.)

Corrosion Fatigue

Crack Growth

Irradiation-Assisted Stress Corrosion Cracking

Radiation-Induced Segregation

Residual Stress

Stress Corrosion Cracking

A106-Gr B Steel

A533-Gr B Steel

Type s 304,316 , and 316 NG Stainless Steel

Alloys 600 and 690

NRC FORM 335 (2-89)

\begin{tabular}{|c|}
\hline $\begin{array}{l}\text { 13. AVAILABILITY STATEMENT } \\
\text { Unlimited }\end{array}$ \\
\hline 14. SECURITY CLASSIFICATION \\
\hline (This Page) \\
\hline Unclassified \\
\hline (This Report) \\
\hline Unclassified \\
\hline 15. NUMBER OF PAGES \\
\hline 16. PRICE \\
\hline
\end{tabular}

